\title{
Bunker Hill Sediment Characterization Study
}

Neal A. Yancey

Debby F. Bruhn

December 2009

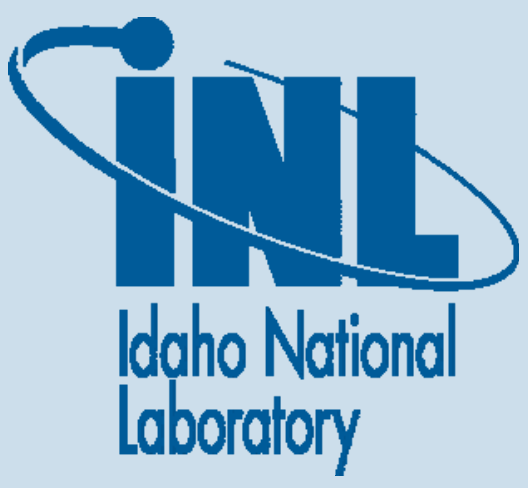

The INL is a U.S. Department of Energy National Laboratory operated by Battelle Energy Alliance 


\section{DISCLAIMER}

This information was prepared as an account of work sponsored by an agency of the U.S. Government. Neither the U.S. Government nor any agency thereof, nor any of their employees, makes any warranty, expressed or implied, or assumes any legal liability or responsibility for the accuracy, completeness, or usefulness, of any information, apparatus, product, or process disclosed, or represents that its use would not infringe privately owned rights. References herein to any specific commercial product, process, or service by trade name, trademark, manufacturer, or otherwise, does not necessarily constitute or imply its endorsement, recommendation, or favoring by the U.S. Government or any agency thereof. The views and opinions of authors expressed herein do not necessarily state or reflect those of the U.S. Government or any agency thereof. 


\title{
Bunker Hill Sediment Characterization Study
}

\author{
Neal A. Yancey \\ Debby F. Bruhn
}

December 2009

\section{Idaho National Laboratory \\ Idaho Falls, Idaho 83415}

http://www.inl.gov

Prepared for the

Environmental Protection Agency and for the

U.S. Department of Energy

Under DOE Idaho Operations Office

Contract DE-AC07-05ID14517 



\section{Bunker Hill Sediment Characterization Study}

INL/EXT-09-16499

December 2009

Approved by:

Name

Date

Title [optional]

Name

Title [optional]

Date

Name

Title [optional]

Date 



\section{EXECUTIVE SUMMARY}

The INL was contacted by the Coeur d'Alene Basin Commission in the summer of 2008 and asked to conduct a series of extraction procedures and leach tests on soil from the area of the Central Impoundment Area (CIA) and in the Osborn Flats area. Exposed minerals from historic mining activities have contributed to contamination in the South Fork Coeur d'Alene River and its tributaries. Due to the challenge of cleanup, a preliminary study of metal availability and release from sediments from the area was performed to help understand the factors that affect metal mobility. Three groups of experiments were conducted:

- Sequential extraction tests to determine the operational speciation of the metals in the sediment

- Leaching tests to determine the effect of $\mathrm{pH}$ on metal leached and,

- Leaching tests to provide insight into the effect of aerobic and anoxic conditions on the metal leached.

Core samples were collected in August 2008 from four locations, three from just outside of the CIA and one from the Osborn Flats area. Core samples were collected from various depths down to 9 feet. The samples were stored in liquid nitrogen until the extraction tests were conducted. The core samples from each depth underwent a modified sequential extraction procedure which separated the metals into 4 fractions: extractable, carbonate bound or acid soluble, organic/oxide/sulfide-bound, and residual.

Metal-bearing minerals were mined from subsurface sulfide deposits, with the principal ore minerals being galena $(\mathrm{PbS})$, sphalerite $(\mathrm{ZnS})$, and argentiferous tetrahedrite $\left[(\mathrm{Cu}, \mathrm{Fe})_{12} \mathrm{Sb}_{4} \mathrm{~S}_{13}\right]$ with lesser amounts of chalcopyrite $\left(\mathrm{CuFeS}_{2}\right)$. Pyrite $\left(\mathrm{FeS}_{2}\right)$ is common but amounts vary from site to site. Once the ores were disturbed or extracted by mining, contaminant metals were distributed along the tributaries, lake and rivers of the region. Contaminant metals continue to be redistributed between a wide range of chemical and physical states depending on exposure to oxidizing or reducing conditions (which can vary seasonally). Chemical processes that contribute to this redistribution include complexation with solutes such as carbonate, variations in $\mathrm{pH}$, sorption by other mineral phases such as iron oxides and by organic matter, and co-precipitation with iron and manganese oxides. Microbial processes also affect the oxidation and reduction of various metals depending on other environmental factors.

The primary metals of concern were zinc, cadmium, and lead. In addition, calcium, iron, magnesium, manganese, sulfur, and selenium were also measured. The sediment samples were subjected to a sequential extraction protocol that segregates the metals into four operationally defined fractions: ion-exchangable fraction (Phase 1), acid-soluble fraction (Phase 2), organic/oxide/sulfide-bound fraction (Phase 3), and the residual fraction (Phase 4). Cadmium tended to be the most mobile metal, although it was present in the lowest concentrations. Iron was the least mobile, suggesting that most of the iron existed as stable iron oxides or mineral iron. Lead was generally more easily extracted than the zinc and both were present in concentrations higher that was observed for cadmium. 
Leaching tests were conducted to determine how $\mathrm{pH}$ and the presence or absence of oxygen affect the concentration of leached metals. The $\mathrm{pH}$ of the leach solution naturally had a significant effect on the leachability of all of the metals. Cadmium and zinc leached at greater rates as the $\mathrm{pH}$ of the leach solution was reduced. At a $\mathrm{pH}$ of 2, the concentration of $\mathrm{Cd}$ and $\mathrm{Zn}$ was roughly ten times higher in the leach solution than what was observed at $\mathrm{pH} 6$ or 7 . A similar pattern was observed with $\mathrm{Pb}$, although the differences were less dramatic, being about 5 times higher $\mathrm{Pb}$ concentration at $\mathrm{pH} 2$ than 6-7.

Leaching tests were also conducted to determine how the presence or absence of oxygen affected metal concentrations in leach solutions. The tests were conducted following a two week wetting/drying cycle conducted at atmospheric conditions. The most notable observation was that each location reacted very differently from the other locations. However, at each location, cadmium and zinc reacted in the same manner.

Metal concentrations were highest in the sediments collected at SF-BH-EPZ-12 near the CIA. The metal concentrations in locations SF-OB-PZ-13 (Osborn Flats area), BH-E-PZ-16 and BH-E-PZ-24 (both from around the CIA) for cadmium, lead and zinc were relatively similar. In general lead and zinc tend to not be as easily mobilized or extracted for any of the locations, but cadmium was the most easily extracted, particularly in sediments from BH-E-PZ-16 and BH-E-PZ-24.

In experiments conducted at $\mathrm{pH} 7$, many of the elements $(\mathrm{Al}, \mathrm{Cd}, \mathrm{Cu}, \mathrm{Fe}$, $\mathrm{Mg}, \mathrm{Pb}$, and $\mathrm{Zn}$ ) show little or no change with time. The rates of leaching in $\mathrm{pH} 2$ solutions, in contrast to the $\mathrm{pH} 7$ solutions, appear to increase with time for most of the elements. Leached concentrations were also greater at low $\mathrm{pH}$ except for $\mathrm{S}$. Leached $\mathrm{Ca}, \mathrm{Mg}$, and $\mathrm{K}$ concentrations increased over time but appeared to approach a steady state near the end of the experiment. 


\section{CONTENTS}

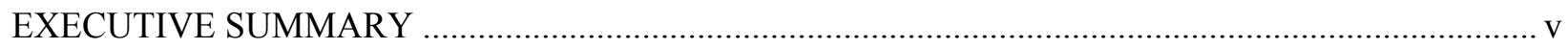

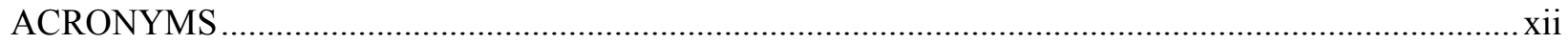

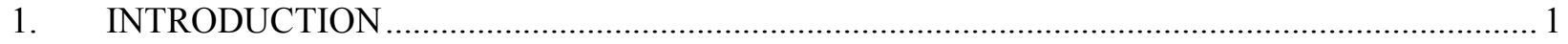

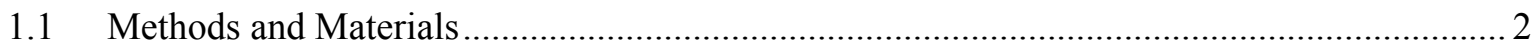

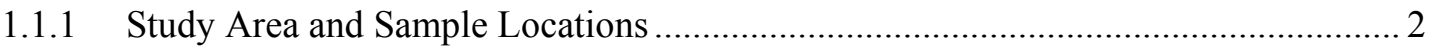

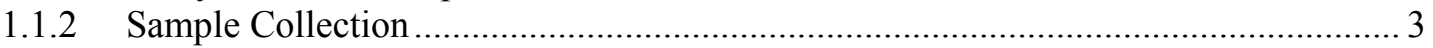

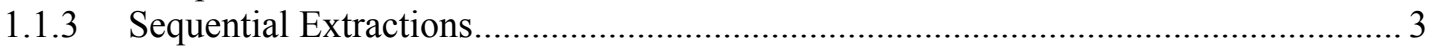

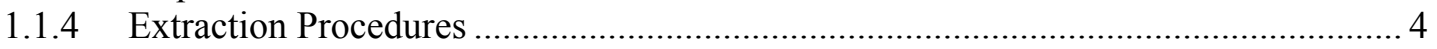

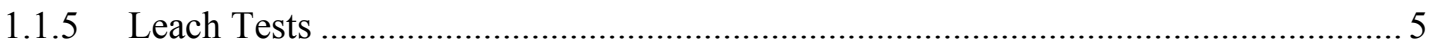

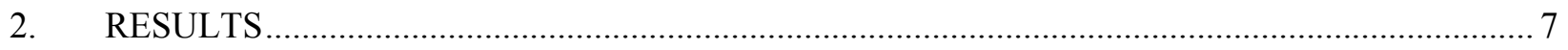

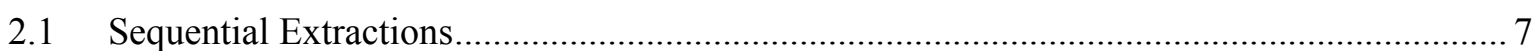

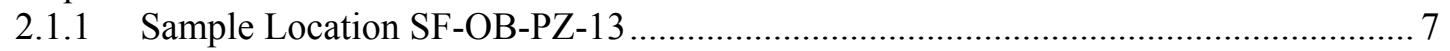

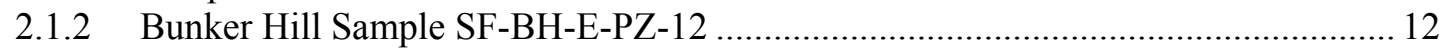

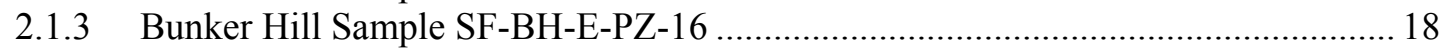

2.1.4 Bunker Hill Sample SF-BH-E-PZ-24 _............................................................... 23

2.1.5 Extraction of Iron from the soil cores .......................................................... 28

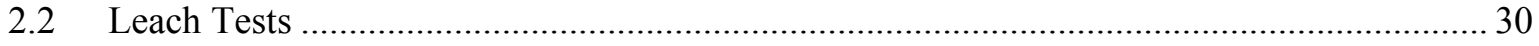

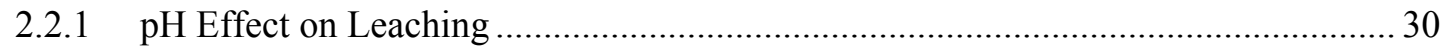

2.2.2 Effect of Aerobic or Anoxic Conditions on Metal Leaching ................................. 41

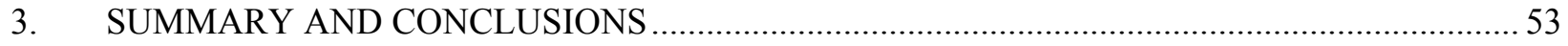

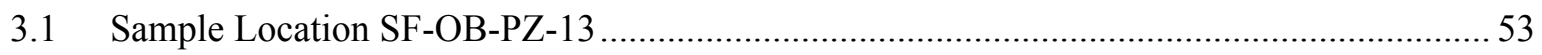

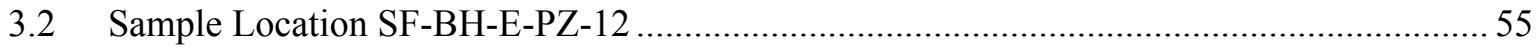

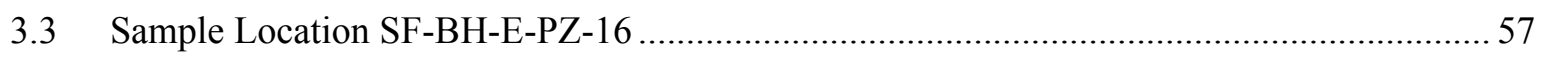

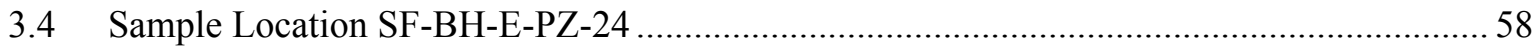

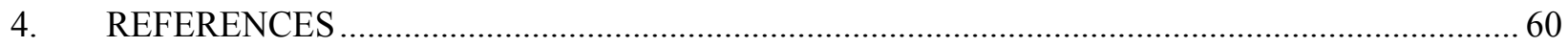

\section{FIGURES}

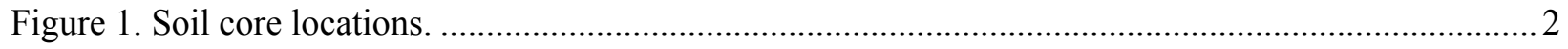

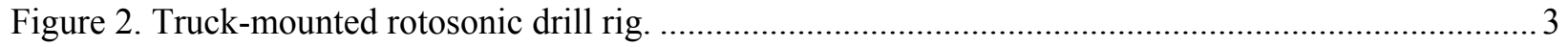

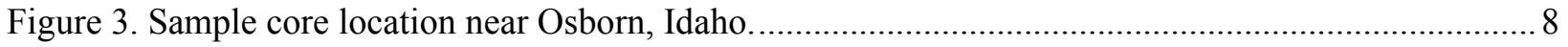

Figure 4. Core sample from location SF-OB-PZ-13, 1.0-1.8-foot depth. ............................................. 8

Figure 5. Core sample from location SF-OB-PZ-13, 3.0-4.0-foot depth. ............................................. 9

Figure 6. Core sample from location SF-OB-PZ-13, 5.0-5.6-foot depth. ............................................. 9

Figure 7. Cadmium percentages present in the Osborn Flats soil core ................................................. 10

Figure 8. Lead percentages present in Osborn Flats soil cores......................................................... 11

Figure 9. Zinc percentages present in Osborn Flats soil core .......................................................... 12 


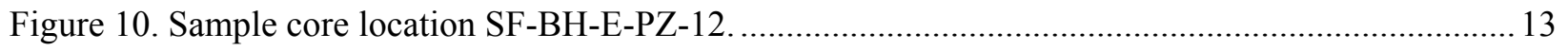

Figure 11. Core sample from location SF-BH-E-PZ-12, 1.0-2.0-foot depth.......................................... 13

Figure 12. Core sample from location SF-BH-E-PZ-12, 3.0-4.0-foot depth......................................... 14

Figure 13. Core sample from location SF-BH-E-PZ-12, 5.0-6.0-foot depth......................................... 14

Figure 14. Core sample from location SF-BH-E-PZ-12, 7.0-8.0-foot depth......................................... 15

Figure 15. Core sample from location SF-BH-E-PZ-12, 8.0-9.0-foot depth........................................... 15

Figure 16. Cadmium percentages present at sample location BH-E-PZ-12. .......................................... 16

Figure 17. Lead percentages present at sample location BH-E-PZ-12 ................................................. 17

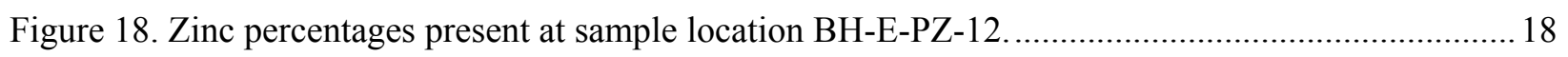

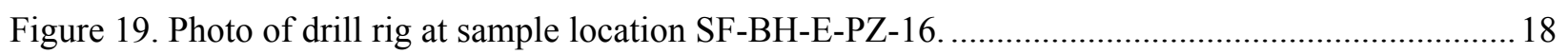

Figure 20. Core sample from location SF-BH-E-PZ-16, 1.0-2.0-foot depth.......................................... 19

Figure 21. Core sample from location SF-BH-E-PZ-16, 3.0-4.0-foot depth.......................................... 19

Figure 22. Core sample from location SF-BH-E-PZ-16, 5.0-6.0-foot depth......................................... 20

Figure 23. Core sample from location SF-BH-E-PZ-16, 7.0-8.0-foot depth......................................... 20

Figure 24. Cadmium percentages present at sample location BH-E-PZ-16. ..........................................2 21

Figure 25. Lead percentages present at sample location BH-E-PZ-16. .................................................22

Figure 26. Zinc percentages present at sample location BH-E-PZ-16 .....................................................2

Figure 27. Collecting the core samples for SF-BH-E-PZ-24 core location. .............................................2 23

Figure 28. Core sample from location SF-BH-E-PZ-24, 1.0-2.0-foot depth............................................ 24

Figure 29. Core sample from location SF-BH-E-PZ-24, 3.0-4.0-foot depth............................................ 24

Figure 30. Core sample from location SF-BH-E-PZ-24, 5.0-6.0-foot depth........................................... 25

Figure 31. Core sample from location SF-BH-E-PZ-24, 7.0-8.0-foot depth......................................... 25

Figure 32. Cadmium percentages present at sample location BH-E-PZ-24. .........................................26

Figure 33. Lead percentages present at sample location BH-E-PZ-24 ..............................................2

Figure 34. Zinc percentages present at sample location BH-E-PZ-24 ..............................................2

Figure 35. Iron released from the four locations during the sequential extraction. .................................29

Figure 36. Effect of different $\mathrm{pH}$ on leaching of cadmium from sediment samples over a 90 day time interval.

Figure 37. Effect of different $\mathrm{pH}$ on leaching of lead from sediment samples over a 90 day time interval.

Figure 38. Effect of different $\mathrm{pH}$ on leaching of zinc from sediment samples over a 90 day time interval.

Figure 39. Effect of different $\mathrm{pH}$ on leaching of iron from sediment samples over a 90 day time interval.

Figure 40. Effect of different $\mathrm{pH}$ on leaching of sulfur from sediment samples over a 90 day time interval. 
Figure 41. Effect of $\mathrm{pH}$ on cadmium concentration over time. ............................................................ 33

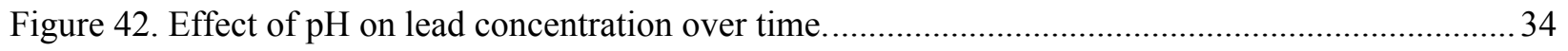

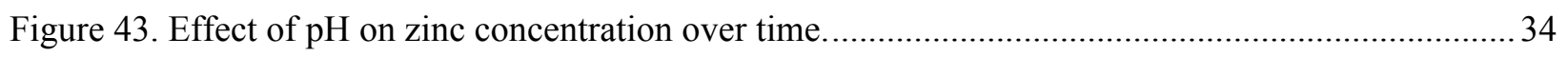

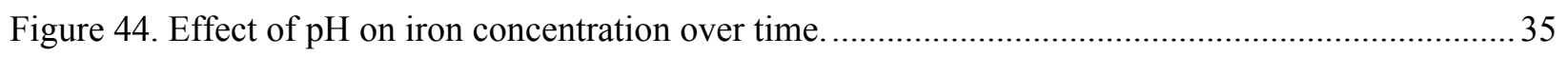

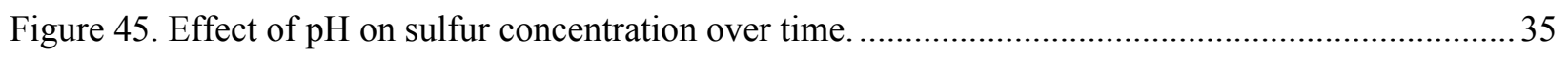

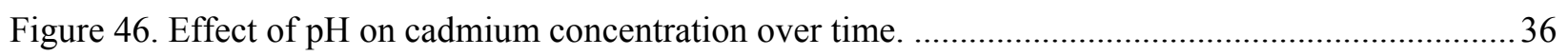

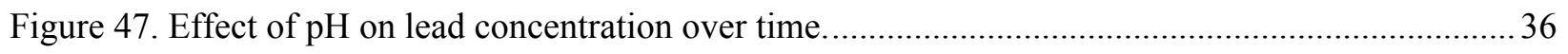

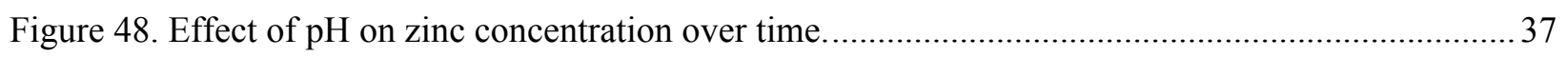

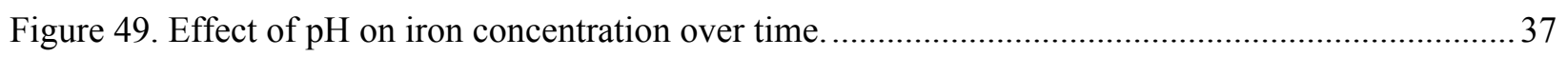

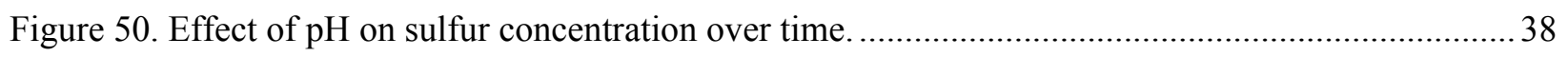

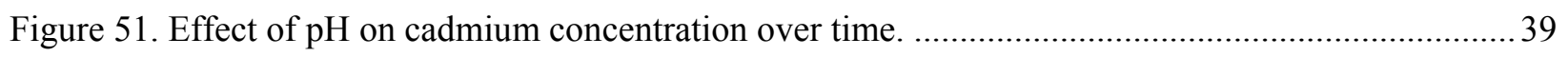

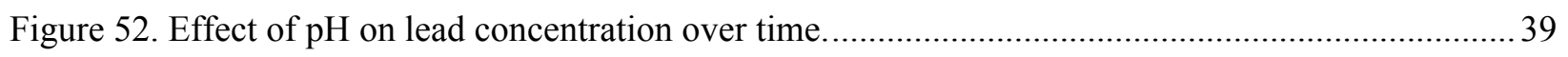

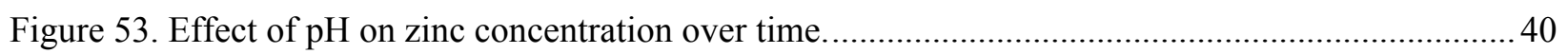

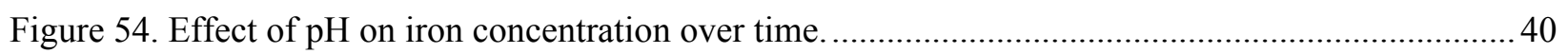

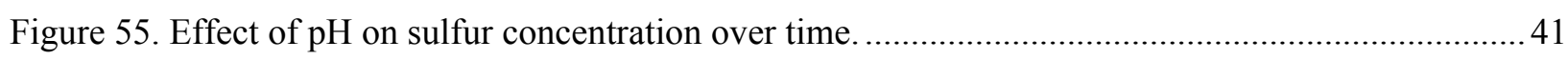

Figure 56. Effect of aerobic and anoxic conditions on cadmium concentration over time........................4 42

Figure 57. Effect of aerobic and anoxic conditions on lead concentration over time............................... 42

Figure 58. Effect of aerobic and anoxic conditions on zinc concentration over time................................ 43

Figure 59. Effect of aerobic and anoxic conditions on iron concentration over time. ............................... 43

Figure 60. Effect of aerobic and anoxic conditions on sulfur concentration over time............................4 44

Figure 61. Effect of aerobic and anoxic conditions on cadmium concentration over time........................45

Figure 62. Effect of aerobic and anoxic conditions on lead concentration over time.............................. 45

Figure 63. Effect of aerobic and anoxic conditions on zinc concentration over time...............................46

Figure 64. Effect of aerobic and anoxic conditions on iron concentration over time. ..............................46

Figure 65. Effect of aerobic and anoxic conditions on sulfur concentration over time...........................4 47

Figure 66. Effect of aerobic and anoxic conditions on cadmium concentration over time....................... 47

Figure 67. Effect of aerobic and anoxic conditions on lead concentration over time................................ 48

Figure 68. Effect of aerobic and anoxic conditions on zinc concentration over time...............................49

Figure 69. Effect of aerobic and anoxic conditions on iron concentration over time. ............................... 49

Figure 70. Effect of aerobic and anoxic conditions on sulfur concentration over time. ...........................50

Figure 71. Effect of aerobic and anoxic conditions on cadmium concentration over time........................50

Figure 72. Effect of aerobic and anoxic conditions on lead concentration over time...............................51

Figure 73. Effect of aerobic and anoxic conditions on zinc concentration over time...............................51

Figure 74. Effect of aerobic and anoxic conditions on iron concentration over time...............................52

Figure 75. Effect of aerobic and anoxic conditions on sulfur concentration over time............................52 
Figure 76. Cadmium, lead, and zinc concentrations in the sediment cores at SF-OB-PZ-13 from the $>2 \mathrm{~mm}$ fraction.

Figure 77. Cadmium, lead, and zinc concentrations in the soil used in the leach tests from the $>2$ mm fraction.

Figure 78. Metal concentrations at each core depth for sample location SF-BH-E-PZ-12 from the $>2 \mathrm{~mm}$ fraction.

Figure 80. Cadmium, lead, and zinc concentrations at SF-BH-E-PZ-24 from the $>2 \mathrm{~mm}$ fraction. .......... 58

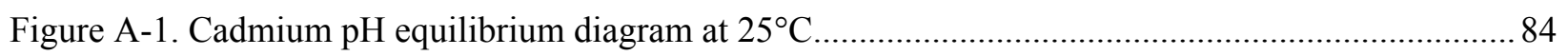

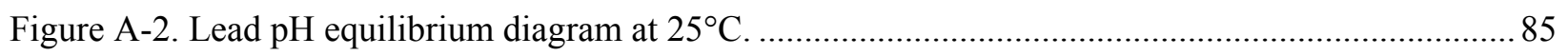

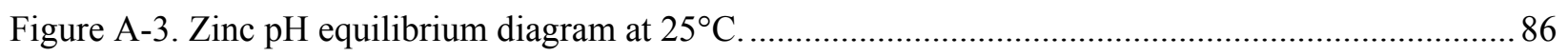

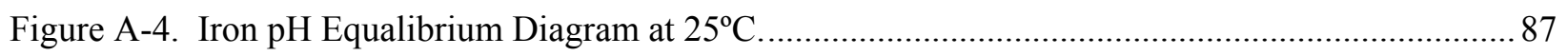

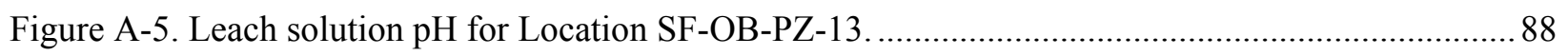

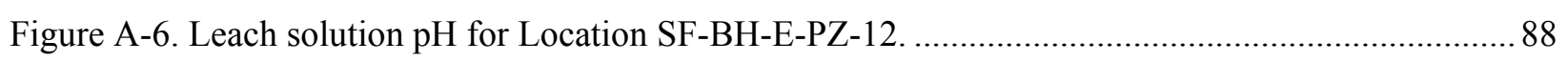

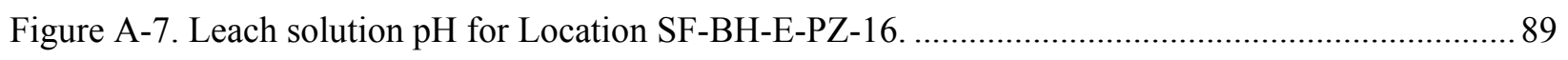

Figure A-8. Leach solution pH for Location SF-BH-E-PZ-24 ........................................................... 90

\section{TABLES}

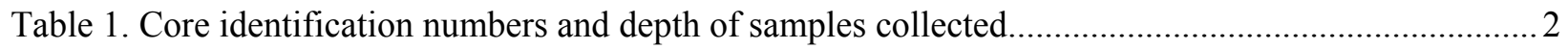

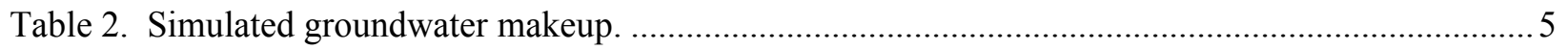

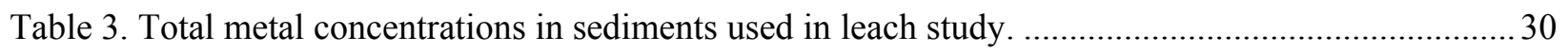

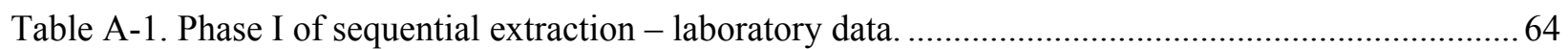

Table A-2. Phase II of Sequential Extraction - Laboratory Data. Note U indicates that the ion was analyzed for but not detected above the sample quantification limit or detection limit.

Table A-3. Phase III of Sequential Extraction - Laboratory Data. Note U indicates that the ion was analyzed for but not detected above the sample quantification limit or detection limit.

Table A-4. Total Concentration in Treated and Untreated Sediments used in Sequential Extractions. .70

Table A-5. Concentrations from $\mathrm{pH}$ leach test from 0-90 days. ........................................................... 72

Table A-6. Concentrations for leach tests in the presence and absence of oxygen from 0-90 days........... 80

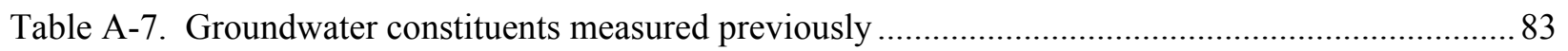

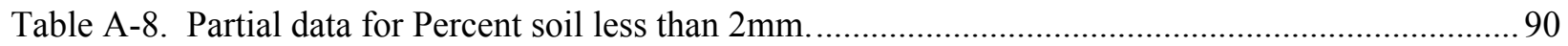




\section{ACRONYMS}

EPA Environmental Protection Agency

INL Idaho National Laboratory

TIC Total Inorganic Carbon

TOC Total Organic Carbon

CIA Central Impoundment Area 


\section{Bunker Hill Sediment Characterization Study}

\section{INTRODUCTION}

The long history of mineral extraction in the Coeur d'Alene Basin has left a legacy of heavy-metalladen mine tailings that have accumulated along the Coeur d'Alene River and its tributaries (U.S. Environmental Protection Agency [EPA], 2001). Silver, lead, and zinc were the primary metals of economic interest in the area, but the ores contained other elements that have become environmental hazards including zinc, cadmium, lead, arsenic, nickel, and copper. The metals have contaminated the water and sediments of Lake Coeur d'Alene, and continue to be transported downstream to Spokane, Washington, via the Spokane River. In 1983, the EPA listed the Bunker Hill Mining and Metallurgical Complex on the National Priorities List. Since that time, many of the most contaminated areas have been stabilized or isolated; however, metal contaminants continue to migrate through the basin.

Identification of primary sources of contamination can help set priorities for cleanup and cleanup options, which can include source removal, water treatment, or no action depending on knowledge about the mobility of contaminants relative to water flow. The mobility of the contaminants under natural or engineered conditions depends on multiple factors including the physical and chemical state (or speciation) of metals and the range of processes, some of which can be seasonal, that cause mobilization of metals.

Metal-bearing minerals were mined from subsurface sulfide deposits, with the principal ore minerals being galena $(\mathrm{PbS})$, sphalerite $(\mathrm{ZnS})$, and argentiferous tetrahedrite $\left[(\mathrm{Cu}, \mathrm{Fe})_{12} \mathrm{Sb}_{4} \mathrm{~S}_{13}\right]$ with lesser amounts of chalcopyrite $\left(\mathrm{CuFeS}_{2}\right)$. Pyrite $\left(\mathrm{FeS}_{2}\right)$ is common but amounts vary from site to site. Once the ores were disturbed or extracted by mining, contaminant metals were distributed along the river tributaries and lake sediments and continue to be redistributed between a wide range of chemical and physical states depending on exposure to oxidizing or reducing conditions (which can vary seasonally). Chemical processes that contribute to this redistribution include complexation with solutes such as carbonate, variations in $\mathrm{pH}$, sorption by other mineral phases such as iron oxides or organic material, and coprecipitation with iron and manganese oxides.

Sediments from Canyon Creek were analyzed previously in May of 2007 by Karen Wright, George Redden, and Carl Palmer (Wright et al., 2007) of the INL. In that study approximately $40 \%$ of the $\mathrm{Zn}$, $\mathrm{Cd}$, and $\mathrm{Pb}$ was removed as exchangeable and acid soluble, and are considered easily leached. Approximately $20 \%$ of the $\mathrm{Pb}, \mathrm{Cd}$, and $\mathrm{Zn}$ removed during the sequential extractions came from the residual fraction, and is considered very difficult to leach. The remaining $40 \%$ that was removed as $\mathrm{Fe} / \mathrm{Mn} / \mathrm{Al}$ hydrous oxide bound and oxidizable organic bound. The ease of leaching from these fractions will depend on the $\mathrm{pH}$ and $\mathrm{Eh}$ of the system. There were no apparent trends in extracted metals with depth that were consistent for all of the locations.

As a follow on to the work completed by Wright et al., 2007, the INL was asked to collect and analyze sediments from the area near the CIA and Osborn Flats area in 2008 in an effort to help understand the factors that affect metal mobility around the CIA and in the Osborn Flats area. Three groups of experiments were conducted:

- Sequential extraction tests to determine the operational speciation of the metals in the sediment

- Leaching tests to determine the effect of $\mathrm{pH}$ on metal leached and,

- Leaching tests to provide insight into the effect of the presence or absence of oxygen on the metal leached. 
The following sections explain the methodology and results from the tests conducted on the core samples collected for this study.

\subsection{Methods and Materials}

\subsubsection{Study Area and Sample Locations}

Soil cores samples were collected from three locations near the CIA. The general locations of three of the cores are shown in Figure 1 below. Soil core number SF-OB-PZ-13 was collected from a different location in the Osborn Flats area. Samples from the cores were collected at various depths in the soil profile. Table 1 lists the core locations along with the associated sample depths that were collected.

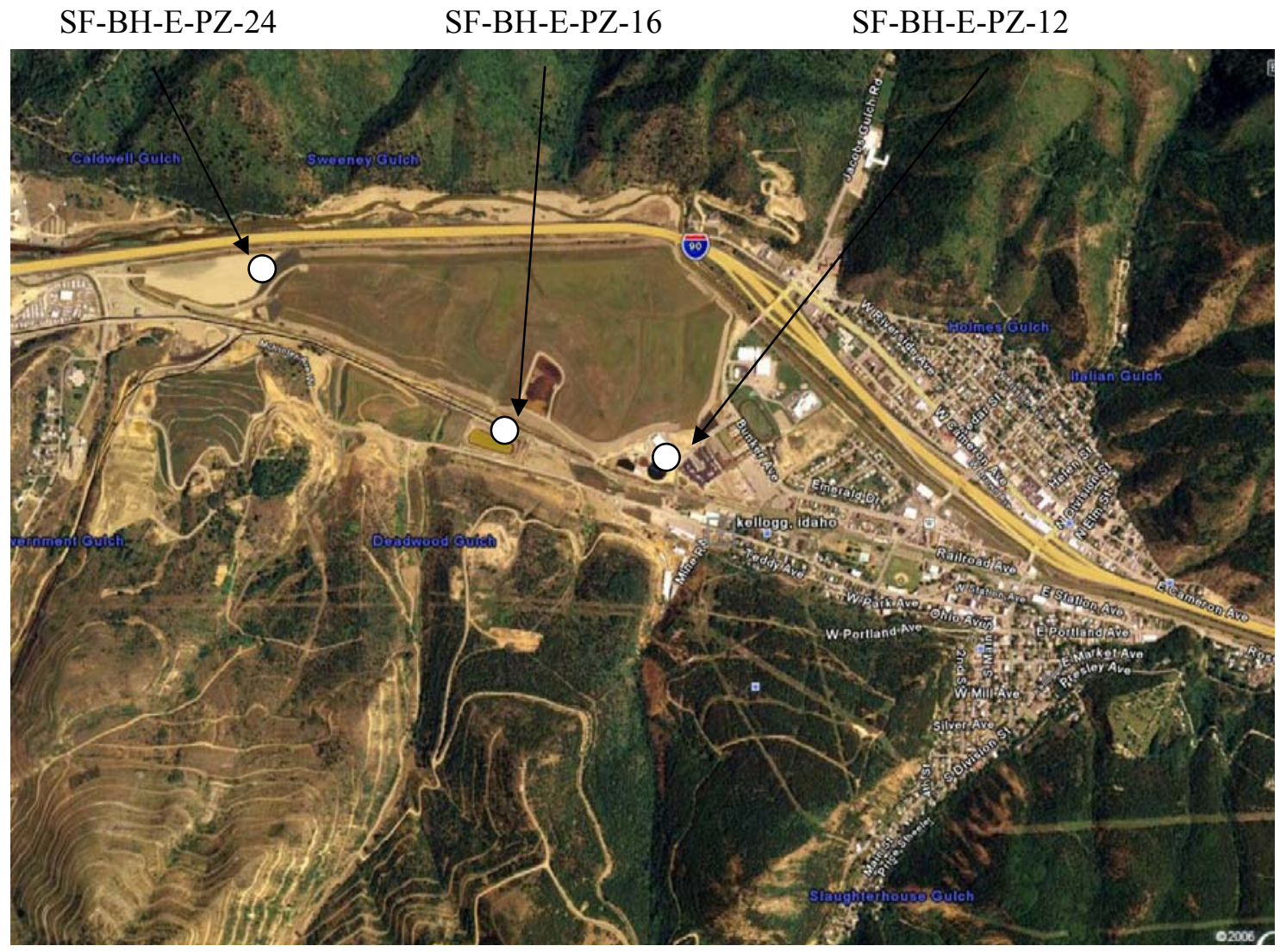

Figure 1. Soil core locations.

Table 1. Core identification numbers and depth of samples collected.

\begin{tabular}{|l|c|c|c|c|c|}
\hline \multicolumn{1}{|c|}{ Core ID } & \multicolumn{5}{|c|}{ Sample Depth } \\
\hline & $1-2$ feet & $3-4$ feet & 5-6 feet & $7-8$ feet & 8-9 feet \\
\hline SF-OB-PZ-13 & $\mathrm{x}$ & $\mathrm{x}$ & $\mathrm{x}$ & No Sample & No Sample \\
\hline SF-BH-E-PZ-12 & $\mathrm{x}$ & $\mathrm{x}$ & $\mathrm{x}$ & $\mathrm{x}$ & $\mathrm{x}$ \\
\hline SF-BH-E-PZ-16 & $\mathrm{x}$ & $\mathrm{x}$ & $\mathrm{x}$ & $\mathrm{x}$ & No Sample \\
\hline SF-BH-E-PZ-24 & $\mathrm{x}$ & $\mathrm{x}$ & $\mathrm{x}$ & $\mathrm{x}$ & No Sample \\
\hline
\end{tabular}




\subsubsection{Sample Collection}

A truck-mounted vibrating coring device known as a rotosonic drill was used to collect the core samples at each location (Figure 2).

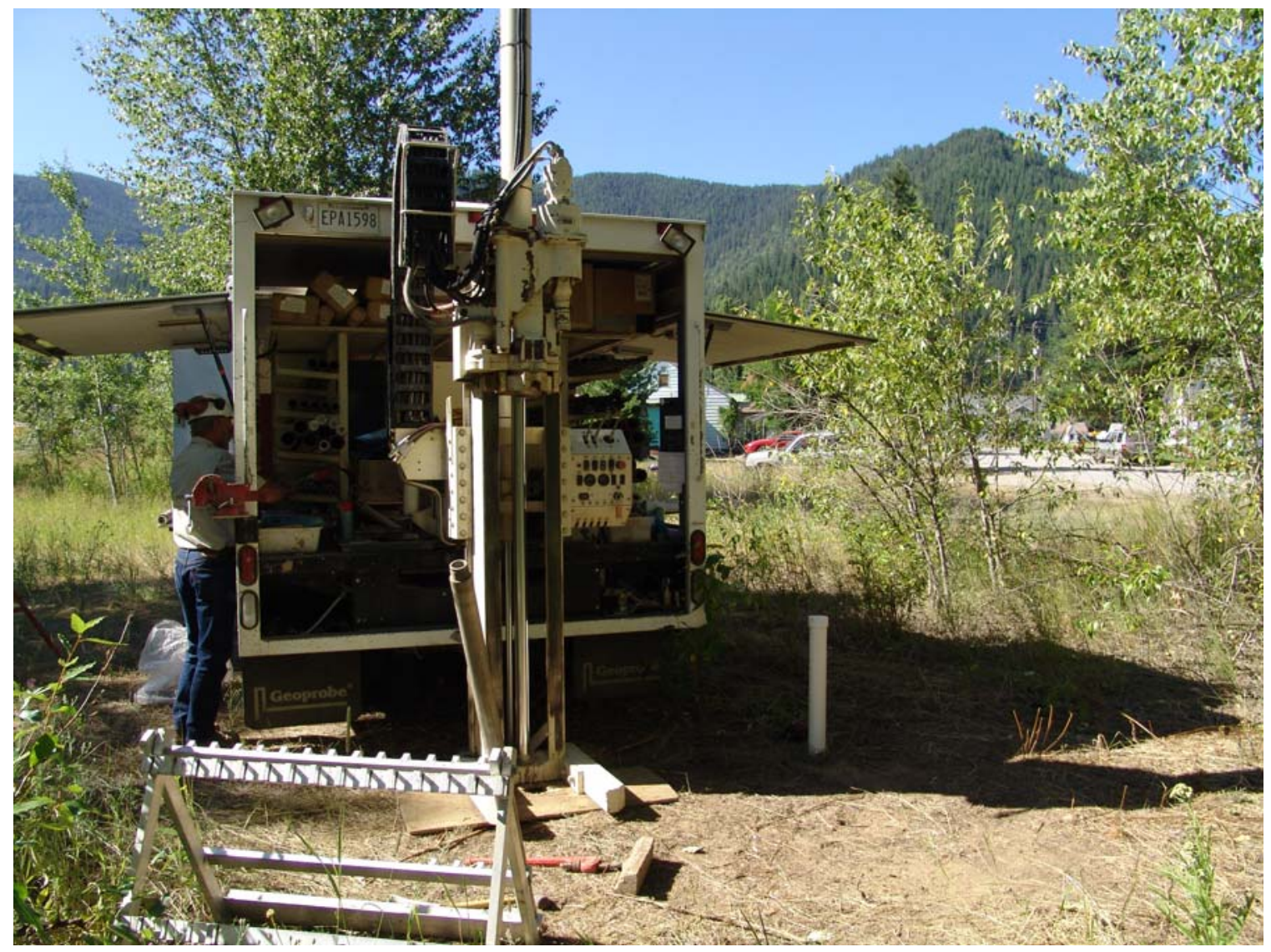

Figure 2. Truck-mounted rotosonic drill rig.

The coring device used a sectioned steel pipe with a 2-in. diameter polycarbonate liner. The pipe was driven into the sediments and cores were retrieved in the polycarbonate liner. The liner was withdrawn from the steel pipe and cut into sections approximately $12 \mathrm{in.} \mathrm{long.} \mathrm{Primary} \mathrm{sub-samples} \mathrm{were} \mathrm{taken} \mathrm{from}$ the top, bottom, and intermediate intervals from each of the three cores. The core sections, still surrounded by the polycarbonate liner, were immediately capped, taped, labeled, placed in liquid nitrogen for storage, and transported to INL for analysis. The cores were held at liquid nitrogen temperatures until testing began. Prior to testing, the sediments were thawed, dried, and sieved in an oxygen free anaerobic chamber, with the $<2 \mathrm{~mm}$ fraction being retained and used in the subsequent extraction and leach tests.

\subsubsection{Sequential Extractions}

The sequential extraction procedure was adapted from the method reported by Tessier (Tessier et al., 1979). There are recognized limitations to using sequential extraction methods for determining metal speciation and many variations to the Tessier standard procedure have been proposed (Gleyzes et al., 2002). Given that the previous study of the Canyon Creek area used this method, the same procedure was used to facilitate comparison of results (Wright et al., 2007). The Tessier method (Tessier, 1979) was followed with the exceptions of eliminating Step 3 (Fe/Mn/Al hydrous oxide bound) to reduce cost. The residue sediment remaining after the extractions were complete was sent to an EPA contract laboratory 
for the final total digestion and analysis step (Phase 4 below). Briefly, the extraction procedure subjects the sample to conditions that should preferentially remove metals associated with different environments: ion-exchangable, acid-soluble, oxides/organic-bound/sulfides, and the residual. Extractant solutions from each step were adjusted to $\mathrm{pH} 2$ with $\mathrm{HNO}_{3}$ and stored in labeled polypropylene centrifuge tubes in a refrigerator at $4{ }^{\circ} \mathrm{C}$ until shipped to the EPA-specified contract laboratories for analysis. The first two steps of the sequential extraction, ion-exchangable and acid-soluble were conducted in an anaerobic chamber with low to now oxygen present.

The water used in the following extraction procedures was 18-Mohm deionized water, and was prepared by reverse osmosis using a Barnstead deionization unit. All reagents used were reagent grade.

Phase 1 (ion-exchangable): $1 \mathrm{M} \mathrm{MgCl}_{2}: 203.33 \mathrm{~g} \mathrm{MgCl}_{2} 6 \mathrm{H}_{2} \mathrm{O}$ was dissolved in deionized water and diluted to $1 \mathrm{~L}$ with deionized water. The solution $\mathrm{pH}$ was adjusted to $\mathrm{pH} 7$ with $\mathrm{NaOH}$ or $\mathrm{HNO}_{3}$ as needed.

Phase 2 (acid-soluble): 82.03g Na-acetate was dissolved in $\sim 800 \mathrm{ml}$ water. The $\mathrm{pH}$ was adjusted to 5 using acetic acid and diluted to $1 \mathrm{~L}$ with deionized water.

Phase 3 (oxidizable, organic-bound, and some sulfides): A mixture of $9 \mathrm{~mL} 0.02 \mathrm{M} \mathrm{HNO}$ and $15 \mathrm{~mL}$ $30 \% \mathrm{H}_{2} \mathrm{O}_{2}$ were adjusted to $\mathrm{pH} 2$ with $\mathrm{HNO}_{3}, 3.2 \mathrm{M}$ ammonium acetate was prepared by dissolving 246.7 $\mathrm{g}$ of reagent grade $\mathrm{CH}_{3} \mathrm{COONH}_{4}$ in $20 \% \mathrm{HNO}_{3}$ and diluting to $1 \mathrm{~L}$ with $20 \% \mathrm{HNO}_{3}$.

Phase 4 (residual): For the residual phase, the remaining sediment was collected and shipped to an EPA contract laboratory for analysis.

\subsubsection{Extraction Procedures}

- Phase 1: Approximately $3 \mathrm{~g}$ dry sediment was placed in a 50-ml polypropylene centrifuge tube. Twenty four $\mathrm{mL} 1 \mathrm{M} \mathrm{MgCl}_{2}$ at $\mathrm{pH}=7$ was added and the mixture was agitated for 1 hour. The suspension was centrifuged at 12,000 rpm for 30 minutes and the supernatant was decanted and saved for analysis. Twenty-four $\mathrm{mL}$ water was added to the suspension and the contents mixed, and centrifuged again at 12,000 rpm for 30 minutes. The liquid rinse was decanted and discarded.

- Phase 2: Twenty-four $\mathrm{mL} 1 \mathrm{M}$ sodium acetate at $\mathrm{pH} 5$ was added to the sediment from Phase 1 and agitated for 5 hours. The $\mathrm{pH}$ was monitored and adjusted to $\mathrm{pH} 5$ if necessary with additional measured volumes of acetic acid. The suspension was centrifuged and the supernatant saved for analysis. The residue was mixed with $24 \mathrm{~mL}$ water, centrifuged as before and the supernatant discarded.

- Phase 3: To the sediment from Phase 2 was added $9 \mathrm{~mL} 0.02 \mathrm{M} \mathrm{HNO}_{3}$ and $15 \mathrm{ml} 30 \% \mathrm{H}_{2} \mathrm{O}_{2}$ (adjusted to $\mathrm{pH} 2$ with $\mathrm{HNO}_{3}$ ). The mixture was loosely capped, weighed, and heated to $85^{\circ} \mathrm{C}$ for 2 hours with occasional agitation. After 2 hours the sample was brought back to the original weight with a 3:5 mixture of $0.02 \mathrm{M} \mathrm{HNO}_{3}$ and $30 \% \mathrm{H}_{2} \mathrm{O}_{2}$. Fifteen $\mathrm{mL}$ of $30 \% \mathrm{H}_{2} \mathrm{O}_{2}$ (adjusted to $\mathrm{pH} 2$ with $\mathrm{HNO}_{3}$ ) were added and the sample was weighed and heated to $85^{\circ} \mathrm{C}$ with occasional agitation. After 3 hours the samples were cooled to room temperature and the original weight was regained with the addition of more $30 \% \mathrm{H}_{2} \mathrm{O}_{2}$. Fifteen $\mathrm{mLs}$ of $3.2 \mathrm{M} \mathrm{CH}_{3} \mathrm{COONH}_{4}$ in $20 \% \mathrm{v} / \mathrm{v} \mathrm{HNO}_{3}$ was added with water to dilute the sample to $60 \mathrm{~mL}$ total volume. The mixture was agitated for 30 minutes, and then centrifuged and washed as in the previous steps.

- Phase 4: The remaining sediment after the above extractions were collected was shipped to an EPA contract laboratory for analysis.

The collected phases and residue from each test were analysized for the following elements: $\mathrm{Ca}, \mathrm{Cd}$, $\mathrm{Fe}, \mathrm{Mg}, \mathrm{Mn}, \mathrm{Pb}, \mathrm{S}$ and $\mathrm{Zn}$. 


\subsubsection{Leach Tests}

Two types of leach tests were carried out. The first series of leach tests were conducted under anoxic conditions at 6 different $\mathrm{pH}$ levels $(2,3,4,5,6$, and 7$)$ to observe the effect of $\mathrm{pH}$ on the leachability of the elements. This test was conducted on the sediments samples under anaerobic conditions to simulate sediments that are held under saturated anoxic conditions. The second series of leach tests were performed on sediments which had been exposed to air and several wet/dry cycles in order to simulate microbial sulfide oxidation that would exist above the saturated zone. The tests were completed using composites of all of the cores from each location. The leach tests were carried out as described in the next two sections.

\subsubsection{Leach test to indicate the sensitivity to a lower $\mathrm{pH}$}

Composites of all the cores ( $2 \mathrm{~mm}$ sieved samples) from each location were made. This was accomplished by combining all of the remaining material from the core location and tumbling the container for 2 minutes. Fifty gram sub-samples of sediment were added to a $500 \mathrm{ml}$ bottle in an anaerobic chamber to which $500 \mathrm{ml}$ of simulated groundwater was added (Table 2). Simulated groundwater was formulated from groundwater data collected on 9/25/08 for SF-OB-PZ-13, and data collected on 10/09/08 for SF-BH-E-PZ-12, SF-BH-E-PZ-16, SF-BH-E-PZ-24 (Table 2). Six different pH

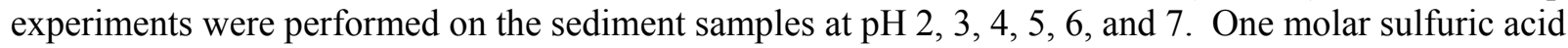
was used to adjust $\mathrm{pH}$ down and $200 \mathrm{mM}$ sodium hydroxide was used to adjust $\mathrm{pH}$ up as necessary.

Simulated groundwater (Table 2.) was autoclaved to decrease the oxygen concentration in the water. The simulated groundwater was then placed in an anaerobic chamber for 3 days for further removal of $\mathrm{O}_{2}$. The sediment samples were handled in a sealed chamber with nitrogen $(90 \%)$, carbon dioxide (5\%), and hydrogen $(5 \%)$ gasses and a palladium catalyst to scavenge oxygen from the air in the glovebox. The sediment samples were place into bottles, the leaching solution was added, and the bottles were sealed inside the anaerobic chamber. The sealed bottles were placed on a shaker at $\sim 120 \mathrm{rpm}$. Leaching was done for 3 months, with a $10 \mathrm{ml}$ solution sample pulled at time zero, 8 hours, 16 hours, 24 hours, 3 days, 7 days, 1 month, 2 months, and 3 months. All aliquot samples were diluted to $20 \mathrm{~mL}$ with $\mathrm{pH} 2 \mathrm{HNO}_{3}$ and sent to an EPA approved laboratory for analysis. The $\mathrm{pH}$ was adjusted with $1 \mathrm{M} \mathrm{H}_{2} \mathrm{SO}_{4}$ or $0.2 \mathrm{M}$ $\mathrm{NaOH}$ to bring each experiment back to the original $\mathrm{pH}$ when sampling or at least once per week.

Table 2. Simulated groundwater makeup.

\begin{tabular}{|l|l|l|l|l|}
\hline $\mathrm{g} / \mathrm{L}$ & SF-OB-PZ-13 & SF-BH-E-PZ-12 & SF-BH-E-PZ-16 & SF-BH-E-PZ-24 \\
\hline $\mathrm{Mg}_{2} \mathrm{SO}_{4} \cdot 7 \mathrm{H}_{2} \mathrm{O}$ & 0.05 & 0.207 & 0.93 & 0.99 \\
\hline $\mathrm{KCl}$ & 0.002 & 0.0056 & 0.0075 & 0.013 \\
\hline $\mathrm{CaCO}$ & 0.056 & 0.08 & 0.01 & 0.23 \\
\hline $\mathrm{NaCl}$ & 0.01 & 0.0027 & 0 & 0 \\
\hline $\mathrm{NaNO}_{2}$ & 0.0001 & 0.00001 & 0.00001 & 0.0001 \\
\hline $\mathrm{NaNO}_{3}$ & 0.0001 & 0.00001 & 0.00001 & 0 \\
\hline $\mathrm{K}_{2} \mathrm{HPO}_{4}$ & 0.0002 & 0 & 0.004 & 0.0042 \\
\hline $\mathrm{Na}_{2} \mathrm{SO}_{4}$ & 0.014 & 0.035 & 0.014 & 0.0327 \\
\hline$\left(\mathrm{NH}_{4}\right)_{2} \mathrm{SO}_{4}$ & 0.00002 & 0 & 0 & 0 \\
\hline $\mathrm{FeSO}_{4}$ & 0 & 0.02 & 0.0001 & 0.111 \\
\hline
\end{tabular}

\subsubsection{Leach Test to compare the effects of wet/dry cycling followed by aerobic or anoxic conditions}

Two sets of leaching experiments were conducted to compare different conditions that may result from sulfide oxidation. The first leaching experiment used soil samples that were fully exposed to air for two weeks of wet/dry cycles followed by leaching with simulated infiltrating surface water (deionized 
water) under aerobic conditions. The second leaching test used soil samples that were fully exposed to air for two weeks of wet/dry cycles followed by leaching with simulated groundwater under low/no oxygen conditions.

The first leaching experiment (aerobic) was conducted using composites of all the cores $(<2 \mathrm{~mm}$ sieved samples) from each location. Fifty grams of soil was taken from each location and placed in aluminum trays. These were left at room temperature with full air exposure for 2 weeks. Samples were sprayed 1-3 times per day, until the sediment was saturated with deionized water to stimulate a wet/dry cycle (rain water) resulting from precipitation events. After the two week time interval, five hundred $\mathrm{ml}$ of deionized water was added to the four $50 \mathrm{~g}$ soil samples and these were shaken aerobically at $\sim 120 \mathrm{rpm}$ for the duration of the test. Leaching was done for 3 months, with $10 \mathrm{ml}$ samples pulled from each soil sample. Liquid samples were taken at time zero, 8 hours, 16 hours, 24 hours, 3 days, 7 days, 1 month, 2 months, and 3 months. Samples were diluted to $20 \mathrm{~mL}$ with $\mathrm{pH} 2 \mathrm{HNO}_{3}$ and sent to an EPA approved laboratory for analysis. The $\mathrm{pH}$ of the samples was measured but not adjusted during the testing interval.

The second leaching experiment (anoxic) was conducted using composites of all the cores $(<2 \mathrm{~mm}$ sieved samples) from each location. Fifty grams of soil was taken from each location and placed in aluminum trays. These were left at room temperature with full air exposure for 2 weeks. Samples were sprayed 1-3 times per day, until the sediment was saturated with deionized water to stimulate a wet/dry cycle (rain water) resulting from precipitation events. Groundwater data collected on 9/25/08 for SF-OBPZ-13, and groundwater data collected on 10/09/08 for SF-BH-E-PZ-12, SF-BH-E-PZ-16, SF-BH-E-PZ24 was used to formulate the simulated groundwater (see Table 2). Oxygen was removed from the simulated groundwater as above and $500 \mathrm{ml}$ was added to each $50 \mathrm{~g}$ sample of soil in the anaerobic chamber. The anoxic soil samples were then sealed and placed on a shaker at $\sim 120 \mathrm{rpm}$. Leaching was done for 3 months, with $10 \mathrm{ml}$ samples pulled in the anaerobic chamber for anoxic soil samples. Liquid samples were taken at time zero, 8 hours, 16 hours, 24 hours, 3 days, 7 days, 1 month, 2 months, and 3 months. Samples were diluted to $20 \mathrm{~mL}$ with $\mathrm{pH} 2 \mathrm{HNO}_{3}$ and sent to an EPA approved laboratory for analysis. The $\mathrm{pH}$ of the samples was measured but not adjusted during the testing interval. 


\section{RESULTS}

The results of this project are separated into two sections: Sequential Extractions and Leach Tests. The data for each is presented in section 2.1 and 2.2 respectively. Prior to conducting the tests, samples were maintained in an anoxic frozen condition to prevent oxidation and reaction (biological and chemical) from occurring.

\subsection{Sequential Extractions}

The first step in the sequential extraction (shown as phase I in the Figures below) represents the most easily extractable or exchangeable portion of the elements present in the sediment. It is extracted by leaching the soil with $1 \mathrm{M} \mathrm{MgCl}_{2}(\mathrm{pH}=7)$ for 1 hour. This step of the sequential extraction was conducted under anoxic conditions to minimize the effect of oxidation prior to or during the extraction procedure.

The second step of the extraction is designed to liberate the specifically sorbed or carbonate bound elements. This phase is extracted by leaching the soil with $1 \mathrm{M}$ sodium acetate adjusted to $\mathrm{pH} 5$ with acetic acid for 5 hours. This step of the sequential extraction was also conducted in a low- to no-oxygen environment, again to remove outside influences of oxidation on the samples. In the figures below, the second fraction is presented as Phase II.

The third extraction step represents a combination of the organic bound fraction, and some of the $\mathrm{Fe} / \mathrm{Mn} / \mathrm{Al}$ hydrous oxide bound fraction (that would have been released in the $0.04 \mathrm{M}$ hydroxylamineHCL in $25 \% \mathrm{v} / \mathrm{v}$ acetic acid step) and some sulfides of the elements present in the soil. These elements are frequently bound to various forms of organic matter, however, because the step that selectively removes the oxide fraction was skipped, this third extraction will also remove some metal oxides resulting from exposure to air and pyrometallurgical ore processing. In addition, some portion of the residual metal sulfides that are present will be extracted. Under strong oxidizing conditions organic matter, $\mathrm{Fe} / \mathrm{Mn} / \mathrm{Al}$ hydrous oxide bound and some sulfides can be degraded to release the soluble elements. This fraction is extracted by leaching with $0.02 \mathrm{M} \mathrm{HNO}_{3}$ and $30 \% \mathrm{H}_{2} \mathrm{O}_{2}$ (adjusted to $\mathrm{pH} 2$ with $\mathrm{HNO}_{3}$ ) for five hours at $85^{\circ} \mathrm{C}$, and then add $3.2 \mathrm{M} \mathrm{CH}_{3} \mathrm{COONH}_{4}$ in $20 \% \mathrm{v} / \mathrm{v} \mathrm{HNO}_{3}$ for 30 minutes. In the figures below, the third extraction is presented as Phase III. The remaining sediment was sent to an EPA laboratory where it underwent a total digestion and analysis for remaining elements. This fraction is referred to as the residual or total fraction of metal.

The fractions shown in the following graphs represent the concentrations of elements present only in the soil that was in the $>2 \mathrm{~mm}$ fraction. In general there were no consistent trends in the first three phases of the extraction. But there was a general trend in the residual metal concentrations in the soil. Typically, the concentrations of elements remaining in the residual fraction, was highest near the surface. Assuming that the material is generally consistent with depth with respect to the origination of the material, the material at the surface contains material that is typically harder to extract with the 3 extraction methods used in this study. This is consistent with years of oxidation occurring near the surface of the material.

\subsubsection{Sample Location SF-OB-PZ-13}

This site was located near Osborn, Idaho. Figure 3 shows the location where the core samples were collected. Figures $4-6$ show the core samples collected from this location as they were opened in an oxygen free glovebox. 


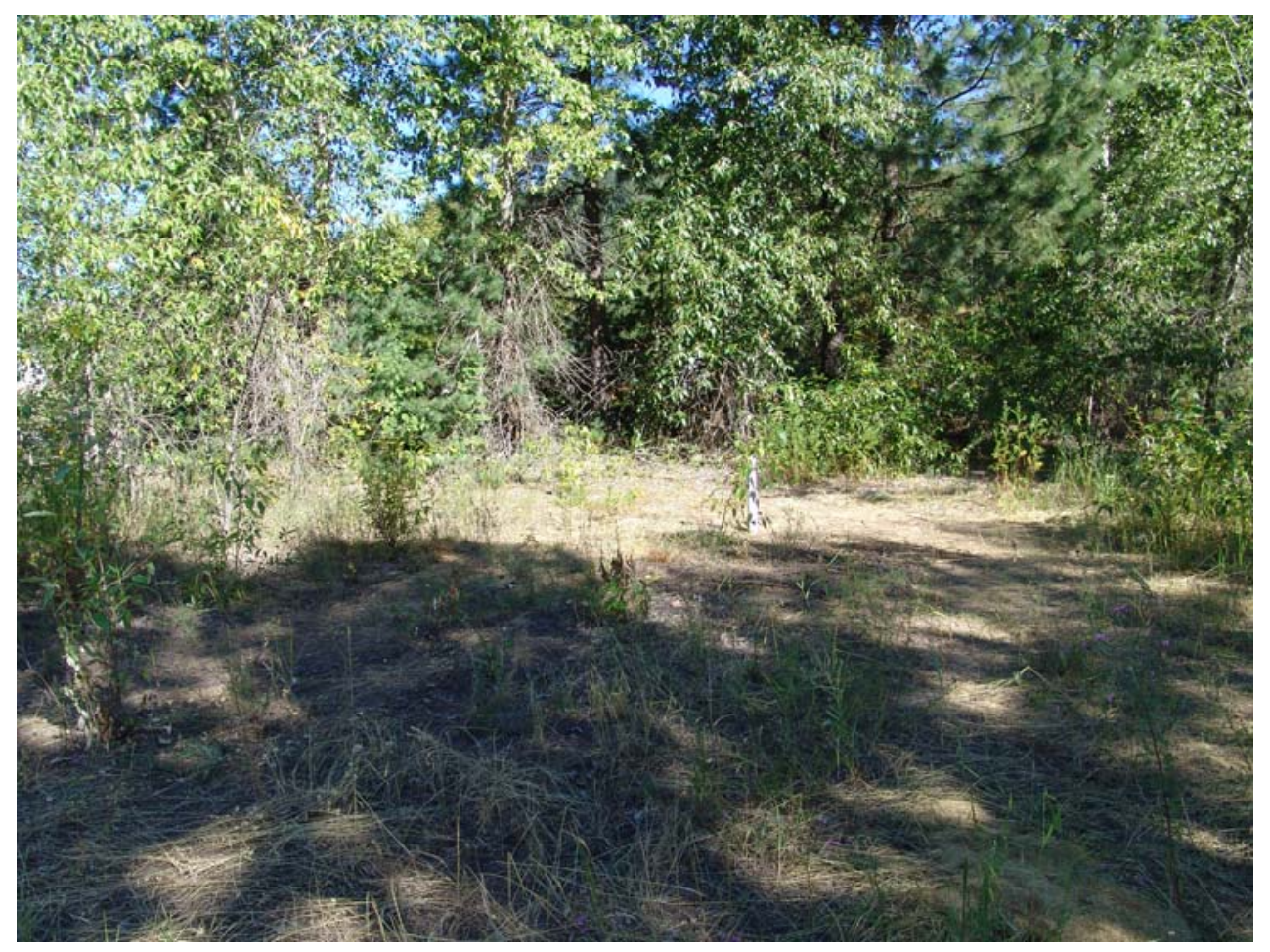

Figure 3. Sample core location near Osborn, Idaho.

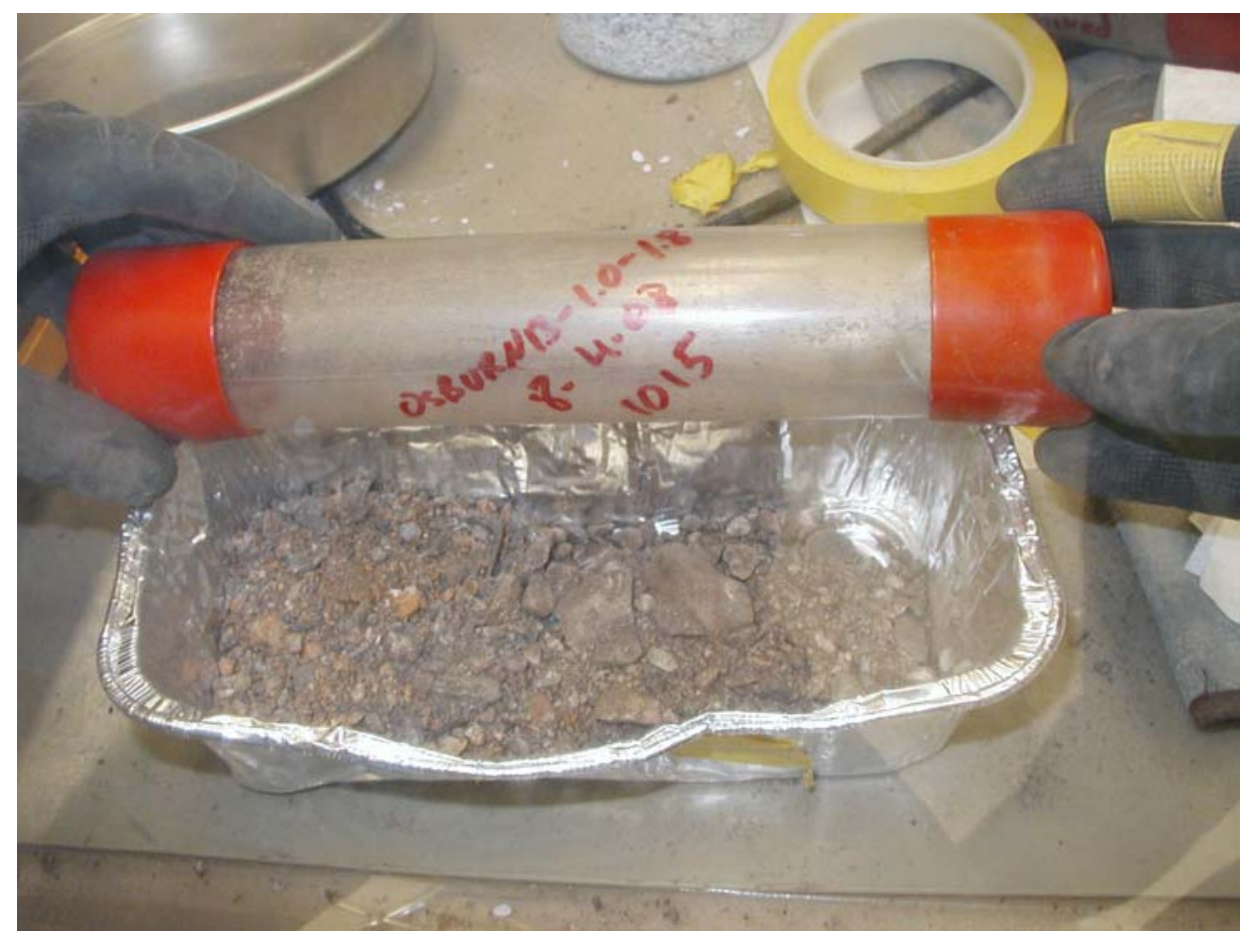

Figure 4. Core sample from location SF-OB-PZ-13, 1.0-1.8-foot depth. 


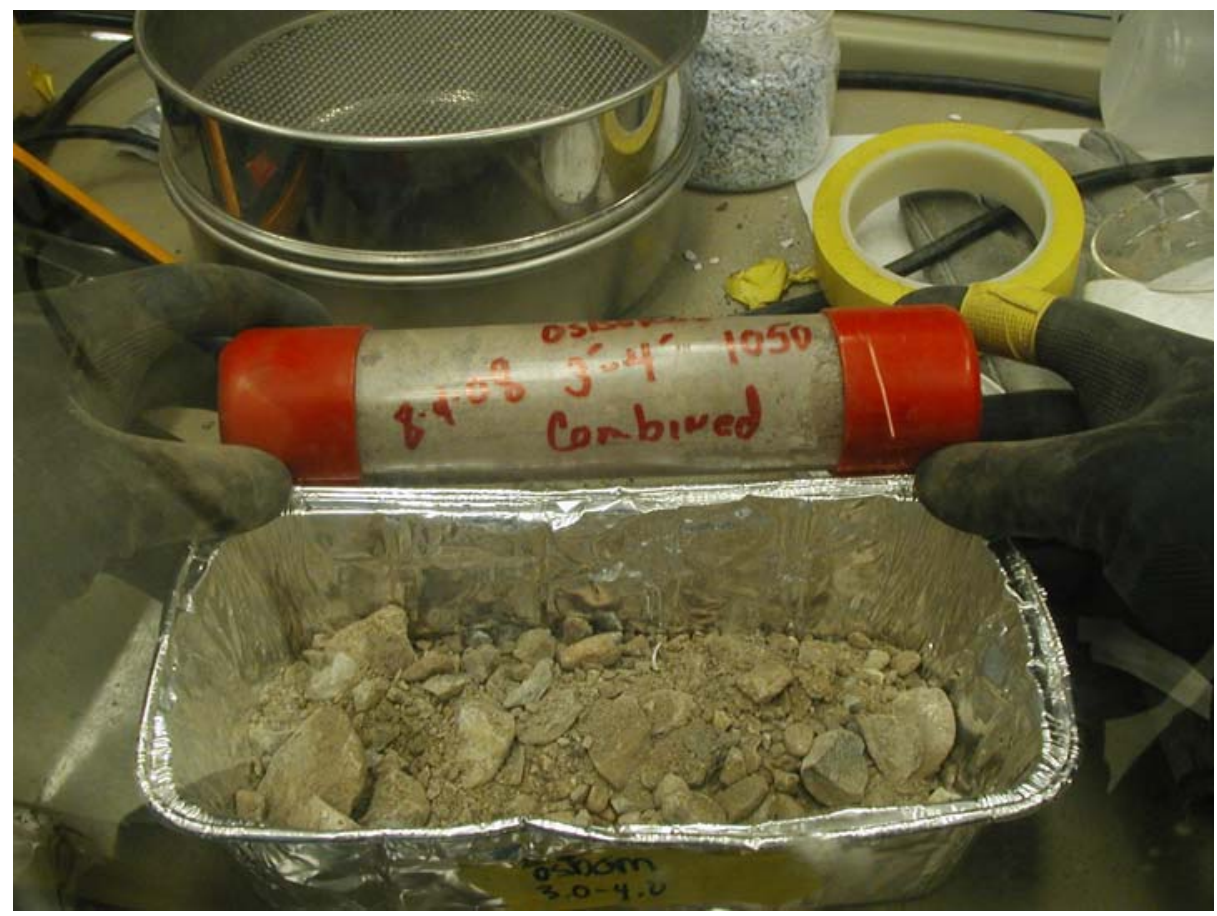

Figure 5. Core sample from location SF-OB-PZ-13, 3.0-4.0-foot depth.

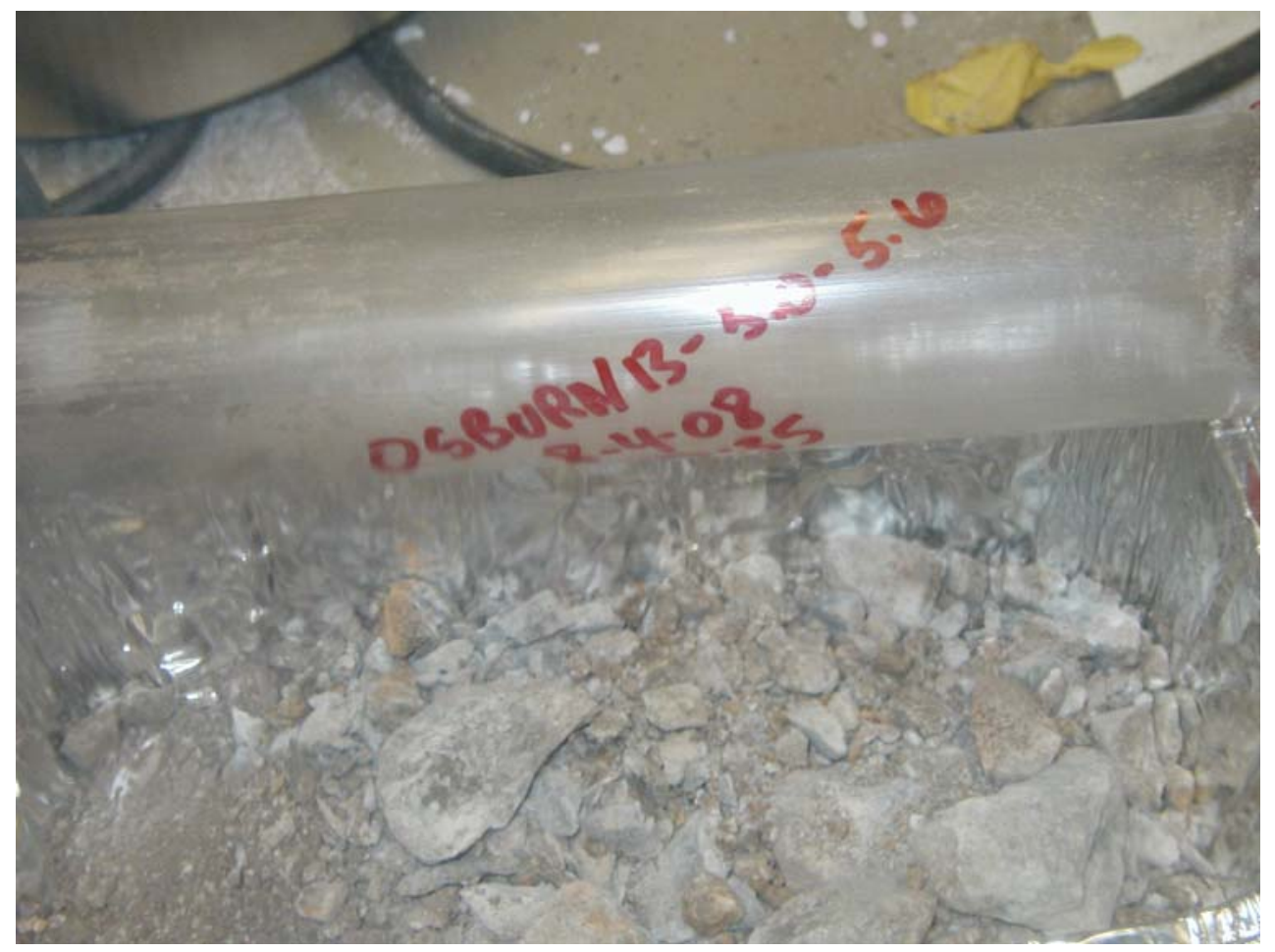

Figure 6. Core sample from location SF-OB-PZ-13, 5.0-5.6-foot depth.

The following series of graphs shows the relative amounts of elements leached from the sediment samples. Figure 7 shows the relative amount of cadmium found at the three soil depths tested. Cadmium concentrations in these sediment samples vary from $72.4 \mathrm{mg} / \mathrm{kg}$ at the surface to $6.3 \mathrm{mg} / \mathrm{kg}$ at 3-4 feet 
and $21.9 \mathrm{mg} / \mathrm{kg}$ at $5-6$ feet below the surface. Comparing Figure 7 with Figures 8 and 9 shows that while the exchangeable cadmium (Phase I) is much higher than the exchangeable lead and zinc, the total concentration of cadmium is much lower than the lead and zinc. For instance the total cadmium concentration in the 3-4 foot depth was measured to be $6.3 \mathrm{mg} / \mathrm{kg}$. The exchangeable cadmium extracted resulted in over $40 \%$ of the cadmium present at this depth, but this represents only $2.5 \mathrm{mg} / \mathrm{kg}$ of Cd. Cadmium is by nature more mobile than most other metals. The amount of cadmium present in the carbonate extractable fraction (Phase II) appears to represent an additional 5-15\% of the total cadmium, and another $10-20 \%$ is found in the organic/oxide/sulfide bound phase (Phase III). Over time, the exchangeable cadmium will be released first. If conditions become more acidic, the carbonate bound cadmium will be released and over time, the cadmium bound to organic matter or as oxides or sulfides will release even slower.

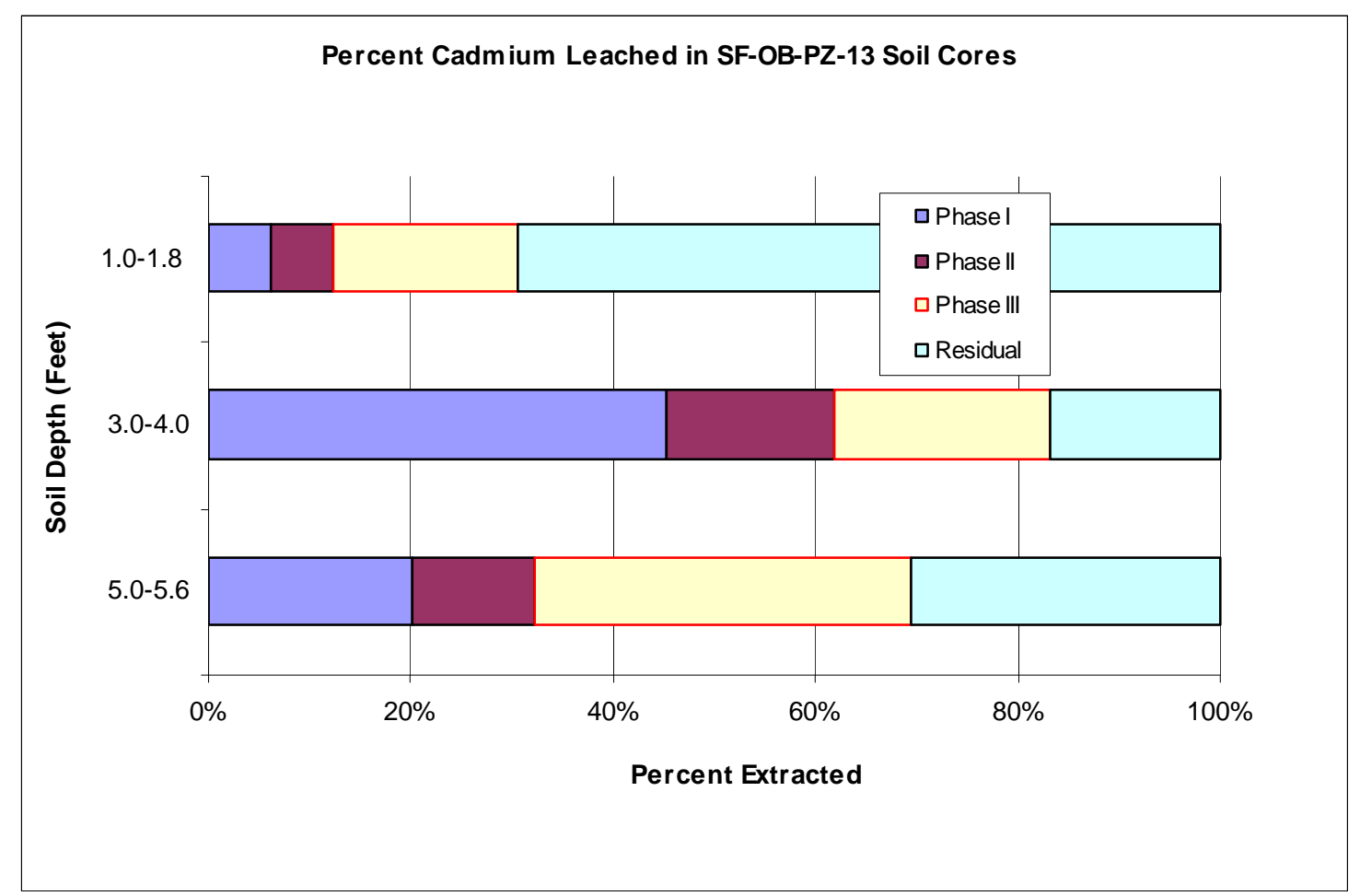

Figure 7. Cadmium percentages present in the Osborn Flats soil core.

The concentration of lead in this soil was measured and ranged from $11,300 \mathrm{mg} / \mathrm{kg}$ at the surface to $1,920 \mathrm{mg} / \mathrm{kg}$ at 3-4 feet, and 3,730 $\mathrm{mg} / \mathrm{kg}$ at 5-6 feet. While the concentration of lead at the surface was quite high, the percent of exchangeable lead in the surface soil was less than $1 \%$ and below $5 \%$ for the $3-4$ foot and the 5-6 foot range as shown in Figure 8. However, the carbonate bound lead accounted for 20$40 \%$ and the organic/oxide/sulfide bound lead accounted for $30-40 \%$ of the total lead in the soil. The amount of lead released from the third extraction step or as an organic bound, oxide, or sulfide was uniform with depth. 
The results show that under normal (non acidic) conditions, the lead in the sediments will tend to remain immobile. However, under increasingly acidic condition, the release of lead will increase and under highly acidic conditions, organic/oxide/ sulfide bound lead will also be released.

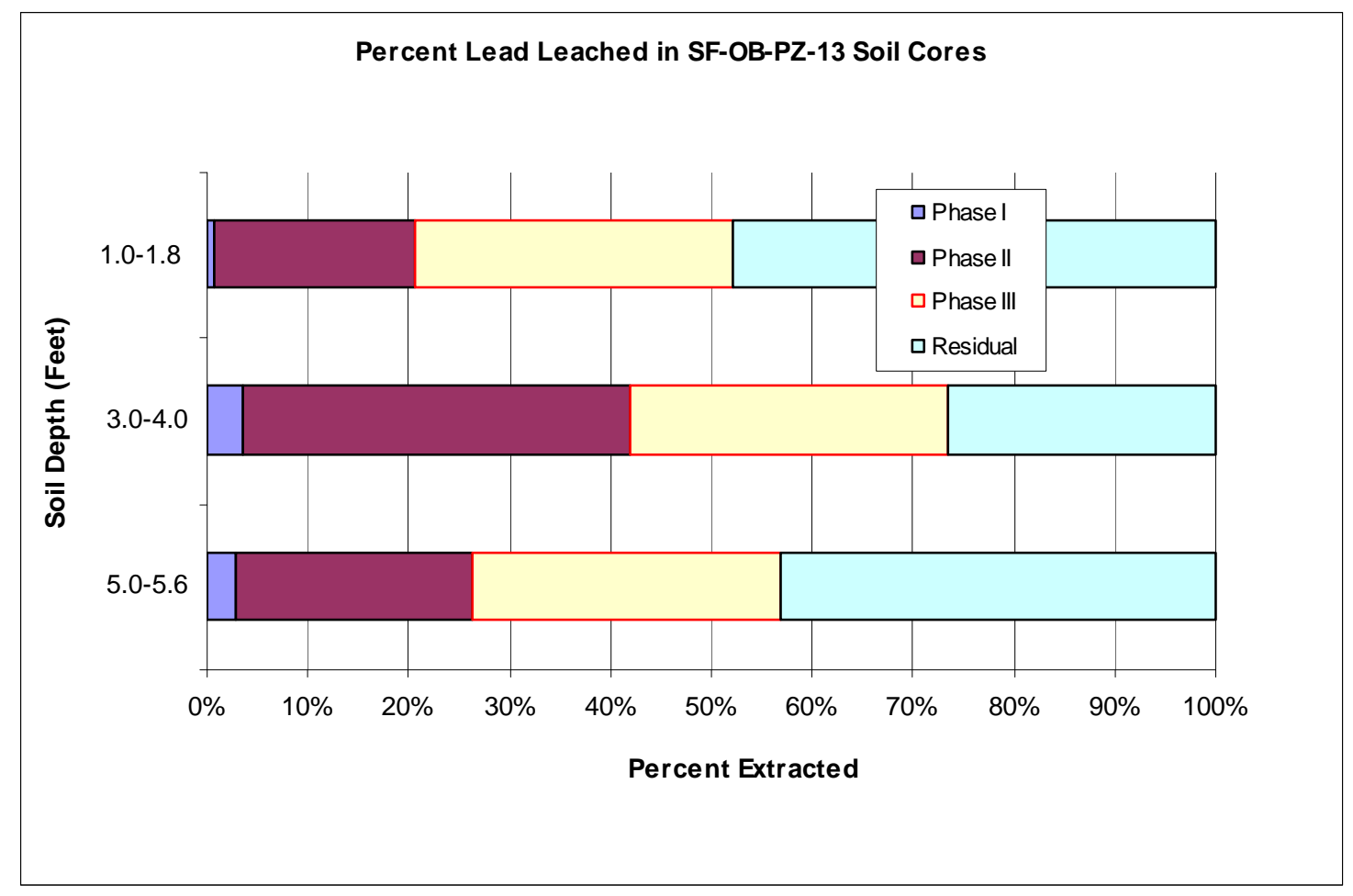

Figure 8. Lead percentages present in Osborn Flats soil cores.

Soil from the Osborn Flats area was analyzed for total zinc, which ranged from $8,560 \mathrm{mg} / \mathrm{kg}$ at the surface to $886 \mathrm{mg} / \mathrm{kg}$ at a depth of 3-4 feet and $3040 \mathrm{mg} / \mathrm{kg}$ at a depth of 5-6 feet. The results in Figure 9 show that only a small amount of the zinc in the soil is present in an exchangeable form (Phase I extraction). In addition, the results from the Phase II and Phase III extractions also show that not more than about $43 \%$ of the zinc is extracted at any depth. Taken together, these results would indicate that the major portion of zinc present in the soil is in some form of refractory mineral, perhaps as a zinc silicate or bound up in another silicate mineral. However, without further analysis of the minerals present in the soil (perhaps by X-ray diffraction) this premise cannot be confirmed. 


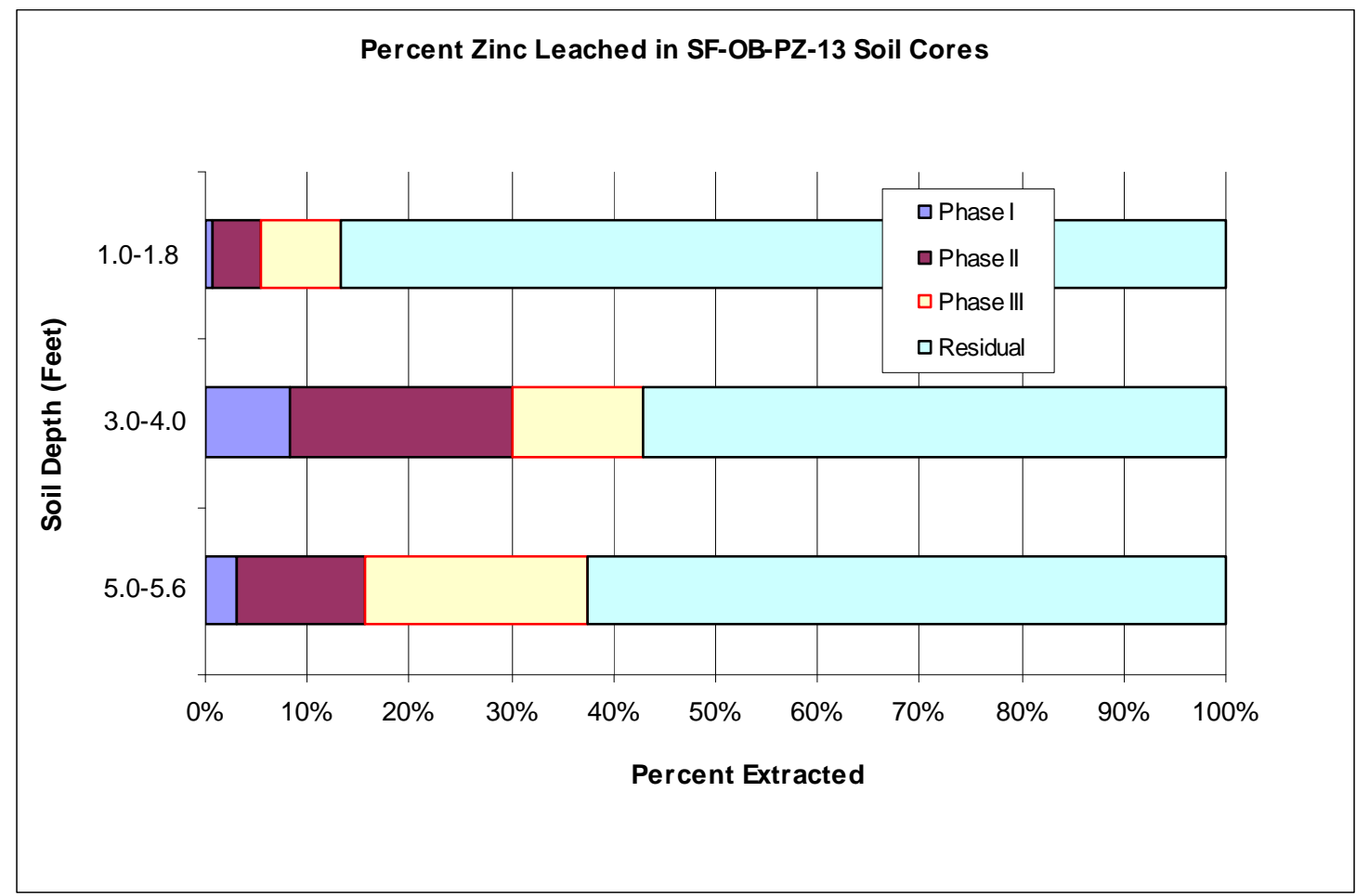

Figure 9. Zinc percentages present in Osborn Flats soil core.

\subsubsection{Bunker Hill Sample SF-BH-E-PZ-12}

Three locations were sampled near the CIA. The first location, near the south east side of the repository, labeled SF-BH-E-PZ-12 on the map above in Figure 1 had cadmium concentrations that ranged from $37.9 \mathrm{mg} / \mathrm{kg}$ at $1-2$ feet, $14.7 \mathrm{mg} / \mathrm{kg}$ at $3-4$ feet, $2.9 \mathrm{mg} / \mathrm{kg}$ at $5-6$ feet, $123 \mathrm{mg} / \mathrm{kg}$ at $7-8$ feet, and $254 \mathrm{mg} / \mathrm{kg}$ at $8-9$ feet. Figure 10 shows the location of this core sample. Figures 11-15 show the core samples as they were opened in the glovebox. Note that in the 8-9 foot section, there was noticeable moisture and the color was a blue grey, much different than the cores taken at other locations. 


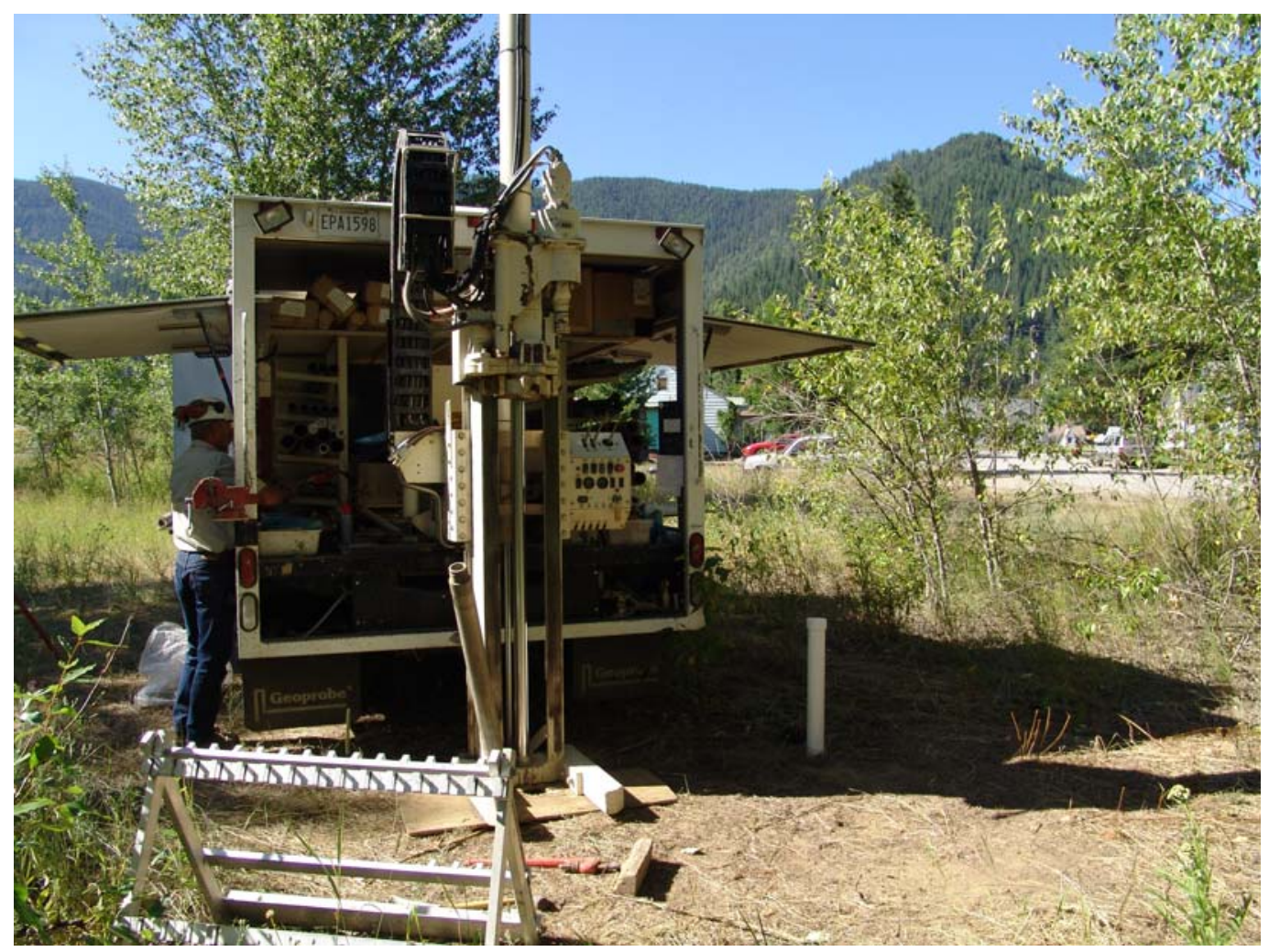

Figure 10. Sample core location SF-BH-E-PZ-12.

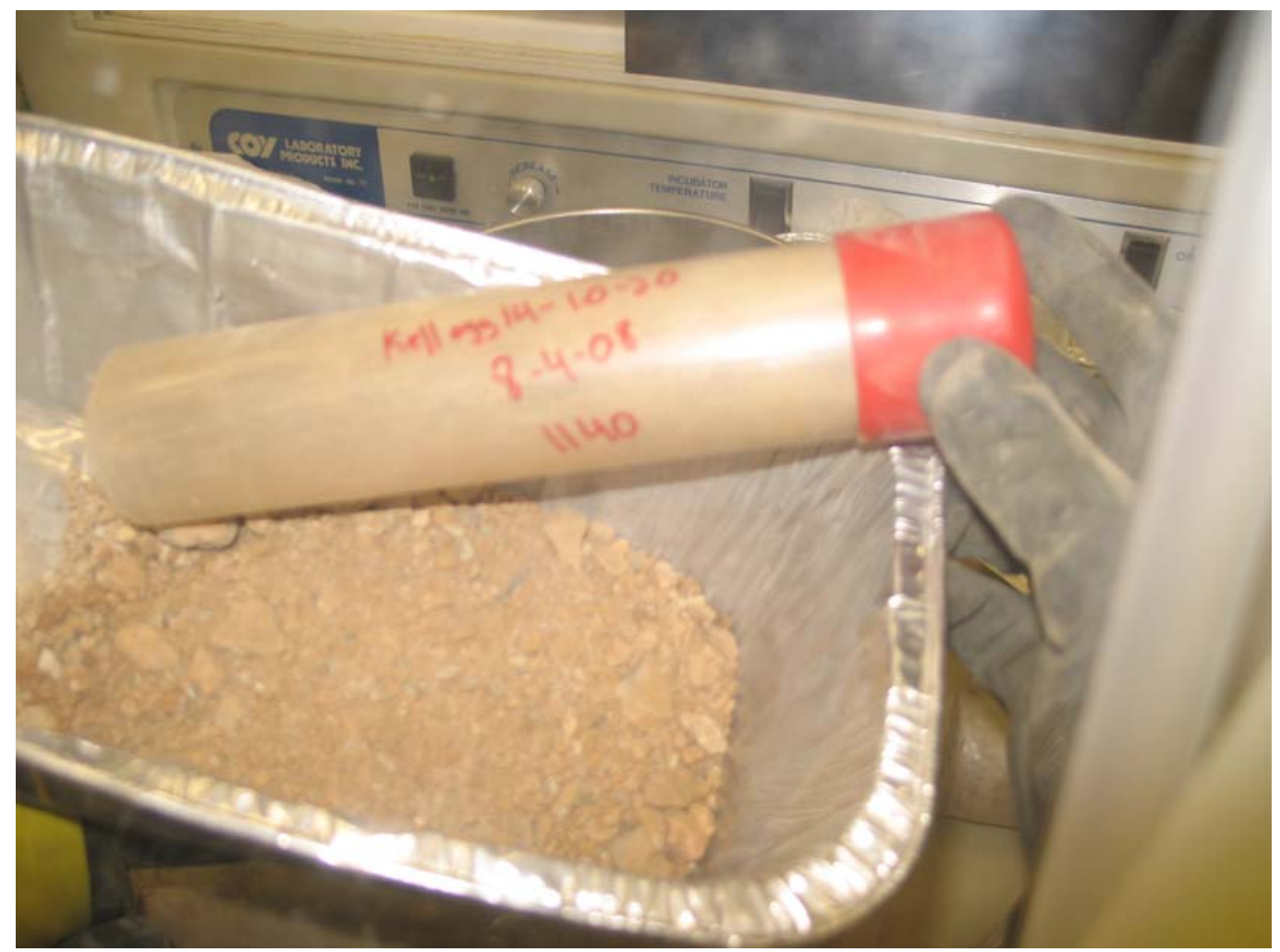

Figure 11. Core sample from location SF-BH-E-PZ-12, 1.0-2.0-foot depth. 


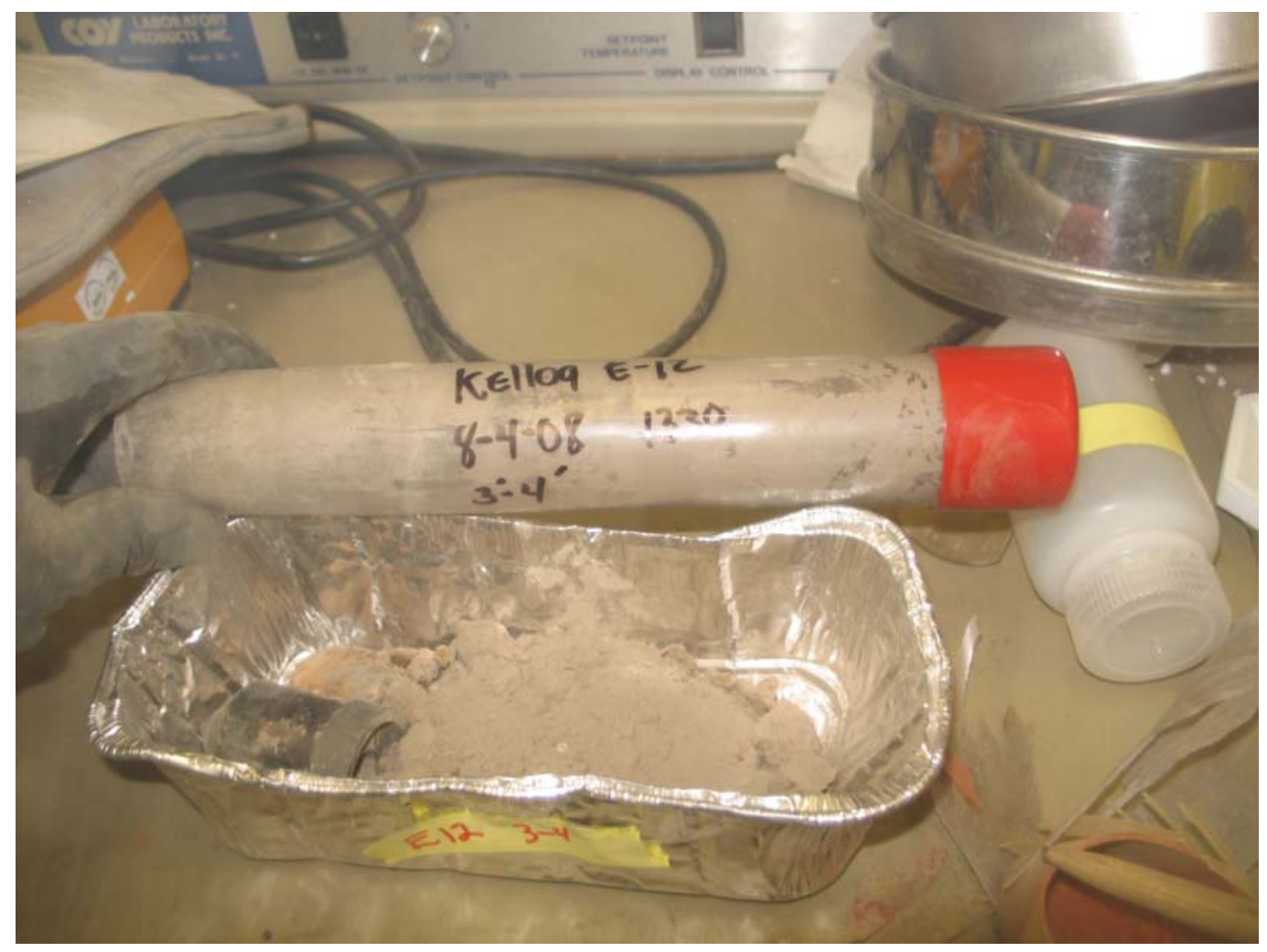

Figure 12. Core sample from location SF-BH-E-PZ-12, 3.0-4.0-foot depth.

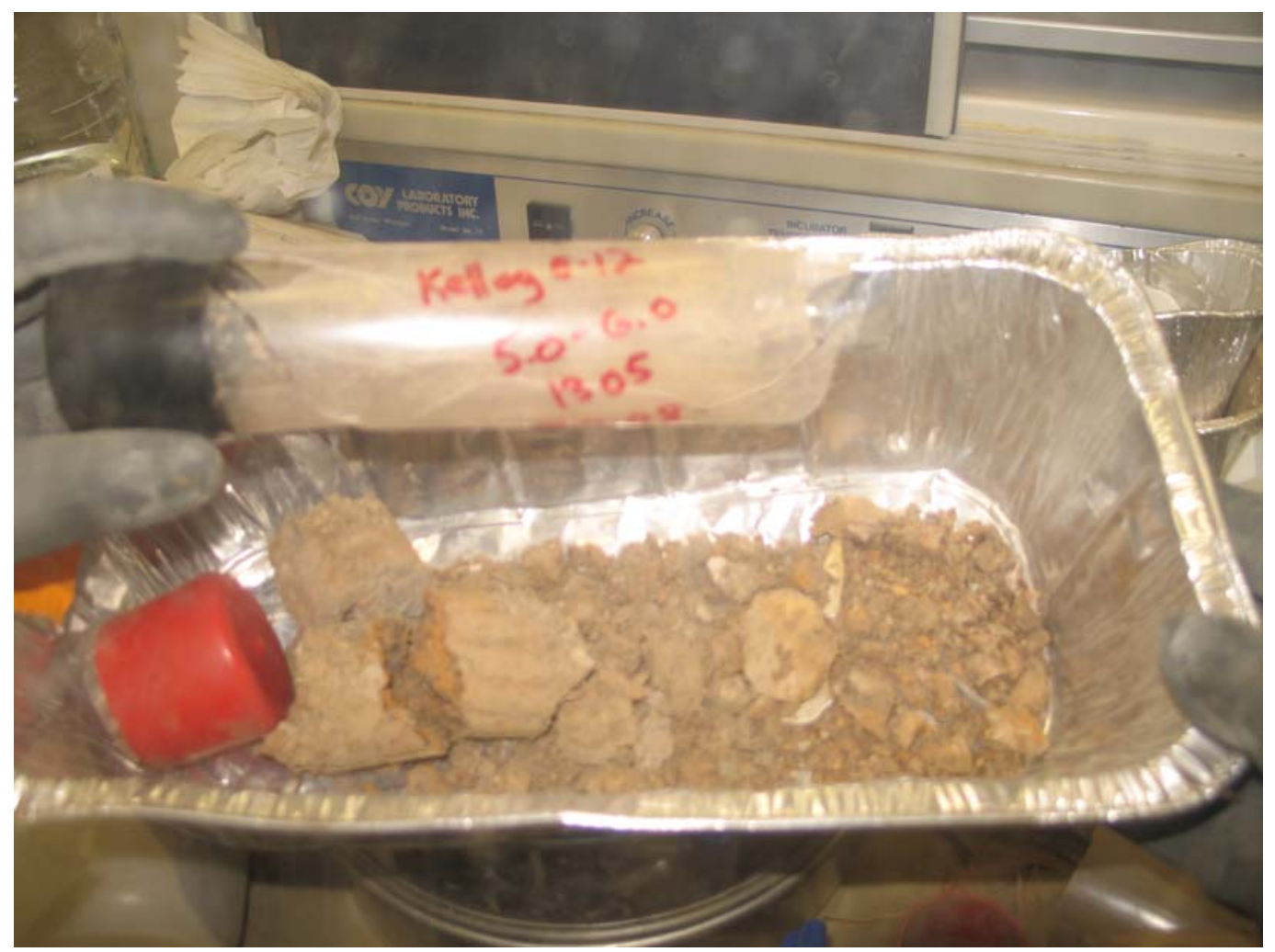

Figure 13. Core sample from location SF-BH-E-PZ-12, 5.0-6.0-foot depth. 


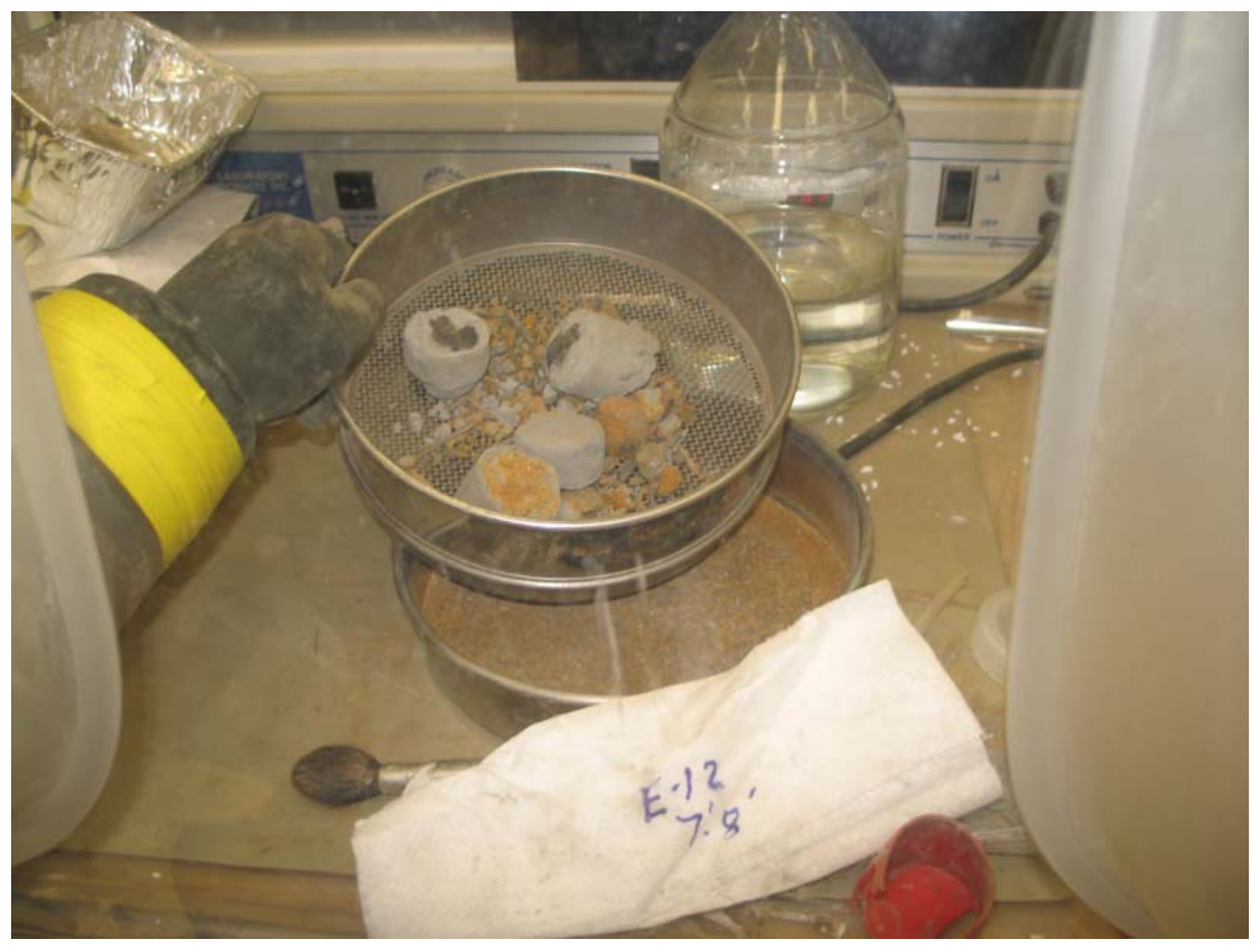

Figure 14. Core sample from location SF-BH-E-PZ-12, 7.0-8.0-foot depth.

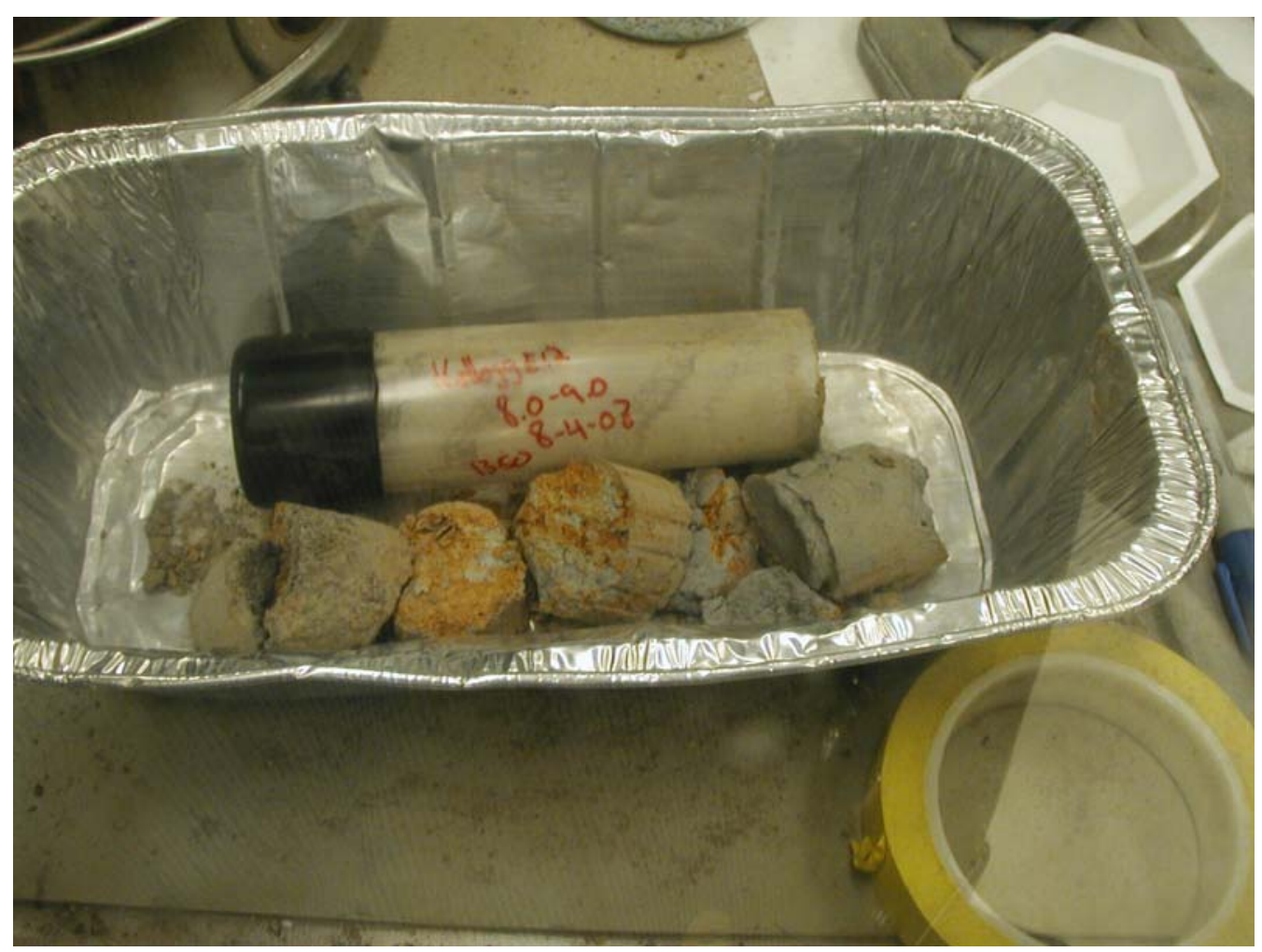

Figure 15. Core sample from location SF-BH-E-PZ-12, 8.0-9.0-foot depth. 
Similar to the Osborn Flats location, the amount of exchangeable cadmium represents a higher percentage than the exchangeable lead or zinc (Phase I, Figure 16-18). At the surface, the carbonate bound cadmium represents a higher percentage, but that percentage decreases with depth. However, at lower depths, the organic/oxide/sulfide bound cadmium accounts for the highest percentage. The results from the 5-6 foot depth would indicate that the cadmium is present in a refractory form at this depth and is difficult to leach (only $17 \%$ of the cadmium was removed). This location is the only one that showed significant trends with depth, with the cadmium being more available near the surface.

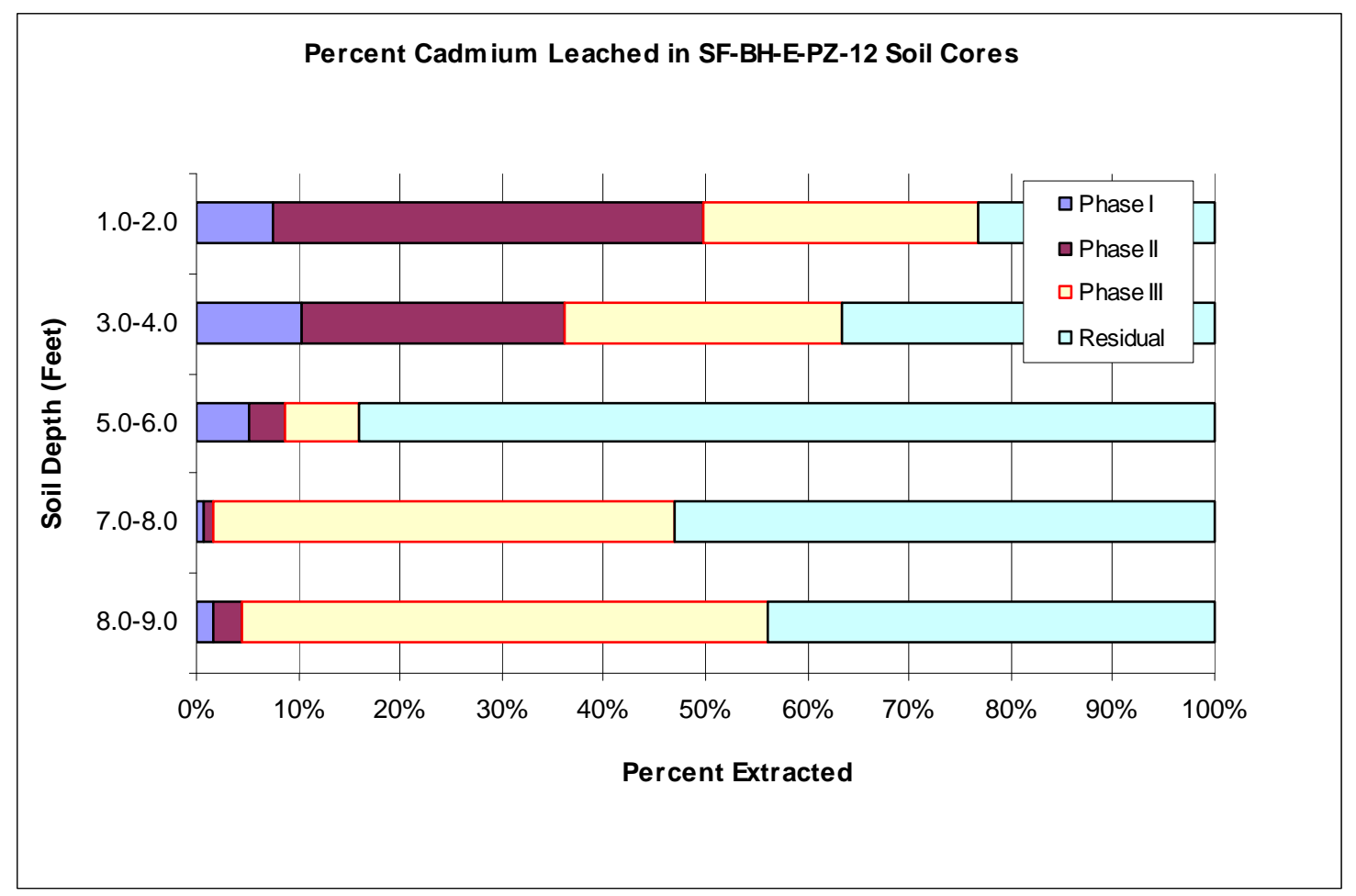

Figure 16. Cadmium percentages present at sample location BH-E-PZ-12.

Lead concentrations measured in the soil at this location ranged from $12,100 \mathrm{mg} / \mathrm{kg}$ at $1-2$ feet, 6,890 $\mathrm{mg} / \mathrm{kg}$ at $3-4$ feet, $7,190 \mathrm{mg} / \mathrm{kg}$ at $5-6$ feet, $116,000 \mathrm{mg} / \mathrm{kg}$ at $7-8 \mathrm{feet}$, and $17,300 \mathrm{mg} / \mathrm{kg}$ at $8-9$ feet. As shown in Figure 17, the exchangeable lead accounted for less than $5 \%$ of the total at any depth, but because the total concentration of lead in the soil is high, the exchangeable phase is significant. The carbonate bound phase (Phase II) also represented a significant amount of the total lead, ranging from 30$50 \%$ of the total lead (Figure 17). The organic/oxide/sulfide bound lead varied from less than 5\% to as much as $35 \%$ of the total lead. The most notable observation is the high concentrations of carbonate bound lead near the surface. Changes in $\mathrm{pH}$ could impact this fraction of lead more easily than at the 5 foot and lower sections. The lead bound to the organic matter/oxide/sulfide, which represents a significant amount in this soil is fairly stable and will be release slowly over a long period of time. 


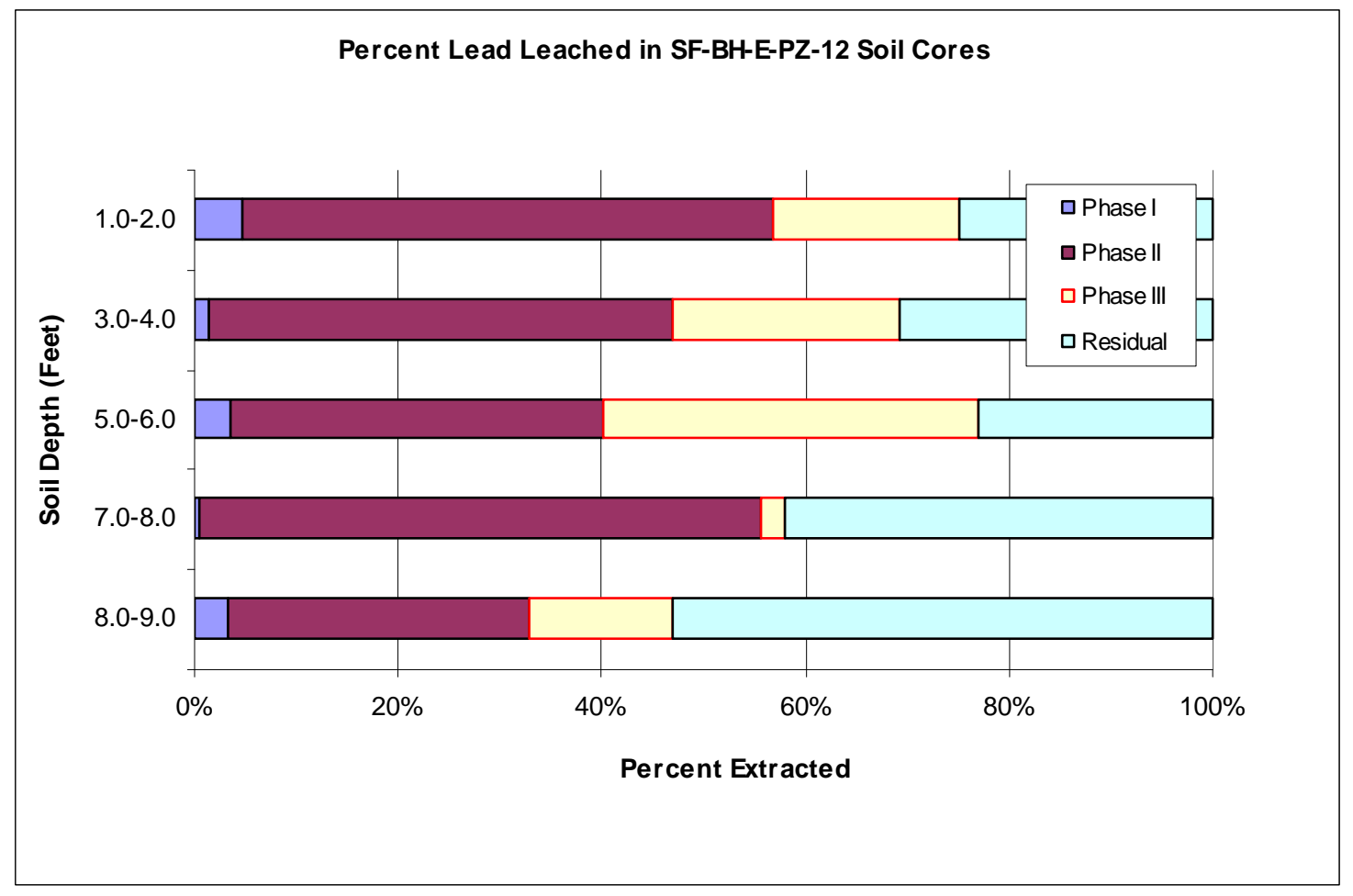

Figure 17. Lead percentages present at sample location BH-E-PZ-12.

This location had zinc concentrations that ranged from $4,820 \mathrm{mg} / \mathrm{kg}$ at $1-2$ feet, $2,870 \mathrm{mg} / \mathrm{kg}$ at 3-4 feet, $1,110 \mathrm{mg} / \mathrm{kg}$ at $5-6$ feet, $11,800 \mathrm{mg} / \mathrm{kg}$ at $7-8$ feet, and $24,300 \mathrm{mg} / \mathrm{kg}$ at $8-9$ feet. These concentrations were as much as an order of magnitude higher than those measured at Osborn Flats. Similar to the Osborn Flats results, the exchangeable zinc (Phase I) at this location accounted for much less than the cadmium or lead measured in this location (Figure 18). The exchangeable zinc was less than $5-10 \%$ of the total zinc concentration at all depths. The carbonate bound zinc represented nearly $20 \%$ of the total zinc in the top 3-4 feet, but generally less than $10 \%$ beyond that. The organic bound/oxide/sulfide zinc accounted for 20-40\%, except for the 5-6 foot depth which had less than 5\%. Similar to the cadmium results at the 5 to 6 foot depth (Figure 15), the zinc is apparently present at this depth as some form of refractory mineral which is resistant to leaching. 


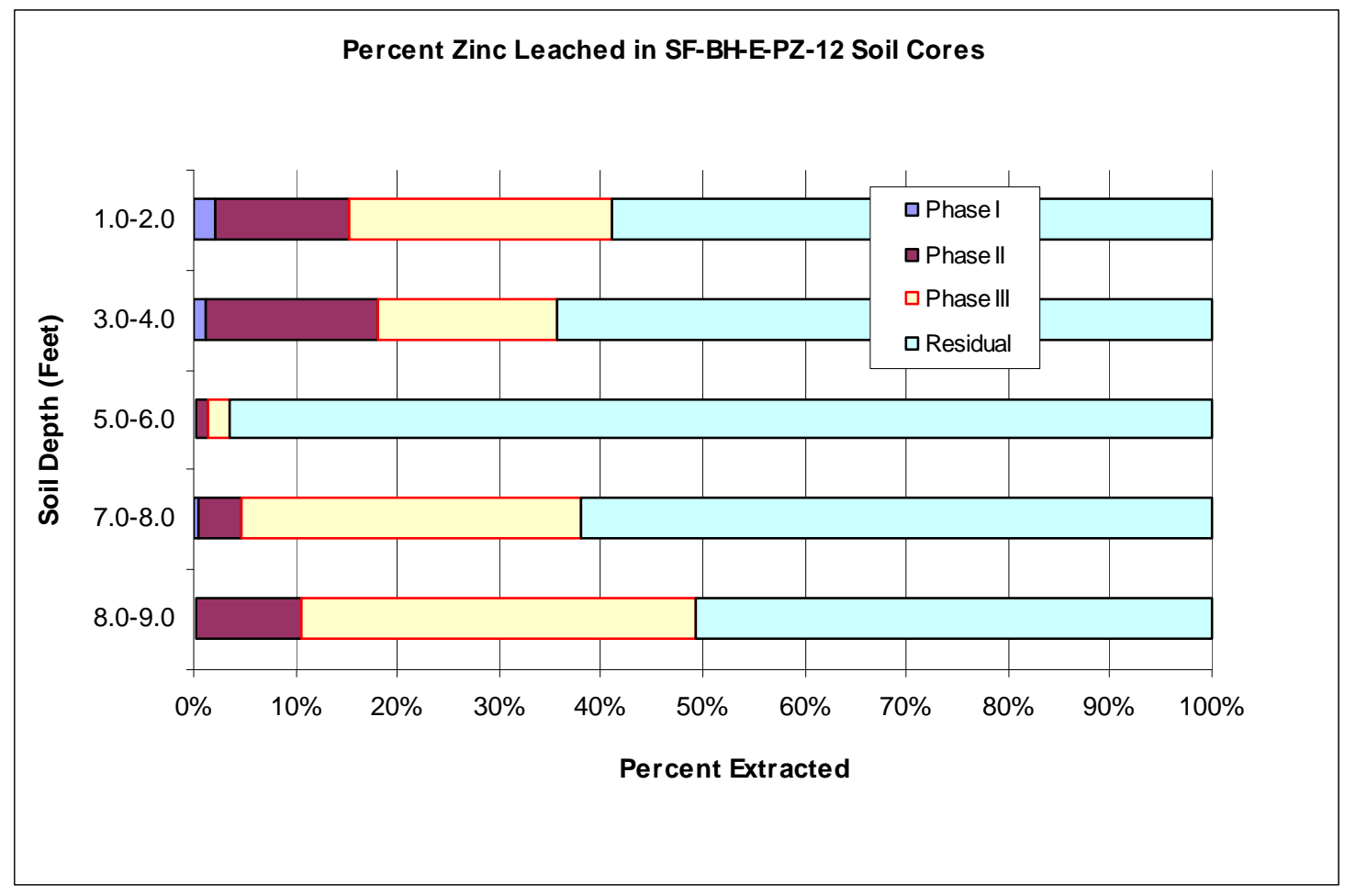

Figure 18. Zinc percentages present at sample location BH-E-PZ-12.

\subsubsection{Bunker Hill Sample SF-BH-E-PZ-16}

The core from this location was also taken near the CIA. Figure 19 shows the location of this core sample. Figures 20-23 show the core samples from each depth sampled at this location. Note that the core samples in this location are reddish brown, particularly in the 5-6 foot section, indicating the presence of oxidized iron in the sediments.

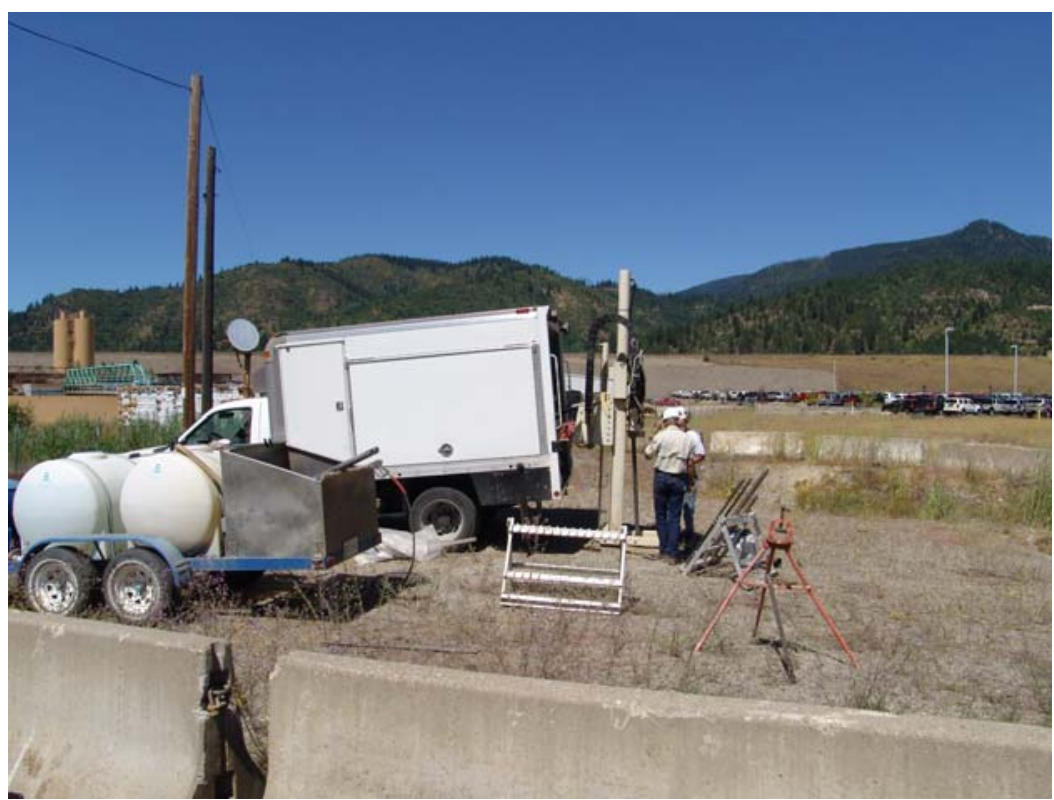

Figure 19. Photo of drill rig at sample location SF-BH-E-PZ-16. 


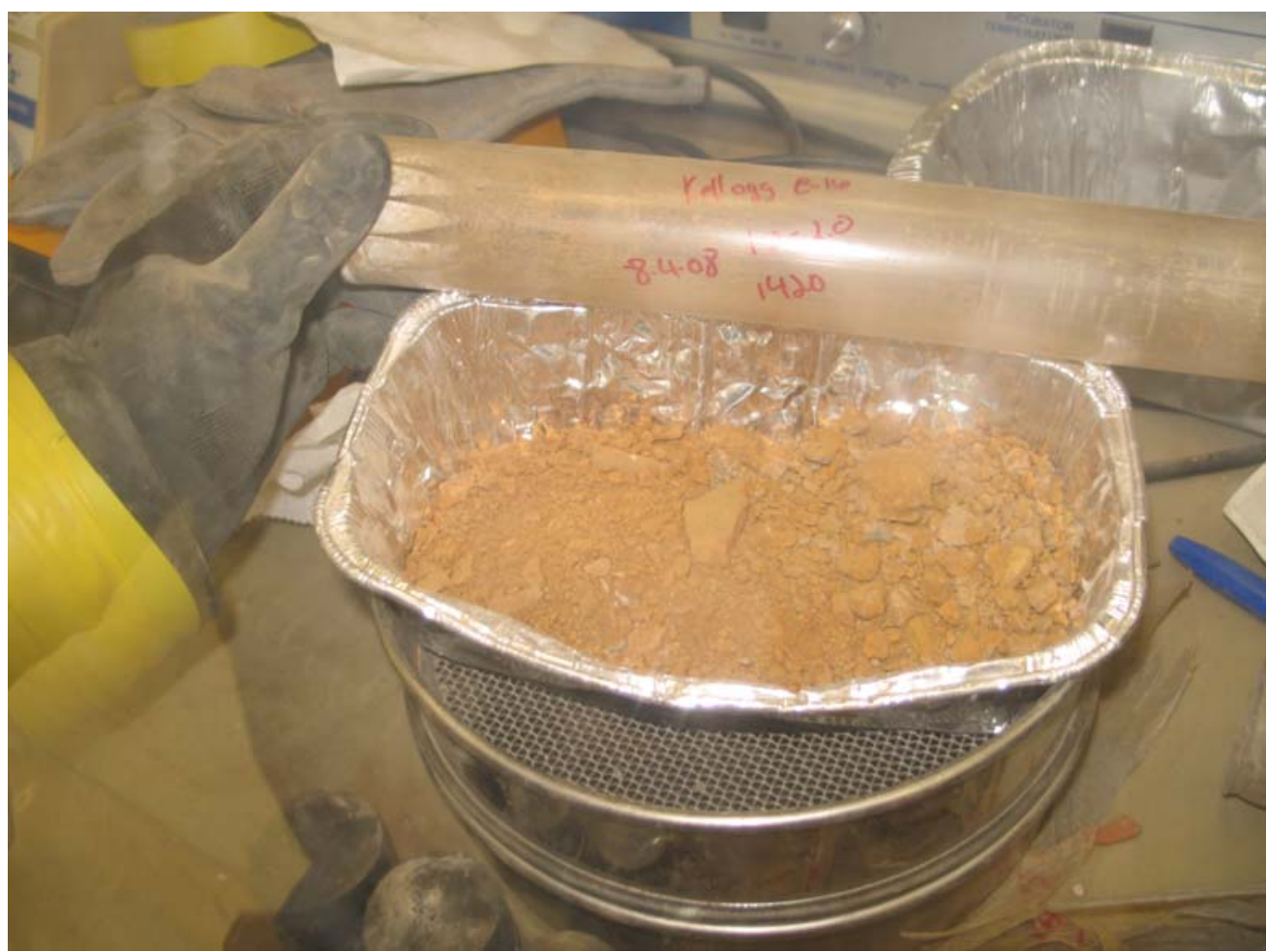

Figure 20. Core sample from location SF-BH-E-PZ-16, 1.0-2.0-foot depth.

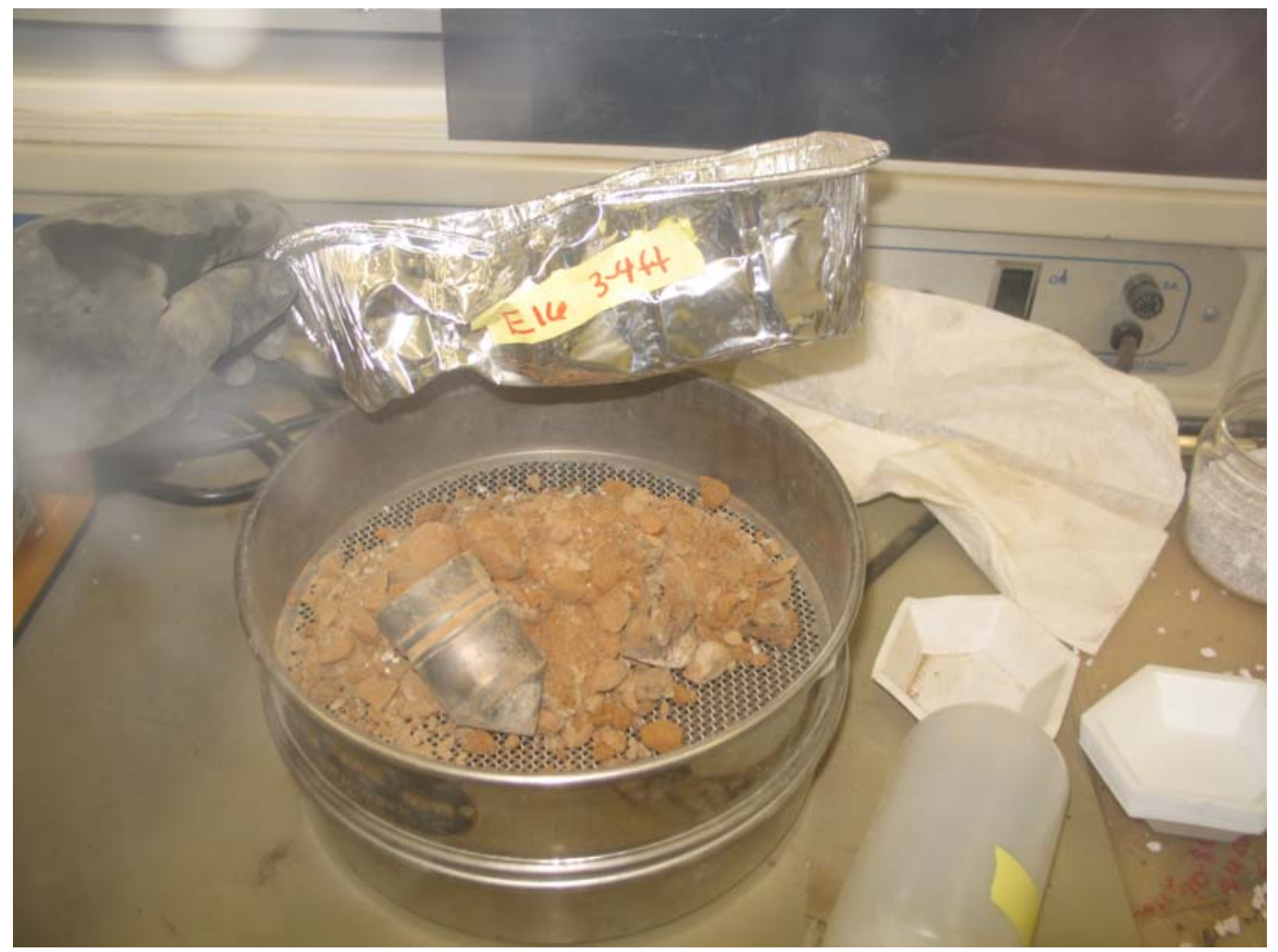

Figure 21. Core sample from location SF-BH-E-PZ-16, 3.0-4.0-foot depth. 


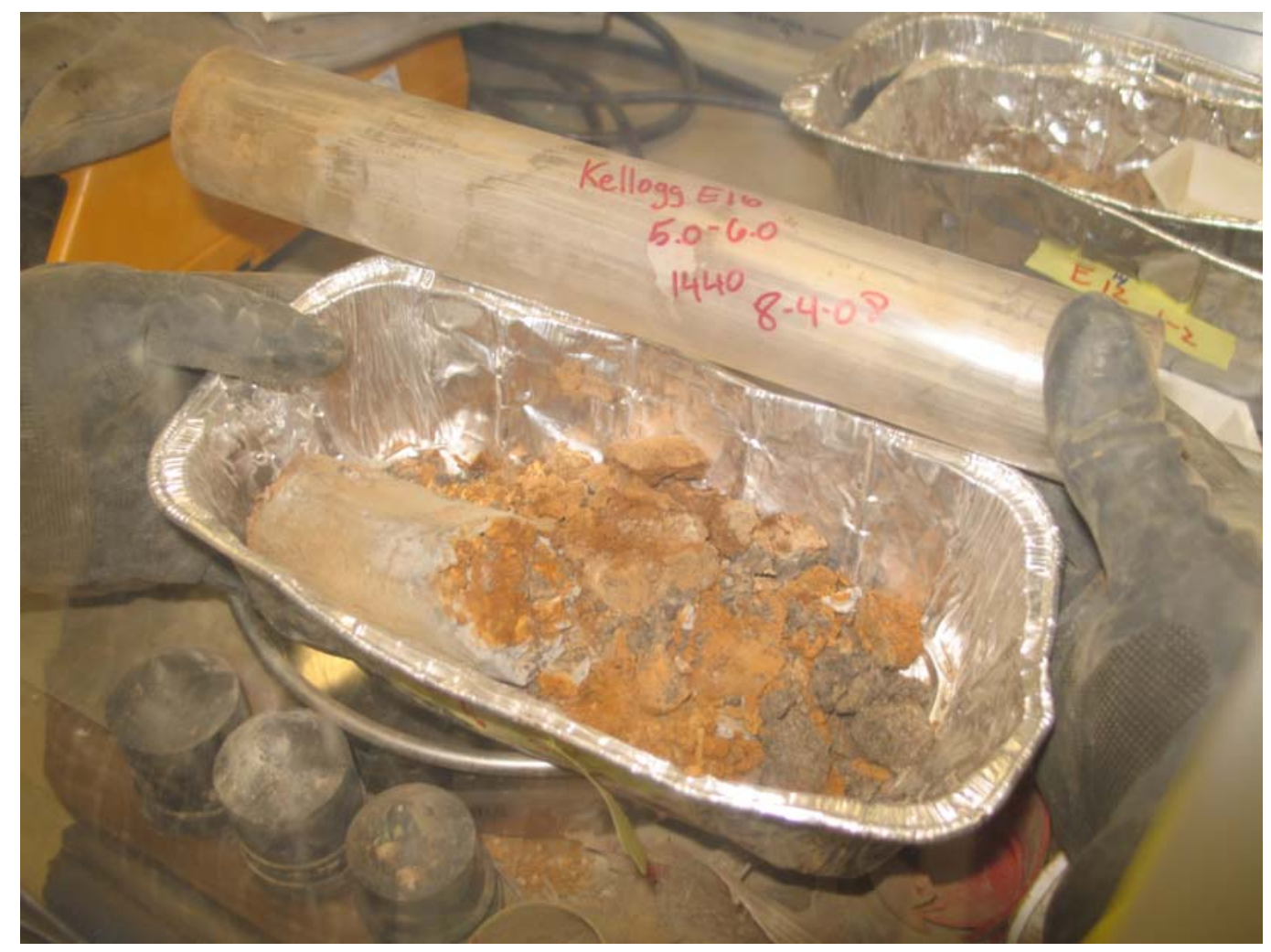

Figure 22. Core sample from location SF-BH-E-PZ-16, 5.0-6.0-foot depth.

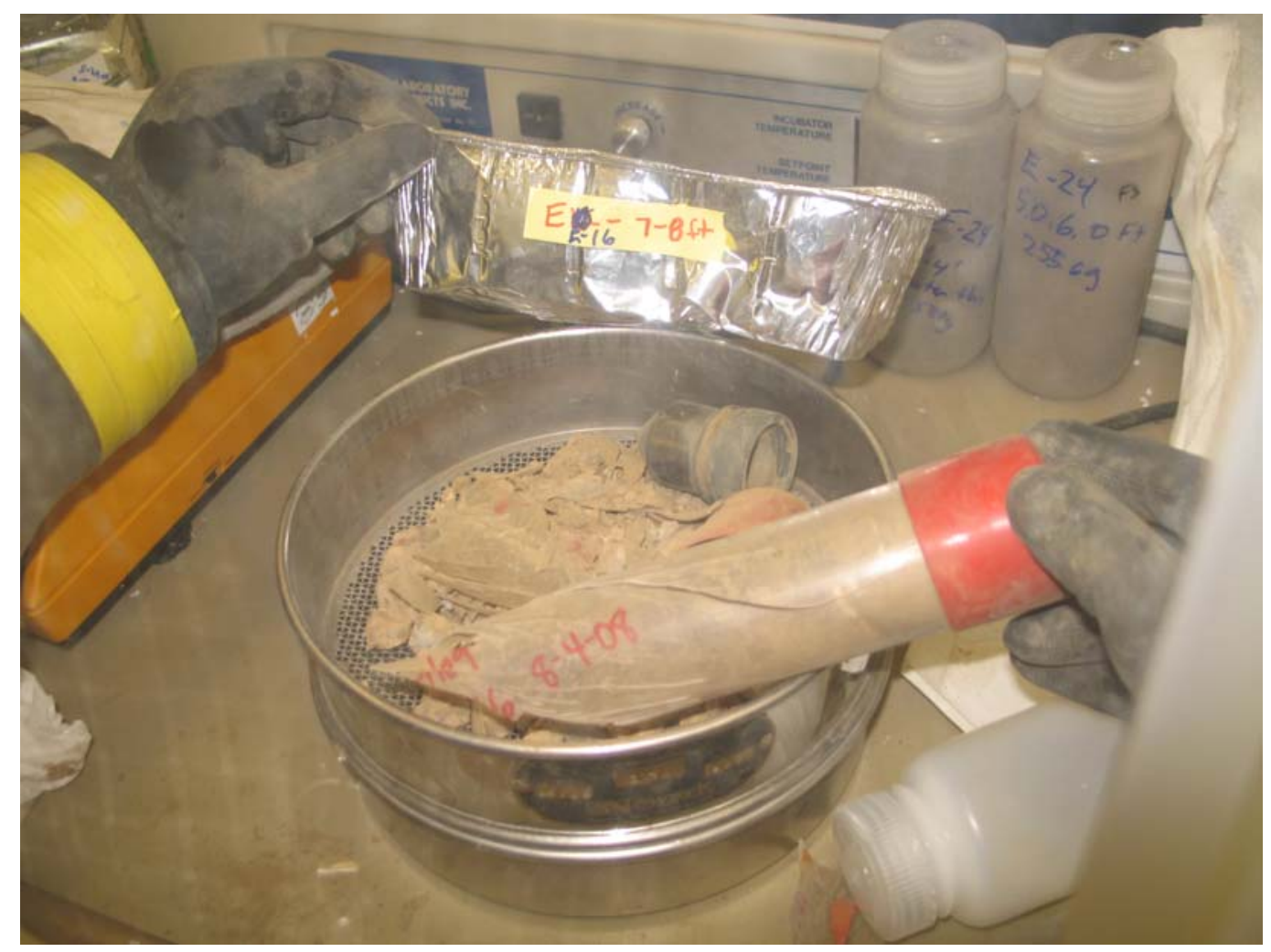

Figure 23. Core sample from location SF-BH-E-PZ-16, 7.0-8.0-foot depth. 
The amount of cadmium present at this location varied from $19.2 \mathrm{mg} / \mathrm{kg}$ at $1-2$ feet, $43.8 \mathrm{mg} / \mathrm{kg}$ at the 3-4 foot depth, $72.8 \mathrm{mg} / \mathrm{kg}$ at the 5-6 foot depth, and $13.8 \mathrm{mg} / \mathrm{kg}$ at the $7-8$ foot depth. These concentrations are roughly comparable to the previous location, but the percent of exchangeable cadmium is much higher at this location as was the case for zinc and lead (Figures 24-26). This location is less stable than the other locations. Oxidation reduction potential (ORP) values were an order of magnitude higher from groundwater taken at this location in September and October 2008 than any of the other locations (Table A-7). Iron values in the water were low indicating that the iron may have oxidized and precipitated as ferric oxyhydroxides. This result would then lead to a higher percentage of cadmium, lead, and zinc in the exchangeable phase. Alternatively, the soil may have experienced a lower $\mathrm{pH}$ condition at various times of the year, which could have resulted in the breakdown of carbonates minerals - thus liberating the carbonate bound cadmium, which would then likely show up in the exchangeable phase. Either way, the exchangeable fraction of metal as this location is higher than other locations.

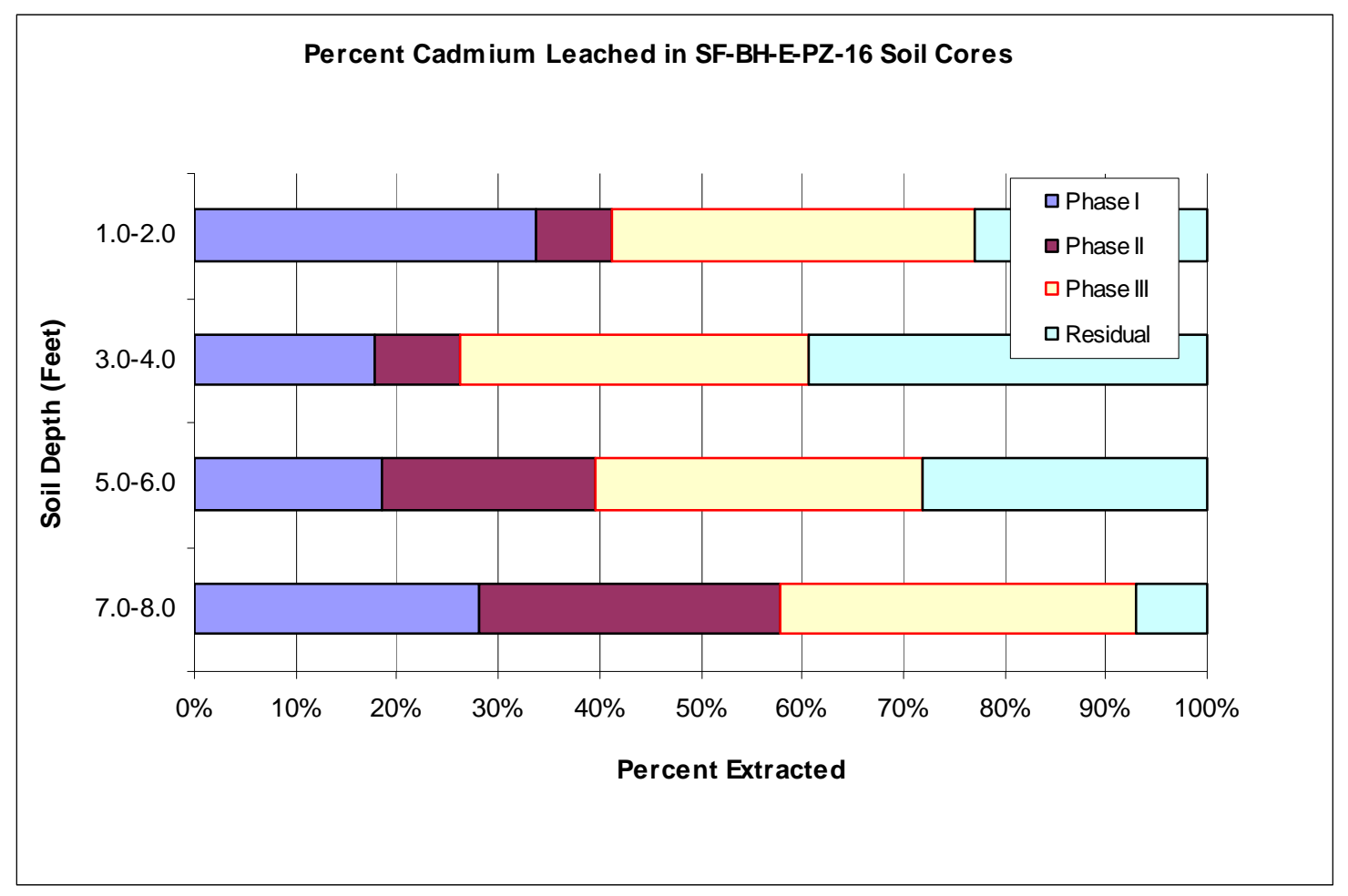

Figure 24. Cadmium percentages present at sample location BH-E-PZ-16.

The amount of lead present in the soil at this location was measured to be $8,130 \mathrm{mg} / \mathrm{kg}$ in the $1-2$ foot range, $5,290 \mathrm{mg} / \mathrm{kg}$ at the 3-4 foot range, 5,970 at the 5-6 foot range and 1,110 at the 7-8 foot range. While these concentrations are lower than the E-12 location, the exchangeable lead is higher. At 3-4 feet the exchangeable lead exceeds $20 \%$ (Figure 25). That is to say, of the $5,970 \mathrm{mg} / \mathrm{kg}$ lead present in the soil, roughly $1,200 \mathrm{mg} / \mathrm{kg}$ lead is more easily exchangeable. The amount of carbonate bound lead is similar, but the lead bound to organic matter/oxides/sulfides is less. 


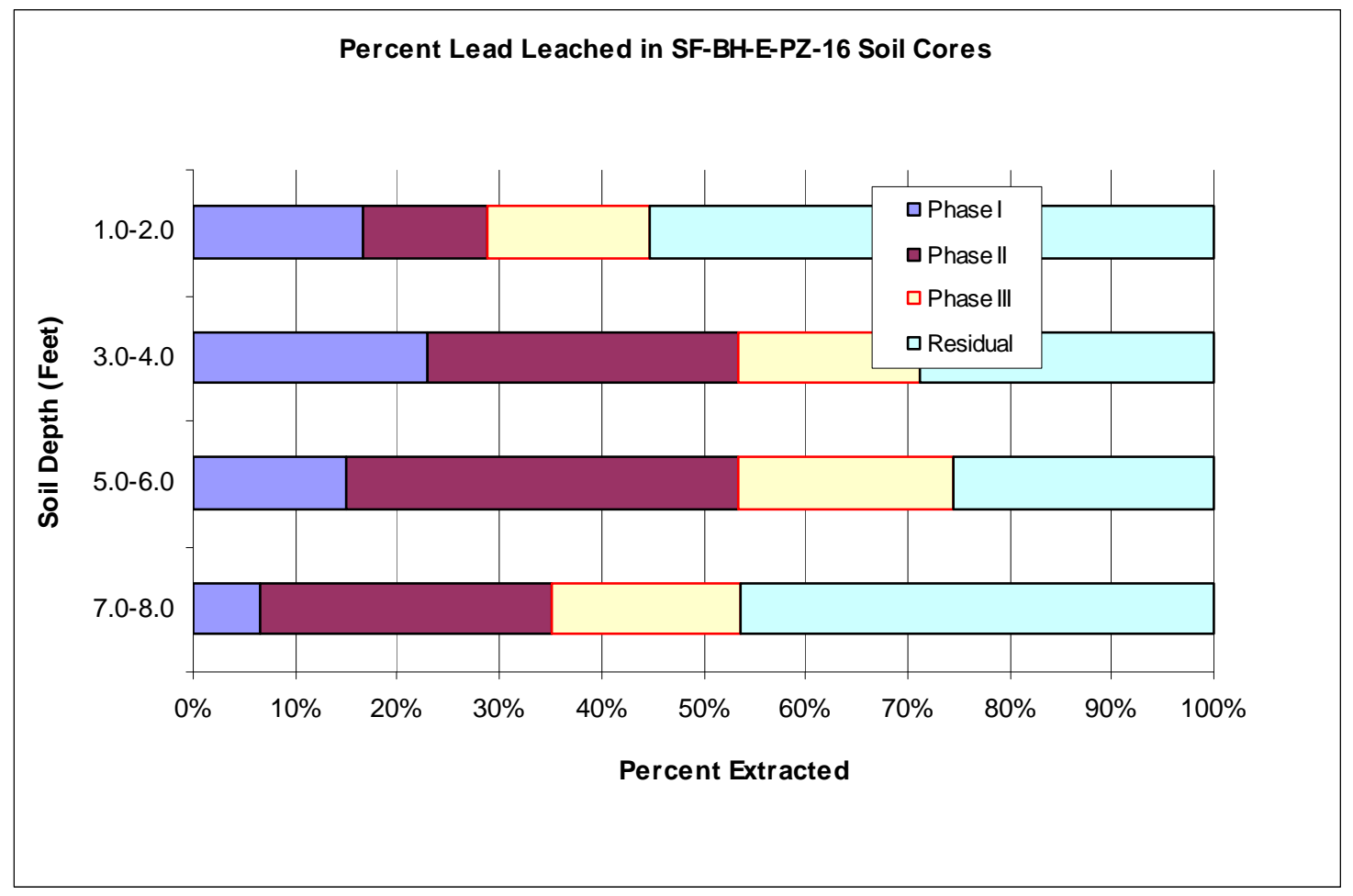

Figure 25. Lead percentages present at sample location BH-E-PZ-16.

The concentrations of zinc at this location were $3,730 \mathrm{mg} / \mathrm{kg}$ in the $1-2$ foot range, $6,800 \mathrm{mg} / \mathrm{kg}$ at the 3-4 foot range, $11,700 \mathrm{mg} / \mathrm{kg}$ at the 5-6 foot range, and $1,690 \mathrm{mg} / \mathrm{kg}$ at the $7-8$ foot range. At this location, there was a slightly higher percentage of exchangeable zinc than at the previous two locations (Figure 26). The exchangeable zinc is highest near the surface. However, the carbonate bound zinc is greater at 5-6 and 7-8 feet than it is above those levels. The amount of zinc bound in the organic/oxide/sulfide phase is similar to the previous described location. 


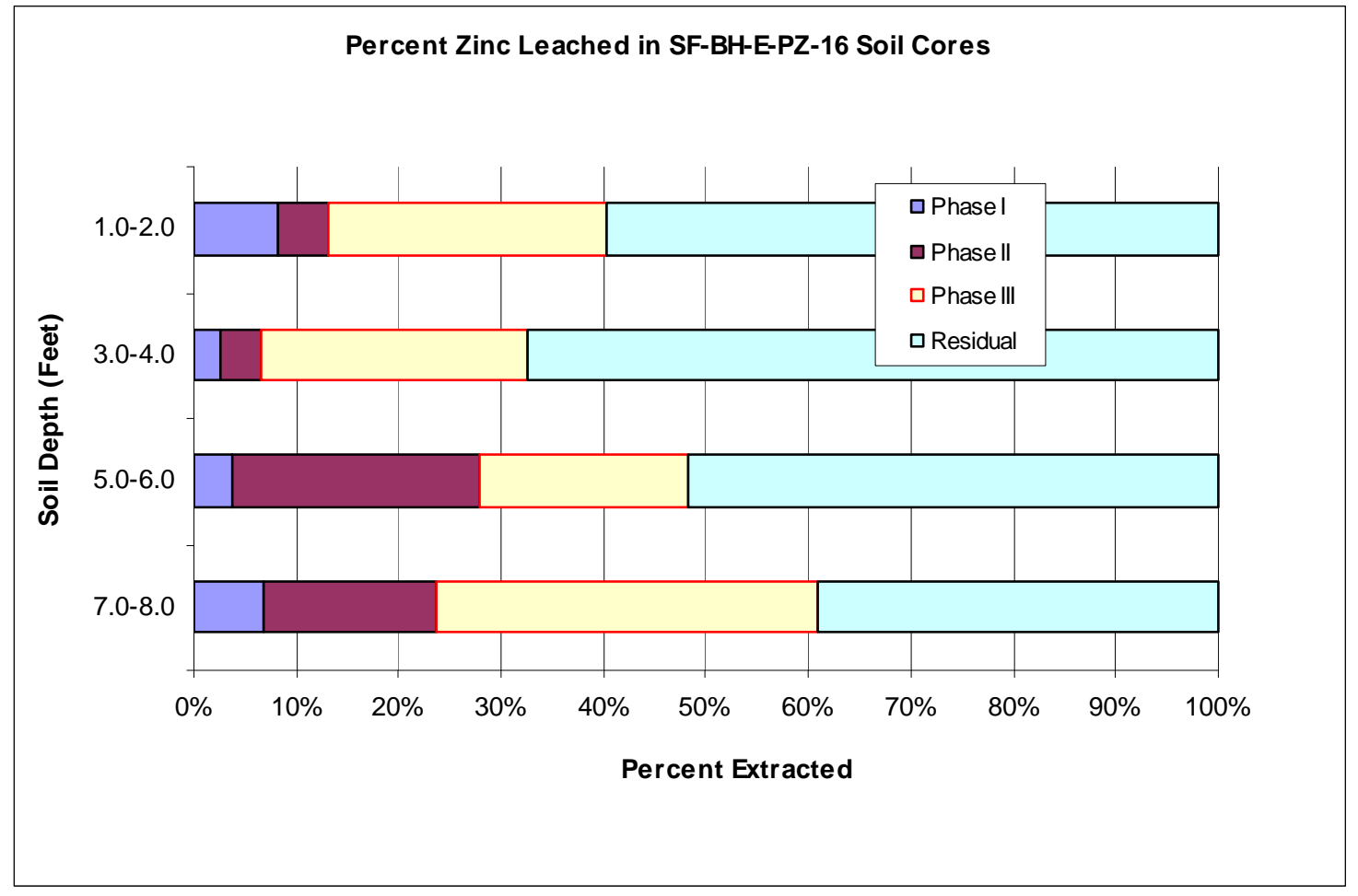

Figure 26. Zinc percentages present at sample location BH-E-PZ-16.

\subsubsection{Bunker Hill Sample SF-BH-E-PZ-24}

The core samples for this section were also collected near the CIA. Figure 27 shows the location where the drill rig collected the cores in the field. Figures 28-31 show the cores from each depth.

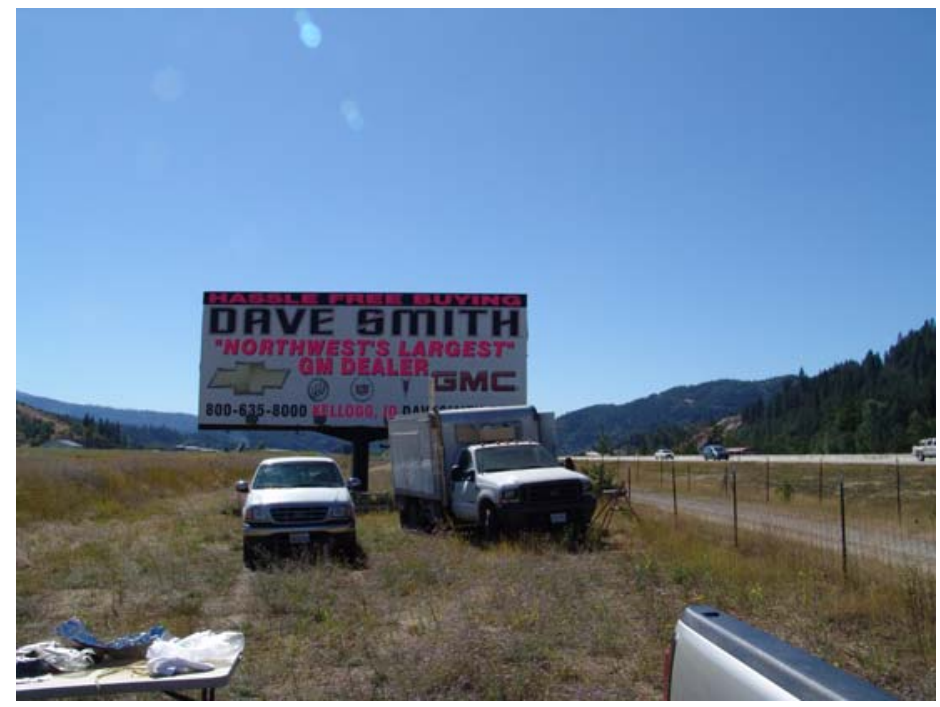

Figure 27. Collecting the core samples for SF-BH-E-PZ-24 core location. 


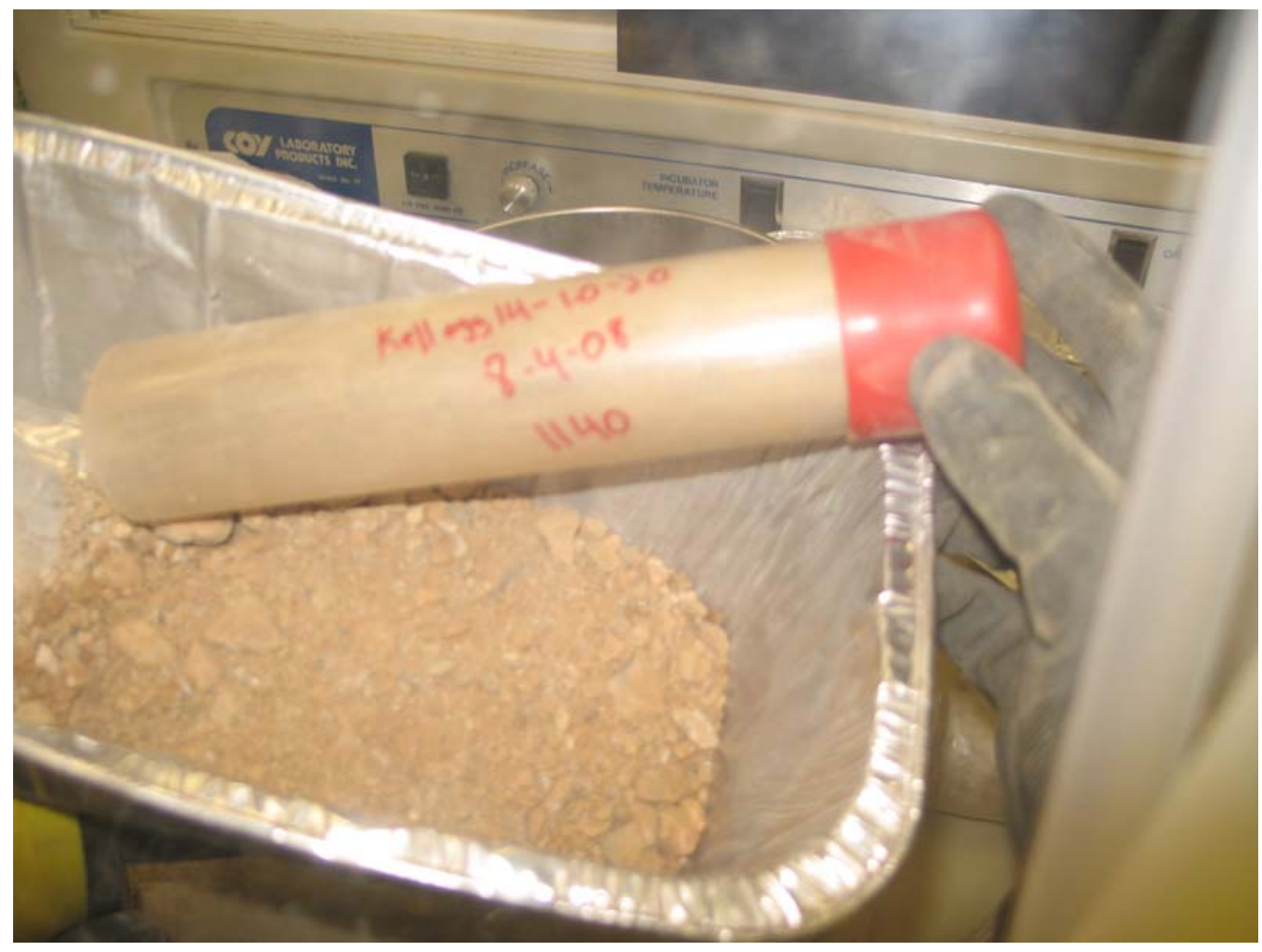

Figure 28. Core sample from location SF-BH-E-PZ-24, 1.0-2.0-foot depth.

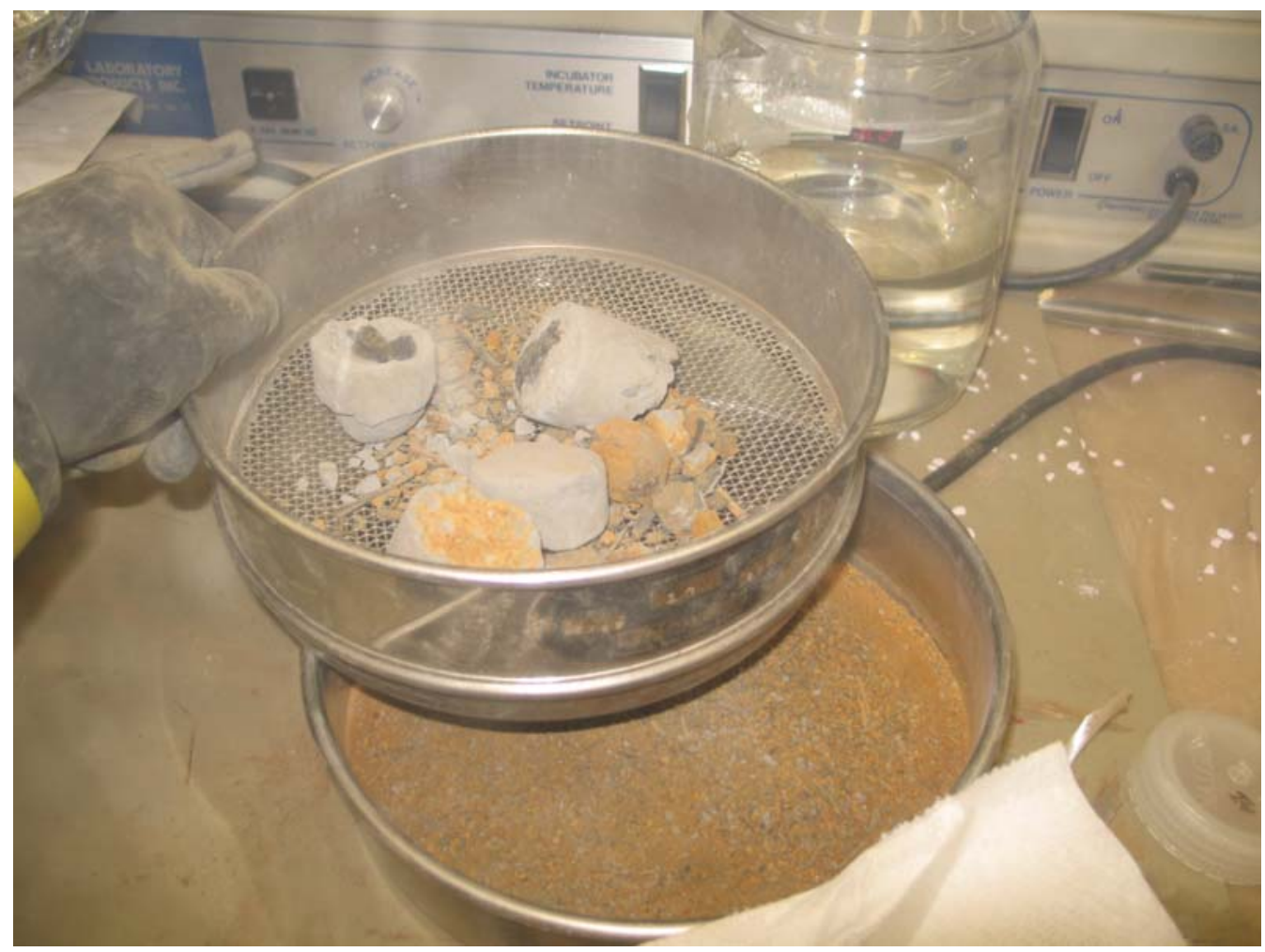

Figure 29. Core sample from location SF-BH-E-PZ-24, 3.0-4.0-foot depth. 


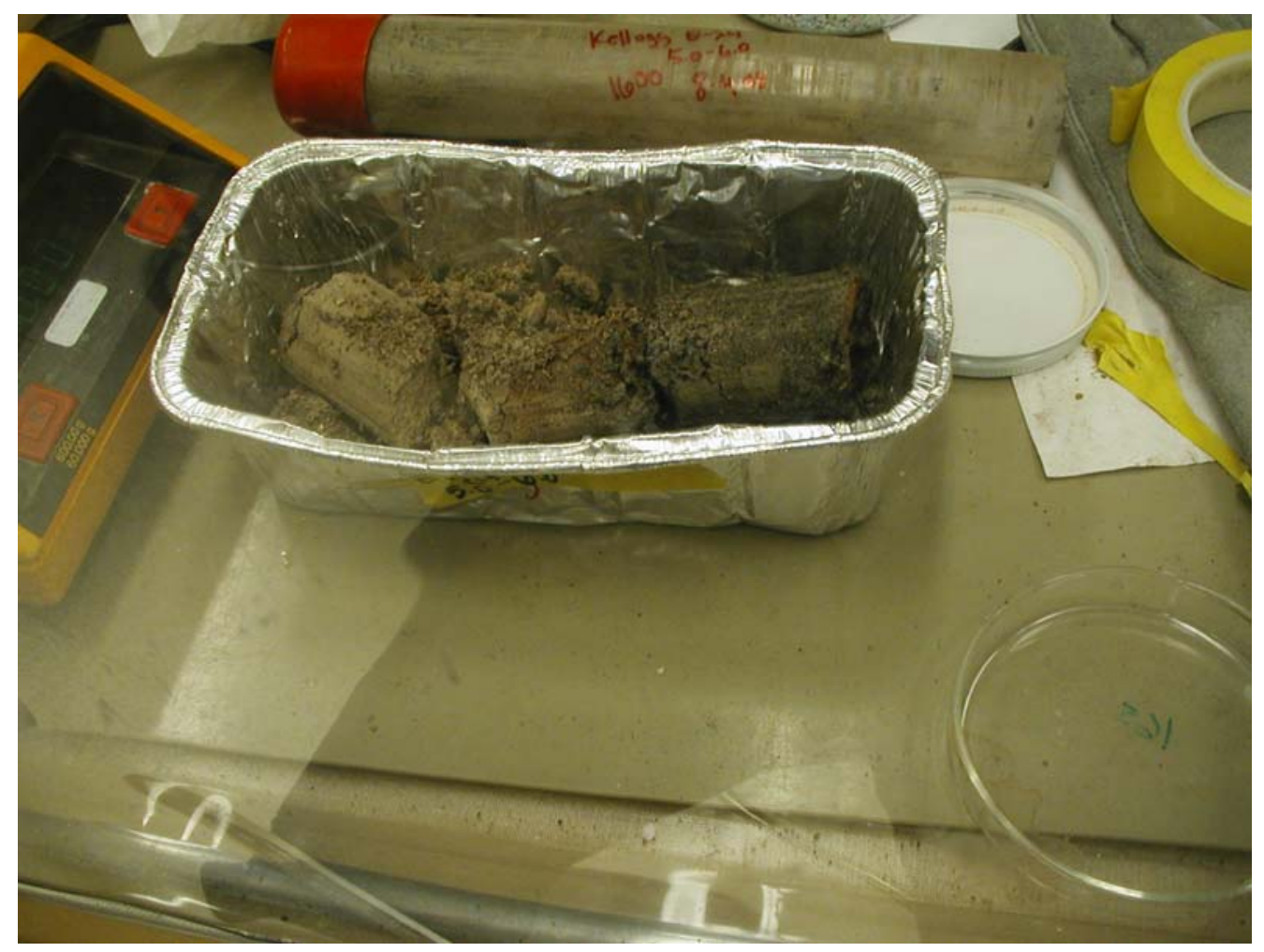

Figure 30. Core sample from location SF-BH-E-PZ-24, 5.0-6.0-foot depth.

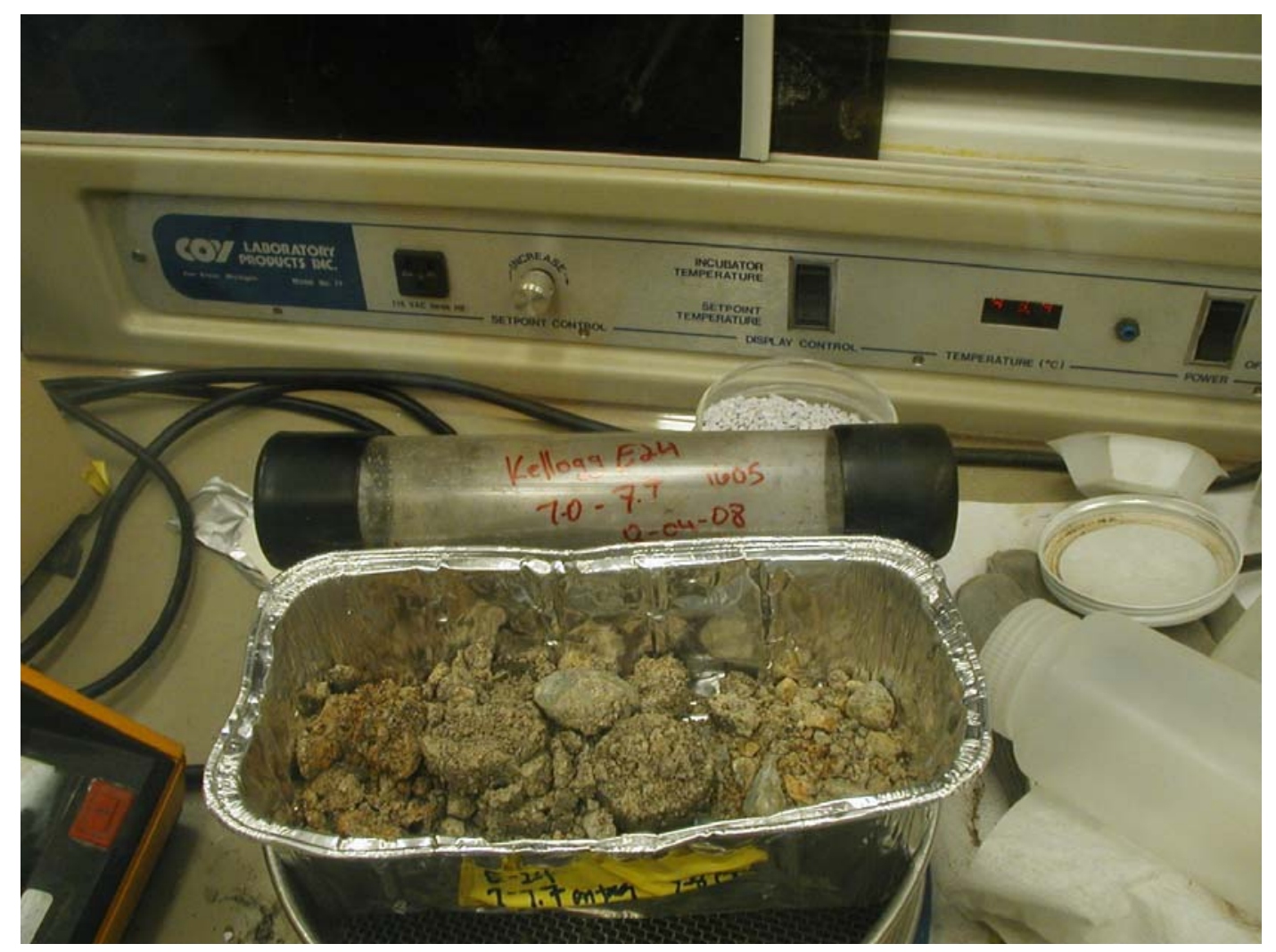

Figure 31. Core sample from location SF-BH-E-PZ-24, 7.0-8.0-foot depth. 
Cadmium concentrations in the soil range from $26.7 \mathrm{mg} / \mathrm{kg}$ at $1-2$ feet, $13.5 \mathrm{mg} / \mathrm{kg}$ at $3-4$ feet, $54.6 \mathrm{mg} / \mathrm{kg}$ at 5-6 feet, to $9.2 \mathrm{mg} / \mathrm{kg}$ at 7-8 feet. Cadmium is the most mobile of the metals of concern. Nearly $45 \%$ of the cadmium is readily exchangeable in the 7-8 foot region (Figure 32), and nearly a third is exchangeable at the 5-6 foot depth. At the lower depths, more than $90 \%$ of the cadmium is found as exchangeable, carbonate bound, and organic matter/oxide/sulfide bound cadmium combined. Under wet, slightly acidic environmental conditions, it would be possible to remove over $50 \%$ of the cadmium from the 5-6 foot and 7-8 foot sections soil in a short amount of time.

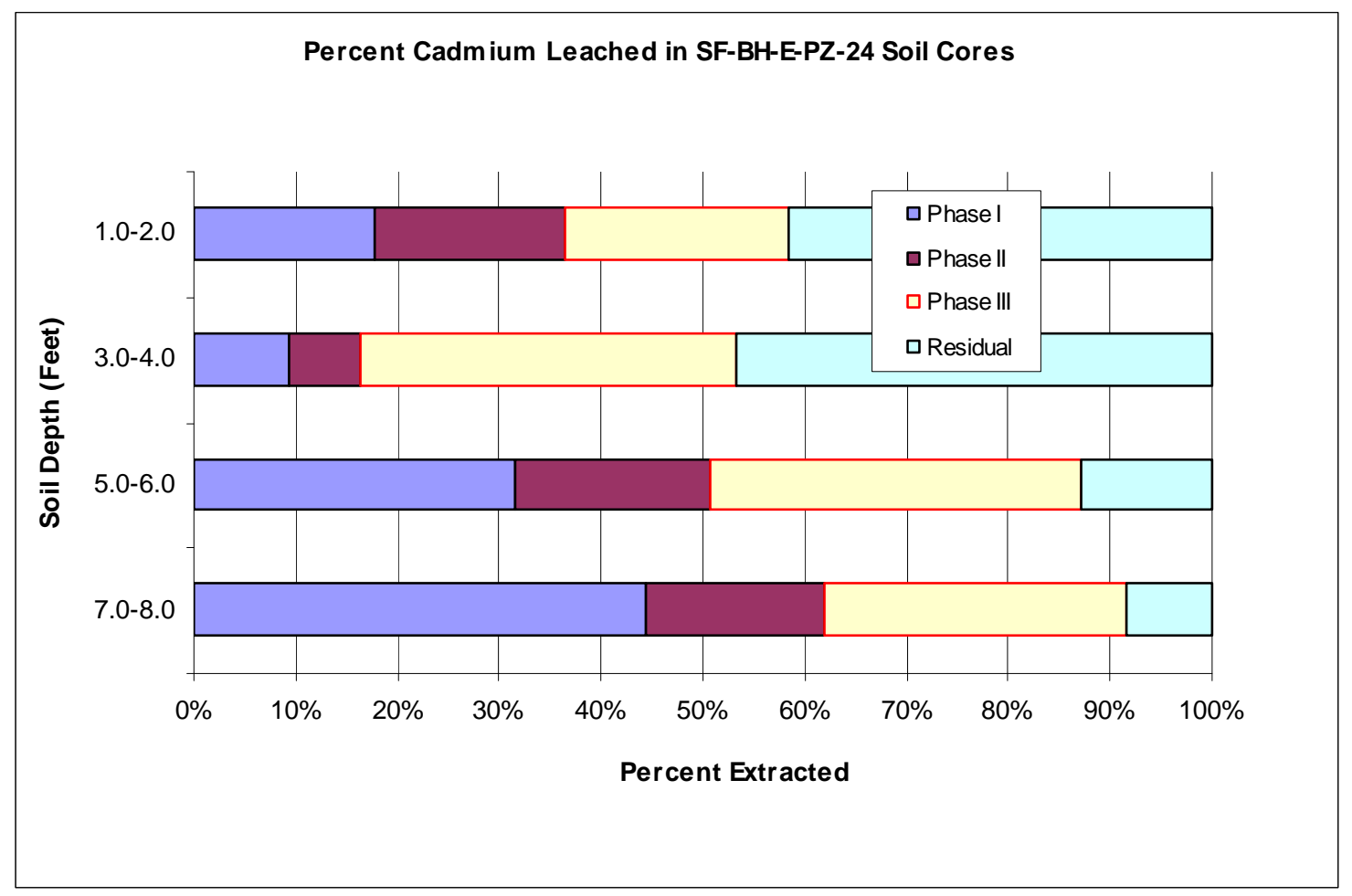

Figure 32. Cadmium percentages present at sample location BH-E-PZ-24.

The concentration of lead at this location ranges from $6,130 \mathrm{mg} / \mathrm{kg}$ at the $1-2$ foot range; $3,490 \mathrm{mg} / \mathrm{kg}$ at the $3-4$ foot range; $5,900 \mathrm{mg} / \mathrm{kg}$ at the $5-6$ foot range, and $258 \mathrm{mg} / \mathrm{kg}$ at $7-8$ feet. Similar to previous Osborn Flats and BH-E-PZ-12 samples, only a small percent of the lead is present as exchangeable lead (Figure 33). The carbonate bound lead was higher (Phase II), and the organic matter bound/oxide/sulfide bound lead (Phase III) contained approximately 10-20\% of the total lead. In general the lead in the soil at this location would not be extracted at neutral $\mathrm{pH}$, but a downward shift (more acidic) in $\mathrm{pH}$ could release more than $60 \%$ of the lead in the 5-6 foot soil depth. 


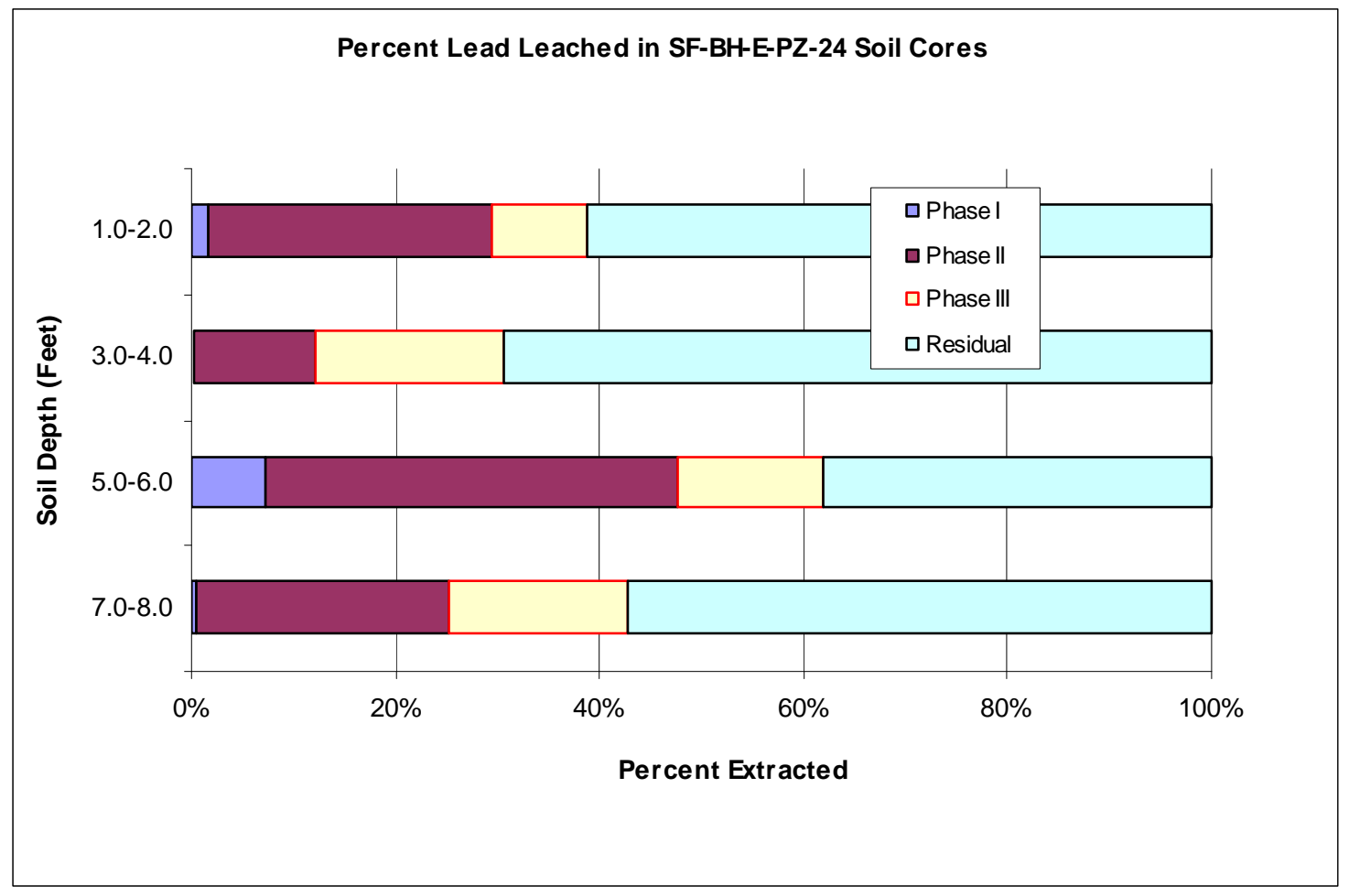

Figure 33. Lead percentages present at sample location BH-E-PZ-24.

The zinc concentrations at this location were higher in the top two elevations than at lower depths. The concentration of zinc ranges from $11,000 \mathrm{mg} / \mathrm{kg}$ at $1-2$ feet; $11,900 \mathrm{mg} / \mathrm{kg}$ at the $3-4$-foot range; $3,300 \mathrm{mg} / \mathrm{kg}$ at the 5-6-foot range; and $1,080 \mathrm{mg} / \mathrm{kg}$ at $7-8 \mathrm{feet}$. Although the concentrations of zinc were much higher in the top two cores, the exchangeable zinc was much lower (Figure 34). The same is true of the carbonate bound zinc and the percentage of zinc bound to organic matter/oxide/sulfide. This suggests that although the zinc concentrations are fairly high in the top 4 feet of soil, it is in a fairly stable form. 


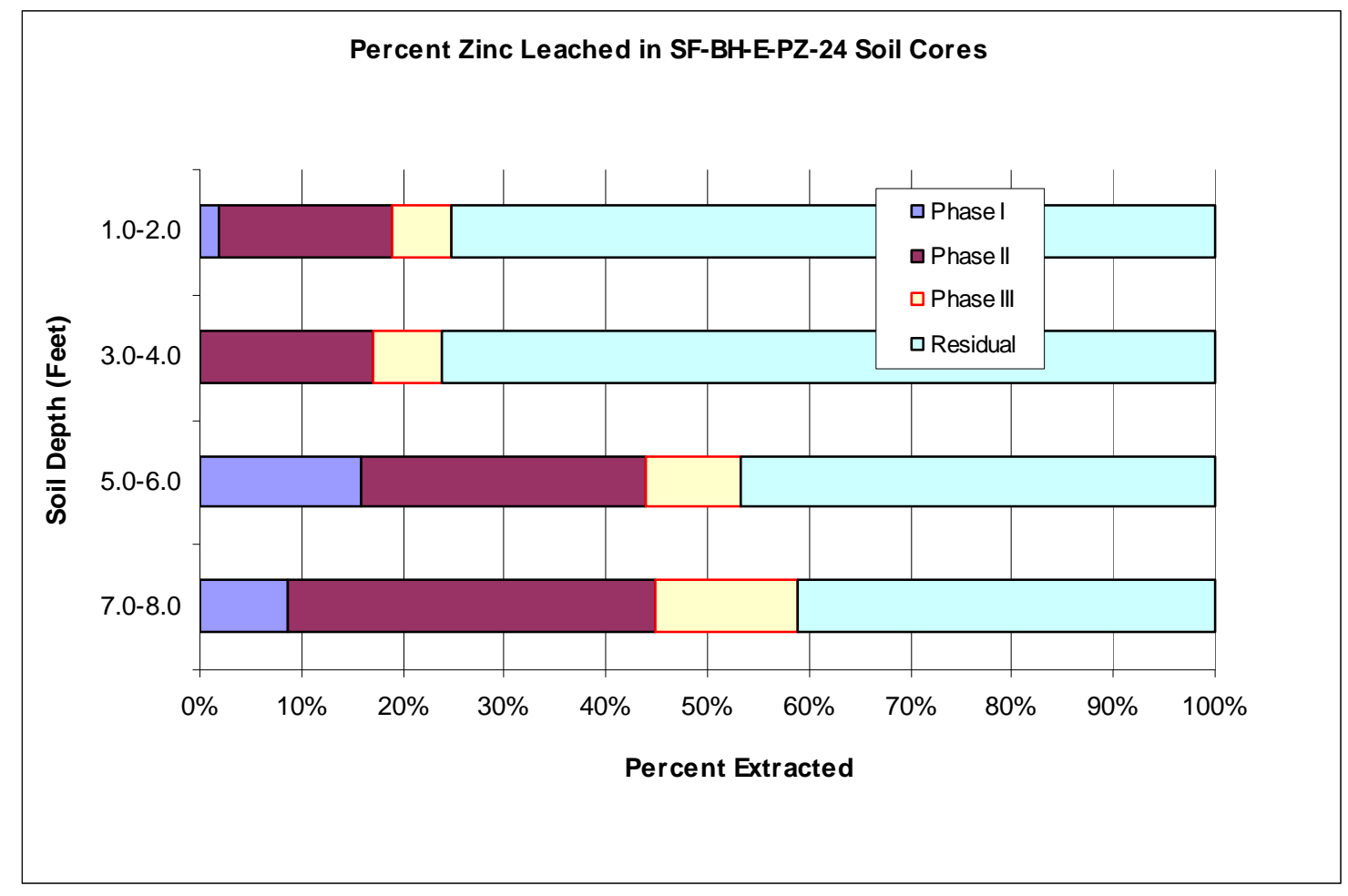

Figure 34. Zinc percentages present at sample location BH-E-PZ-24.

\subsubsection{Extraction of Iron from the soil cores}

Very little iron was extracted at all locations, except at BH-E-PZ-24 (E-24 in figure below) where approximately 10 to $12 \%$ was released as exchangeable (See Figure 35 below). These results suggest that most of the iron in the cores is present in a form only extractable by hydrofluoric acid digestion (residual fraction). Under low $\mathrm{pH}$ high oxidizing conditions (nitric acid and hydrogen peroxide) most iron will remain insoluble and will show up in the residual fraction. In the Canyon Creek Study (Wright et al., 2007), where the $3^{\text {rd }}$ step of Tessier (1979) sequential extraction procedure was done; only $5-10 \%$ of the iron was present in the oxide form. The exception is at BH-E-PZ-24 where, since the iron is more available (Phase II extractable), possibly in the form of a reduced iron carbonate or sulfate. 

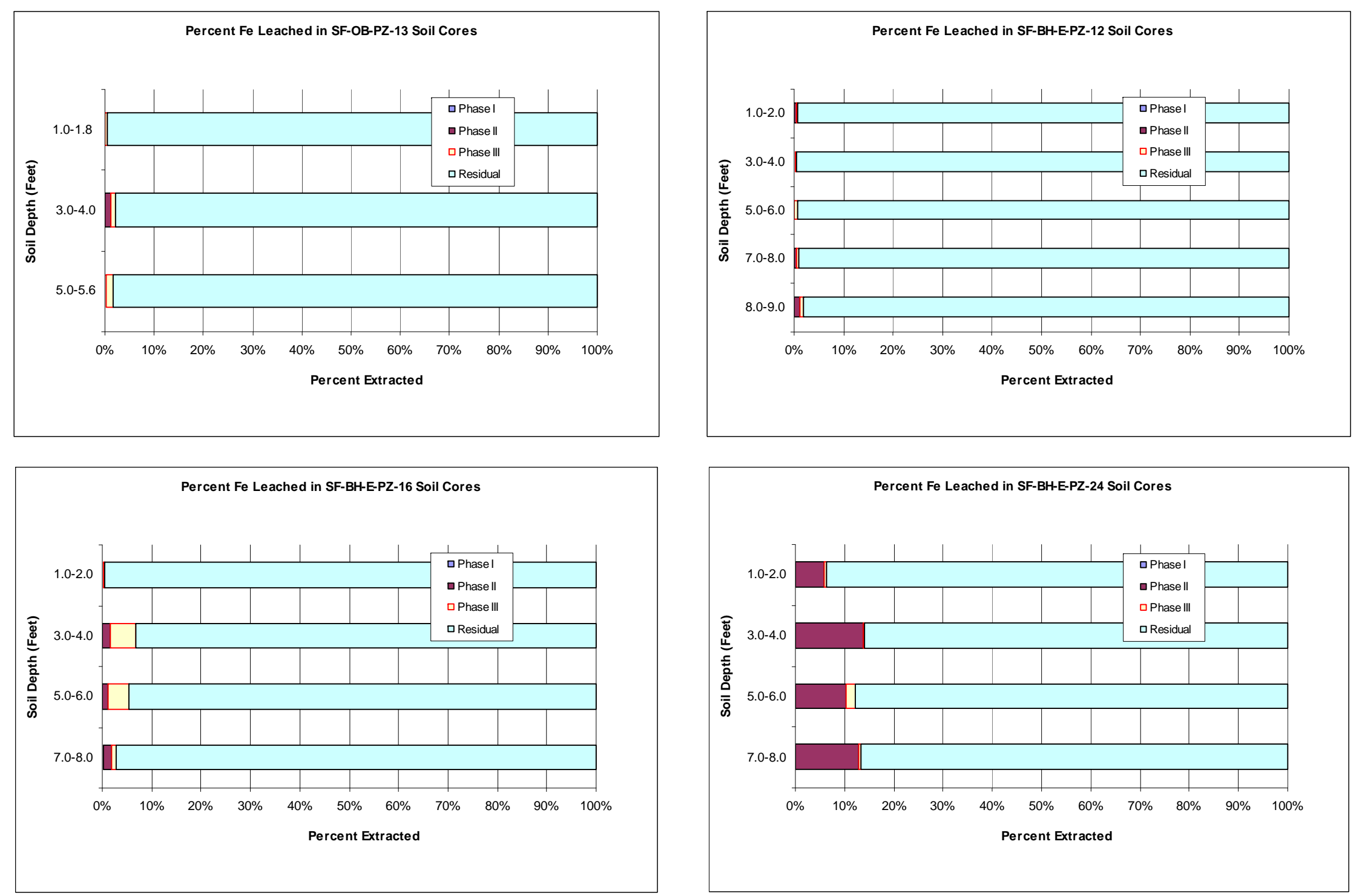

Figure 35. Iron released from the four locations during the sequential extraction. 


\subsection{Leach Tests}

A series of leaching tests were conducted for each coring location to determine the effects of $\mathrm{pH}$ and redox potential on metal leachability. Core samples (only the $<2 \mathrm{~mm}$ fraction) from each depth at each location were combined to form a single sample for that location. The different depth samples from each location were mixed to achieve a homogeneous soil sample for the set of leach studies conducted.

The leach studies were divided into two tests. The first leach test looked at the effect of $\mathrm{pH}$ on metal leaching. The second test compared leaching between soils exposed to oxygen atmosphere with wet/dry cycle then either leached with distilled water to represent rainwater under normal atmospheric conditions or simulated groundwater and no oxygen, simulating saturated subsurface conditions. Prior to beginning the tests, sediment from each location was sent to the EPA laboratory and the total metal concentrations were measured. Table 3 shows the concentrations of the elements of interest for the composited samples of each location. The following sections will present the results of these two tests.

Table 3. Total metal concentrations in sediments used in leach study.

\begin{tabular}{|c|c|c|c|c|c|c|c|c|c|}
\hline \multicolumn{10}{|c|}{ Concentrations for Elements of Interest $(\mathrm{mg} / \mathrm{kg})$} \\
\hline Location & $\mathrm{Cd}$ & $\mathrm{Ca}$ & $\mathrm{Fe}$ & $\mathrm{Pb}$ & $\mathrm{Mg}$ & $\mathrm{Mn}$ & $\mathrm{Se}$ & $\mathrm{Zn}$ & $\mathrm{S}$ \\
\hline SF-OB-PZ-13 & 31.4 & 939 & 57,800 & 7,550 & 1,110 & 5,860 & 3.5 & 5,310 & 2,630 \\
\hline SF-BH-E-PZ-12 & 103 & 2,630 & 117,000 & 82,400 & 4,080 & 12,000 & 3.5 & 21,100 & 19,000 \\
\hline SF-BH-E-PZ-16 & 34.0 & 2,350 & 95,300 & 5,240 & 2,950 & 7,430 & 3.4 & 7,710 & 12,600 \\
\hline SF-BH-E-PZ-24 & 13.7 & 34,600 & 98,300 & 3,070 & 3,900 & 10,600 & 3.5 & 9,960 & 4,510 \\
\hline
\end{tabular}

\subsection{1 pH Effect on Leaching}

Homogenized soil from each of the four locations (SF-OB-PZ-13, SF-BH-E-PZ-12, SF-BH-E-PZ-16, SF-BH-E-PZ-24) was divided into 6 subsamples. Each subsample was exposed to simulated groundwater adjusted to one of $6 \mathrm{pH}$ levels ( $\mathrm{pH} 2,3,4,5,6$, and 7) for a duration of 90 days. For each test, 50 grams of soil was mixed with $500 \mathrm{~mL}$ of the $\mathrm{pH}$ adjusted, simulated groundwater from each site (Table 2). The samples were sealed in an oxygen free environment and placed on a shaker at $120 \mathrm{rpm}$. For the first 30 days, the $\mathrm{pH}$ of each solution was monitored twice weekly and adjusted to maintain the required $\mathrm{pH}$. After 30 days the samples were checked weekly to maintain $\mathrm{pH}$ levels (see Figures A-5, A-6, A-7 and A8). Ten $\mathrm{ml}$ solute aliquots were collected at time 0,8 hours, 16 hours, 24 hours, 3 days, 7 days, 1 month, 2 months, and 3 months. The samples were diluted to $20 \mathrm{~mL}$ with deionized water, acidified to less than pH 2 with concentrated nitric acid and shipped to an offsite laboratory for analysis. The following sections discuss the results for the conditions tested.

\subsubsection{Core Location SF-OB-PZ-13}

Figure 36 shows the effect of $\mathrm{pH}$ on cadmium leaching over time. The results show that as the $\mathrm{pH}$ is reduced, cadmium extraction and concentration in the solution increases. Figure 37 shows the effect of $\mathrm{pH}$ on lead leachability. There was an initial release of lead followed by a decrease over time in lead concentration due to precipitation of the lead with sulfates in the simulated groundwater except for the result at $\mathrm{pH}$ 7(Pourbaix, 1974). Lead sulfides could also be formed if sulfate reducing bacteria are active. At day 60 , the concentration was measured at $48,400 \mathrm{ug} / \mathrm{L}$ lead. The scale on the graph was held at a maximum of $30,000 \mathrm{ug} / \mathrm{L}$ to allow the reader greater detail in viewing the lower concentrations. For unknown reasons, the concentration of lead was highest at $\mathrm{pH} 7$ at this location. One possible explanation is that the sediment at this location is not homogeneous and there was a higher lead concentration than in the other samples. Below $\mathrm{pH} 7$, the concentrations behaved more as would be expected, with concentrations at $\mathrm{pH} 2$ being higher than the remaining $4 \mathrm{pH}$ levels and lead concentrations at $\mathrm{pH} 5$ and 6 
were lower than the other $\mathrm{pH}$ values. Zinc removal followed a pattern similar to cadmium, with lower $\mathrm{pH}$ resulting in higher concentrations of zinc in solution (Figure 38).

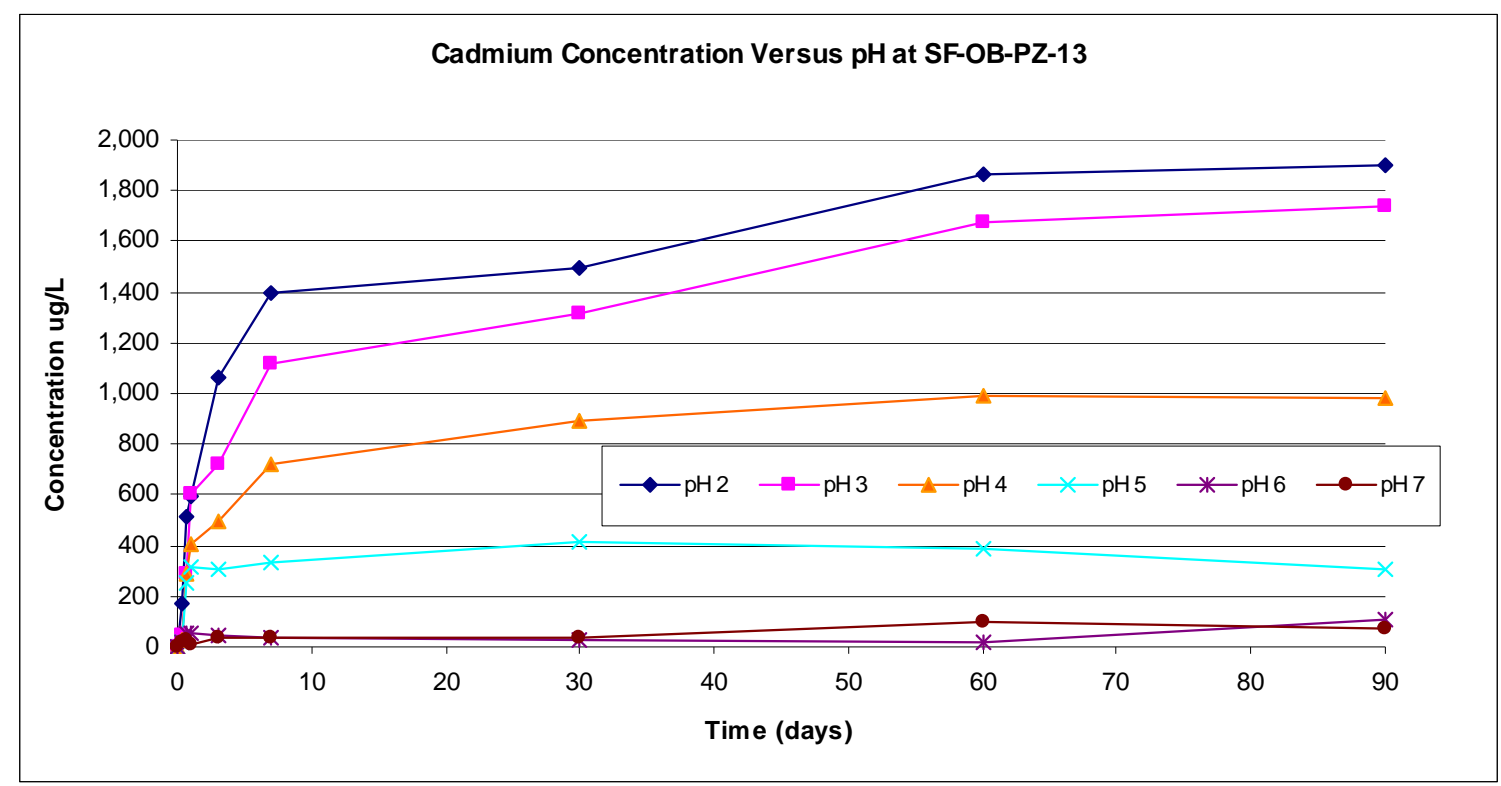

Figure 36. Effect of different $\mathrm{pH}$ on leaching of cadmium from sediment samples over a 90 day time interval.

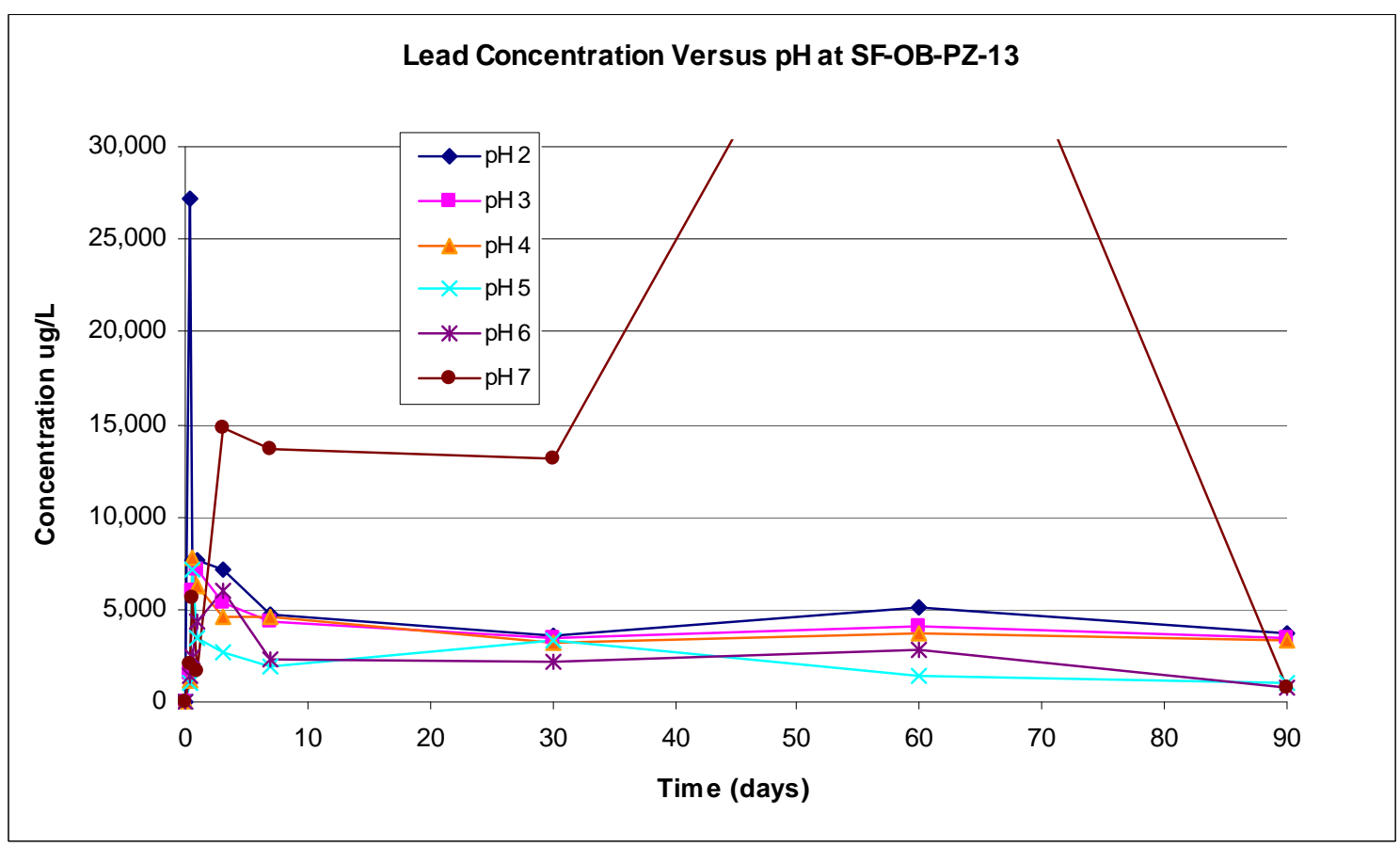

Figure 37. Effect of different $\mathrm{pH}$ on leaching of lead from sediment samples over a 90 day time interval. 


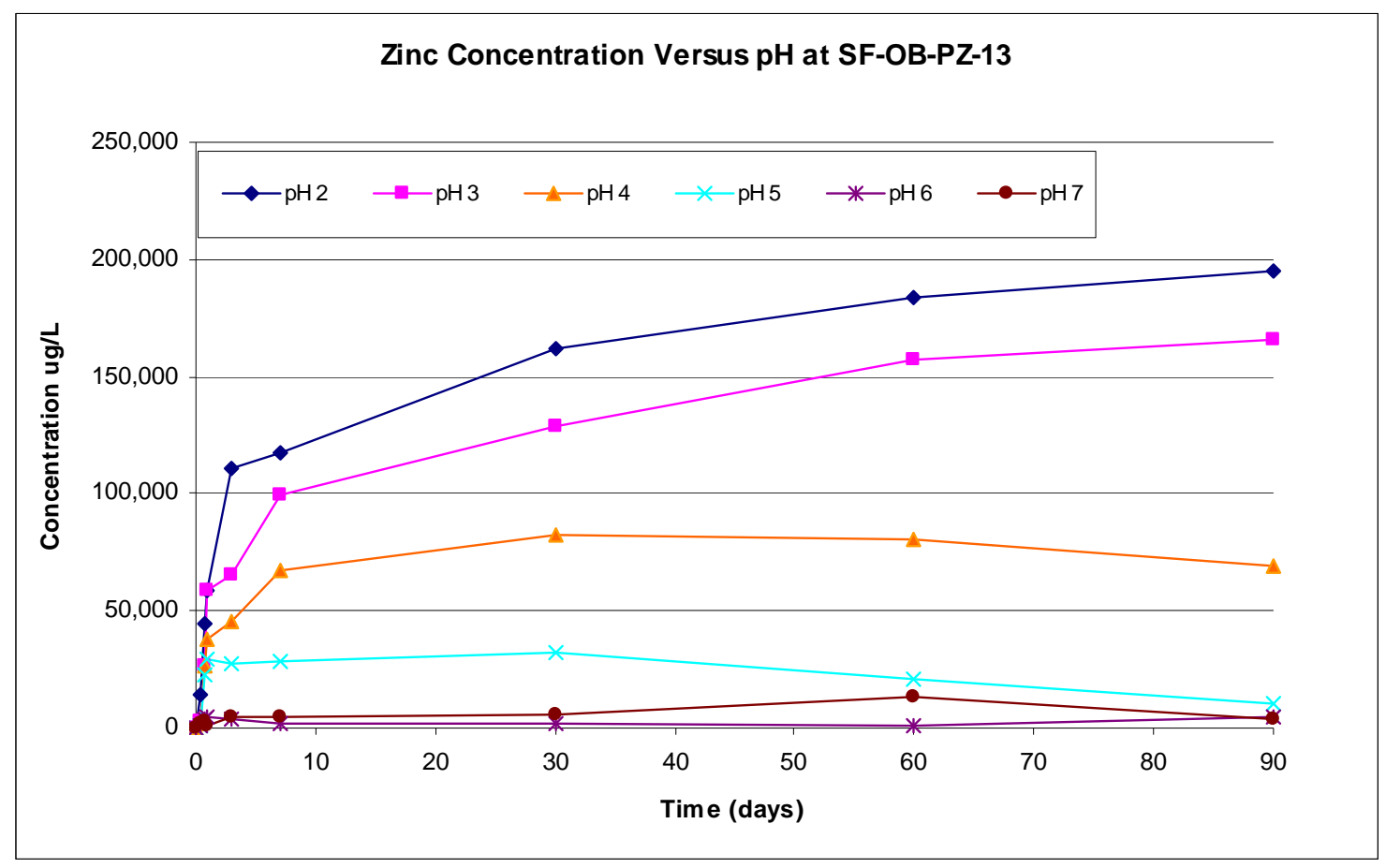

Figure 38. Effect of different $\mathrm{pH}$ on leaching of zinc from sediment samples over a 90 day time interval.

Iron remained fairly insoluble except at $\mathrm{pH} 2$, and a slightly elevated extraction at $\mathrm{pH} 3$ (Figure 39). The iron concentration at $\mathrm{pH} 2$ continued to increase over time, which is typical of the release of iron from oxides/hydroxides under low Eh and low $\mathrm{pH}$ conditions. From Figure 40, it can be seen that sulfur removal also increases as the $\mathrm{pH}$ is reduced. The sulfur in the soil at this location may be in the form of an iron oxy/hydroxy sulfate or pyritic minerals, which, as conditions become more acidic, releases more sulfur (as sulfate) and iron into solution, which is supported by the data presented in Figures 39 and 40. ..

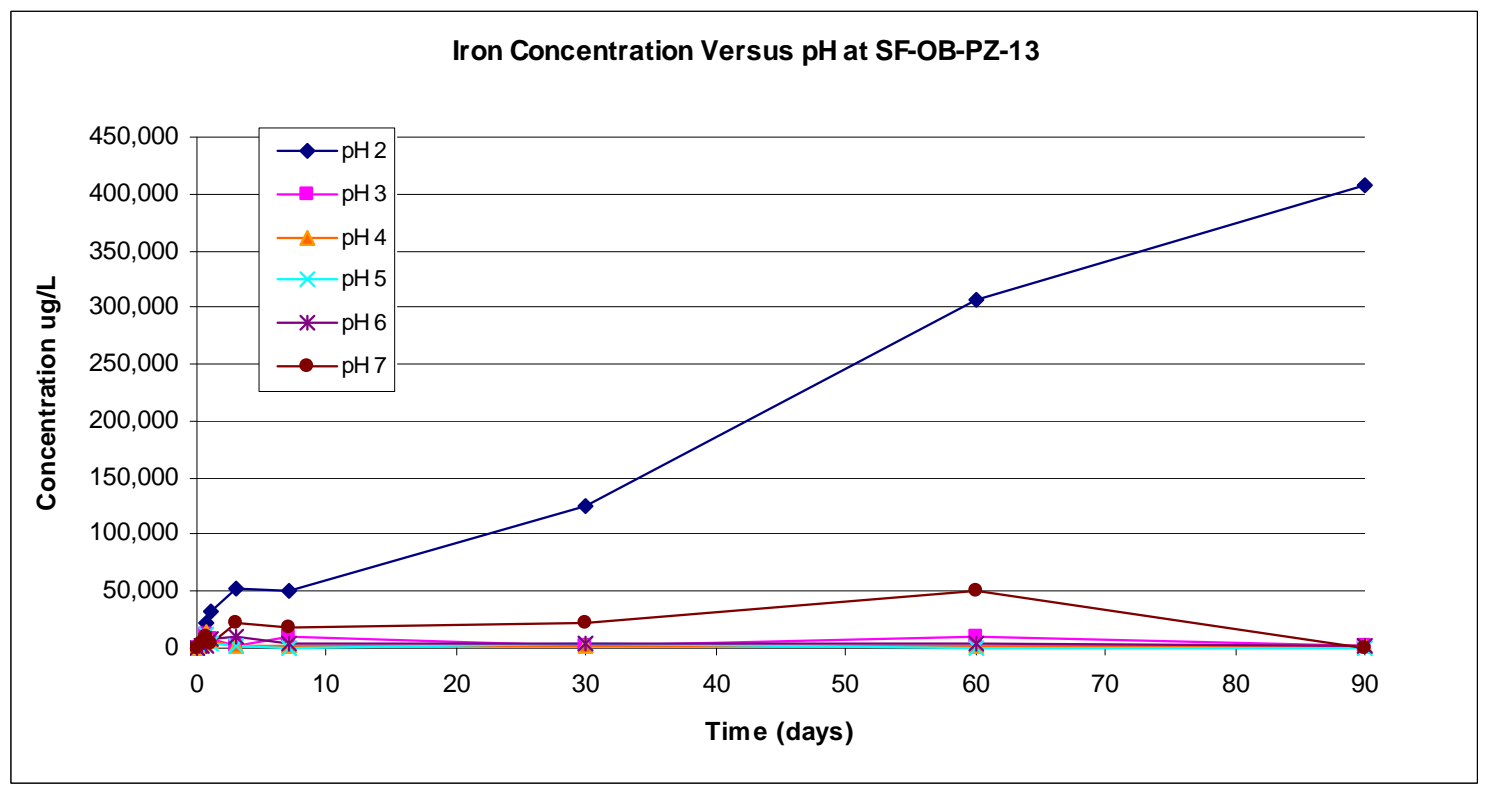

Figure 39. Effect of different $\mathrm{pH}$ on leaching of iron from sediment samples over a 90 day time interval. 


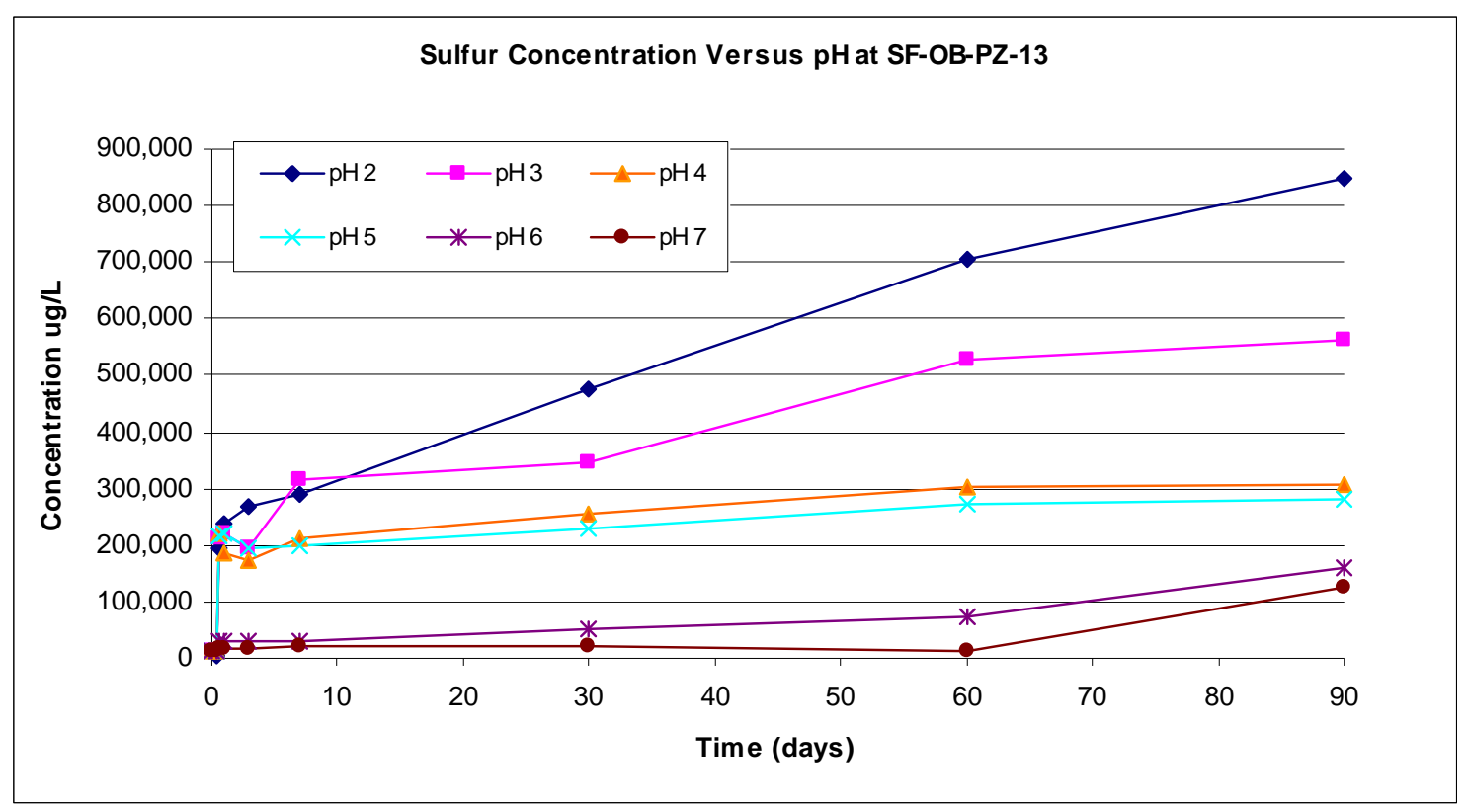

Figure 40. Effect of different $\mathrm{pH}$ on leaching of sulfur from sediment samples over a 90 day time interval.

\subsubsection{Core Location SF-BH-E-PZ-12}

The second location where core samples were collected was from the Southeast side of the CIA (Figure 1). Figures 41-45 show the concentrations of $\mathrm{Cd}, \mathrm{Pb}, \mathrm{Zn}, \mathrm{Fe}$, and $\mathrm{S}$ as a function of time and $\mathrm{pH}$. All of these data show a similar trend: A decrease in $\mathrm{pH}$ results in an increase in ion release with time. As with the Osborn Flats sample, lead concentration in solution decreases over time, most likely due to precipitation lead with sulfate which is sparingly soluble (Pourbaix, 1974) present in the simulated groundwater. Iron and sulfur responded similarly to the Osborn Flats sediments.

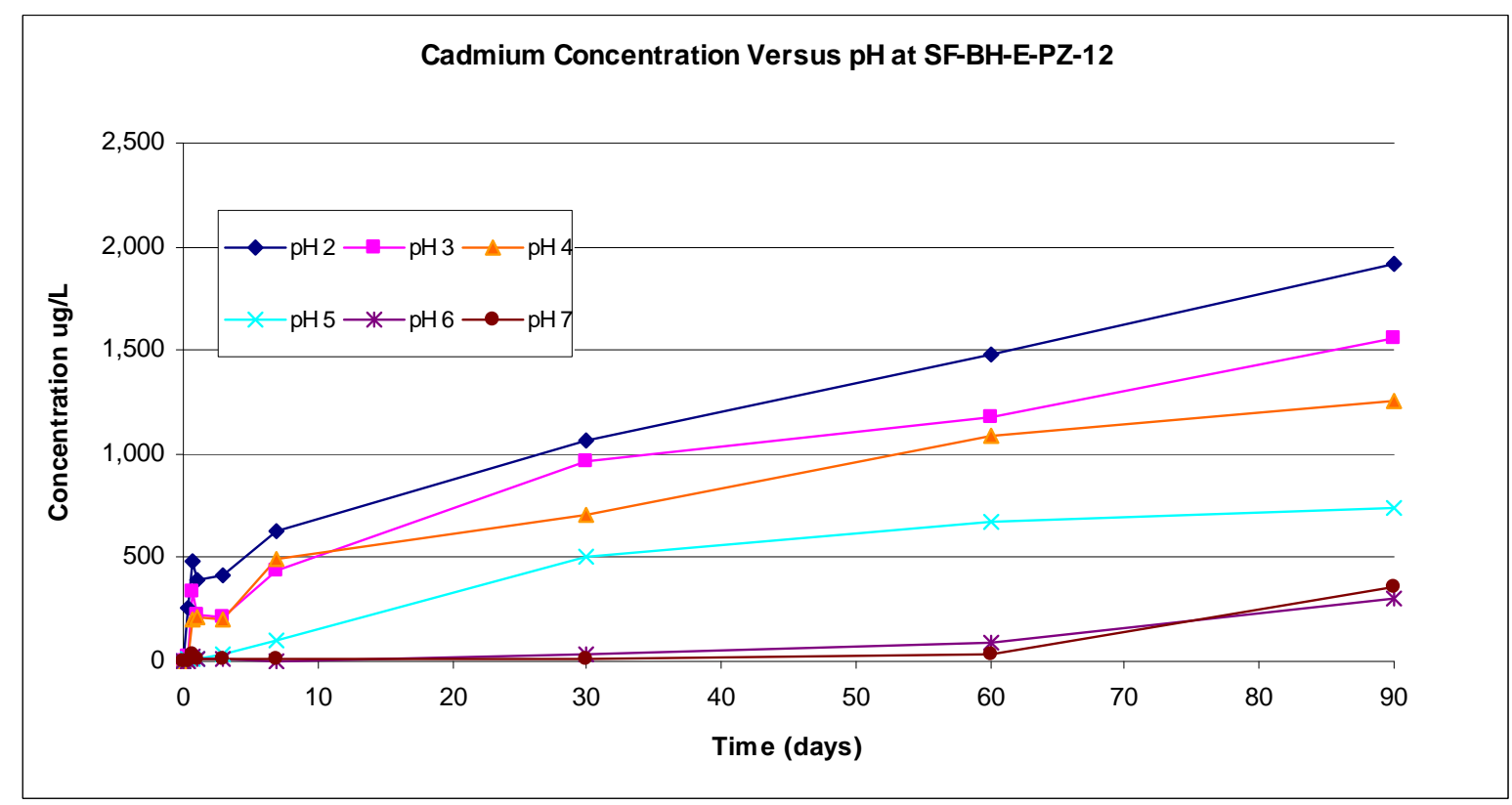

Figure 41. Effect of $\mathrm{pH}$ on cadmium concentration over time. 


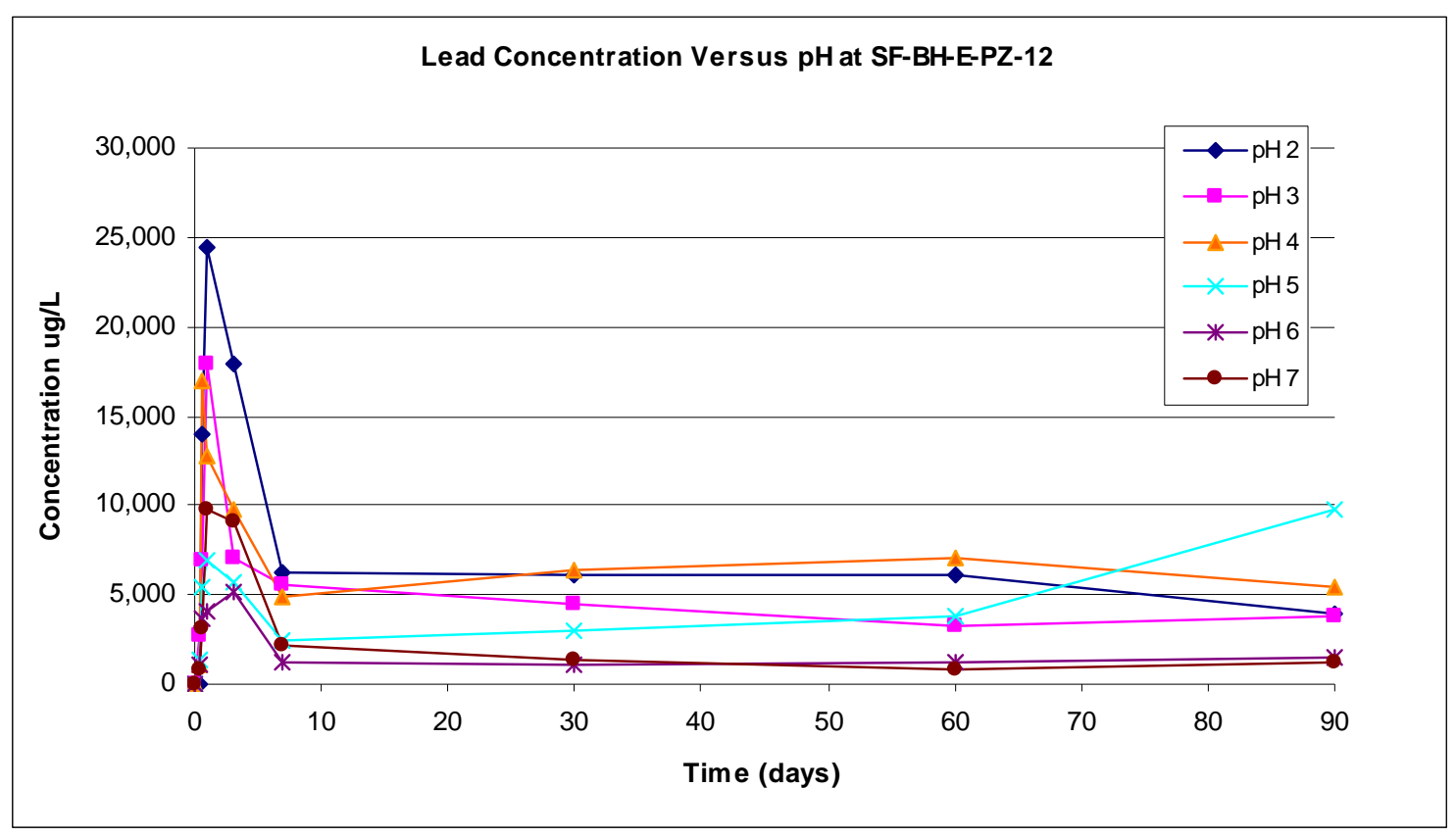

Figure 42. Effect of $\mathrm{pH}$ on lead concentration over time.

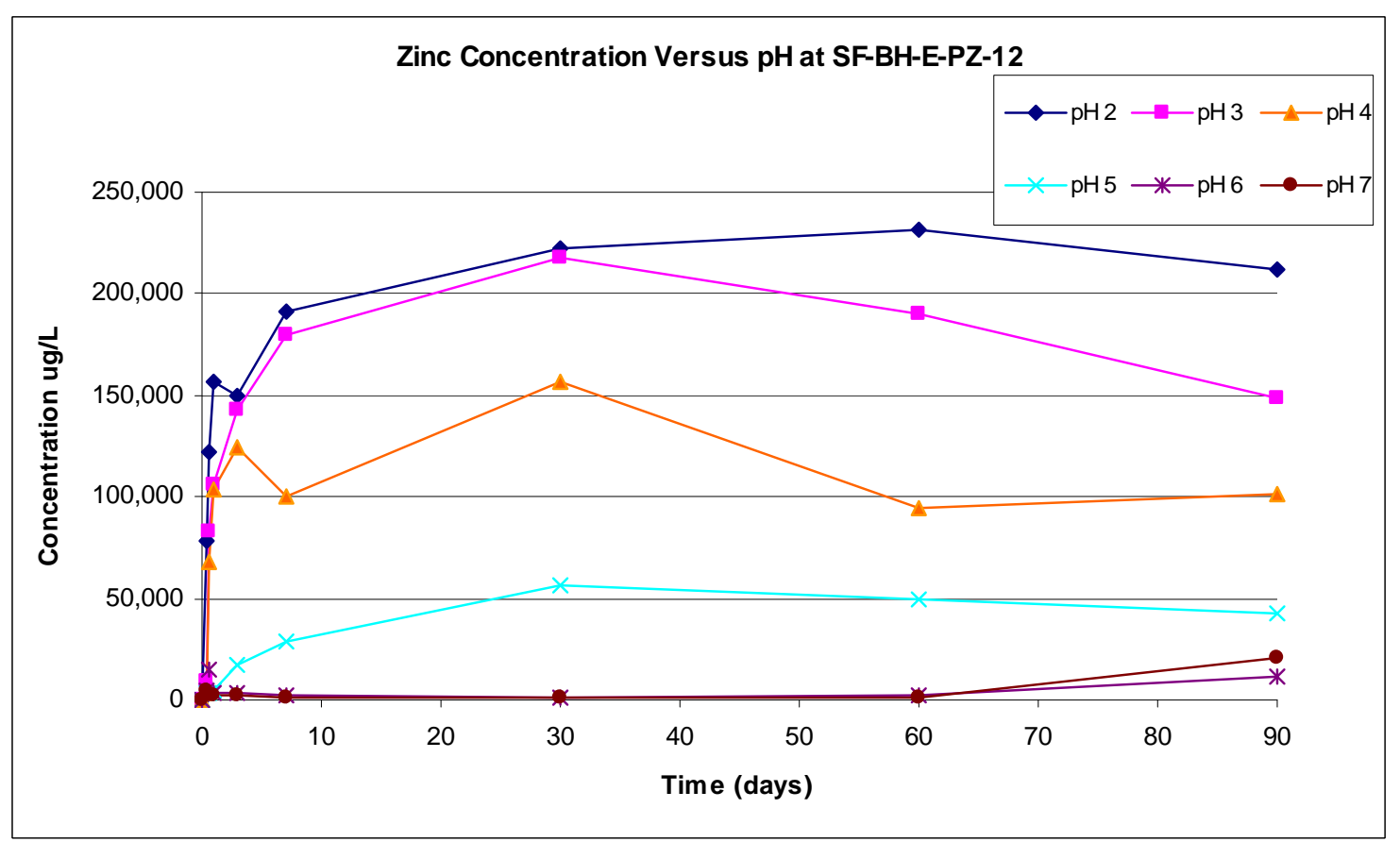

Figure 43. Effect of $\mathrm{pH}$ on zinc concentration over time. 


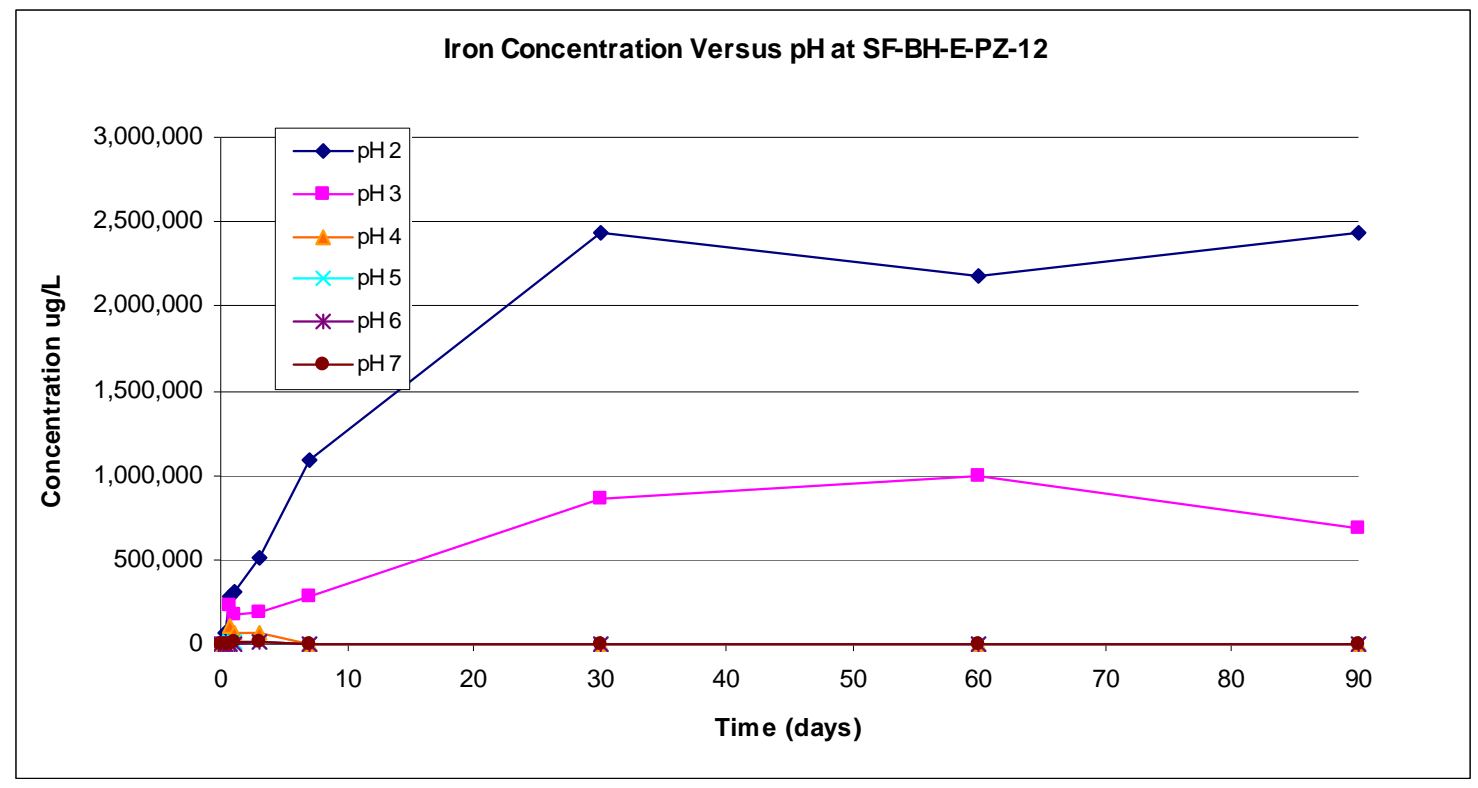

Figure 44. Effect of $\mathrm{pH}$ on iron concentration over time.

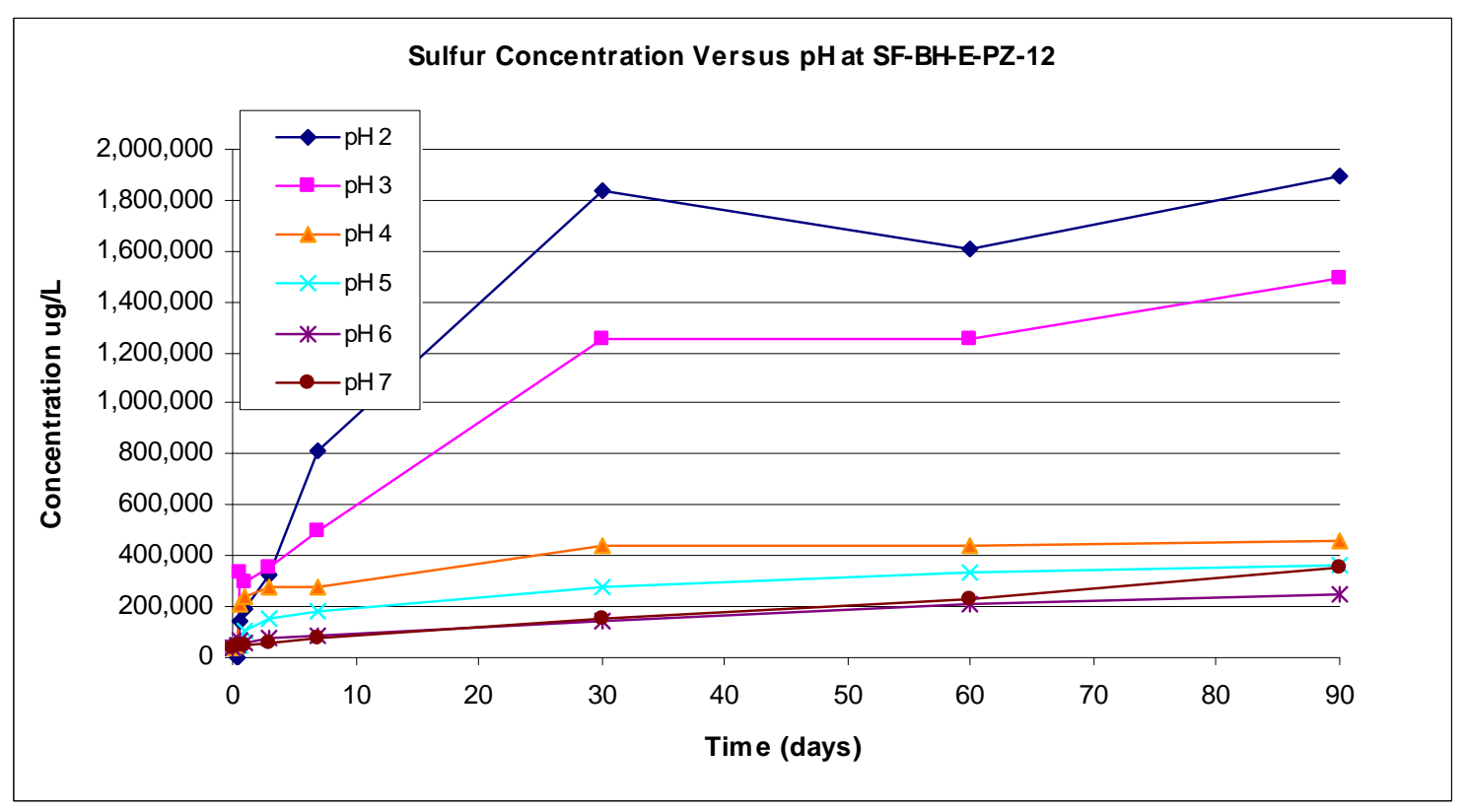

Figure 45. Effect of $\mathrm{pH}$ on sulfur concentration over time.

\subsubsection{Core Location SF-BH-E-PZ-16}

The third location where core samples were collected was from directly south of the CIA -- see Figure 1. Figures 46-50 show the concentrations of $\mathrm{Cd}, \mathrm{Pb}, \mathrm{Zn}, \mathrm{Fe}$, and $\mathrm{S}$ over time as a function of $\mathrm{pH}$. The pattern of metal and sulfur extraction (and subsequent lead precipitation) follows a similar trend as the previous location (SF-BH-E-PZ-12), that is reducing the $\mathrm{pH}$ results in an increase in ion concentration in solution. 


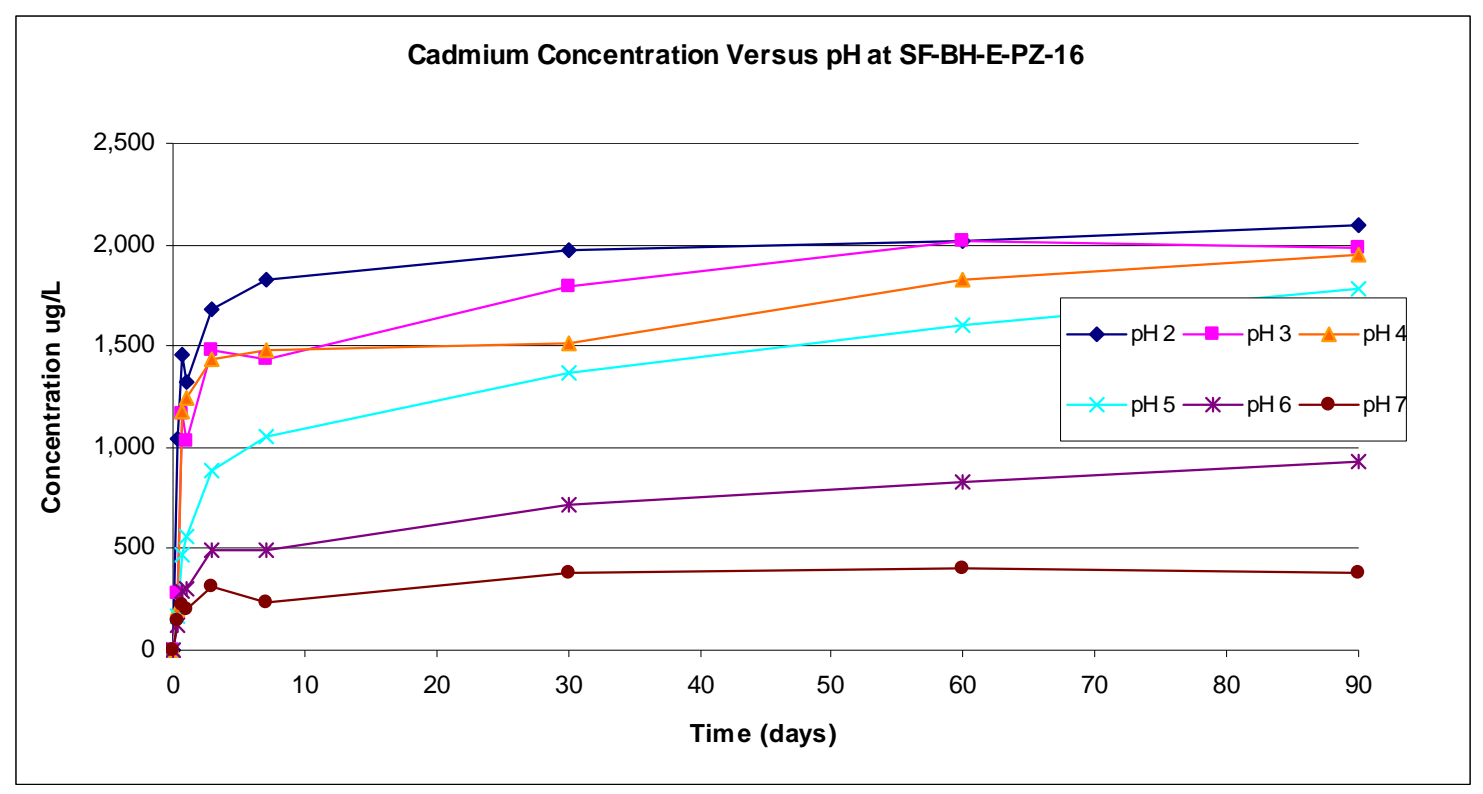

Figure 46. Effect of $\mathrm{pH}$ on cadmium concentration over time.

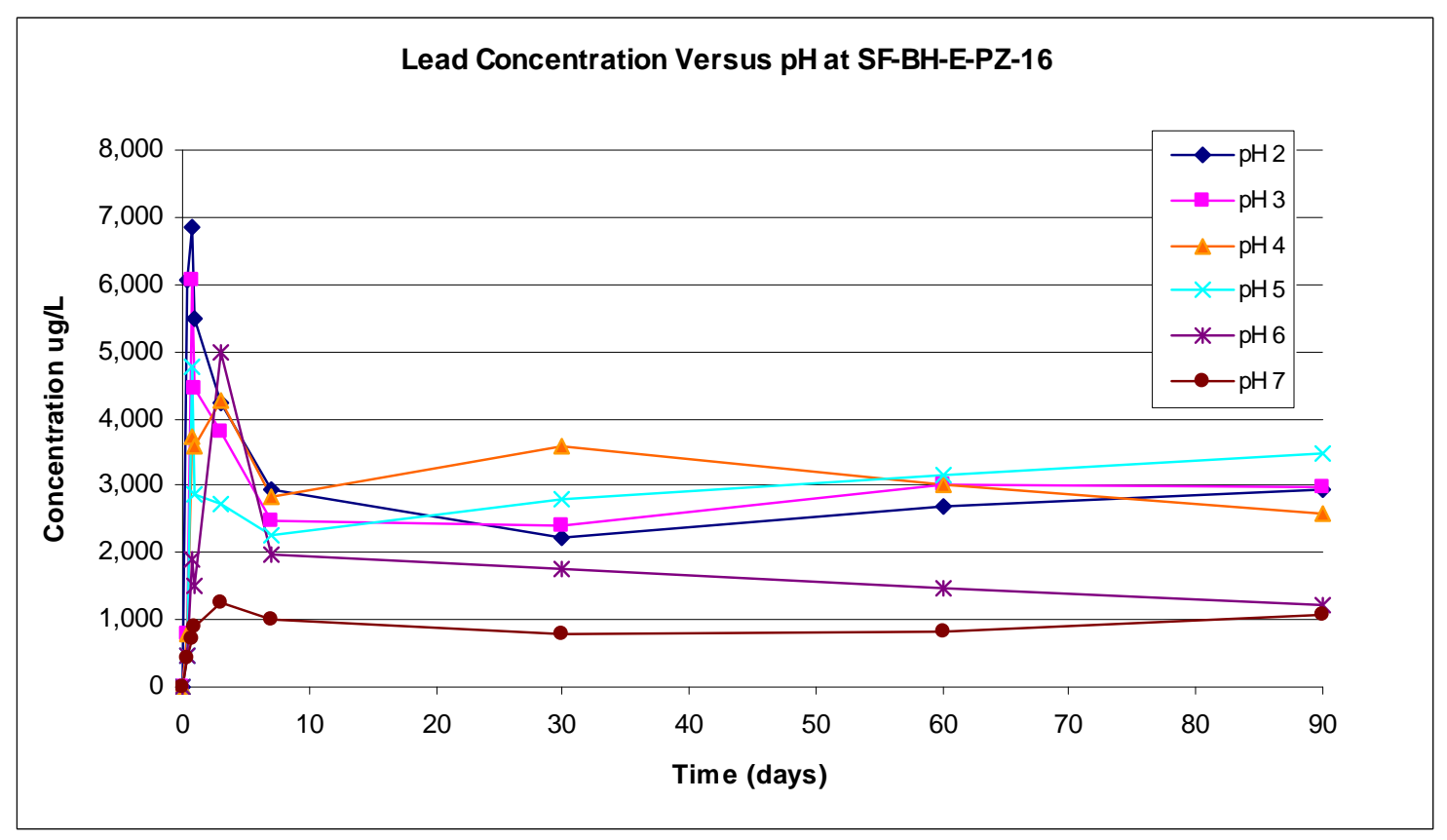

Figure 47. Effect of $\mathrm{pH}$ on lead concentration over time. 


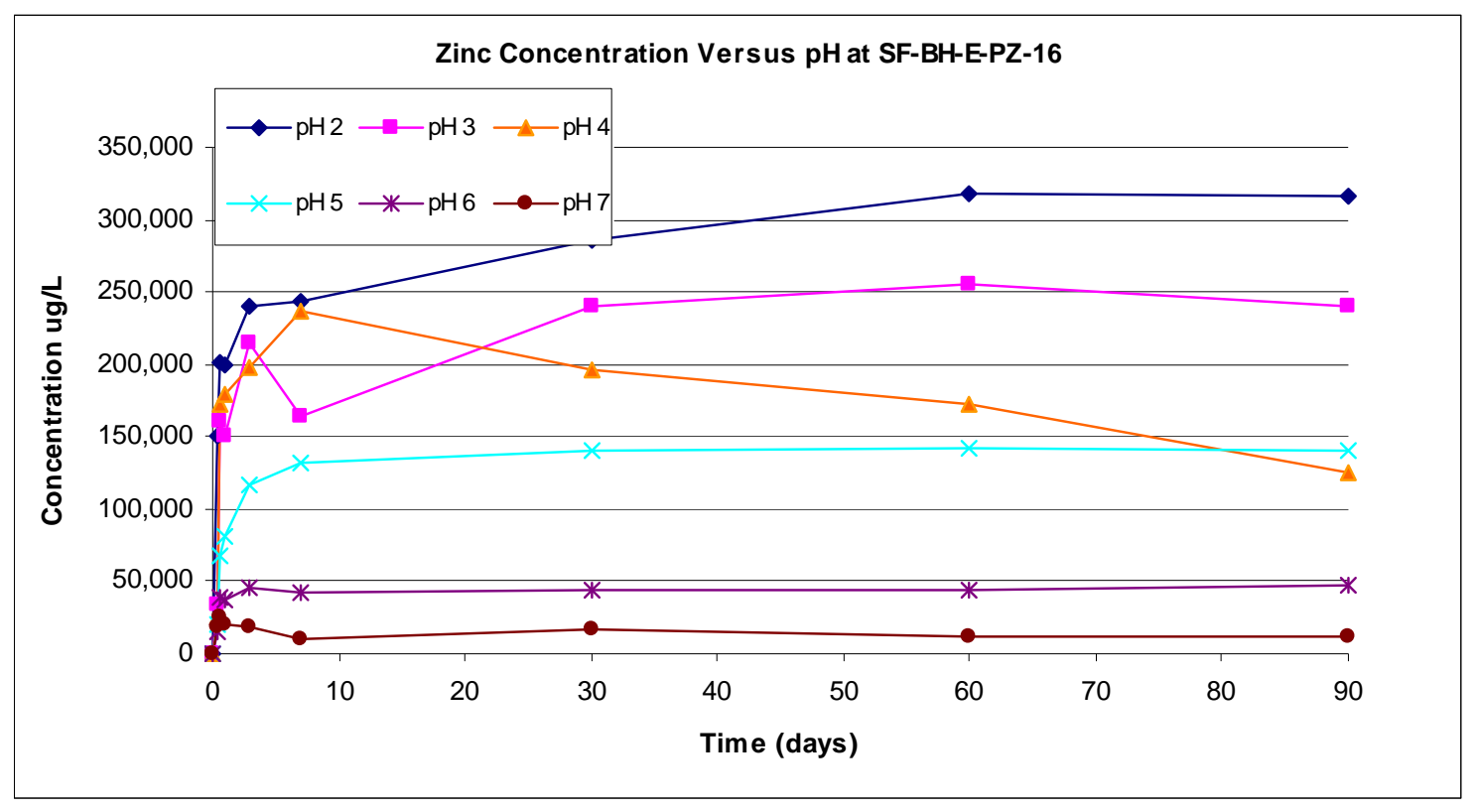

Figure 48. Effect of $\mathrm{pH}$ on zinc concentration over time.

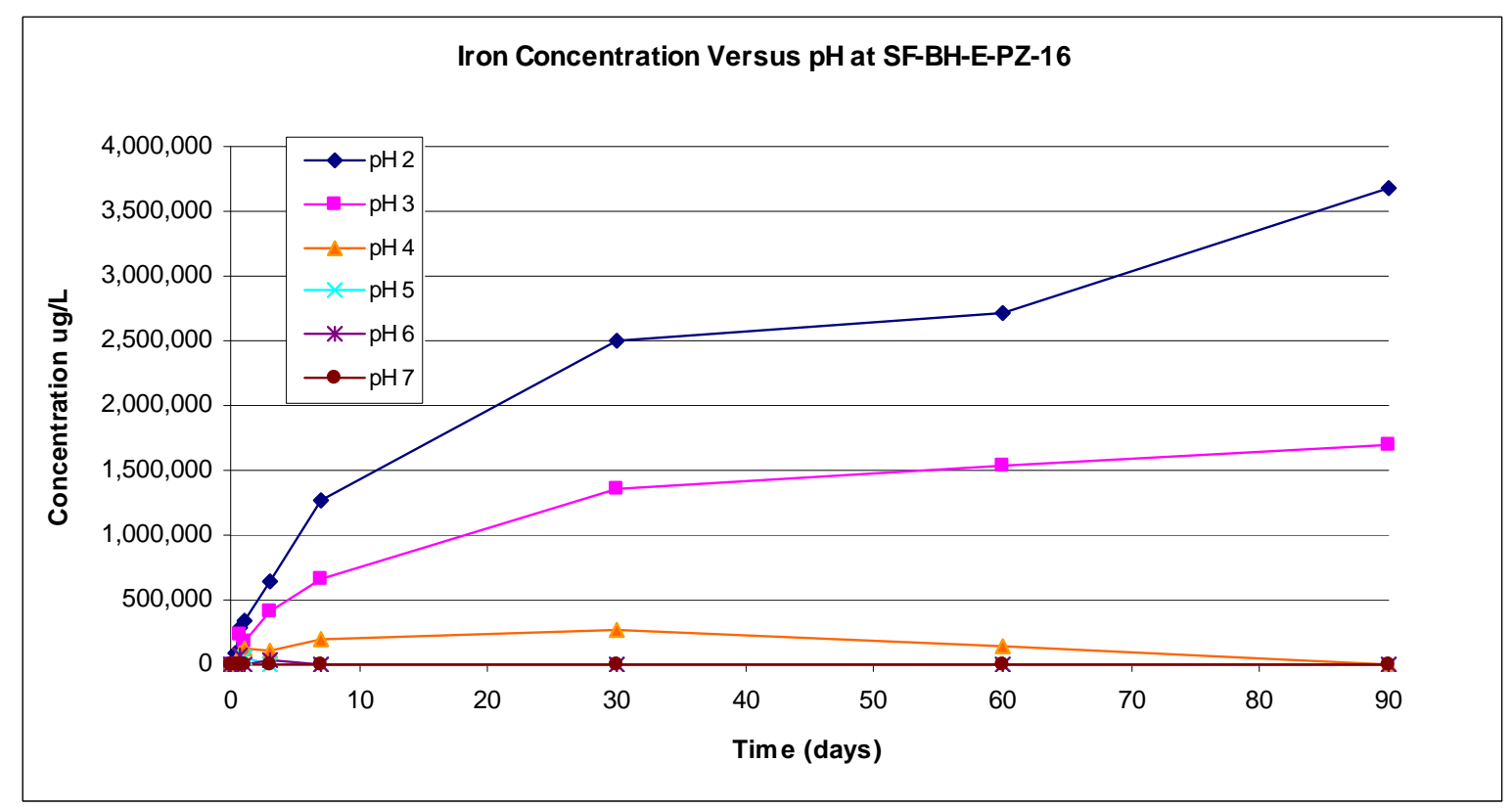

Figure 49. Effect of $\mathrm{pH}$ on iron concentration over time. 


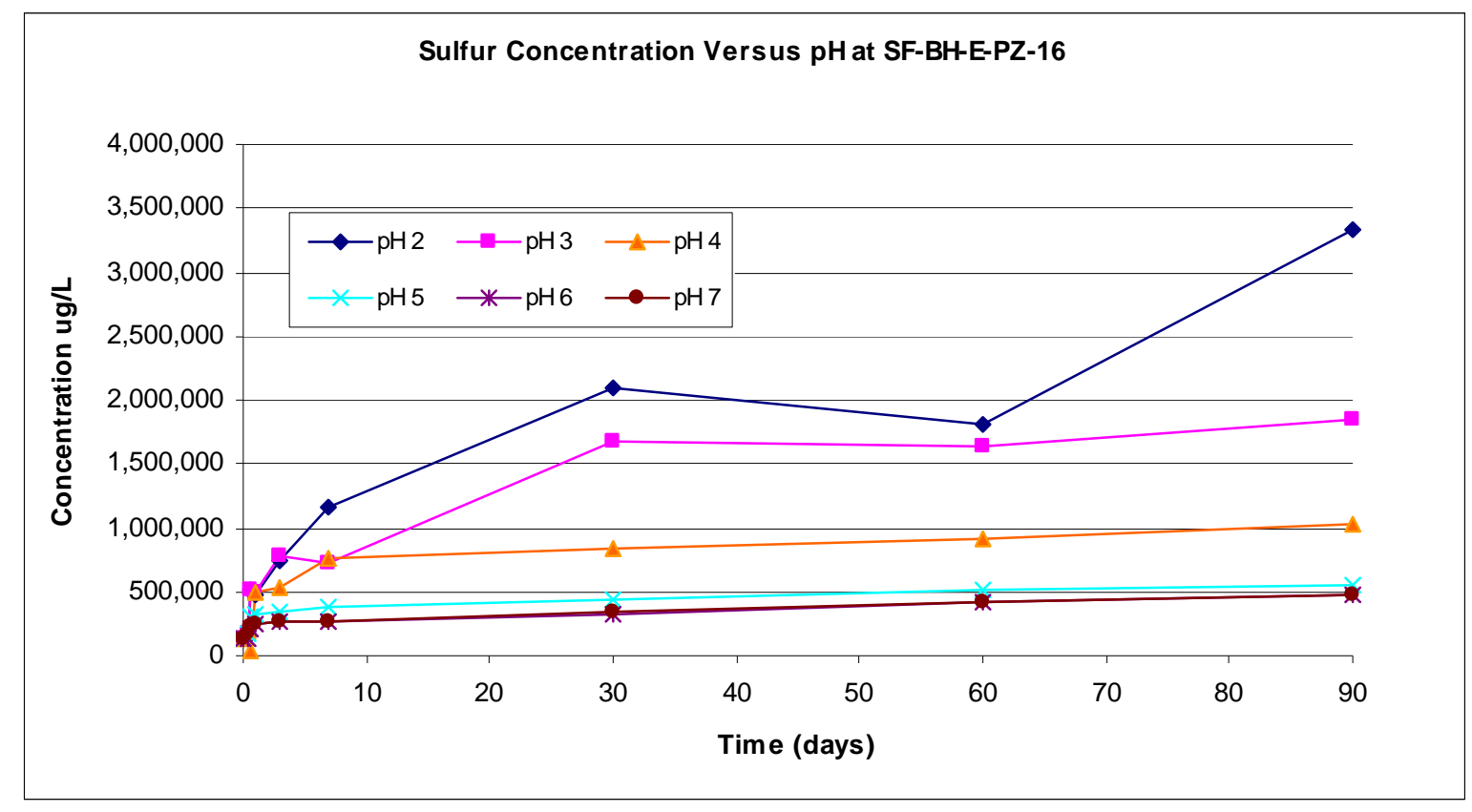

Figure 50. Effect of $\mathrm{pH}$ on sulfur concentration over time.

\subsubsection{Core Location SF-BH-E-PZ-24}

The final location where core samples were collected was from the west side of the CIA - see Figure 1. Figures 51-55 show the concentrations of $\mathrm{Cd}, \mathrm{Pb}, \mathrm{Zn}, \mathrm{Fe}$, and $\mathrm{S}$ as a function of time and $\mathrm{pH}$. The leaching trends of these elements from this location also are similar to the previous CIA locations. Based on the trends from previous locations, it appears that the $\mathrm{pH} 2$ and 3 samples on day 60 mislabeled prior to analysis. On the figures presented below, the data points for $\mathrm{pH} 2$ and $\mathrm{pH} 3$ for day 60 were swapped on each graph to represent what was believed to be the correct values, as it appeared that they were switched before the analysis of the samples. Also the value for the $\mathrm{pH} 2$ day 90 was $2500 \mathrm{ug} / \mathrm{L}$. The scale for the graph was kept at $1500 \mathrm{ug} / \mathrm{L}$ to give more detail to the lower concentrations. Like the other leach tests, as the $\mathrm{pH}$ is reduced the concentration of the ions of interest increases. The metals of interest at this location were more stable at $\mathrm{pH}$ values 5 and higher. The concentrations of the cadmium and zinc showed little change until the $\mathrm{pH}$ dropped to 4 or less. Iron concentrations changed very little until the pH dropped to 2 . 


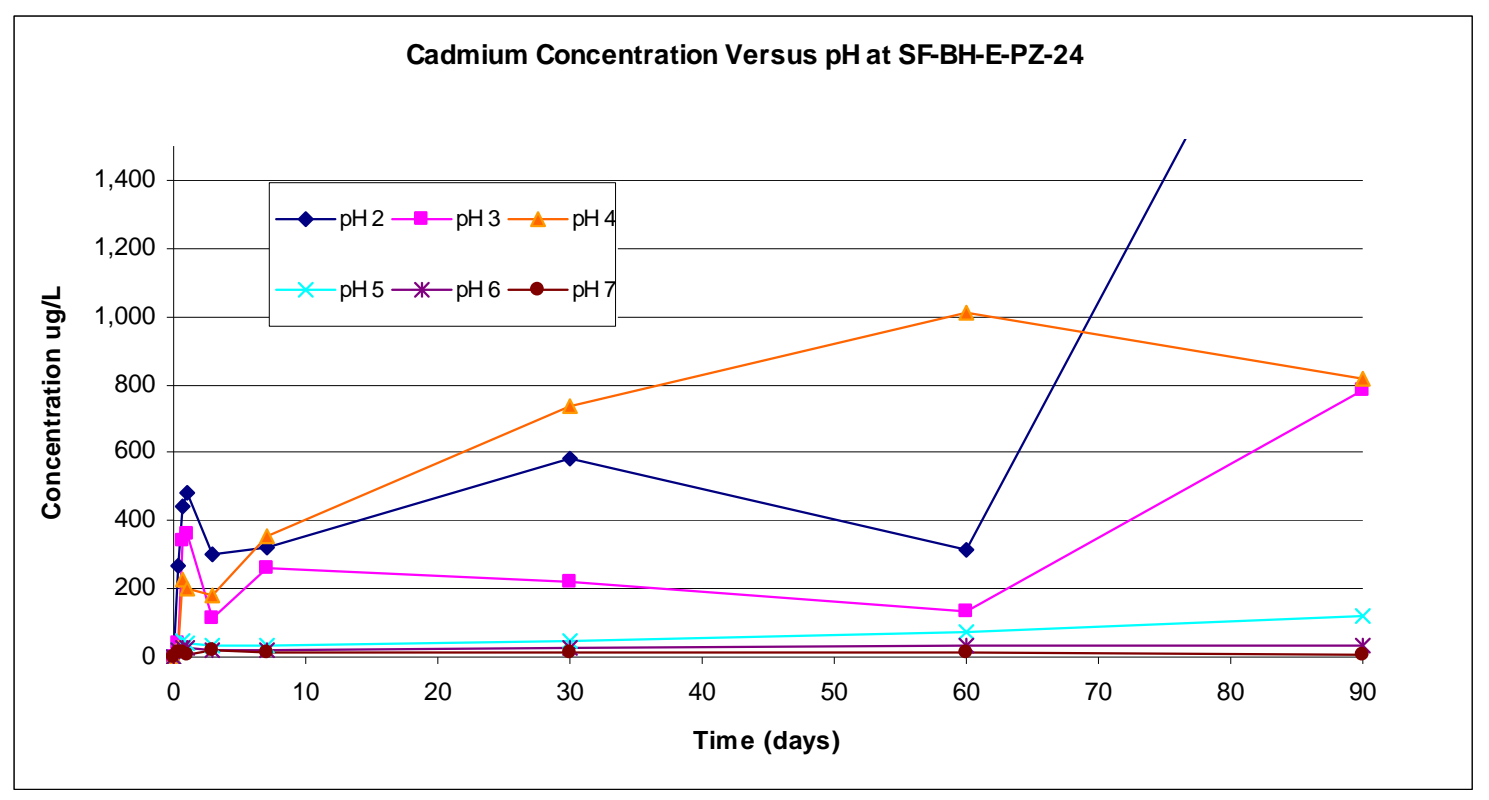

Figure 51. Effect of $\mathrm{pH}$ on cadmium concentration over time.

* Day 60 for $\mathrm{pH} 2$ and $\mathrm{pH} 3$ were switched.

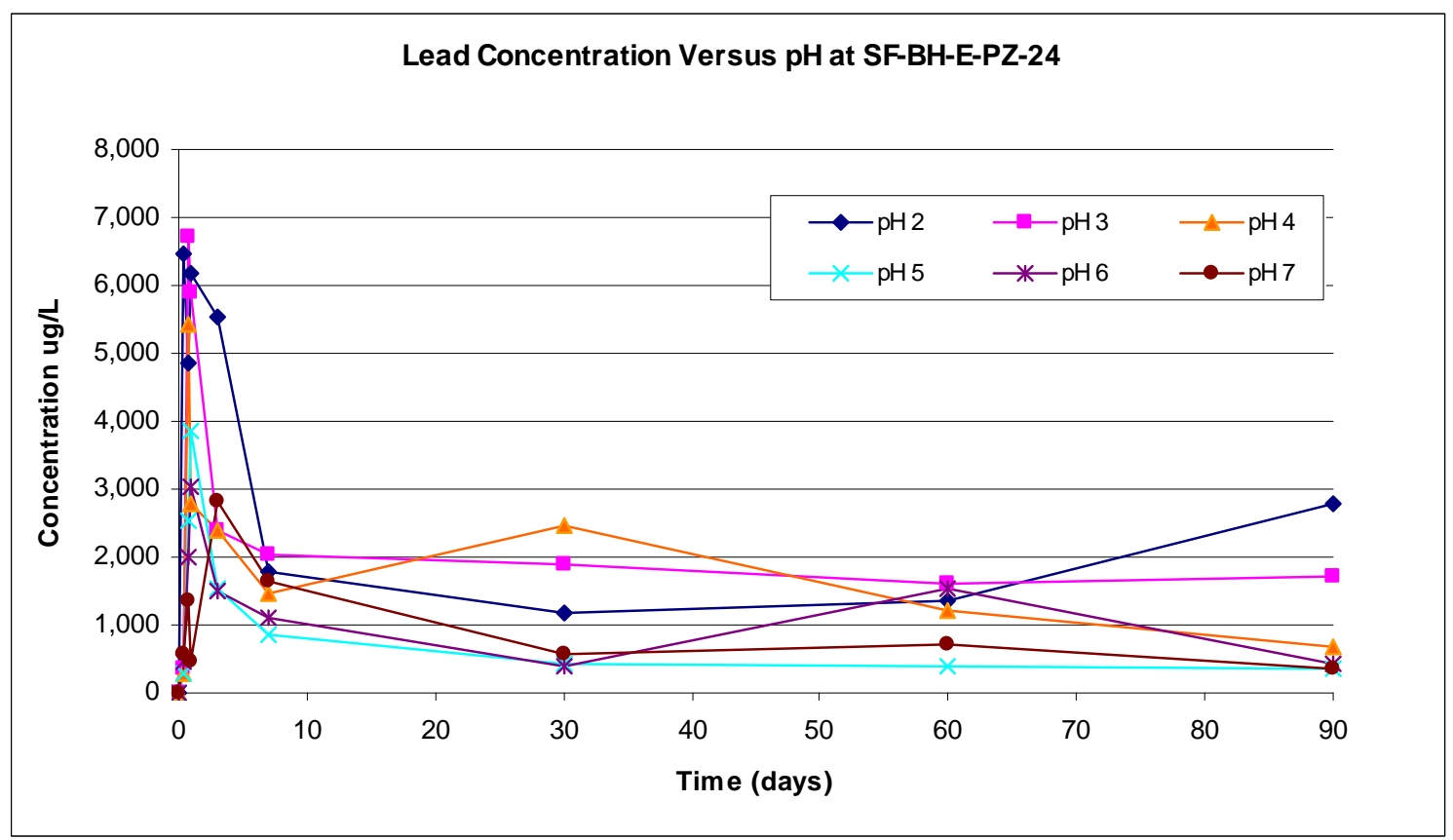

Figure 52. Effect of $\mathrm{pH}$ on lead concentration over time.

* Day 60 for $\mathrm{pH} 2$ and $\mathrm{pH} 3$ were switched. 


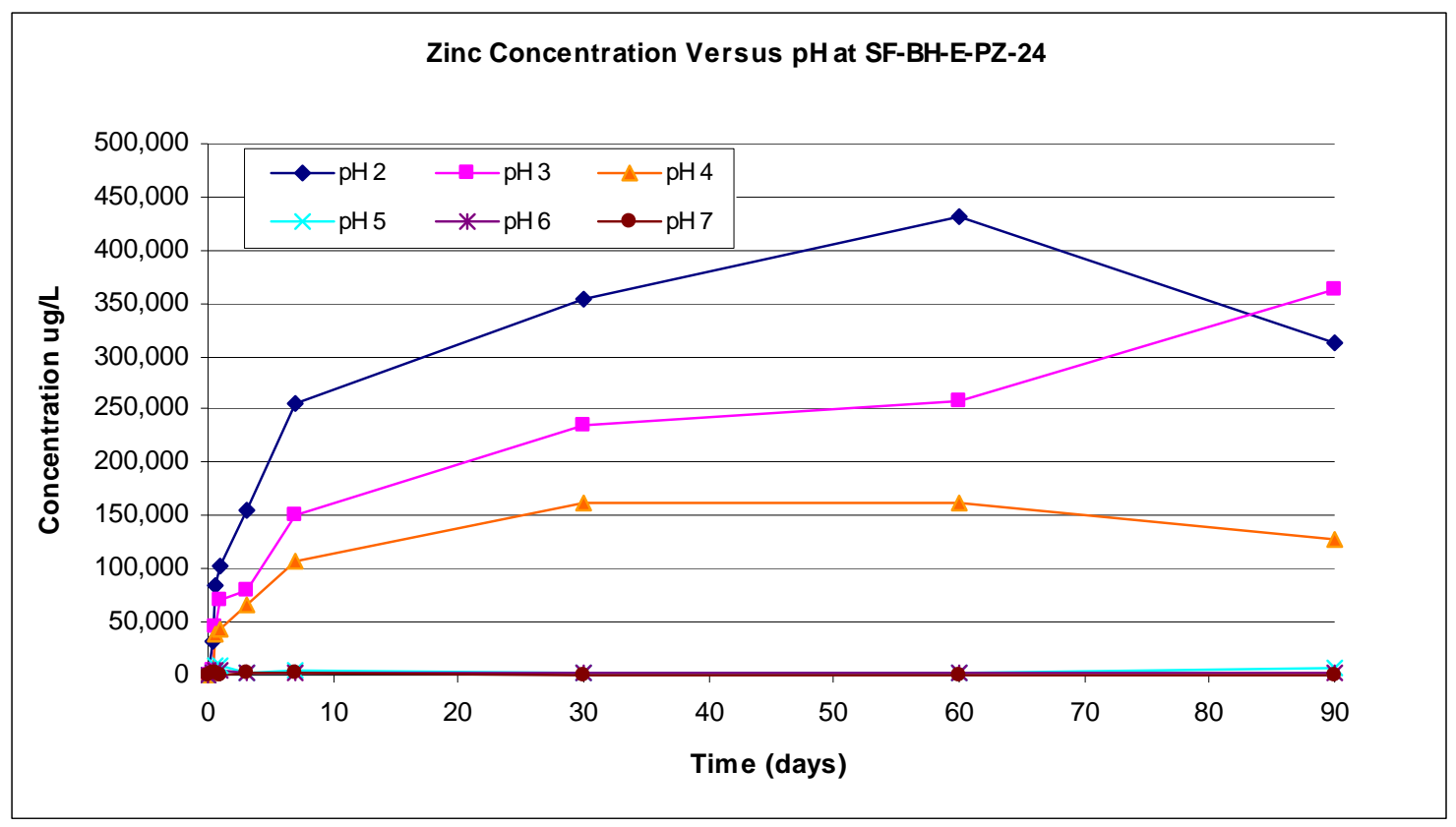

Figure 53. Effect of $\mathrm{pH}$ on zinc concentration over time.

* Day 60 for $\mathrm{pH} 2$ and $\mathrm{pH} 3$ were switched.

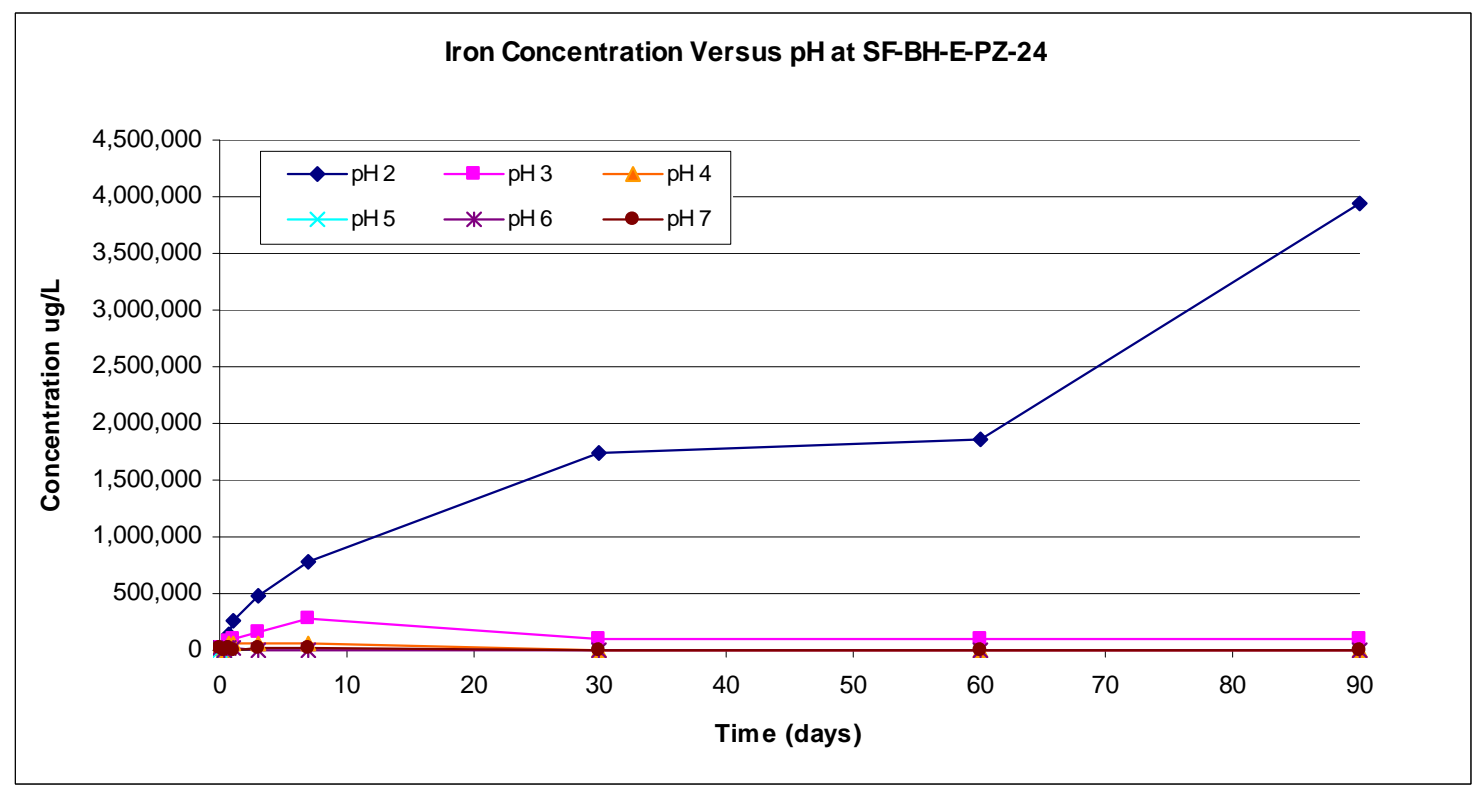

Figure 54. Effect of $\mathrm{pH}$ on iron concentration over time.

* Day 60 for $\mathrm{pH} 2$ and $\mathrm{pH} 3$ were switched. 


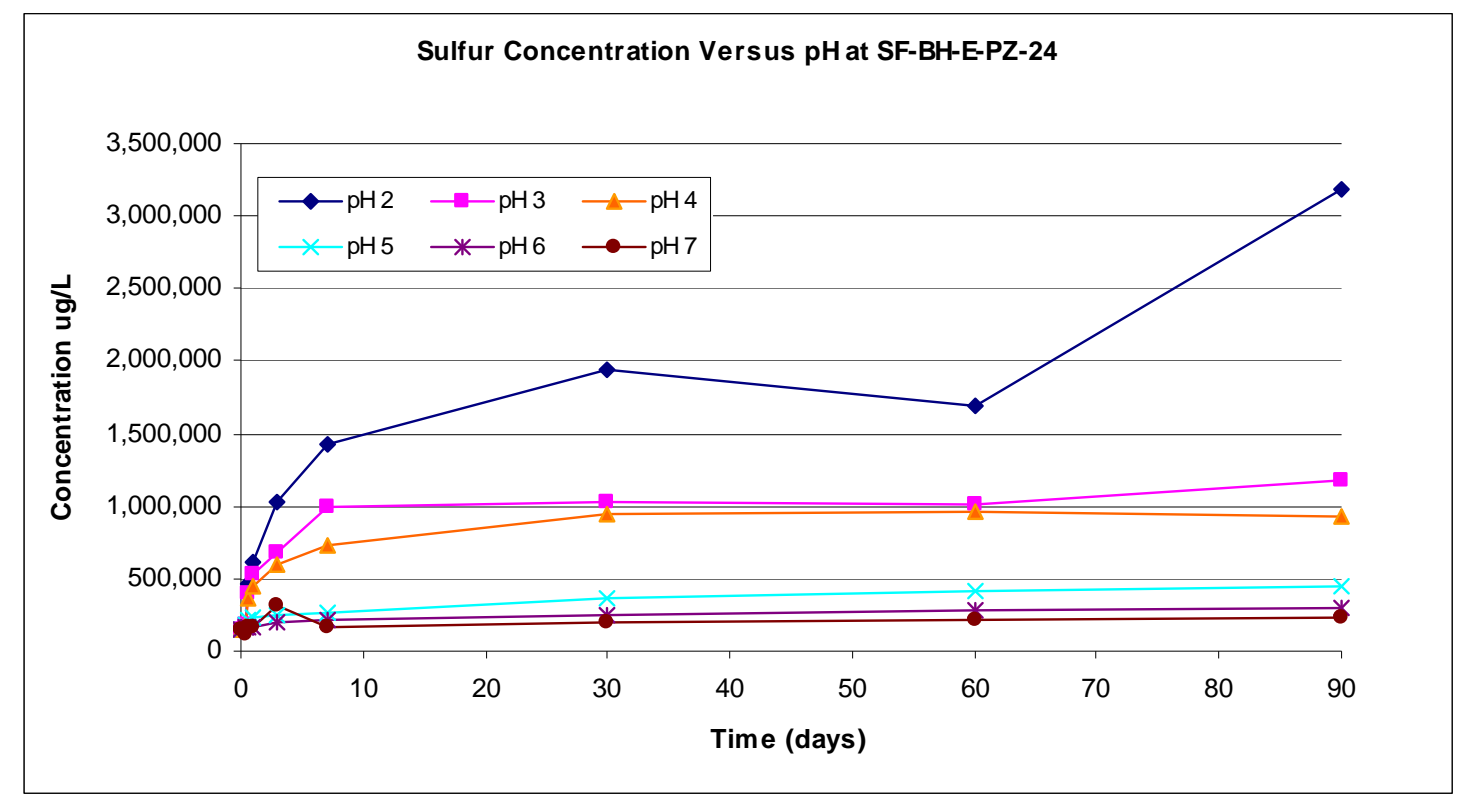

Figure 55. Effect of $\mathrm{pH}$ on sulfur concentration over time.

* Day 60 for $\mathrm{pH} 2$ and $\mathrm{pH} 3$ were switched.

\subsubsection{Effect of Aerobic or Anoxic Conditions on Metal Leaching}

This test consisted of two treatments. Both treatments received a two week wet/dry cycle under aerobic conditions. In the first treatment, 50 grams of soil was mixed with $500 \mathrm{~mL}$ of the simulated rainwater (deionized water) and mixed for the duration of the study. The soil and solution was exposed to the atmosphere during the 90 day test. Under the second treatment, 50 grams of soil was mixed with 500 $\mathrm{mL}$ of the simulated groundwater and mixed for the duration of the study, but in this case the samples were maintained in oxygen free environment. Leachate samples were collected at time 0,8 hours, 16 hours, 24 hours, 3 days, 7 days, 1 month, 2 months, and 3 months. The $\mathrm{pH}$ was monitored, but not altered. The sample size collected was $10 \mathrm{~mL}$. The $10 \mathrm{~mL}$ samples was diluted to $20 \mathrm{~mL}$ with deionized water, acidified to less than $\mathrm{pH} 2$ with concentrated nitric acid and shipped to an offsite laboratory for analysis. The following graphs show the metal concentrations for the conditions tested. To compare the effect of the wet/dry cycles (oxygenated soils) with leaching under anoxic conditions, data from the leaching tests from the previous section where $\mathrm{pH}$ effect was studied under anoxic conditions was added. For each graph below a third line was added that shows the metal concentration under anoxic conditions for the $\mathrm{pH}$ that this soil stabilized at in this leach test. The $\mathrm{pH}$ was selected based on the steady state $\mathrm{pH}$ of the sediments being tested in this leach test (Figure A-5). For the location SF-OB-PZ-13 below, the $\mathrm{pH}$ tended to be closest to $\mathrm{pH} 5$. So the cadmium concentration from the previous leach study versus $\mathrm{pH}$ (at $\mathrm{pH} 5$ ) for this location was added onto the graph. The same procedure was done for each of the other consecutive graphs.

\subsubsection{Sample Location SF-OB-PZ-13}

The cadmium concentrations at this location did not show significant differences between the sample exposed to oxygen continuously and those maintained in an oxygen-free environment (Figure 56). There was an initial small spike of cadmium released, which was then followed by steady concentration for the remainder of the test. While other factors certainly impact this as well, the effect of the two-week wetting/drying cycle significantly reduced the amount of cadmium released when compared to the release of cadmium from the soil that was not exposed to the wet/dry cycles or oxygen. 


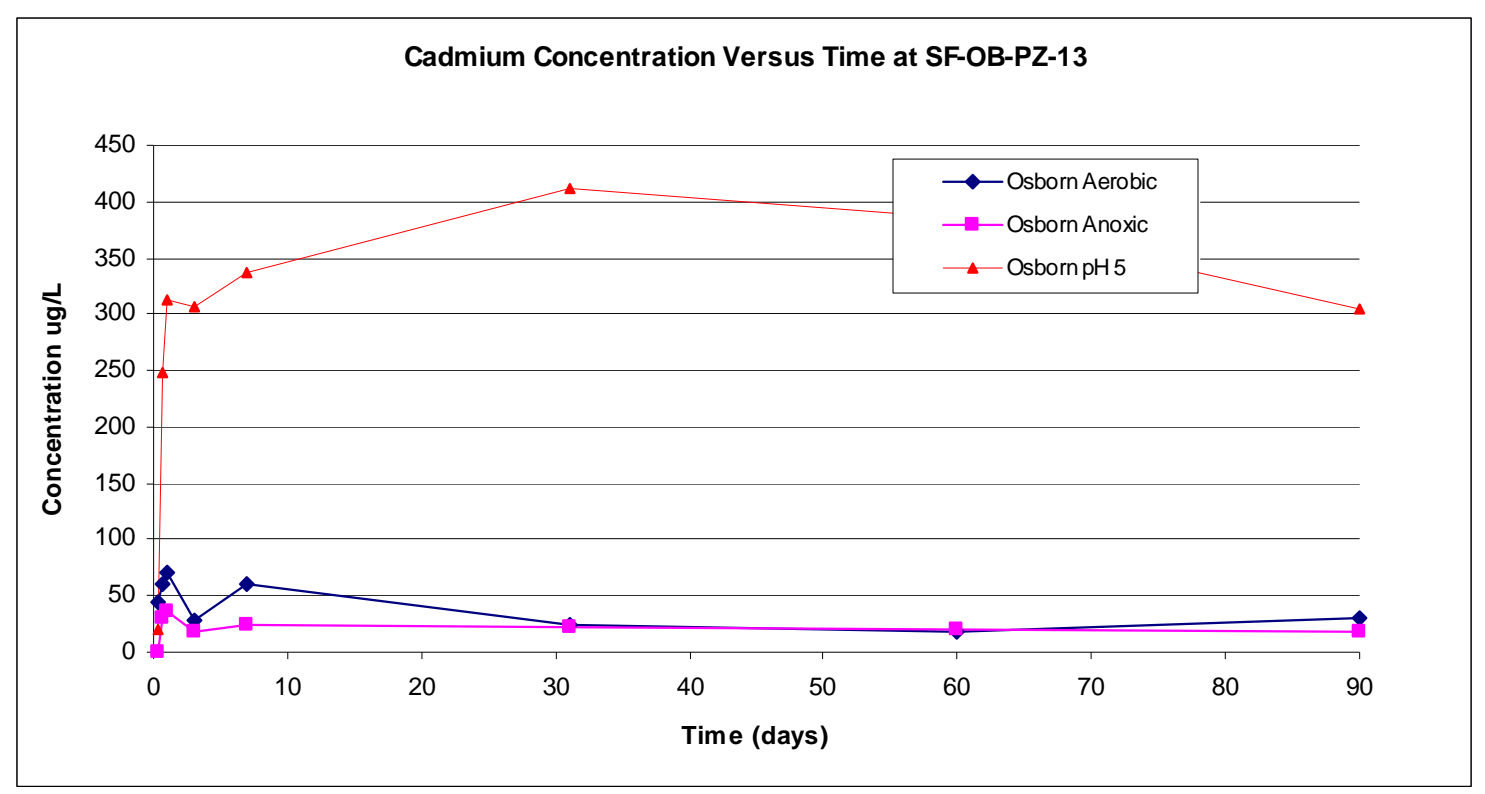

Figure 56. Effect of aerobic and anoxic conditions on cadmium concentration over time.

The concentration of lead in the $\mathrm{pH}$ leach test at $\mathrm{pH} 5$ was similar to the lead concentrations from this redox leach test; however, the oxygen free sample resulted in slightly lower lead concentrations over time and the distilled water oxygenated sample release more lead than both (Figure 57). As with the cadmium, there was an initial release of lead from the wet/dry cycle which then precipitated out of solution over time. The zinc concentrations leached from the two samples were similar to the pattern seen for cadmium (Figure 56 and 58). Again, there was not a significant difference between zinc released from the aerobic sample versus the anaerobic sample. But the amount of zinc released from the $\mathrm{pH} 5$ study showed higher release rates than the two tests conducted following the wet dry cycle.

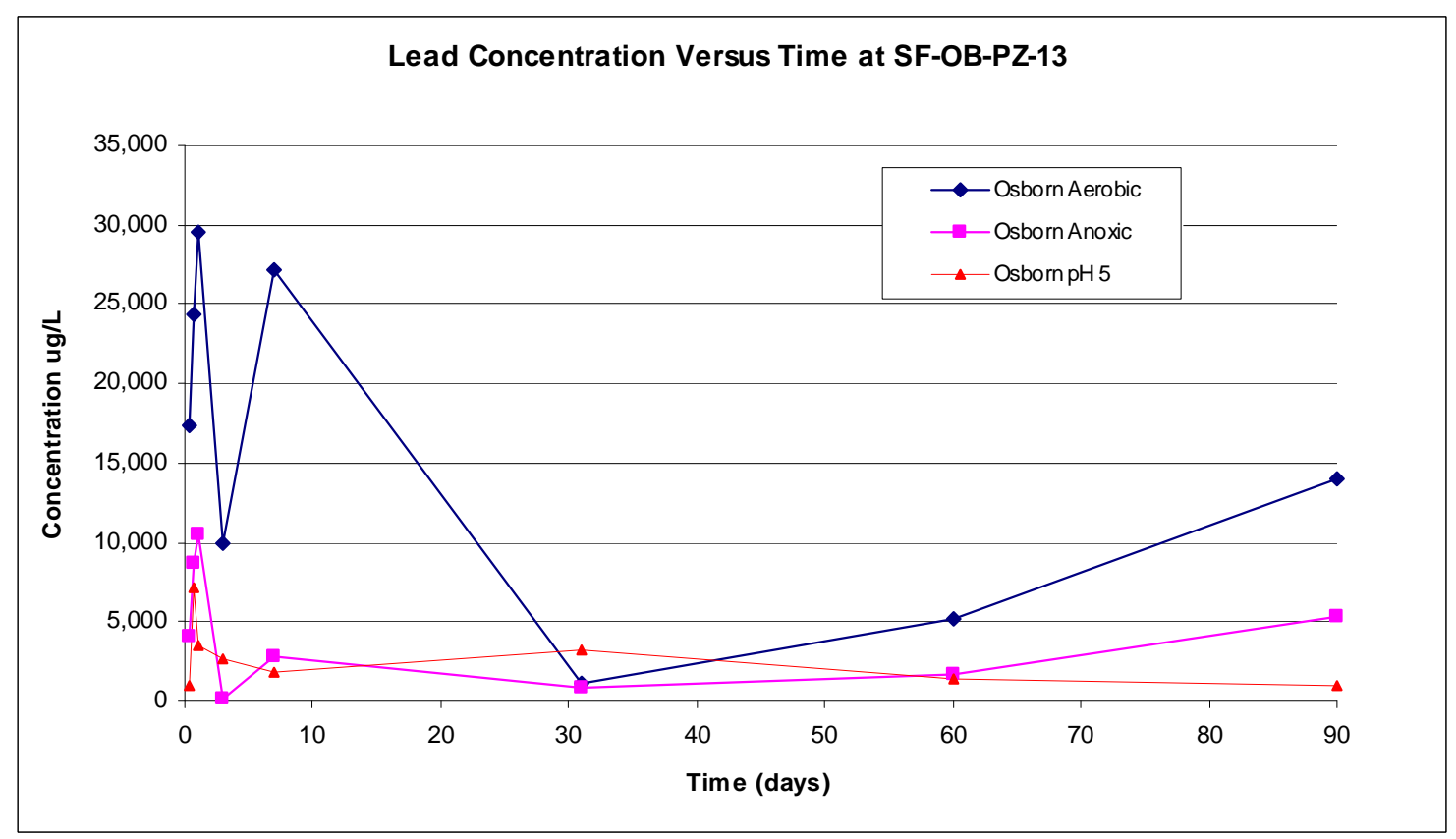

Figure 57. Effect of aerobic and anoxic conditions on lead concentration over time. 


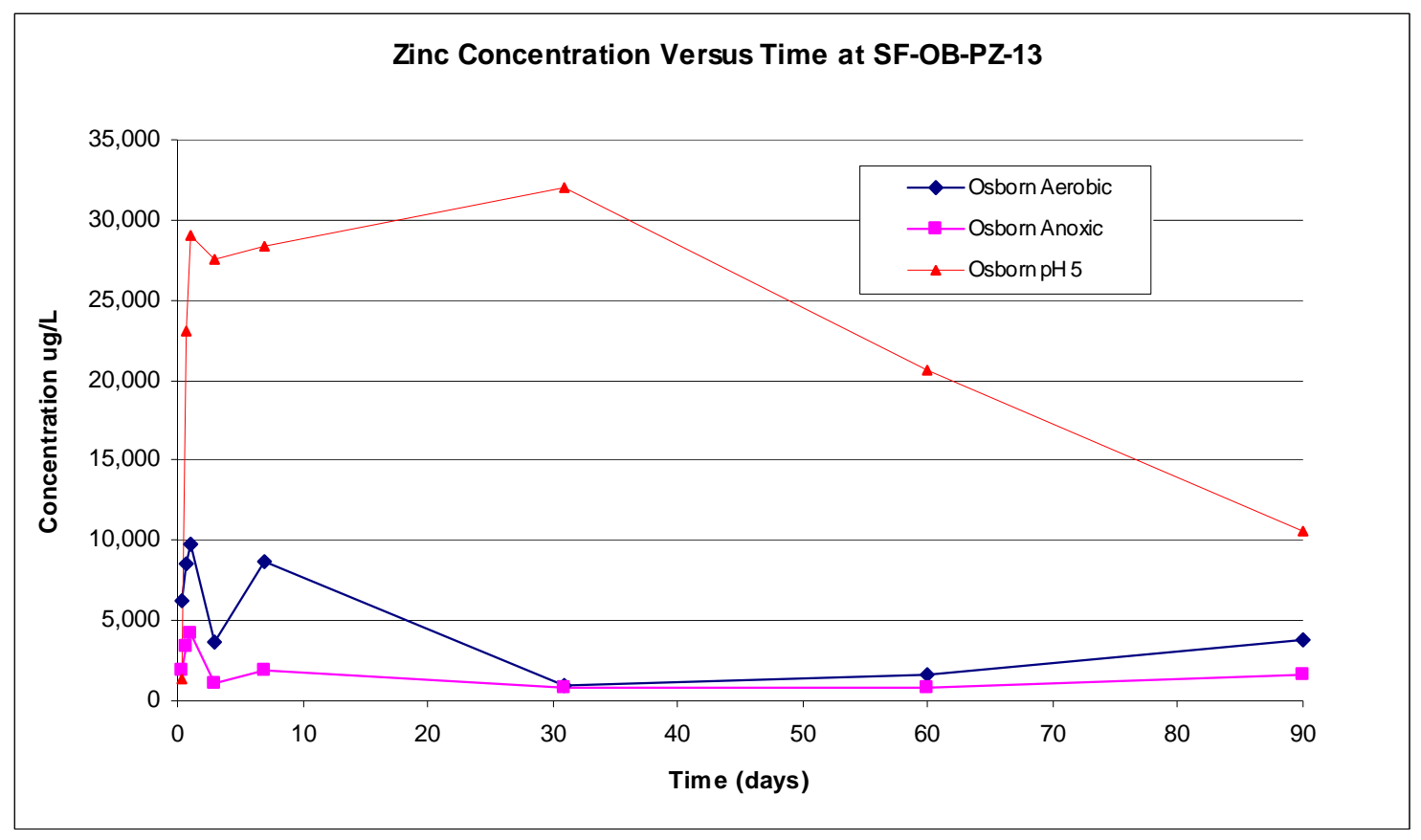

Figure 58. Effect of aerobic and anoxic conditions on zinc concentration over time.

The iron concentration spiked early due to the wet/dry cycling, but quickly fell to concentrations below $5000 \mathrm{ug} / \mathrm{L}$ (Figure 59). As the iron precipitated out, it would likely take with it the other metals also. This would also explain the drops in concentration of the other elements. Sulfur concentrations for this aerobic versus anoxic leach test reacted similarly to each other. The increased concentration in the subsurface sample was due to the presence of trace amounts of sulfur in the simulated groundwater (Figure 60). The sulfur concentration in the $\mathrm{pH} 5$ leach test was much higher, but did not undergo a 2 week wet/dry cycle and was maintained in an oxygen free environment throughout the test.

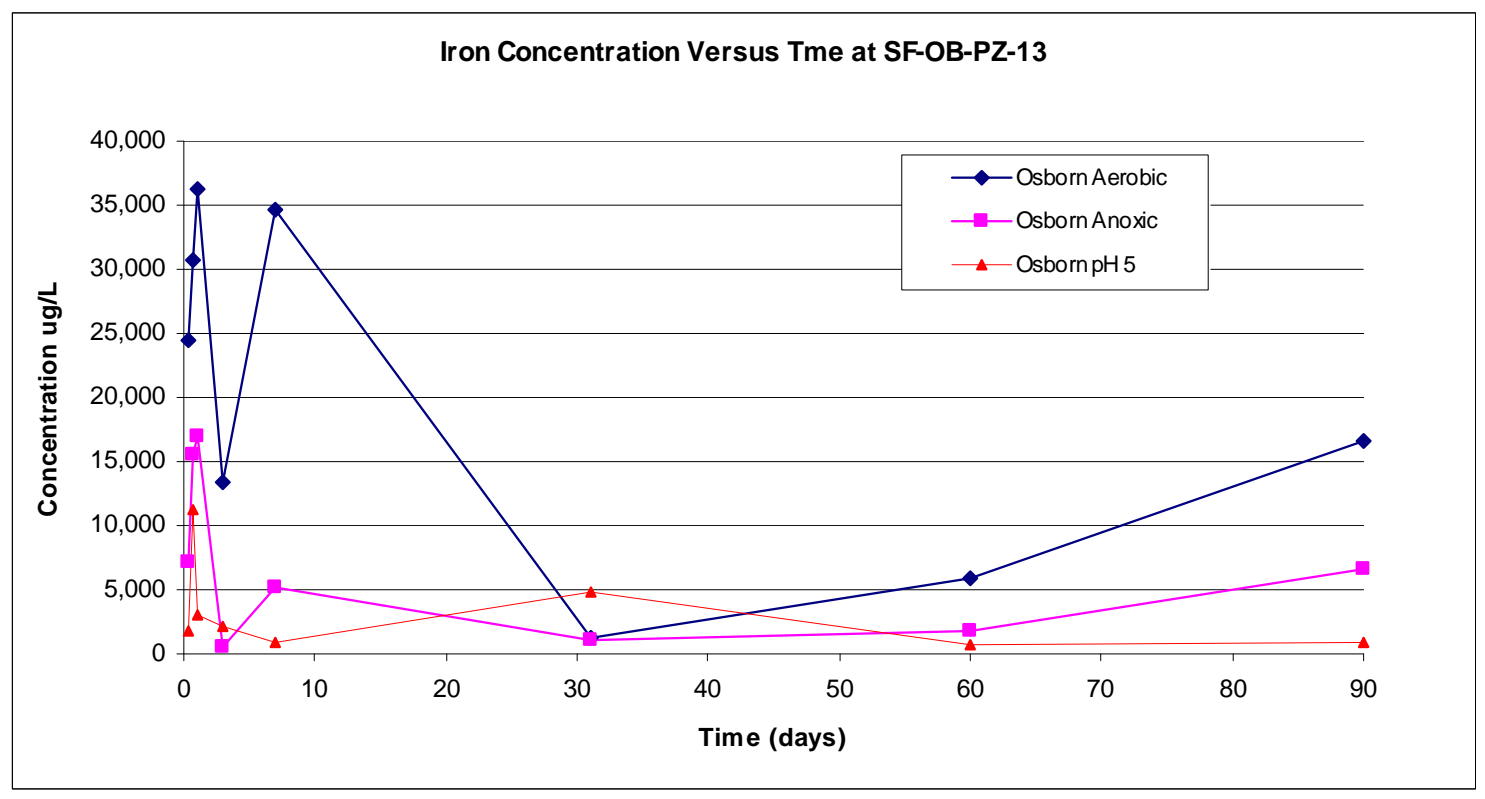

Figure 59. Effect of aerobic and anoxic conditions on iron concentration over time. 


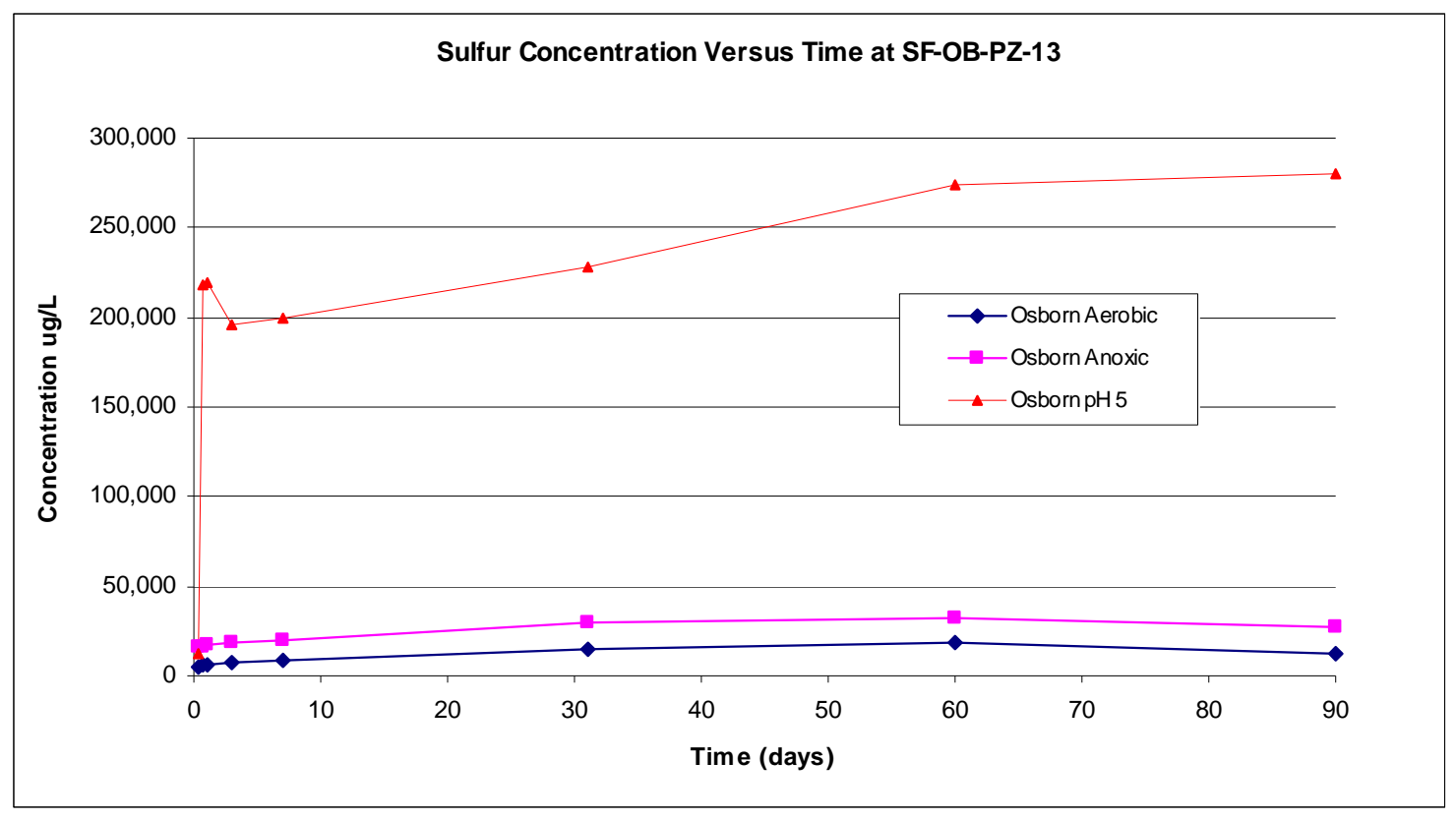

Figure 60. Effect of aerobic and anoxic conditions on sulfur concentration over time.

\subsubsection{Sample Location SF-BH-E-PZ-12}

This core location was located on the South East side of the CIA (Figure 1). Figures 61-65 show the concentrations of $\mathrm{Cd}, \mathrm{Pb}, \mathrm{Zn}, \mathrm{Fe}$, and $\mathrm{S}$ as a function of time. The samples were exposed to a two week wet/dry cycling followed by a 90 day leach test using deionized water for one treatment and simulated groundwater for a second treatment. For this location, the cadmium concentration increased significantly over time for the anaerobic sample, but to a much lower extent with the aerobic sample (Figure 61). At this location the $\mathrm{pH}$ of the solution stabilized near a $\mathrm{pH}$ of 5 (Figure A-6). The cadmium concentration from the anaerobic sample was also similar to the concentration of cadmium from the pH5 leach test. Under aerobic conditions, oxidized iron compounds will precipitate and also adsorb other elements, which could be the reason for the low concentration of cadmium in solution under aerobic conditions. Lead concentrations from both samples showed a similar pattern to the Osborn Flats samples (Figure 62), again most likely due to precipitation of lead over time as an insoluble oxides or sulfides. Like the other locations, there was an initial spike associated with the release of metals from the wet/dry cycle. This was followed by a sharp drop in concentration, then a slight increase over time. 


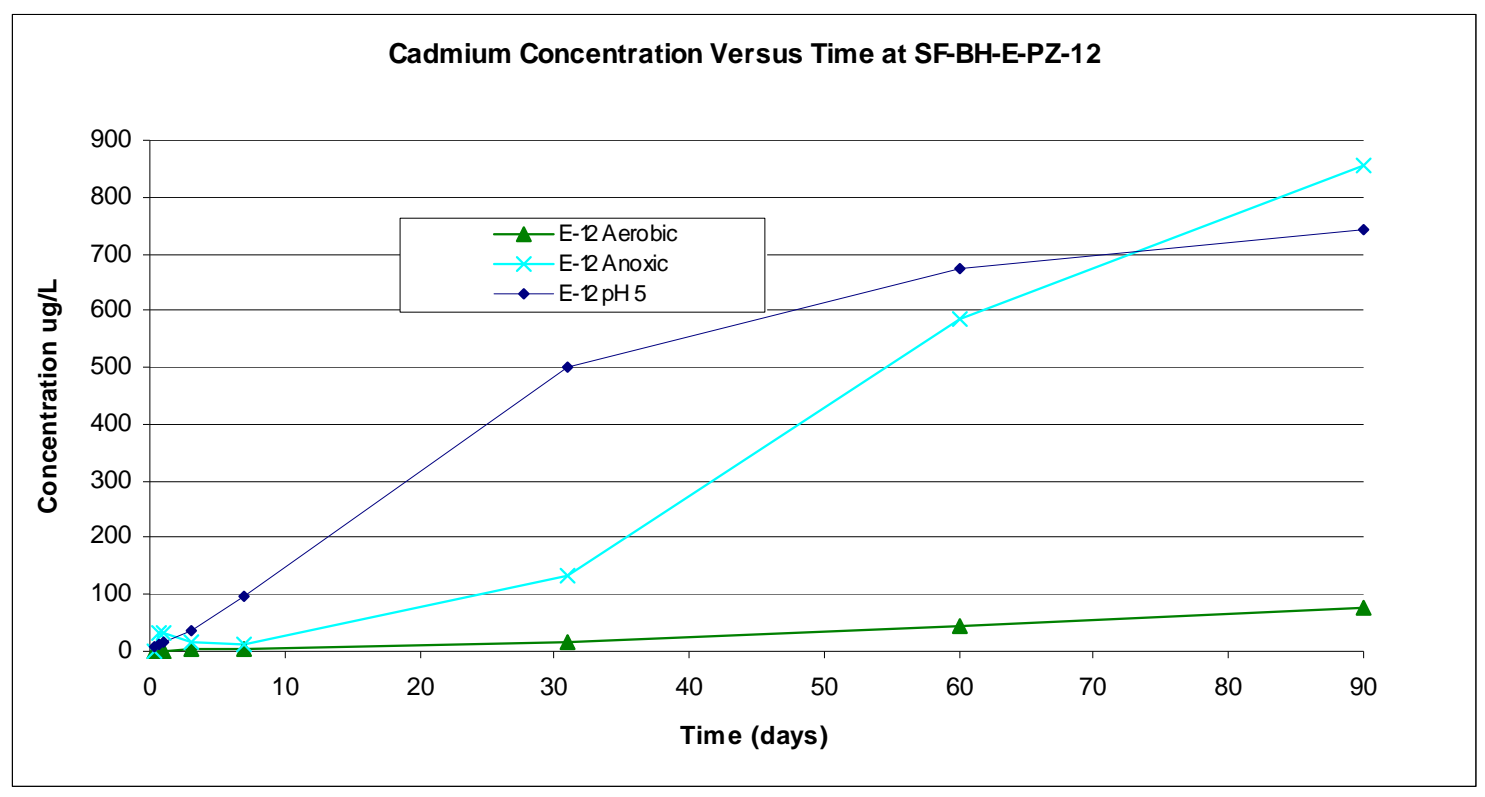

Figure 61. Effect of aerobic and anoxic conditions on cadmium concentration over time.

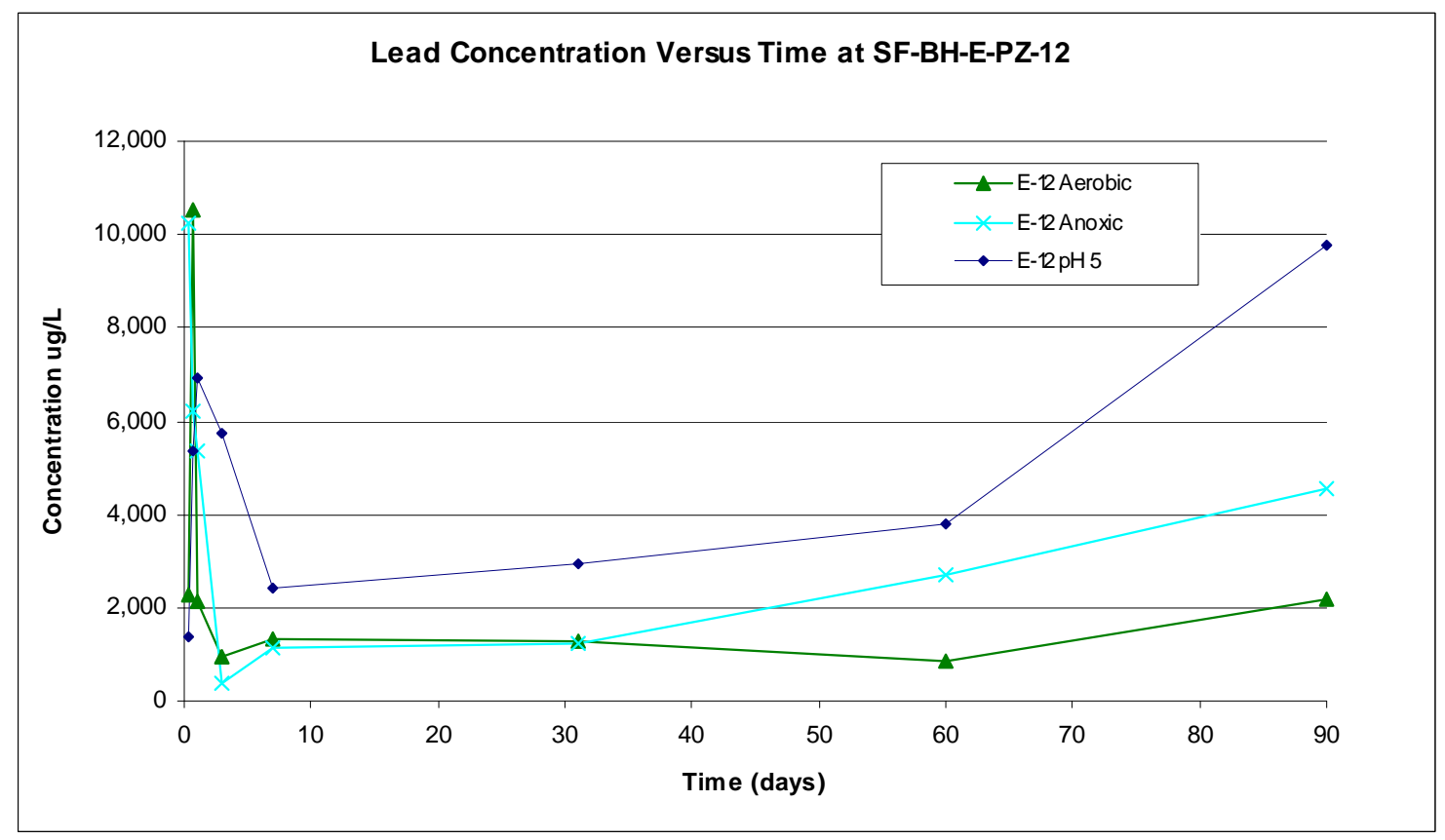

Figure 62. Effect of aerobic and anoxic conditions on lead concentration over time.

Zinc reacted similarly to cadmium at this location. For SF-OB-BZ-13 anaerobic $\mathrm{pH} 5$ is high and wet/dry sample both show a small spike followed by a flat steady concentration in the leach solution. For SF-BH-E-PZ-12, the anaerobic $\mathrm{pH} 5$ test steadily climbs, the groundwater test starts low and climbs, but is lower than $\mathrm{pH} 5$ and the surface test is low and stays that way. The zinc concentration in the oxygen free samples continued to increase over time, while in the samples containing oxygen, the zinc concentration remained relatively constant. In the $\mathrm{pH} 5$ treatment, the concentration of zinc increased more rapidly, but still achieved about the same overall concentration as the sample maintained in the oxygen free groundwater. In the $\mathrm{pH} 5$ treatment, the sediments did not undergo the 2 week wet/dry cycle. 
The iron did not react much differently regardless of whether oxygen was present during the leaching or not, but there was a spike during the first start of the leaching, primarily resulting from the wet/dry cycling.

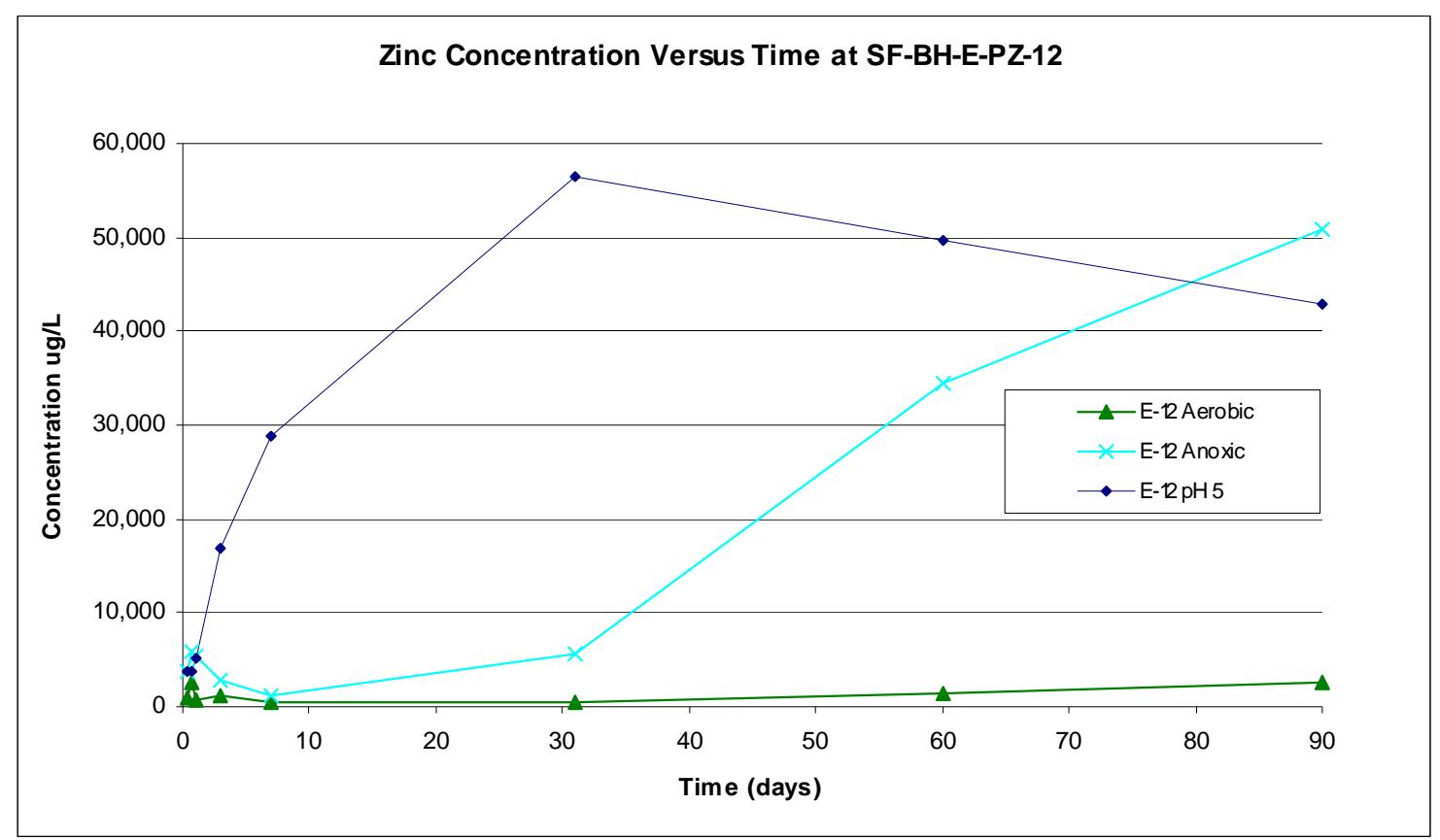

Figure 63. Effect of aerobic and anoxic conditions on zinc concentration over time.

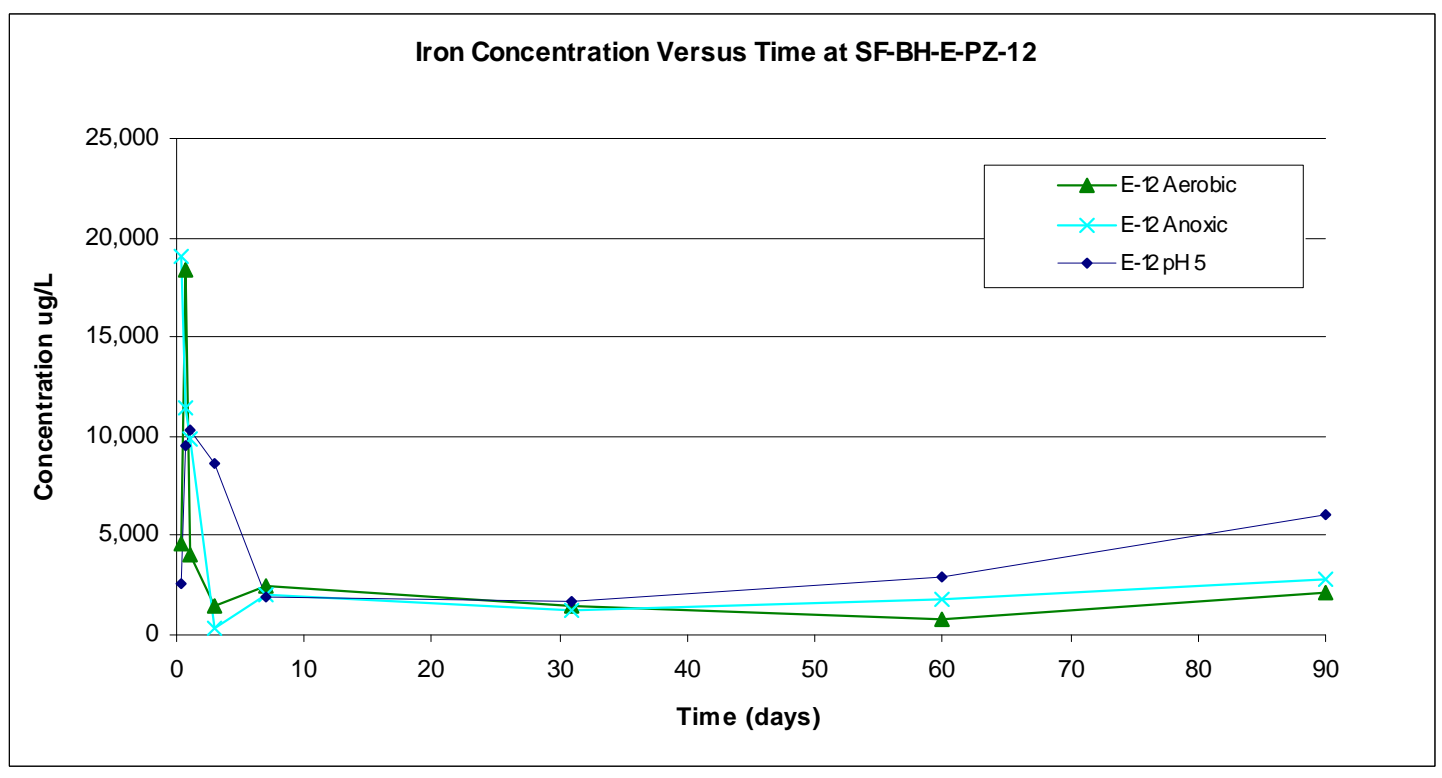

Figure 64. Effect of aerobic and anoxic conditions on iron concentration over time.

Sulfur concentrations reacted similarly to the previous location (Figure 65). The surface or oxygenated samples had the lowest release concentrations, and the $\mathrm{pH} 5$ treatment and the oxygen-free 
treatment had higher measured concentrations. Again it should be noted that sulfur was present in the simulated groundwater, but not in the simulated rainwater, which would account for the difference in concentrations.

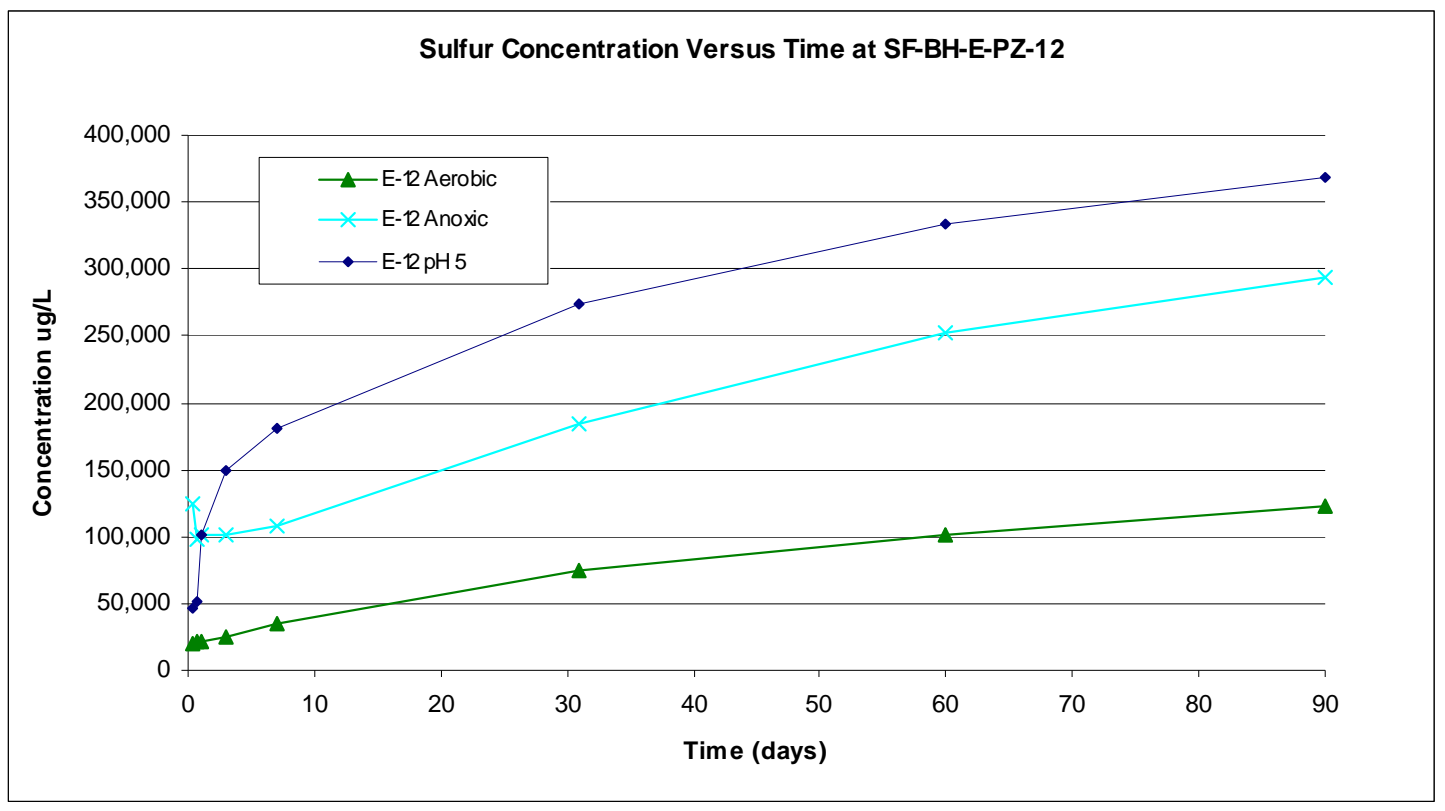

Figure 65. Effect of aerobic and anoxic conditions on sulfur concentration over time.

\subsubsection{Sample Location SF-BH-E-PZ-16}

There were no differences in cadmium concentrations at this location between the surface (oxygen present) sample and the subsurface (oxygen-free) sample. The $\mathrm{pH} 5$ treatment increased more initially, but then continued to increase at the same rate as the other two treatments.

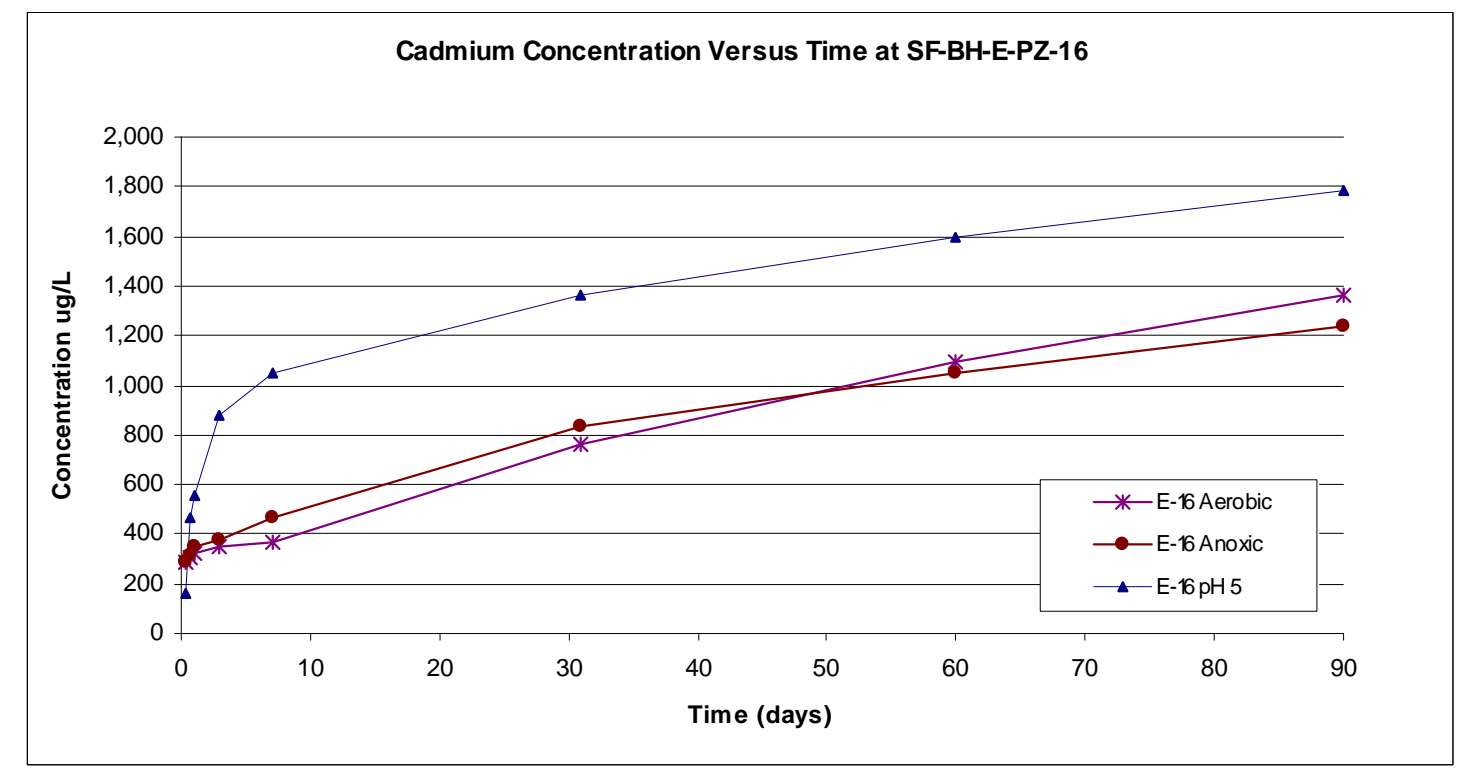

Figure 66. Effect of aerobic and anoxic conditions on cadmium concentration over time. 
Lead responded similarly to the other locations, with an initial spike in concentration followed by a quick reduction in concentration. Very little difference was observed between the simulated surface and simulated subsurface treatments. The $\mathrm{pH} 5$ treatment experienced the same types of lead concentration increase, although the overall concentration was higher than the surface and subsurface treatment (Figure 67).

Zinc also responded like the other metals as this location. The concentration continued to increase throughout the duration of the leach test. There were no differences in zinc concentrations at this location between the surface (oxygen present) sample and the subsurface (oxygen-free) sample. The $\mathrm{pH} 5$ treatment increased more initially, but then continued to increase at the same rate as the other two treatments as with cadmium. There was more exchangeable lead and zinc at this location compared to the previous two locations measured during the sequential extractions. This would support the leach data here where more lead and zinc were leached than the other locations.

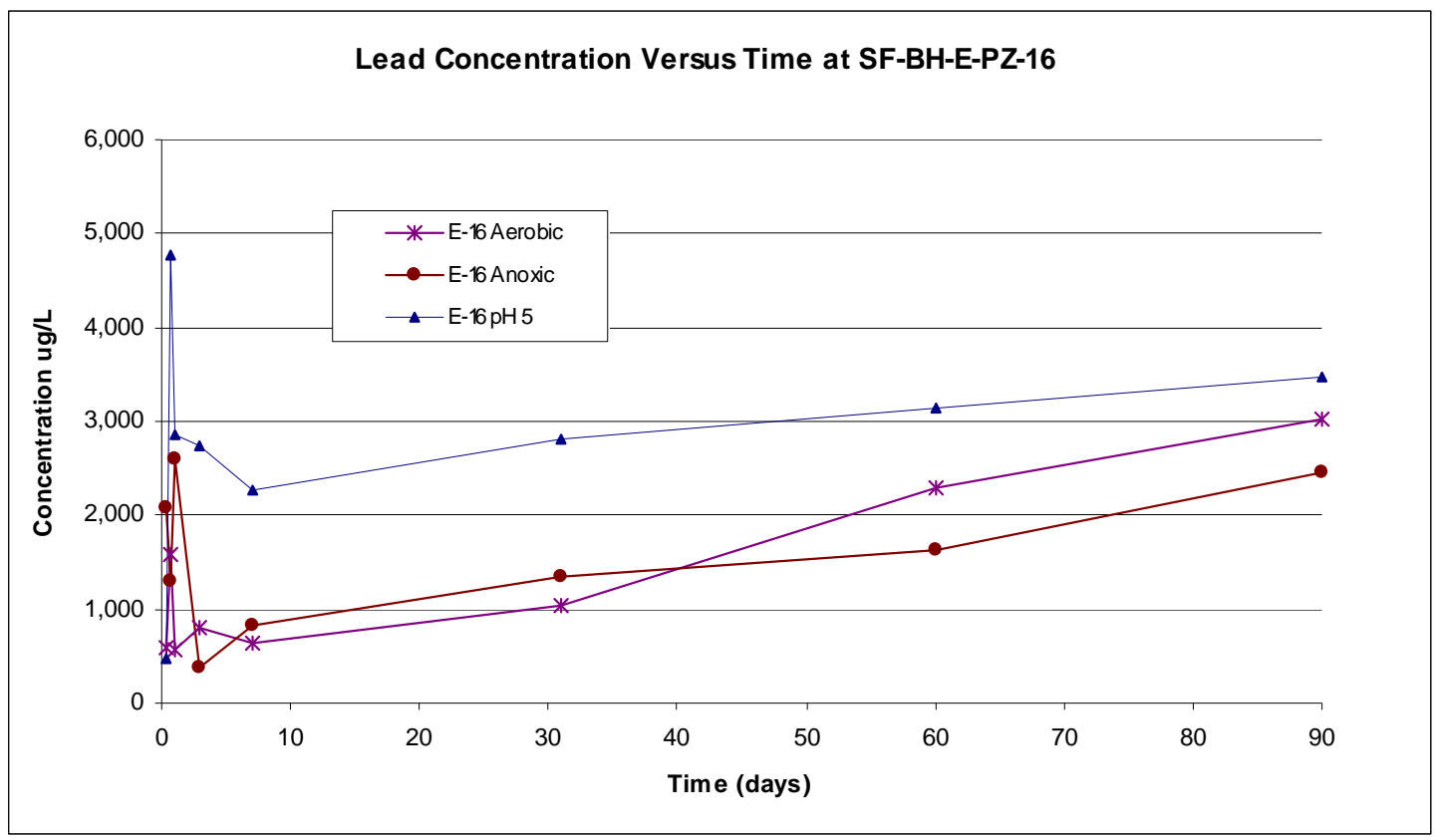

Figure 67. Effect of aerobic and anoxic conditions on lead concentration over time. 


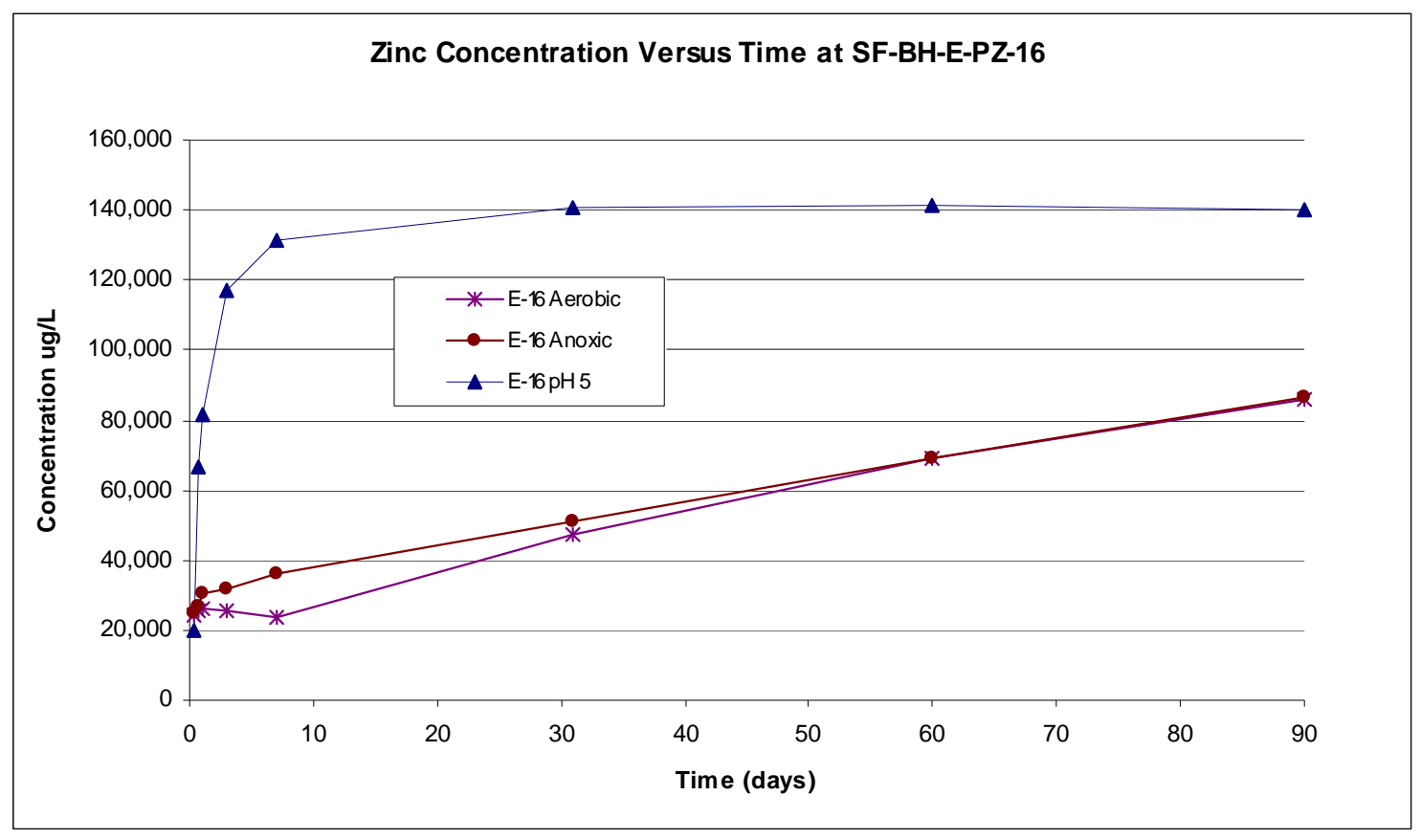

Figure 68. Effect of aerobic and anoxic conditions on zinc concentration over time.

Iron concentrations spiked initially, but dropped quickly and remained constant, which was consistent all locations, probably due to the higher $\mathrm{pH}$. Any iron that is released is oxidized to ferric and is not stable above $\mathrm{pH} 2$ (Figure 69). Sulfur concentrations responded in similar manner as the previous two locations also (Figure 70).

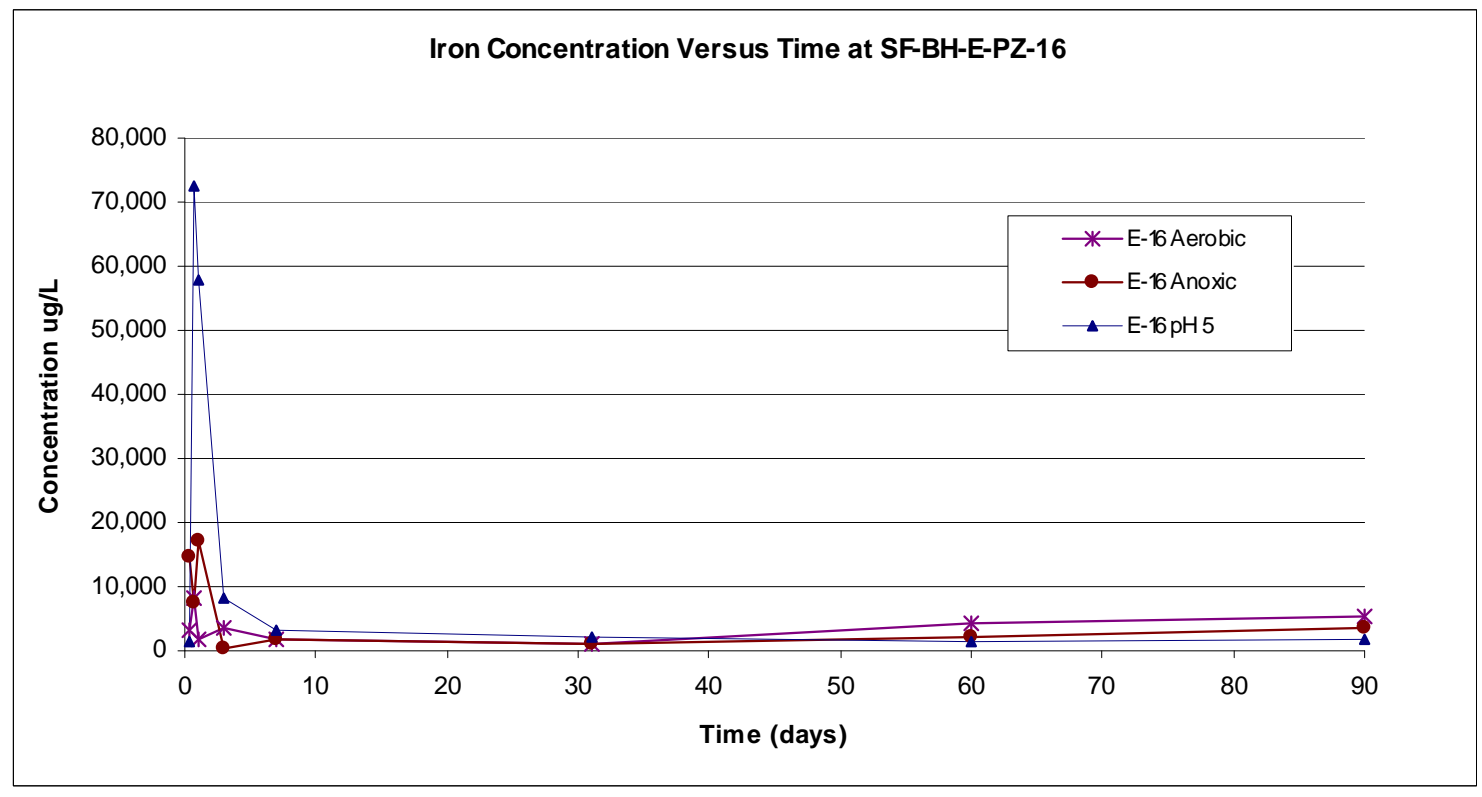

Figure 69. Effect of aerobic and anoxic conditions on iron concentration over time. 


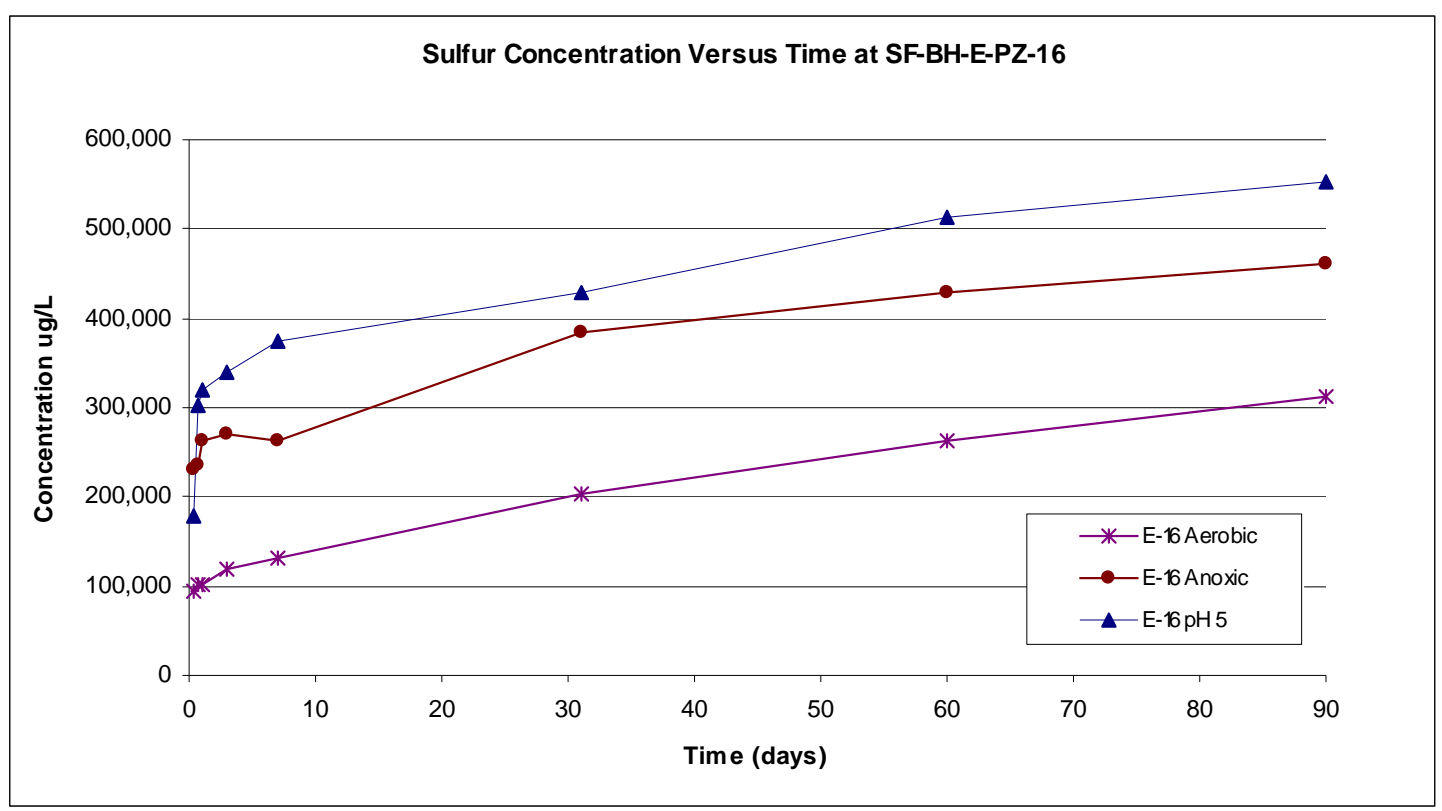

Figure 70. Effect of aerobic and anoxic conditions on sulfur concentration over time.

\subsubsection{Sample Location SF-BH-E-PZ-24}

Cadmium concentration at this last location did not increase over time like the cadmium concentrations at the previous CIA locations. A noticeable initial spike in cadmium concentration resulted from the wet/dry cycling prior to starting the leach test (Figure 71). The concentration of lead responded similarly to the cadmium concentration at this location (Figure 72).

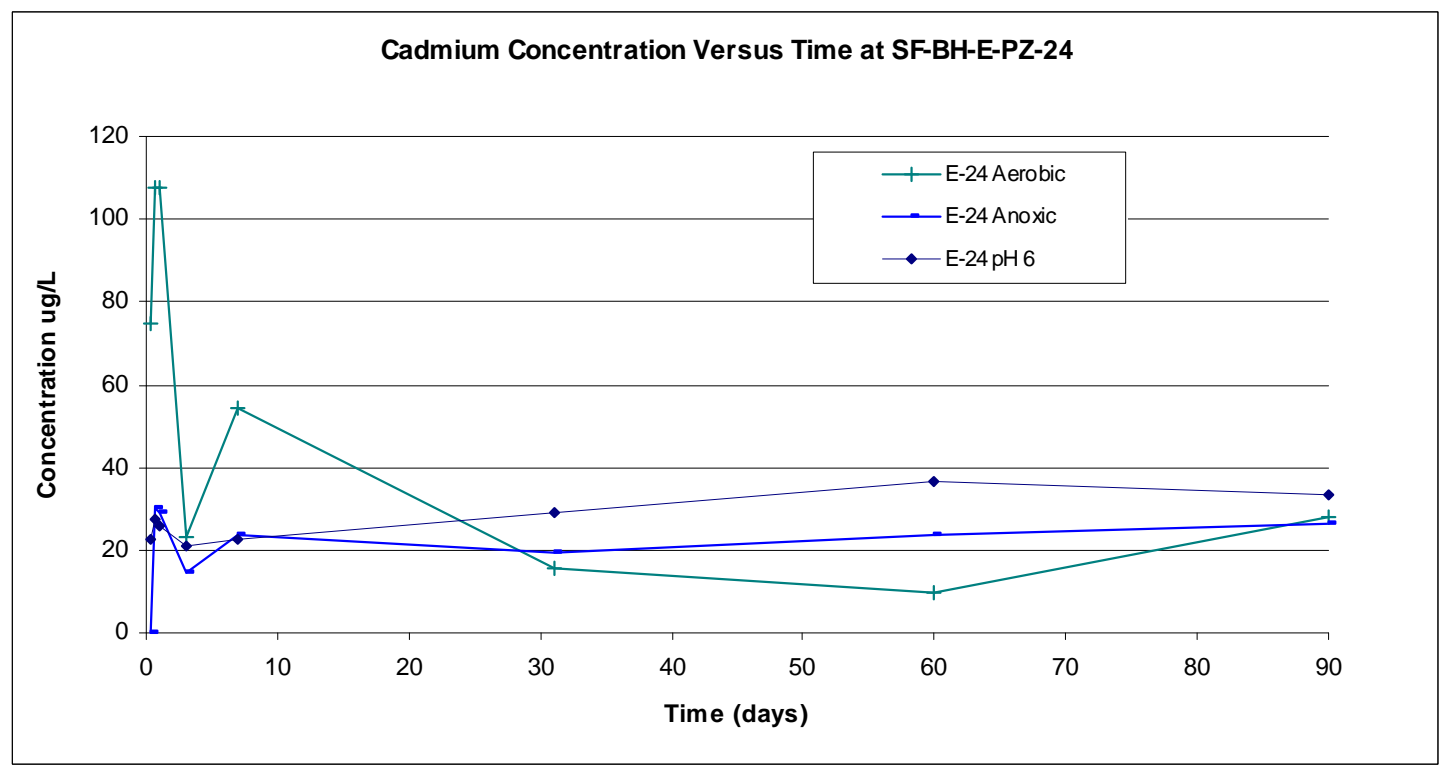

Figure 71. Effect of aerobic and anoxic conditions on cadmium concentration over time. 


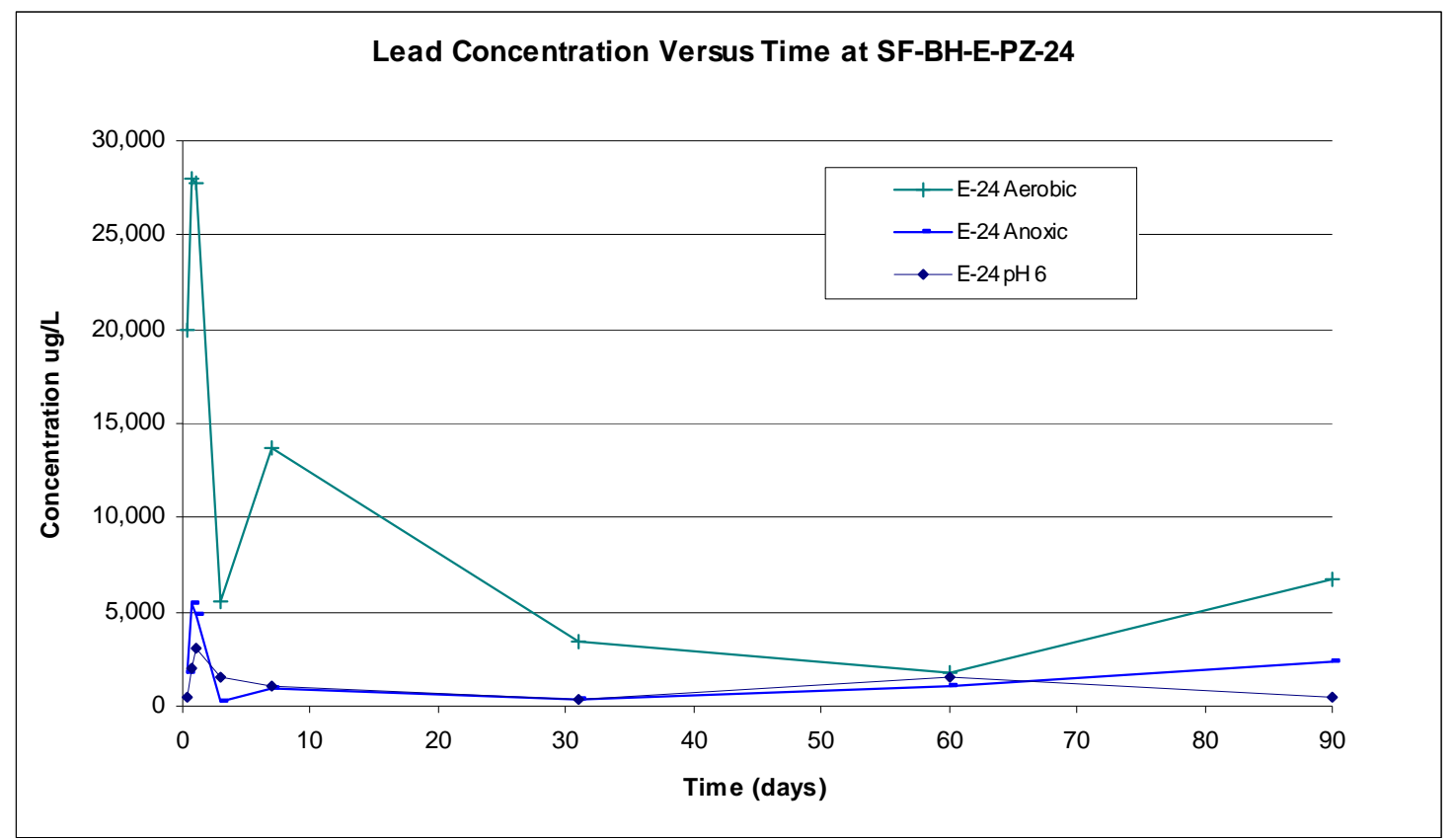

Figure 72. Effect of aerobic and anoxic conditions on lead concentration over time.

Zinc concentrations followed the same trend as cadmium and lead at this location. The initial concentration of zinc spiked early following the wet dry cycle then quickly precipitated out of solution and remained at a much lower concentration. This is likely due to a combination of the reaction of the elements with the constituents in the leach solution (simulated groundwater), the presence of high concentrations of other ions that were leached from solution, and the interaction with the iron in solution. Iron and sulfur reacted similarly to other locations.

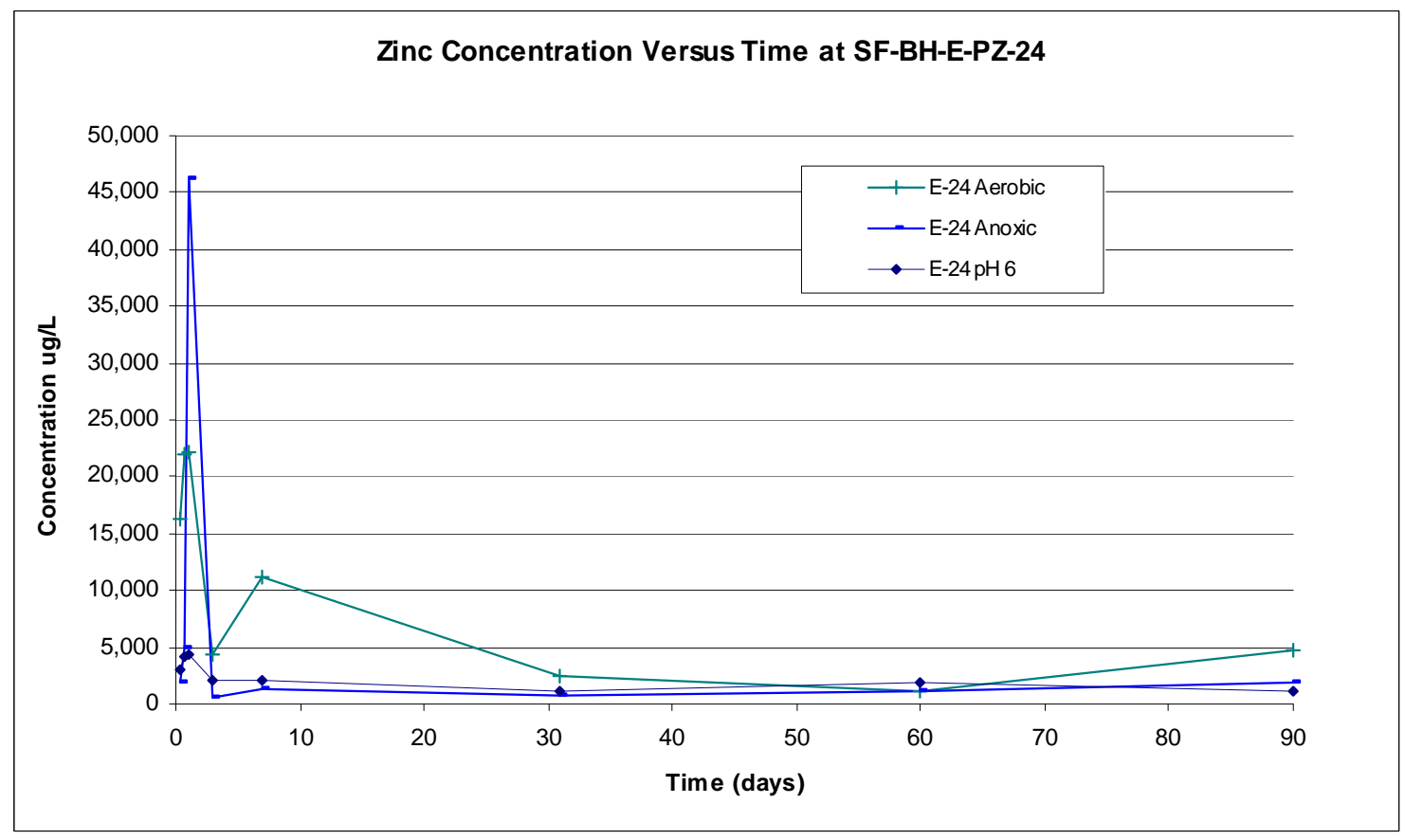

Figure 73. Effect of aerobic and anoxic conditions on zinc concentration over time. 


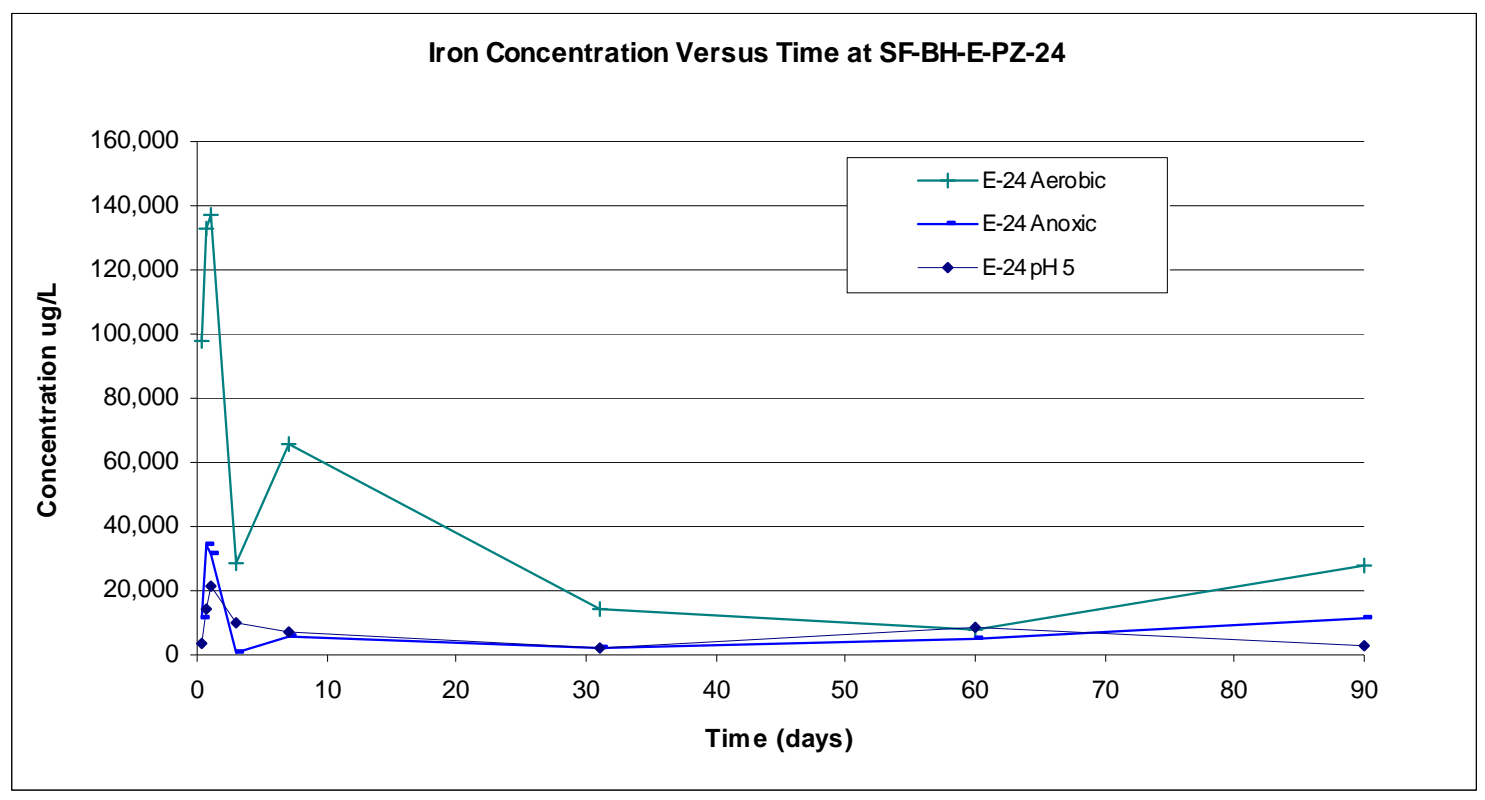

Figure 74. Effect of aerobic and anoxic conditions on iron concentration over time.

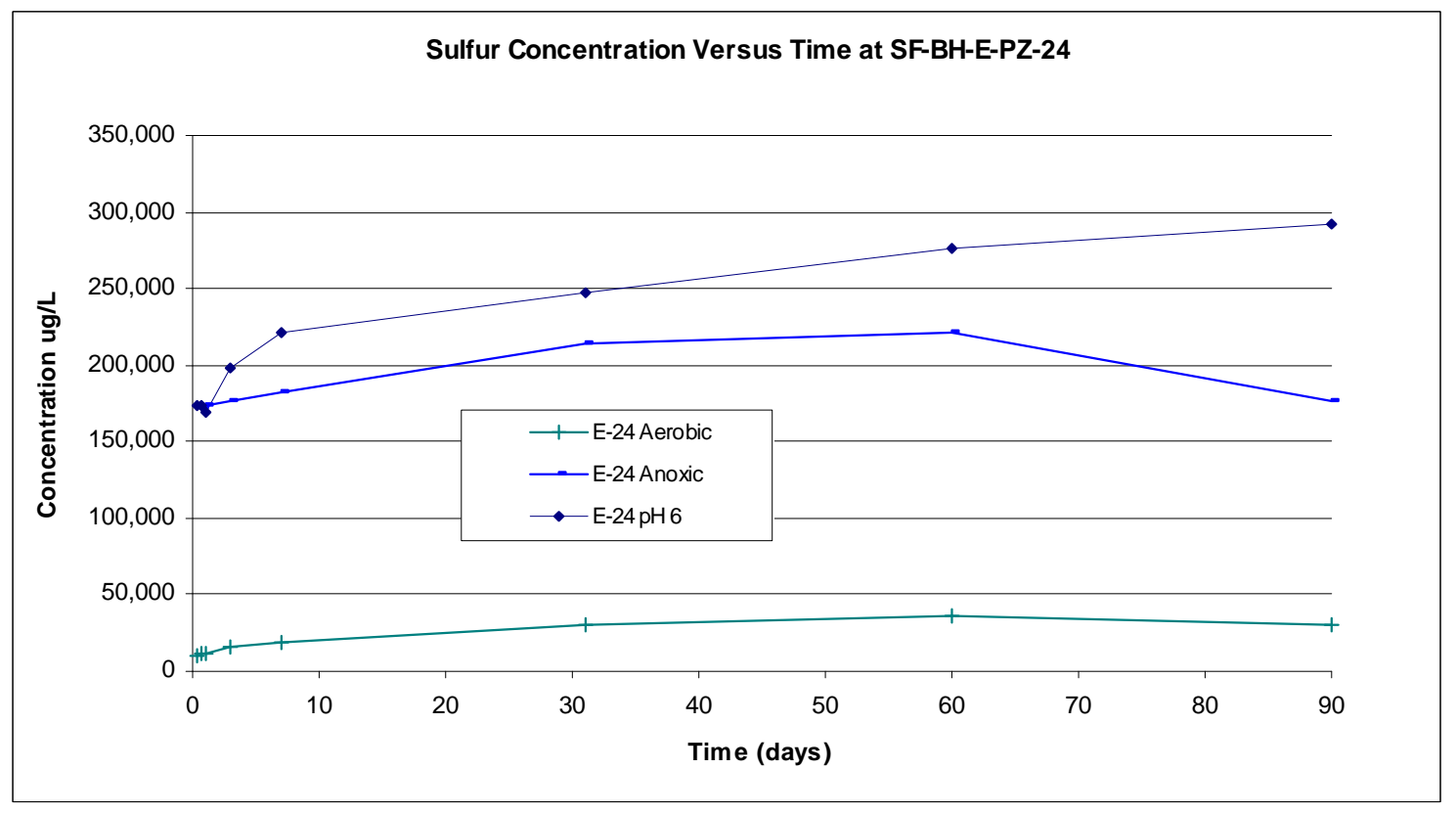

Figure 75. Effect of aerobic and anoxic conditions on sulfur concentration over time. 


\section{SUMMARY AND CONCLUSIONS}

The results of the sequential extractions, $\mathrm{pH}$ leach study, and aerobic vs anoxic leach study have been presented above. This section summarizes the data collected at each location and provides additional interpretation where noteworthy conditions or results were found.

\subsection{Sample Location SF-OB-PZ-13}

The core for sample SF-OB-PZ-13 was taken in the Osborn Flats area. This section summarizes the data generated from the sequential extractions, $\mathrm{pH}$ leach studies, and aerobic/anoxic leach studies. Figure 76 shows the total cadmium, lead, and zinc concentrations at this location. Note that the total concentrations were only measured in the soil fraction less than $2 \mathrm{~mm}$. The cadmium, lead, and zinc concentrations were highest at the surface and lowest in the 3-4foot depth. All three metals presented followed a similar trend, although the total concentrations for the lead and zinc were 100 times greater than the cadmium.

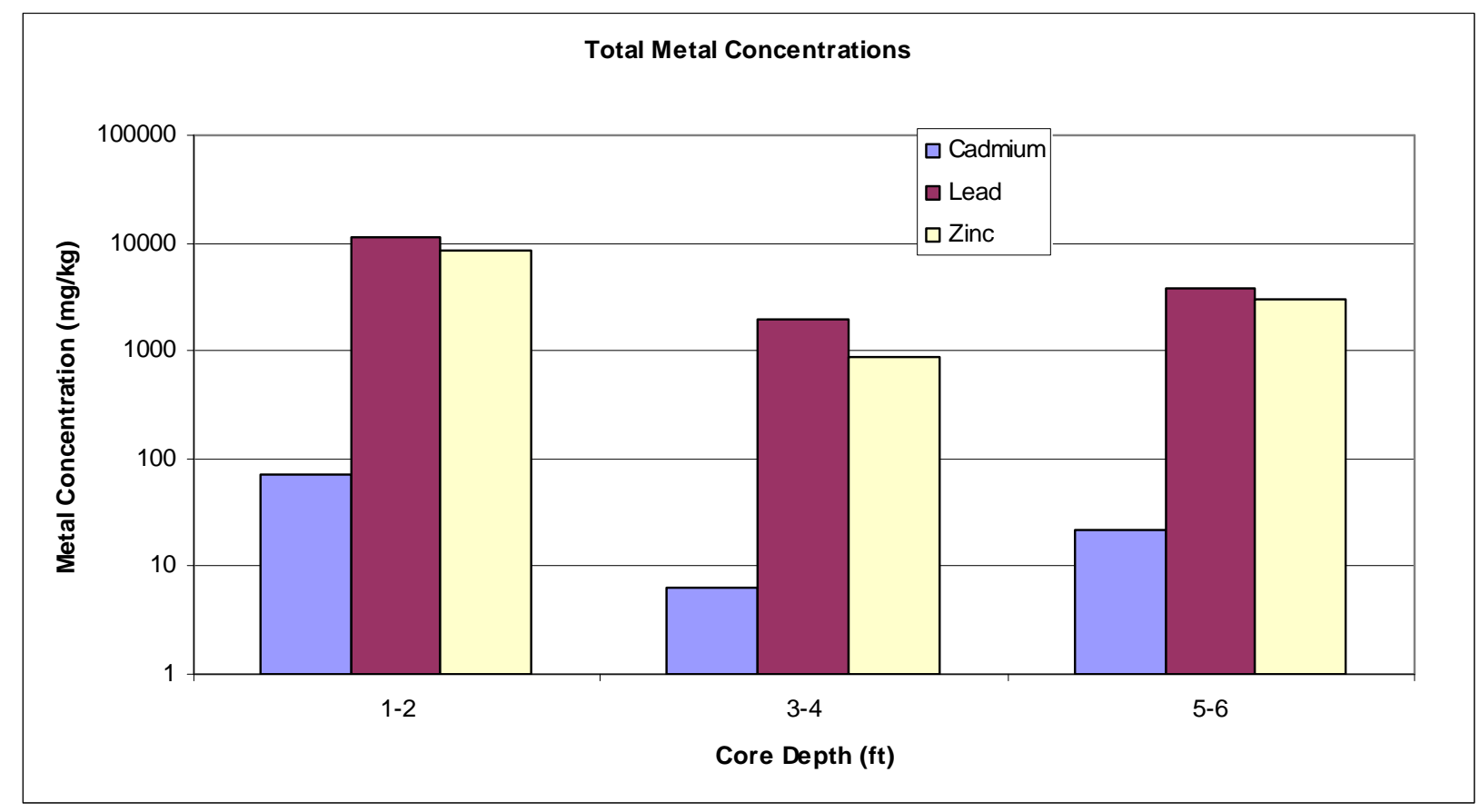

Figure 76. Cadmium, lead, and zinc concentrations in the sediment cores at SF-OB-PZ-13 from the > $2 \mathrm{~mm}$ fraction.

While the total cadmium concentrations were highest at the surface, the cadmium was more stable, or more difficult to extract, at the surface than at the 3-4 foot depth or the 5-6 foot depth (see Figure 7). The cadmium concentration was least stable, or more easily extracted, in the 3-4 foot depth, however, the cadmium concentration was also lowest at this depth. The cadmium in the 1-2 foot depth was most likely associated with stable oxide complexes, while the metals at lower depths were released in the exchangeable phase making them more mobile. There was less variability in the lead mobility as shown in the sequential extraction data in Figure 8, but the same trend was observed, that is, the lead was more stable at the surface and less stable at depth, with the 3-4 foot depth having the highest concentrations of lead in the leach solution. Zinc also followed the same trend, with the surface having the least available 
zinc and the 3-4 foot depth having the most easily extractable zinc. There was a general trend for the residual or total remaining metals to represent the higher proportions at or near the surface. This suggests that years of oxidation have resulted in higher concentrations of refractory metals at or near the surface.

For the leach tests, the cores from each depth were combined from each location in order to have enough material to complete the leach tests. A subsample was sent to the EPA laboratory for analysis and the results are presented below in Figure 77. The cadmium concentrations were, again, much lower than the lead and zinc.

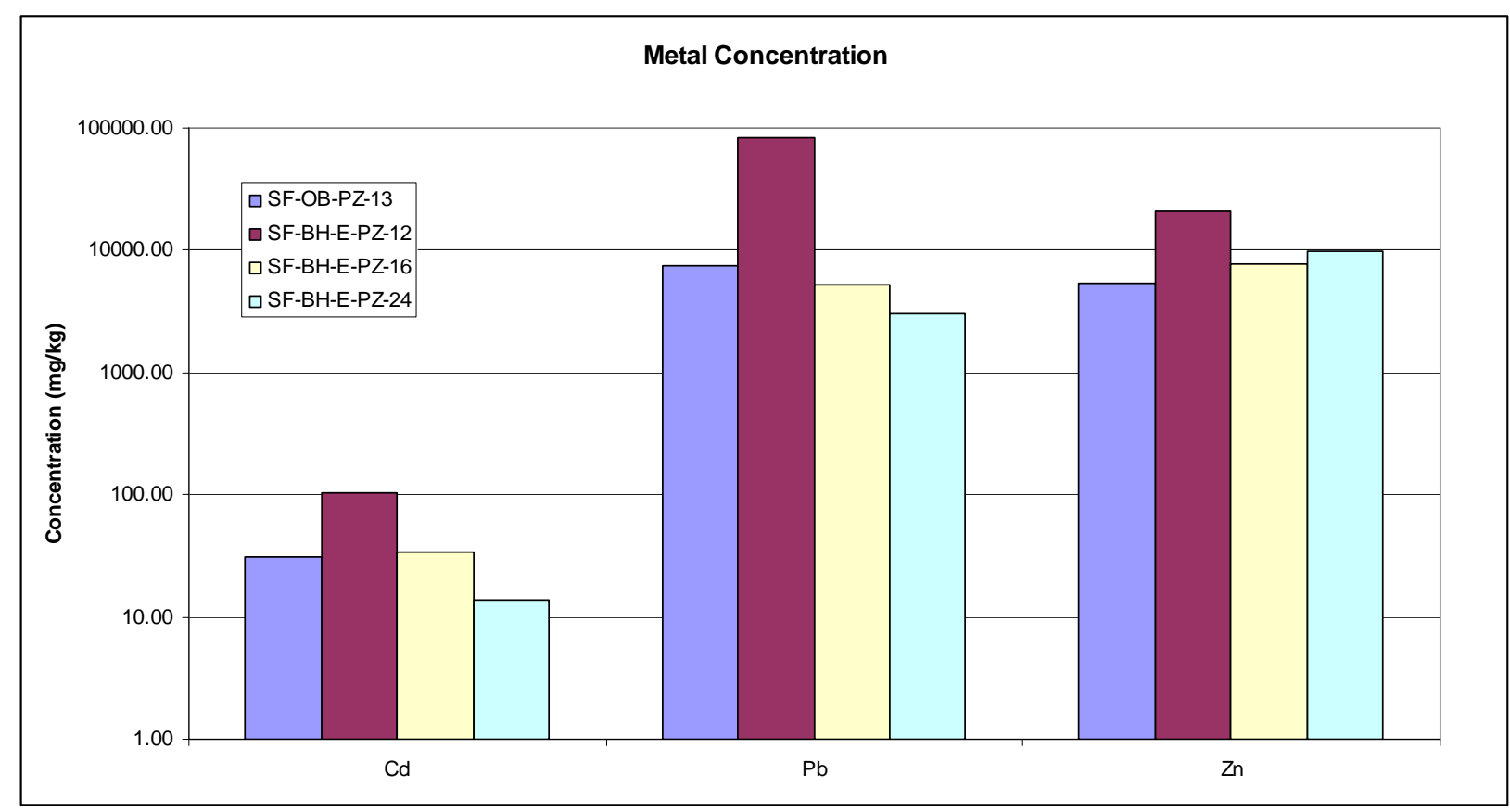

Figure 77. Cadmium, lead, and zinc concentrations in the soil used in the leach tests from the $>2 \mathrm{~mm}$ fraction.

The cadmium concentrations during the leach test were significantly affected by $\mathrm{pH}$. As $\mathrm{pH}$ increased, cadmium concentrations in the leachate decreased. At $\mathrm{pH}$ values less than 6.5 and Eh levels above -0.4 , cadmium tends to remain in the $\mathrm{Cd} 2+$ state (see Figure A-1 in the Appendix). $\mathrm{Cd} 2+$ is generally more mobile than it is in other speciations, but can be easily absorbed to hydrous oxides such as iron oxy-hydroxide or organic matter. The data did show that at $\mathrm{pH} 2-3$ (Figure 36), the concentrations of cadmium in the leachate were 100 times higher than at $\mathrm{pH} 6-7$, and 2-3 times the concentration found at $\mathrm{pH} 4-5$ which is more consistent with what would be expected naturally. Most of the cadmium extraction had occurred by Day 30, the concentration had become fairly stable for $\mathrm{pH}$ values 4 or higher but continued to increase until Day 60 for $\mathrm{pH} 2$ and 3.

The lead concentrations were generally not as sensitive to $\mathrm{pH}$ except for $\mathrm{pH} 7$ (Figure 37), which had an abnormally high leach rate for lead, until day 90 . The concentrations at day 90 were significantly lower than the previous $\mathrm{pH} 7$ values. Other than that exception, the lead concentrations did not change much relative to $\mathrm{pH}$.

The zinc concentrations followed a much more expected leach pattern than the lead. At lower $\mathrm{pH}$, more zinc was removed. The greatest increase in zinc concentration in the leachate occurred in the first 7 days and began to plateau after that, although, it did continue to increase slightly throughout the duration of the test for $\mathrm{pH} 2$ and 3 (Figure 38). 
The metals will remain stable at this location as long as the $\mathrm{pH}$ remains 5 or greater. Cadmium, lead, and zinc are all fairly insoluble while the $\mathrm{pH}$ of the soil solution remains greater than 5 . When the sediment was exposed to a wet/dry oxidizing cycle, the cadmium concentration over time tended to stabilize at about the same concentration regardless of the presence or absences of oxygen, or simulated rainwater or simulated groundwater. There was a trend for high leach rates for cadmium initially from the sediments exposed to oxygen in the first 7 days, but after that the concentrations were about the same regardless of the presence or absence of oxygen. For this location, the simulated groundwater contained very little magnesium, potassium, and calcium compared to the other locations (Table 2). These ions can mobilize the cadmium, lead and zinc from the exchangeable sites where they are bound. The simulated groundwater from the other locations had higher concentrations of these exchangeable ions and thus resulted in higher leach rates. However, 5 to 10 times as much cadmium was released from the sediment with no exposure to oxygen and leaching with simulated groundwater at the same $\mathrm{pH}$. The same trend was seen for zinc as cadmium. For lead, slightly higher concentrations were observed in the leachate from the sediments exposed to air, and leached with distilled water relative to the ones that were maintained in an anoxic condition and leached with simulated groundwater. This may be due to anions in the simulated groundwater that will precipitate lead. In addition, sediments containing iron or other metal-absorbing oxides and exposed to oxygen will tend to adsorb and precipitate most cationic metals more rapidly than under reducing conditions.

\subsection{Sample Location SF-BH-E-PZ-12}

The data from the sequential extractions and leach test for sample location SF-BH-E-PZ-12 is summarized in this section. Five depths were collected from this sample site. The zinc, cadmium and lead concentrations were highest at this location relative to the other three locations tested. At this location cadmium, lead, and zinc concentrations were greater at the 7-8 and 8-9-foot cores than at the surface. The concentrations of these three metals were lowest in the 5-6-foot cores.

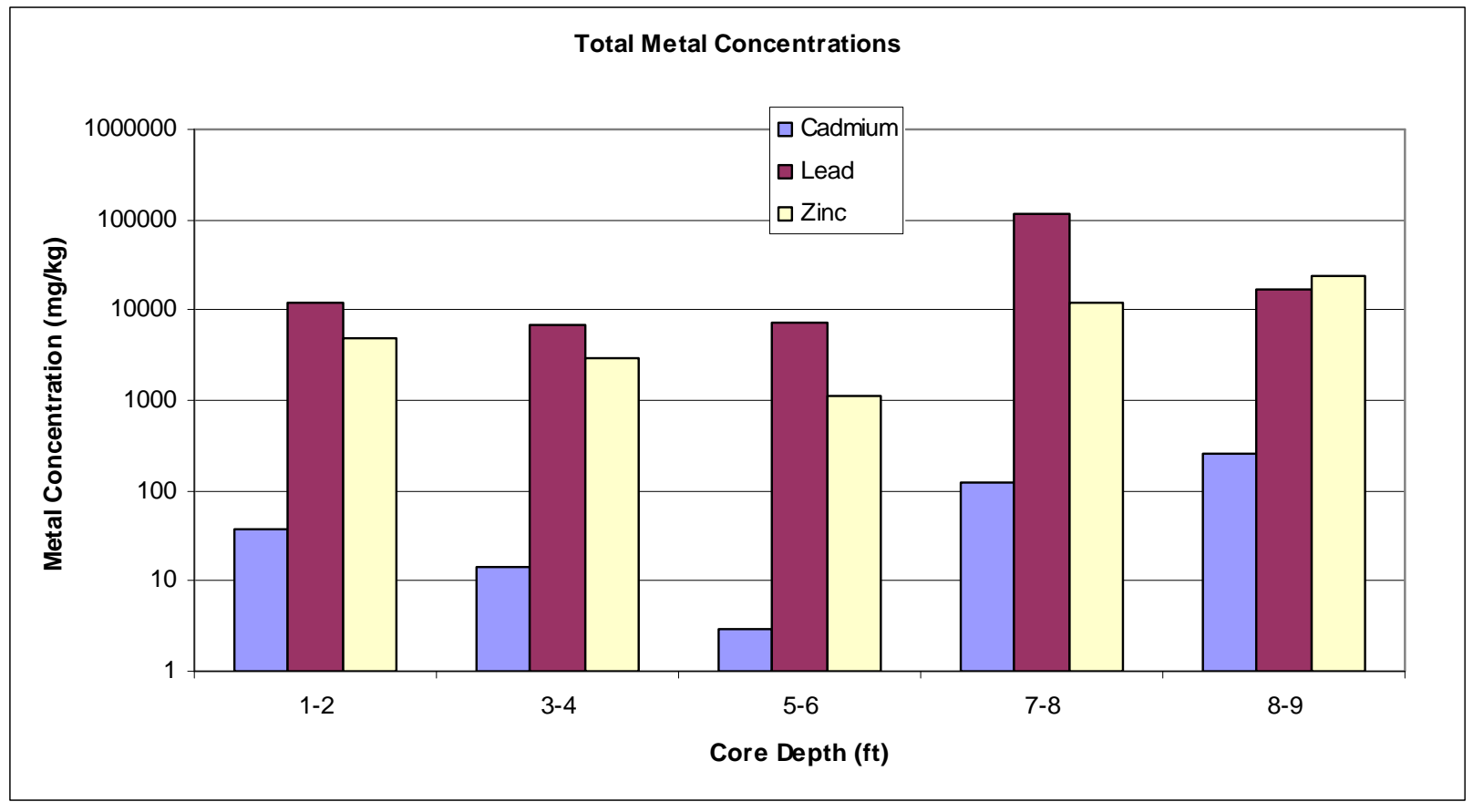

Figure 78. Metal concentrations at each core depth for sample location SF-BH-E-PZ-12 from the $>2 \mathrm{~mm}$ fraction. 
At this location, $40-50 \%$ of the cadmium could be extracted with the first two extraction steps at the 1-2 and 3-4-foot depths, while less than 10\% could be extracted below that. Hence, cadmium was less stable in the top 1-4 feet and more stable at depths below 4 feet (Figure 16). Lead tended to have less variability in extraction characteristics regardless of depth. The first step in the extraction process removed less than $10 \%$ of the lead. The second step was able to remove an additional $30-50 \%$ (Figure 17). Zinc was more stable than either of the other two metals discussed. Less than $5 \%$ was readily exchangeable, and less than $20 \%$ was released in the second stage of the sequential extraction procedure (Figure 18). In the previous location, SF-OB-PZ-13, there was a general trend for the residual or total remaining metals to represent the higher proportions at or near the surface. This was not the case in this location. Residual $\mathrm{Cd}, \mathrm{Pb}$, and $\mathrm{Zn}$ concentrations were not consistently patterned with depth.

For the leach tests, the cores from each depth were combined for each location in order to have enough material to complete the leach tests. For this location the cores from the 1-2, 3-4, 5-6, 7-8, and 89 foot depths were combined, forming a single sample. A subsample was sent to the EPA laboratory for total metal analysis and the results are presented above in Figure 77. The cadmium concentrations were again, much lower than the lead and zinc. During the leach tests where $\mathrm{pH}$ was compared between treatments, the cadmium concentration continued to increase during the 90 day test. It never reached a state of equilibrium. Of course the concentration was highest in the low $\mathrm{pH}$ and decreased as $\mathrm{pH}$ was increased (Figure 41). Lead tended to be less sensitive to $\mathrm{pH}$ changes (Figure 42). There was, however, a large release of lead initially which then decreased by day 7 and remained fairly constant for the remainder of the study. For SF-BH-E-PZ-12 more lead is released at lower $\mathrm{pH}$ 's but since it precipitates out at all $\mathrm{pH}$ 's you don't see the $\mathrm{pH}$ difference over time that was observed in cadmium and zinc. Zinc leachability tended to react more classically as did the cadmium release. At lower $\mathrm{pH}$, more zinc was released than at high $\mathrm{pH}$. The $\mathrm{pH}$ has a significant impact on zinc release. At $\mathrm{pH} 6$ and 7 very little release was observed. At $\mathrm{pH} 5$, the concentration stabilized at about 50,000 ug/L, at $\mathrm{pH} 4$ it doubled to $100,000 \mathrm{ug} / \mathrm{L}$, and at $\mathrm{pH} 2-3$, the concentration ranged from 150,000 - over 200,000 ug/L (Figure 43). At $\mathrm{pH}$ 2-3 iron became very mobile, but at $\mathrm{pH} 4$ and greater, any iron released would oxidize to ferric iron and precipitate out and was not observed in solution (Figure 44). Sulfur also exhibited increases in leach values at lower $\mathrm{pH}$ (Figure 45).

This location reacted uniquely to the presence or absence of oxygen during the 90 day leach test. Cadmium and zinc concentrations continued to rise for the duration of the study after initial exposure to oxygen then leaching with simulated groundwater under anoxic conditions, but under the presence of oxygen and leaching with distilled water, the cadmium concentrations increased only slightly (see Figure 61). One possible reason for this is the higher concentrations of magnesium, potassium, and calcium in the simulated groundwater, which could displace the zinc and cadmium from exchange sites in the soil in the anoxic leach test. Also, based on the sequential extraction results, the percent of residual (metals bound to oxides/hydroxides) cadmium and zinc is highest in this soil. Under low oxygen, the oxides/hydroxides could be less stable and could release more of the bound cadmium and zinc.

Lead concentrations were high during the start of the leach test (over 10,000 ug/L), probably due to the two week wetting and drying cycle. By day 3, the concentrations had dropped off significantly (about $1,000 \mathrm{ug} / \mathrm{L}$ ) probably due to precipitation and increased only slightly through the remainder of the test (Figure 62). Zinc reacted similarly to cadmium in sediment with initial exposure to oxygen then leaching with simulated groundwater which increased continuously for the duration of the 90 day test, while in the oxygenated sample leached with distilled water, the zinc only increased slightly during the 90 day test (Figure 63). Iron remained fairly constant throughout the tests, following an initial spike regardless of the test treatment. At pH 5 any release of iron would likely be ferric and would precipitate out. Sulfur concentrations increased continuously over the 90 days, with the concentrations in the anoxic samples increasing at a higher rate. 
The cadmium, lead and zinc concentrations were highest at this location, although a lower percentage of cadmium, lead, zinc leached from the soil compared to the other 3 locations.

\subsection{Sample Location SF-BH-E-PZ-16}

At this location there tended to be less variation in cadmium, lead and zinc concentrations between the 4 core depths sampled (Figure 79). The concentrations at this site are similar to sample location SF-OBPZ-13 and SF-BH-E-PZ-24, but less than SF-BH-E-PZ-12. The core samples showed more oxidized iron at this location than the other three locations based on visual observations (see Figures 20-23). In addition, the oxidation reduction potential from the groundwater collect in September and October of 2008 at this location was 5 to 10 times higher than the other locations (see Table A-7).

The exchangeable cadmium ranged from ranged from 18 to $35 \%$ which was consistent with most of the other locations. 30 to $35 \%$ of the cadmium was extracted in the $3^{\text {rd }}$ step or the organic/oxide/sulfide bound phase. The lead was more easily extracted from this location, ranging from 7 to $23 \%$ exchangeable. Exchangeable zinc tended to follow the same patterns as the other sample locations, with most of the zinc being tightly bound and only able to be liberated by total digestion of the sample. Like SF-OB-PZ-13, there was a general trend for the residual or total remaining elements to represent the higher proportions at or near the surface. This suggests that years of oxidation have resulted in higher concentrations of refractory metals at or near the surface.

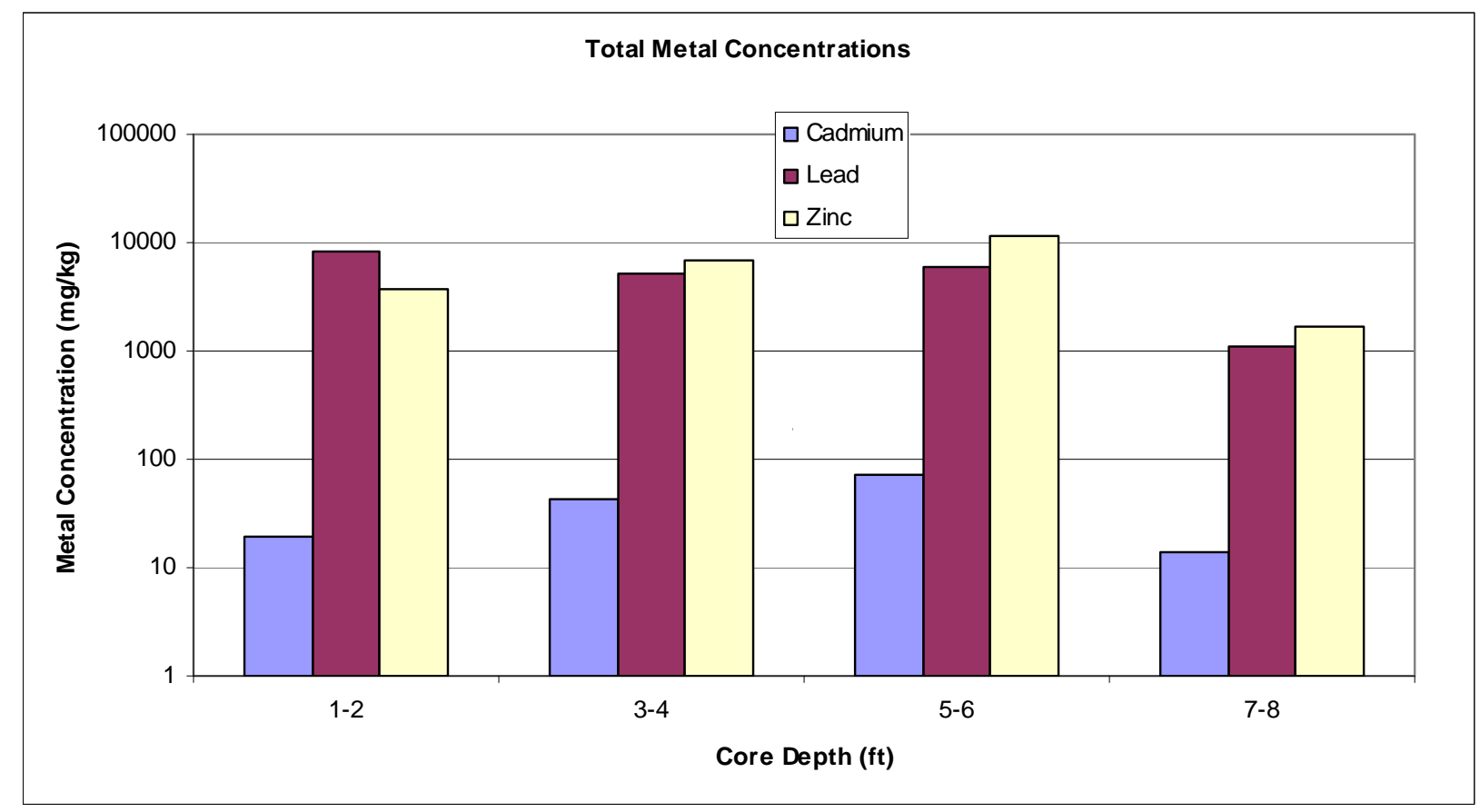

Figure 79. Metal concentrations at each core depth for sample location SF-BH-E-PZ-16 from the $>2 \mathrm{~mm}$ fraction.

The leach tests reacted consistently with the expected outcomes, with more cadmium and zinc being released at lower $\mathrm{pH}$, and less at higher $\mathrm{pH}$. Typically, by the end of the first month, the concentration had begun to plateau. Lead concentrations had a spike early in the leach test consistent with leaching of the surface oxidized material. This same pattern was observed in Canyon Creek on the leach study conducted there (Wright et al., 2007). The concentration then stabilized at a lower concentration 
probably due to precipitation with sulfates. At $\mathrm{pH}$ values between 2 and 5 there was only slight differences in lead concentration and at $\mathrm{pH} 6$ and 7 less lead was leached.

There were very little differences observed in the cadmium, lead and zinc concentrations exposed to oxygen and then leached with distilled water, or exposed to oxygen then leached with simulated groundwater under anoxic conditions. For all three metals (cadmium, lead and zinc), the concentration of released metal was higher in the sample not exposed to oxygen and leached with simulated groundwater. The concentration continued to increase over the 3 month test in both treatments. The lead analysis showed an initial spike, but that quickly dropped, then slowly rebounded over time. Like the other locations, sulfur concentrations were highest in the leach tests using simulated groundwater, which had additional sulfates added.

\subsection{Sample Location SF-BH-E-PZ-24}

This section discusses the results of the sequential extractions and leach tests for sample location SFBH-E-PZ-24, which in near the CIA. Lead and zinc concentrations tended to be highest at the surface at this site (Figure 80) and decreased with depth. Cadmium concentrations were highest at 5-6 feet. This location has some of the highest levels of exchangeable cadmium, particularly at 5-8 feet, where almost $50 \%$ of the cadmium is in the exchangeable form. On the other hand, the lead is very stable. Less than $5 \%$ of the lead is in the exchangeable fraction at this location. The zinc is more easily extracted in the 5-8 foot depth also, but the biggest difference at this site is that the zinc is more easily removed with a weak acid (like that used in the second step of the sequential extraction) than the other locations. Monitoring and controlling $\mathrm{pH}$ may have a greater impact on zinc at this location than other locations. There was a general trend for the residual or total $\mathrm{Cd}$ and $\mathrm{Zn}$ remaining to represent the higher proportions at or near the surface. This was not true with $\mathrm{Pb}$. Again, this suggests that years of oxidation have resulted in higher concentrations of refractory metals at or near the surface.

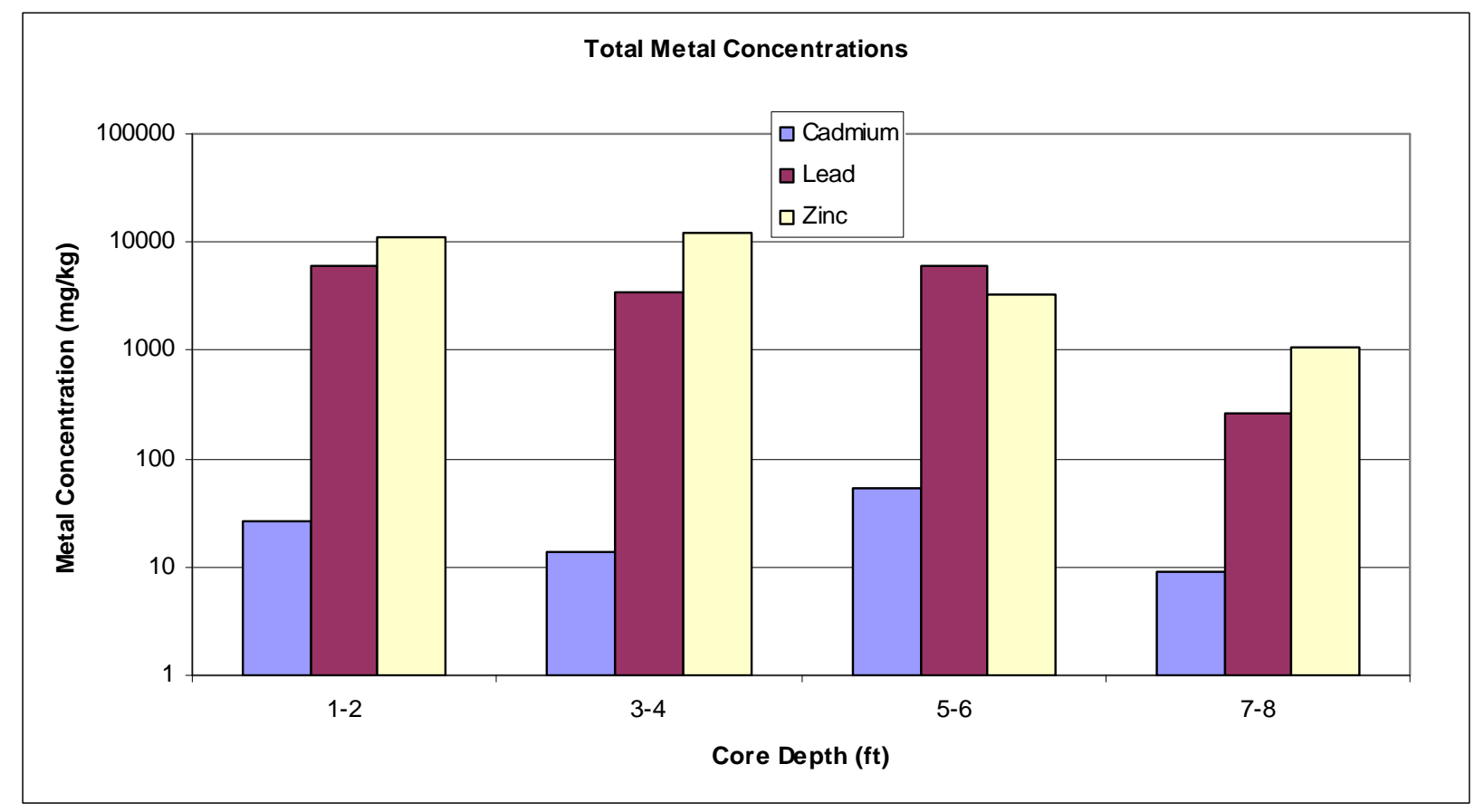

Figure 80. Cadmium, lead, and zinc concentrations at SF-BH-E-PZ-24 from the $>2 \mathrm{~mm}$ fraction.

Lead and zinc leach rates tended to respond to variations in $\mathrm{pH}$ similarly to the other locations. Data collected from groundwater in September and October of 2008 at this location showed higher levels of 
phosphorus, iron, magnesium, manganese, potassium, and zinc than the other three locations. This may explain the tendency of cadmium, which leached at slightly lower rates compared to the other three locations. The high concentration of other ions (magnesium, potassium, and calcium) in the groundwater and sediments resulted in substitution of cadmium for these ions initially. This was followed by a drop in concentration, likely associated with precipitation of cadmium with iron and sulfates present in the leach solution. The cadmium present in the leach solution was on order of magnitude lower than the other three sites. Conversely, the total concentration of cadmium present in the soil was only slightly lower than the other locations. The cadmium in the soil was fairly stable and resistant to leaching.

After the first month of leaching there were verily small differences between the aerobic and anoxic treatments for cadmium. The aerobic treatment resulted in slightly higher leach concentrations for lead than the anoxic treatment. Zinc concentrations were not greatly affected by the presence or absence of oxygen, but compared to the other two CIA core locations, this location leached much lower concentrations of zinc, by almost an order of magnitude. This again can be attributed to the high concentrations of phosphorous and iron in the groundwater which will scavenge the zinc and cadmium ions from solution. Another contributing factor is that the $\mathrm{pH}$ of the groundwater in this location is slightly higher. At this location, the $\mathrm{pH}$ is close to 6 , whereas the $\mathrm{pH}$ of the groundwater in the other three locations is closer to 5 (see Figures A-5 through A-8).

Leaching tests were conducted on the sediments samples under anaerobic conditions to simulate sediments that are held under saturated anoxic conditions. Under these conditions anaerobic bacteria, especially sulfate reducing bacteria, would be active and could reduce existing metal ions to sulfide minerals. These cores were stored under liquid nitrogen for several months and any sulfate reducing bacteria that were present, probably were killed. The presence of sulfated reducing bacteria may have changed the anoxic leaching test results. The second series of leach tests were performed on sediments which had been exposed to air and several wet/dry cycles in order to simulate microbial sulfide oxidation that would exist above the saturated zone. As stated above, most acidophilic sulfur and iron oxidizing bacteria were probably killed by liquid nitrogen storage. The addition acidophilic sulfur and iron oxidizing bacteria to leaching experiments after wet/dry exposure, could also have changed the results of these leaching experiments. These acidophiles readily oxidize mineral sulfide to metal ions and sulfate, and can reduce the $\mathrm{pH}$ dramatically. If similar leaching test are done in the future, addition of leaching with bacteria added would be beneficial. 


\section{REFERENCES}

Gleyzes, C., S. Tellier, and M. Astruc. (2002). "Fractionation studies of trace elements in contaminated soils and sediments: a review of sequential extraction procedures." Trac-Trends In Analytical Chemistry 21(6-7): 451-467.

Pourbaix, Marcel. Atlas of Electrochemical Equilibria in Aqueous Solutions. 1974. National Association Of Corrosion Engineers, 2400 West Loop South, Houston, Texas 77027.

Tessier, A., P. G. C. Campbell, and M. Bisson. (1979). "Sequential extraction procedure for the speciation of particulate trace metals." Anal. Chem. 51(7): 844-851.

U.S. Environmental Protection Agency (2001). Remedial Investigation Report, Coeur d'Alene Basin, Vol. 2, Part 2. 64

Wright, K., G. Redden, and C. Palmer. Canyon Creek Groundwater Metal Source Characterization. May 2007. Idaho National Laboratory. 
Appendix A 


\section{Appendix A}

Table A-1. Phase I of sequential extraction - laboratory data.

\begin{tabular}{|c|c|c|c|c|c|c|c|c|c|}
\hline \multirow[b]{2}{*}{$\begin{array}{c}\text { Sample } \\
\text { Number }\end{array}$} & \multirow[b]{2}{*}{ Sample Name-Depth-Replicate \# } & \multicolumn{2}{|c|}{ Conc. (ug/L) } & \multicolumn{6}{|c|}{ First Extraction of the 3 step Sequential Extraction } \\
\hline & & $\mathrm{Cd}$ & $\mathrm{Ca}$ & $\mathrm{Fe}$ & $\mathrm{Pb}$ & $\mathrm{Mg}$ & $\mathrm{Mn}$ & $\mathrm{S}$ & $\mathrm{Zn}$ \\
\hline MJAJH1 & SF-OB-PZ-13 1.0-1.8" -1 & 641 & 29600 & 694 & 14100 & 23500000 & 13900 & 11400 & 12000 \\
\hline MJAJH2 & SF-OB-PZ-13 1.0-1.8" -2 & 551 & 26600 & 3020 & 13000 & 22200000 & 11800 & 9630 & 10400 \\
\hline MJAJH3 & SF-OB-PZ-13 1.0-1.8" -3 & 527 & 24900 & 8550 & 16500 & 22800000 & 12100 & 9090 & 10900 \\
\hline MJAJH4 & SF-OB-PZ-13 3.0-4.0" -1 & 369 & 52400 & $\mathrm{U}$ & 8510 & 22000000 & 16300 & 2100 & 9400 \\
\hline MJAJH5 & SF-OB-PZ-13 3.0-4.0" -2 & 357 & 50300 & $\mathrm{U}$ & 8790 & 22700000 & 17100 & 2160 & 9640 \\
\hline MJAJH6 & SF-OB-PZ-13 3.0-4.0" -3 & 383 & 55400 & 439 & 8670 & 25300000 & 17900 & 2220 & 9540 \\
\hline MJAJH7 & SF-OB-PZ-13 5.0-5.6" -1 & 543 & 32900 & 1010 & 14500 & 24700000 & 15200 & 5930 & 12600 \\
\hline MJAJH8 & SF-OB-PZ-13 5.0-5.6" -2 & 520 & 32500 & 2410 & 18100 & 24500000 & 18900 & 7570 & 12200 \\
\hline MJAJH9 & SF-OB-PZ-13 5.0-5.6" -3 & 564 & 33600 & 2360 & 17400 & 23800000 & 17600 & 7300 & 13000 \\
\hline MJAJJ0 & SF-BH-E-PZ-12 1.0-2.0" -1 & 378 & 19700 & 1420 & 93300 & 23900000 & 8150 & 14500 & 15800 \\
\hline MJAJJ1 & SF-BH-E-PZ-12 1.0-2.0" -2 & 366 & 19100 & 2930 & 95000 & 23900000 & 7500 & 13500 & 15400 \\
\hline MJAJJ2 & SF-BH-E-PZ-12 1.0-2.0" -3 & 388 & 19800 & 4410 & 96400 & 24100000 & 8170 & 14700 & 16200 \\
\hline MJAJJ3 & SF-BH-E-PZ-12 3.0-4.0" -1 & 186 & 137000 & 1770 & 12800 & 24400000 & 4020 & 18600 & 5680 \\
\hline MJAJJ4 & SF-BH-E-PZ-12 3.0-4.0" -2 & 213 & 144000 & 1860 & 12900 & 29000000 & 4270 & 20900 & 5010 \\
\hline MJAJJ5 & SF-BH-E-PZ-12 3.0-4.0" -3 & 210 & 144000 & 3000 & 12400 & 25300000 & 4340 & 20700 & 5040 \\
\hline MJAJJ6 & SF-BH-E-PZ-12 5.0-6.0" -1 & 83.2 & 67300 & 4470 & 33900 & 28500000 & 5300 & 10500 & 1570 \\
\hline MJAJJ7 & SF-BH-E-PZ-12 5.0-6.0" -2 & 78.8 & 63600 & 1360 & 30100 & 24400000 & 4650 & 9600 & 1270 \\
\hline MJAJJ8 & SF-BH-E-PZ-12 5.0-6.0" -3 & 85.1 & 66800 & 2030 & 32000 & 25000000 & 5900 & 10400 & 1490 \\
\hline MJAJJ9 & SF-BH-E-PZ-12 7.0-8.0" -1 & 112 & 25100 & 7650 & 85900 & 23100000 & 2690 & 13400 & 10400 \\
\hline MJAJK0 & SF-BH-E-PZ-12 7.0-8.0" -2 & 136 & 27700 & 6790 & 87900 & 28000000 & 2790 & 13900 & 10800 \\
\hline MJAJK1 & SF-BH-E-PZ-12 7.0-8.0" -3 & 134 & 26200 & 9630 & 93800 & 29300000 & 2700 & 14100 & 9960 \\
\hline MJAJK2 & SF-BH-E-PZ-12 8.0-9.0" -1 & 475 & 63400 & 9190 & 44200 & 32600000 & 4070 & 9430 & 10300 \\
\hline MJAJK3 & SF-BH-E-PZ-12 8.0-9.0" -2 & 543 & 54400 & 10500 & 53000 & 32500000 & 3770 & 8780 & 10600 \\
\hline
\end{tabular}


Table A-1. (continued).

\begin{tabular}{|c|c|c|c|c|c|c|c|c|c|}
\hline \multirow[b]{2}{*}{$\begin{array}{c}\text { Sample } \\
\text { Number }\end{array}$} & \multirow[b]{2}{*}{ Sample Name-Depth-Replicate \# } & \multicolumn{2}{|c|}{ Conc. (ug/L) } & \multicolumn{6}{|c|}{ First Extraction of the 3 step Sequential Extraction } \\
\hline & & $\mathrm{Cd}$ & $\mathrm{Ca}$ & $\mathrm{Fe}$ & $\mathrm{Pb}$ & $\mathrm{Mg}$ & $\mathrm{Mn}$ & $\mathrm{S}$ & $\mathrm{Zn}$ \\
\hline MJAJK4 & SF-BH-E-PZ-12 8.0-9.0" -3 & 548 & 55700 & 8810 & 45600 & 31400000 & 3520 & 8900 & 9720 \\
\hline MJAJK5 & SF-BH-E-PZ-16 1.0-2.0" -1 & 829 & 129000 & 7170 & 153000 & 25000000 & 16500 & 144000 & 40600 \\
\hline MJAJK6 & SF-BH-E-PZ-16 1.0-2.0" -2 & 818 & 130000 & 5420 & 168000 & 28600000 & 17700 & 146000 & 40900 \\
\hline MJAJK7 & SF-BH-E-PZ-16 1.0-2.0" -3 & 794 & 126000 & 6380 & 156000 & 26200000 & 16600 & 140000 & 39400 \\
\hline MJAJK8 & SF-BH-E-PZ-16 3.0-4.0" -1 & 801 & 116000 & 6990 & 132000 & 28500000 & 17400 & 110000 & 18700 \\
\hline MJAJK9 & SF-BH-E-PZ-16 3.0-4.0" -2 & 780 & 119000 & 9330 & 163000 & 26600000 & 17500 & 116000 & 19800 \\
\hline MJAJL0 & SF-BH-E-PZ-16 3.0-4.0" -3 & 828 & 117000 & 18200 & 174000 & 25900000 & 18600 & 117000 & 21500 \\
\hline MJAJL1 & SF-BH-E-PZ-16 5.0-6.0" -1 & 1430 & 25000 & 5830 & 102000 & 26400000 & 30900 & 60700 & 54200 \\
\hline MJAJL2 & SF-BH-E-PZ-16 5.0-6.0" -2 & 1370 & 25000 & 26000 & 101000 & 25200000 & 31100 & 59100 & 54200 \\
\hline MJAJL3 & SF-BH-E-PZ-16 5.0-6.0" -3 & 1400 & 25100 & 23900 & 99600 & 25800000 & 30600 & 58100 & 53900 \\
\hline MJAJL4 & SF-BH-E-PZ-16 7.0-8.0" -1 & 435 & 71700 & 8120 & 7980 & 26900000 & 21400 & 39100 & 11100 \\
\hline MJAJL5 & SF-BH-E-PZ-16 7.0-8.0" -2 & 429 & 66300 & 10900 & 8320 & 25900000 & 21800 & 35700 & 11800 \\
\hline MJAJL6 & SF-BH-E-PZ-16 7.0-8.0" -3 & 401 & 66500 & 7510 & 7430 & 25600000 & 21900 & 34900 & 11100 \\
\hline MJAJL7 & SF-BH-E-PZ-24 1.0-2.0" -1 & 713 & 120000 & 3900 & 15900 & 25500000 & 5170 & 6370 & 24600 \\
\hline MJAJL8 & SF-BH-E-PZ-24 1.0-2.0" -2 & 701 & 117000 & 4550 & 15400 & 25200000 & 4950 & 5530 & 24100 \\
\hline MJAJL9 & SF-BH-E-PZ-24 1.0-2.0" -3 & 724 & 121000 & 5910 & 17100 & 24800000 & 5090 & 6230 & 25400 \\
\hline MJAJM0 & SF-BH-E-PZ-24 3.0-4.0" -1 & 199 & 199000 & 3630 & 1790 & 28400000 & 23100 & 9400 & 2130 \\
\hline MJAJM1 & SF-BH-E-PZ-24 3.0-4.0" -2 & 158 & 186000 & 3160 & 1250 & 24700000 & 21100 & 8830 & 1610 \\
\hline MJAJM2 & SF-BH-E-PZ-24 3.0-4.0" -3 & 175 & 196000 & 2660 & 1450 & 27600000 & 21900 & 8980 & 1700 \\
\hline MJAJM3 & SF-BH-E-PZ-24 5.0-6.0" -1 & 1570 & 171000 & 5730 & 54300 & 24000000 & 72400 & 11400 & 70600 \\
\hline MJAJM4 & SF-BH-E-PZ-24 5.0-6.0" -2 & 1670 & 183000 & 7770 & 55900 & 25300000 & 82700 & 11900 & 76400 \\
\hline MJAJM5 & SF-BH-E-PZ-24 5.0-6.0" -3 & 1700 & 161000 & 3840 & 48700 & 25600000 & 71600 & 10300 & 72100 \\
\hline MJAJM6 & SF-BH-E-PZ-24 7.0-8.0" -1 & 584 & 59000 & 549 & 249 & 23700000 & 14100 & 8380 & 15100 \\
\hline MJAJM7 & SF-BH-E-PZ-24 7.0-8.0" -2 & 570 & 65100 & 864 & 75.2 & 23200000 & 16200 & 6280 & 14900 \\
\hline MJAJM8 & SF-BH-E-PZ-24 7.0-8.0" -3 & 591 & 73700 & 1420 & 153 & 22200000 & 17500 & 6660 & 16000 \\
\hline
\end{tabular}


Table A-2. Phase II of Sequential Extraction - Laboratory Data. Note U indicates that the ion was analyzed for but not detected above the sample quantification limit or detection limit.

\begin{tabular}{|c|c|c|c|c|c|c|c|c|c|}
\hline \multirow{2}{*}{$\begin{array}{l}\text { Sample } \\
\text { Number }\end{array}$} & \multirow[b]{2}{*}{ Sample Name and Location } & \multicolumn{2}{|c|}{ Concentration ug/L } & \multicolumn{4}{|c|}{$\begin{array}{l}\text { Second Extraction of the } 3 \text { step Sequential } \\
\text { Extraction }\end{array}$} & \multirow[b]{2}{*}{$\mathrm{S}$} & \multirow[b]{2}{*}{$\mathrm{Zn}$} \\
\hline & & $\mathrm{Cd}$ & $\mathrm{Ca}$ & $\mathrm{Fe}$ & $\mathrm{Pb}$ & $\mathrm{Mg}$ & $\mathrm{Mn}$ & & \\
\hline MJAJN4 & SF-OB-PZ-13 1.0-1.8" -1 & 476 & $\mathrm{U}$ & 6590 & 312000 & 113000 & 25400 & 1800 & 52500 \\
\hline MJAJN5 & SF-OB-PZ-13 1.0-1.8" -2 & 665 & $\mathrm{U}$ & 6510 & 425000 & 222000 & 36200 & 2380 & 74400 \\
\hline MJAJN6 & SF-OB-PZ-13 1.0-1.8" -3 & 602 & $\mathrm{U}$ & 6100 & 408000 & 156000 & 30800 & 2200 & 65000 \\
\hline MJAJN7 & SF-OB-PZ-13 3.0-4.0" -1 & 130 & $\mathrm{U}$ & 20700 & 95100 & 124000 & 35800 & 364 & 25900 \\
\hline MJAJN8 & SF-OB-PZ-13 3.0-4.0" -2 & 134 & $\mathrm{U}$ & 25400 & 97000 & 322000 & 39100 & 341 & 24300 \\
\hline MJAJN9 & SF-OB-PZ-13 3.0-4.0" -3 & 138 & $\mathrm{U}$ & 24200 & 96500 & 95600 & 38300 & 291 & 26100 \\
\hline MJAJP0 & SF-OB-PZ-13 5.0-5.6" -1 & 304 & $\mathrm{U}$ & 14900 & 106000 & 113000 & 21700 & 885 & 43500 \\
\hline MJAJP1 & SF-OB-PZ-13 5.0-5.6" -2 & 335 & $\mathrm{U}$ & 11500 & 150000 & 103000 & 28000 & 1090 & 49300 \\
\hline MJAJP2 & SF-OB-PZ-13 5.0-5.6" -3 & 346 & $\mathrm{U}$ & 10300 & 139000 & 140000 & 26300 & 1050 & 54700 \\
\hline MJAJP3 & SF-BH-E-PZ-12 1.0-2.0" -1 & 2080 & $\mathrm{U}$ & 76500 & 947000 & 81700 & 62600 & 3140 & 89500 \\
\hline MJAJP4 & SF-BH-E-PZ-12 1.0-2.0" -2 & 2000 & $\mathrm{U}$ & 75300 & 939000 & 81800 & 61600 & 3110 & 90700 \\
\hline MJAJP5 & SF-BH-E-PZ-12 1.0-2.0" -3 & 2290 & $\mathrm{U}$ & 82400 & 1200000 & 57300 & 68500 & 3200 & 98000 \\
\hline MJAJP6 & SF-BH-E-PZ-12 3.0-4.0" -1 & 493 & 225000 & 202000 & 455000 & 355000 & 105000 & 6220 & 70000 \\
\hline MJAJP7 & SF-BH-E-PZ-12 3.0-4.0" -2 & 495 & 209000 & 178000 & 411000 & 173000 & 100000 & 5720 & 69700 \\
\hline MJAJP8 & SF-BH-E-PZ-12 3.0-4.0" -3 & 513 & 229000 & 189000 & 459000 & 291000 & 116000 & 6420 & 74400 \\
\hline MJAJP9 & SF-BH-E-PZ-12 5.0-6.0" -1 & 54.4 & U & 5380 & 296000 & 198000 & 12100 & 1470 & 4940 \\
\hline MJAJQ0 & SF-BH-E-PZ-12 5.0-6.0" -2 & 55.7 & $\mathrm{U}$ & 6190 & 315000 & 336000 & 13200 & 1500 & 4800 \\
\hline MJAJQ1 & SF-BH-E-PZ-12 5.0-6.0" -3 & 52.5 & $\mathrm{U}$ & 6430 & 378000 & 115000 & 12400 & 1330 & 5450 \\
\hline MJAJQ2 & SF-BH-E-PZ-12 7.0-8.0" -1 & 137 & $\mathrm{U}$ & 64100 & 8420000 & 230000 & 21500 & 2420 & 117000 \\
\hline MJAJQ3 & SF-BH-E-PZ-12 7.0-8.0" -2 & 150 & $\mathrm{U}$ & 67000 & 8200000 & 59800 & 24200 & 2760 & 127000 \\
\hline MJAJQ4 & SF-BH-E-PZ-12 7.0-8.0" -3 & 128 & $\mathrm{U}$ & 57100 & 9850000 & 137000 & 20300 & 2630 & 102000 \\
\hline MJAJQ5 & SF-BH-E-PZ-12 8.0-9.0" -1 & 812 & 129000 & 198000 & 449000 & 156000 & 61500 & 3350 & 317000 \\
\hline MJAJQ6 & SF-BH-E-PZ-12 8.0-9.0" -2 & 826 & 82600 & 186000 & 427000 & 105000 & 65100 & 2440 & 333000 \\
\hline
\end{tabular}


Table A-2. (continued).

\begin{tabular}{|c|c|c|c|c|c|c|c|c|c|}
\hline \multirow[b]{2}{*}{$\begin{array}{l}\text { Sample } \\
\text { Number }\end{array}$} & \multirow[b]{2}{*}{ Sample Name and Location } & \multicolumn{2}{|c|}{ Concentration ug/L } & \multicolumn{4}{|c|}{$\begin{array}{l}\text { Second Extraction of the } 3 \text { step Sequential } \\
\text { Extraction }\end{array}$} & \multirow[b]{2}{*}{$\mathrm{S}$} & \multirow[b]{2}{*}{$\mathrm{Zn}$} \\
\hline & & $\mathrm{Cd}$ & $\mathrm{Ca}$ & $\mathrm{Fe}$ & $\mathrm{Pb}$ & $\mathrm{Mg}$ & $\mathrm{Mn}$ & & \\
\hline MJAJQ8 & SF-BH-E-PZ-16 1.0-2.0" -1 & 162 & 22400 & 26300 & 116000 & 235000 & 29700 & 27900 & 24200 \\
\hline MJAJQ9 & SF-BH-E-PZ-16 1.0-2.0" -2 & 185 & 18400 & 19700 & 110000 & 141000 & 29500 & 28900 & 22700 \\
\hline MJAJR2 & SF-BH-E-PZ-16 3.0-4.0" -2 & 395 & $\mathrm{U}$ & 168000 & 197000 & 143000 & 23600 & 6940 & 30000 \\
\hline MJAJR3 & SF-BH-E-PZ-16 3.0-4.0" -3 & 394 & $\mathrm{U}$ & 175000 & 195000 & 147000 & 23600 & 6860 & 29600 \\
\hline MJAJR4 & SF-BH-E-PZ-16 5.0-6.0" -1 & 1590 & 17000 & 202000 & 256000 & 234000 & 174000 & 8230 & 340000 \\
\hline MJAJR5 & SF-BH-E-PZ-16 5.0-6.0" -2 & 1560 & 17700 & 200000 & 263000 & 230000 & 169000 & 8160 & 349000 \\
\hline MJAJR6 & SF-BH-E-PZ-16 5.0-6.0" -3 & 1580 & 17400 & 195000 & 262000 & 351000 & 163000 & 8480 & 342000 \\
\hline MJAJS0 & SF-BH-E-PZ-24 1.0-2.0" -1 & 792 & 499000 & 881000 & 255000 & 146000 & 252000 & 8570 & 237000 \\
\hline MJAJS1 & SF-BH-E-PZ-24 1.0-2.0" -2 & 707 & 457000 & 756000 & 241000 & 156000 & 193000 & 7910 & 212000 \\
\hline MJAJS2 & SF-BH-E-PZ-24 1.0-2.0" -3 & 769 & 521000 & 865000 & 275000 & 227000 & 210000 & 8670 & 237000 \\
\hline MJAJS3 & SF-BH-E-PZ-24 3.0-4.0" -1 & 122 & 1700000 & 2680000 & 50500 & 247000 & 272000 & 23300 & 287000 \\
\hline MJAJS4 & SF-BH-E-PZ-24 3.0-4.0" -2 & 134 & 1620000 & 2630000 & 52600 & 239000 & 285000 & 23500 & 262000 \\
\hline MJAJS5 & SF-BH-E-PZ-24 3.0-4.0" -3 & 145 & 1520000 & 2450000 & 58600 & 242000 & 269000 & 21900 & 260000 \\
\hline MJAJS6 & SF-BH-E-PZ-24 5.0-6.0" -1 & 943 & 310000 & 606000 & 268000 & 417000 & 164000 & 5890 & 126000 \\
\hline MJAJS7 & SF-BH-E-PZ-24 5.0-6.0" -2 & 907 & 332000 & 654000 & 285000 & 476000 & 177000 & 6250 & 133000 \\
\hline MJAJS8 & SF-BH-E-PZ-24 5.0-6.0" -3 & 1140 & 309000 & 583000 & 317000 & 539000 & 200000 & 5990 & 126000 \\
\hline MJAJS9 & SF-BH-E-PZ-24 7.0-8.0" -1 & 226 & 174000 & 354000 & 6340 & 151000 & 73600 & 2510 & 58000 \\
\hline
\end{tabular}


Table A-3. Phase III of Sequential Extraction - Laboratory Data. Note U indicates that the ion was analyzed for but not detected above the sample quantification limit or detection limit.

\begin{tabular}{|c|c|c|c|c|c|c|c|c|c|}
\hline \multirow{2}{*}{$\begin{array}{c}\text { Sample } \\
\text { Number }\end{array}$} & \multirow[b]{2}{*}{ Sample Name and Location } & \multicolumn{2}{|c|}{ Concentration ug/L } & \multicolumn{5}{|c|}{ First Extraction of the 3 step Sequential Extraction } & \multirow[b]{2}{*}{$\mathrm{Zn}$} \\
\hline & & $\mathrm{Cd}$ & $\mathrm{Ca}$ & $\mathrm{Fe}$ & $\mathrm{Pb}$ & $\mathrm{Mg}$ & $\mathrm{Mn}$ & $\mathrm{S}$ & \\
\hline MJAJT6 & SF-OB-PZ-13 1.0-1.8" -1 & 641 & $\mathrm{U}$ & 23100 & 263000 & $\mathrm{U}$ & 230000 & 5880 & 41500 \\
\hline MJAJT7 & SF-OB-PZ-13 1.0-1.8" -2 & 741 & $\mathrm{U}$ & 22800 & 224000 & $\mathrm{U}$ & 189000 & 7290 & 42700 \\
\hline MJAJT8 & SF-OB-PZ-13 1.0-1.8" -3 & & & & & & & & \\
\hline MJAJT9 & SF-OB-PZ-13 3.0-4.0" -1 & 69 & $\mathrm{U}$ & 7980 & 32200 & $\mathrm{U}$ & 38000 & 9110 & 6050 \\
\hline MJAJW0 & SF-OB-PZ-13 3.0-4.0" -2 & 65.4 & $\mathrm{U}$ & 9550 & 33600 & $\mathrm{U}$ & 35600 & 8080 & 6800 \\
\hline MJAJW1 & SF-OB-PZ-13 3.0-4.0" -3 & 73.9 & $\mathrm{U}$ & 5060 & 28100 & $\mathrm{U}$ & 38700 & 10200 & 5070 \\
\hline MJAJW2 & SF-OB-PZ-13 5.0-5.6" -1 & 446 & $\mathrm{U}$ & 9220 & 56900 & $\mathrm{U}$ & 75400 & 28400 & 38100 \\
\hline MJAJW3 & SF-OB-PZ-13 5.0-5.6" -2 & 371 & $\mathrm{U}$ & 44300 & 78700 & $\mathrm{U}$ & 79300 & 19300 & 31600 \\
\hline MJAJW4 & SF-OB-PZ-13 5.0-5.6" -3 & 386 & $\mathrm{U}$ & 13800 & 72300 & $\mathrm{U}$ & 79800 & 26200 & 34400 \\
\hline MJAJW5 & SF-BH-E-PZ-12 1.0-2.0" -1 & 569 & 29500 & 18000 & 145000 & 52200 & 133000 & 146000 & 76800 \\
\hline MJAJW6 & SF-BH-E-PZ-12 1.0-2.0" -2 & 532 & 29600 & 15600 & 142000 & 49100 & 125000 & 137000 & 73000 \\
\hline MJAJW7 & SF-BH-E-PZ-12 1.0-2.0" -3 & 533 & 32100 & 15500 & 145000 & 49900 & 124000 & 136000 & 72300 \\
\hline MJAJW8 & SF-BH-E-PZ-12 3.0-4.0" -1 & 210 & 18900 & 42600 & 82200 & 20100 & 37700 & 36900 & 29700 \\
\hline MJAJW9 & SF-BH-E-PZ-12 3.0-4.0" -2 & 209 & 19700 & 49800 & 84100 & 18600 & 39000 & 33800 & 29500 \\
\hline MJAJX0 & SF-BH-E-PZ-12 3.0-4.0" -3 & 215 & 20700 & 58400 & 91600 & 20000 & 33100 & 34000 & 29400 \\
\hline MJAJX1 & SF-BH-E-PZ-12 5.0-6.0" -1 & 53.3 & $\mathrm{U}$ & 16700 & 138000 & $\mathrm{U}$ & 113000 & 3600 & 3540 \\
\hline MJAJX2 & SF-BH-E-PZ-12 5.0-6.0" -2 & 36.5 & $\mathrm{U}$ & 16700 & 103000 & $\mathrm{U}$ & 94600 & 5580 & 2830 \\
\hline MJAJX3 & SF-BH-E-PZ-12 5.0-6.0" -3 & 51.1 & $\mathrm{U}$ & 18000 & 157000 & $\mathrm{U}$ & 127000 & 3450 & 3950 \\
\hline MJAJX4 & SF-BH-E-PZ-12 7.0-8.0" -1 & 3290 & 28500 & 10600 & 97700 & 55700 & 148000 & 249000 & 415000 \\
\hline MJAJX5 & SF-BH-E-PZ-12 7.0-8.0" -2 & 2990 & 16100 & 73100 & 192000 & 29700 & 82300 & 158000 & 354000 \\
\hline MJAJX6 & SF-BH-E-PZ-12 7.0-8.0" -3 & 2280 & 15000 & 65100 & 160000 & 25100 & 67800 & 114000 & 280000 \\
\hline MJAJX7 & SF-BH-E-PZ-12 8.0-9.0" -1 & 6510 & 46300 & 45000 & 89900 & 32200 & 99300 & 266000 & 510000 \\
\hline MJAJX8 & SF-BH-E-PZ-12 8.0-9.0" -2 & 5860 & 45900 & 43400 & 83400 & 29900 & 92100 & 245000 & 454000 \\
\hline MJAJX9 & SF-BH-E-PZ-12 8.0-9.0" -3 & 6330 & 45900 & 49400 & 76100 & 32200 & 101000 & 263000 & 529000 \\
\hline
\end{tabular}


Table A-3. (continued).

\begin{tabular}{|c|c|c|c|c|c|c|c|c|c|}
\hline \multirow[b]{2}{*}{$\begin{array}{c}\text { Sample } \\
\text { Number }\end{array}$} & \multirow[b]{2}{*}{ Sample Name and Location } & \multicolumn{2}{|c|}{ Concentration ug/L } & \multicolumn{5}{|c|}{ First Extraction of the 3 step Sequential Extraction } & \multirow[b]{2}{*}{$\mathrm{Zn}$} \\
\hline & & $\mathrm{Cd}$ & $\mathrm{Ca}$ & $\mathrm{Fe}$ & $\mathrm{Pb}$ & $\mathrm{Mg}$ & $\mathrm{Mn}$ & $\mathrm{S}$ & \\
\hline MJAJY0 & SF-BH-E-PZ-16 1.0-2.0" -1 & 387 & 19100 & 7190 & 65900 & $\mathrm{U}$ & 69900 & 136000 & 59400 \\
\hline MJAJY1 & SF-BH-E-PZ-16 1.0-2.0" -2 & 294 & 27400 & 18900 & 52200 & $\mathrm{U}$ & 64200 & 120000 & 40100 \\
\hline MJAJY2 & SF-BH-E-PZ-16 1.0-2.0" -3 & 352 & 17100 & 8920 & 63500 & $\mathrm{U}$ & 66900 & 131000 & 60000 \\
\hline MJAJY3 & SF-BH-E-PZ-16 3.0-4.0" -1 & 773 & 18300 & 222000 & 57800 & 47300 & 91600 & 218000 & 101000 \\
\hline MJAJY4 & SF-BH-E-PZ-16 3.0-4.0" -2 & 548 & 14300 & 239000 & 44500 & 40700 & 83400 & 192000 & 70200 \\
\hline MJAJY5 & SF-BH-E-PZ-16 3.0-4.0" -3 & 552 & 14100 & 241000 & 43900 & 41700 & 83500 & 195000 & 71200 \\
\hline MJAJY6 & SF-BH-E-PZ-16 5.0-6.0" -1 & 991 & 51300 & 285000 & 54200 & 53800 & 141000 & 297000 & 113000 \\
\hline MJAJY7 & SF-BH-E-PZ-16 5.0-6.0" -2 & 938 & 55500 & 313000 & 57400 & 58300 & 138000 & 294000 & 112000 \\
\hline MJAJY8 & SF-BH-E-PZ-16 5.0-6.0" -3 & 992 & 55800 & 328000 & 59200 & 60800 & 141000 & 307000 & 121000 \\
\hline MJAJY9 & SF-BH-E-PZ-16 7.0-8.0" -1 & 223 & $\mathrm{U}$ & 12600 & 10500 & $\mathrm{U}$ & 21700 & 46100 & 27200 \\
\hline MJAJZ0 & SF-BH-E-PZ-16 7.0-8.0" -2 & 209 & $\mathrm{U}$ & 7360 & 8420 & U & 21200 & 40100 & 24000 \\
\hline MJAJZ1 & SF-BH-E-PZ-16 7.0-8.0" -3 & 201 & $\mathrm{U}$ & 16200 & 7710 & $\mathrm{U}$ & 23500 & 36300 & 24100 \\
\hline MJAJZ2 & SF-BH-E-PZ-24 1.0-2.0" -1 & 427 & 87900 & 41500 & 41100 & $\mathrm{U}$ & 25100 & 37100 & 37200 \\
\hline MJAJZ3 & SF-BH-E-PZ-24 1.0-2.0" -2 & 312 & 77200 & 30300 & 32000 & $\mathrm{U}$ & 19300 & 27600 & 28600 \\
\hline MJAJZ4 & SF-BH-E-PZ-24 1.0-2.0" -3 & 316 & 75300 & 18600 & 31600 & $\mathrm{U}$ & 19100 & 28900 & 26200 \\
\hline MJAJZ5 & SF-BH-E-PZ-24 3.0-4.0" -1 & 244 & 87800 & 20800 & 34700 & $\mathrm{U}$ & 36300 & 63700 & 41000 \\
\hline MJAJZ6 & SF-BH-E-PZ-24 3.0-4.0" -2 & 263 & 89800 & 19300 & 34000 & $\mathrm{U}$ & 34700 & 64400 & 36400 \\
\hline MJAJZ7 & SF-BH-E-PZ-24 3.0-4.0" -3 & 332 & 80800 & 26700 & 32500 & 17900 & 57700 & 80900 & 51800 \\
\hline MJAJZ8 & SF-BH-E-PZ-24 5.0-6.0" -1 & 888 & 45300 & 28300 & 42800 & 18400 & 45700 & 40400 & 18800 \\
\hline MJAJZ9 & SF-BH-E-PZ-24 5.0-6.0" -2 & 727 & 35300 & 51200 & 43300 & 19800 & 44000 & 39800 & 17300 \\
\hline MJAK00 & SF-BH-E-PZ-24 5.0-6.0" -3 & 660 & 49000 & 44900 & 37400 & 19500 & 30600 & 34600 & 15900 \\
\hline MJAK01 & SF-BH-E-PZ-24 7.0-8.0" -1 & 155 & 22600 & 8060 & 1840 & $\mathrm{U}$ & 9130 & 9360 & 11500 \\
\hline MJAK02 & SF-BH-E-PZ-24 7.0-8.0" -2 & 165 & 27100 & 5580 & 2100 & $\mathrm{U}$ & 9280 & 9970 & 10700 \\
\hline MJAK03 & SF-BH-E-PZ-24 7.0-8.0" -3 & 143 & 32600 & 9010 & 1830 & $\mathrm{U}$ & 6590 & 10700 & 7080 \\
\hline
\end{tabular}


Table A-4. Total Concentration in Treated and Untreated Sediments used in Sequential Extractions.

\begin{tabular}{|c|c|c|c|c|c|c|c|c|c|c|}
\hline \multirow[b]{2}{*}{$\begin{array}{l}\text { Sample } \\
\text { Number }\end{array}$} & \multirow[b]{2}{*}{$\begin{array}{l}\text { Sample Name and } \\
\text { Location }\end{array}$} & & \multicolumn{2}{|c|}{$\begin{array}{c}\text { Concentration } \\
\mathrm{ug} / \mathrm{L}\end{array}$} & \multicolumn{5}{|c|}{$\begin{array}{c}\text { First Extraction of the 3-step Sequential } \\
\text { Extraction }\end{array}$} & \multirow[b]{2}{*}{$\mathrm{Zn}$} \\
\hline & & & $\mathrm{Cd}$ & $\mathrm{Ca}$ & $\mathrm{Fe}$ & $\mathrm{Pb}$ & $\mathrm{Mg}$ & $\mathrm{Mn}$ & $\mathrm{S}$ & \\
\hline MJAK09 & SF-OB-PZ-13 1.0-1.8' & $\begin{array}{l}\text { Sediment After } \\
\text { Extraction }\end{array}$ & 52.4 & 492 & 103000 & 7390 & 948 & 4410 & 2870 & 9430 \\
\hline MJAK10 & SF-OB-PZ-13 3.0-4.0' & $\begin{array}{l}\text { Sediment After } \\
\text { Extraction }\end{array}$ & 1.1 & 408 & 15100 & 531 & 844 & 369 & 79.7 & 530 \\
\hline MJAK11 & SF-OB-PZ-13 5.0-5.6' & $\begin{array}{l}\text { Sediment After } \\
\text { Extraction }\end{array}$ & 6.6 & 421 & 33100 & 1950 & 891 & 1430 & 500 & 1990 \\
\hline MJAK12 & SF-BH-E-PZ-12 1.0-2.0' & $\begin{array}{l}\text { Sediment After } \\
\text { Extraction }\end{array}$ & 9.3 & 1450 & 129000 & 3940 & 3930 & 8410 & 1930 & 3380 \\
\hline MJAK13 & SF-BH-E-PZ-12 3.0-4.0' & $\begin{array}{l}\text { Sediment After } \\
\text { Extraction }\end{array}$ & 5.7 & 563 & 531000 & 2380 & 2250 & 2640 & 1590 & 2180 \\
\hline MJAK14 & SF-BH-E-PZ-12 5.0-6.0' & $\begin{array}{l}\text { Sediment After } \\
\text { Extraction }\end{array}$ & 10.7 & 514 & 61400 & 1650 & 2050 & 2490 & 2500 & 3350 \\
\hline MJAK15 & SF-BH-E-PZ-12 7.0-8.0' & $\begin{array}{l}\text { Sediment After } \\
\text { Extraction }\end{array}$ & 67.2 & 1200 & 147000 & 53800 & 3850 & 5960 & 14100 & 13100 \\
\hline MJAK16 & SF-BH-E-PZ-12 8.0-9.0' & $\begin{array}{l}\text { Sediment After } \\
\text { Extraction }\end{array}$ & 106 & 1590 & 128000 & 6310 & 4270 & 10900 & 4890 & 13000 \\
\hline MJAK17 & SF-BH-E-PZ-16 1.0-2.0' & $\begin{array}{l}\text { Sediment After } \\
\text { Extraction }\end{array}$ & 4.4 & 417 & 85000 & 4240 & 602 & 1290 & 2060 & 2350 \\
\hline MJAK18 & SF-BH-E-PZ-16 3.0-4.0' & $\begin{array}{l}\text { Sediment After } \\
\text { Extraction }\end{array}$ & 14.2 & 603 & 84000 & 1570 & 2120 & 3060 & 2890 & 4170 \\
\hline MJAK19 & SF-BH-E-PZ-16 5.0-6.0' & $\begin{array}{l}\text { Sediment After } \\
\text { Extraction }\end{array}$ & 17 & 1070 & 139000 & 1380 & 3100 & 5780 & 6560 & 5890 \\
\hline MJAK20 & SF-BH-E-PZ-16 7.0-8.0' & $\begin{array}{l}\text { Sediment After } \\
\text { Extraction }\end{array}$ & 0.83 & 260 & 23700 & 446 & 1320 & 350 & 135 & 527 \\
\hline MJAK21 & SF-BH-E-PZ-24 1.0-2.0' & $\begin{array}{l}\text { Sediment After } \\
\text { Extraction }\end{array}$ & 13.4 & 18900 & 109000 & 4550 & 3160 & 5510 & 1740 & 8060 \\
\hline
\end{tabular}


Table A-4. (continued).

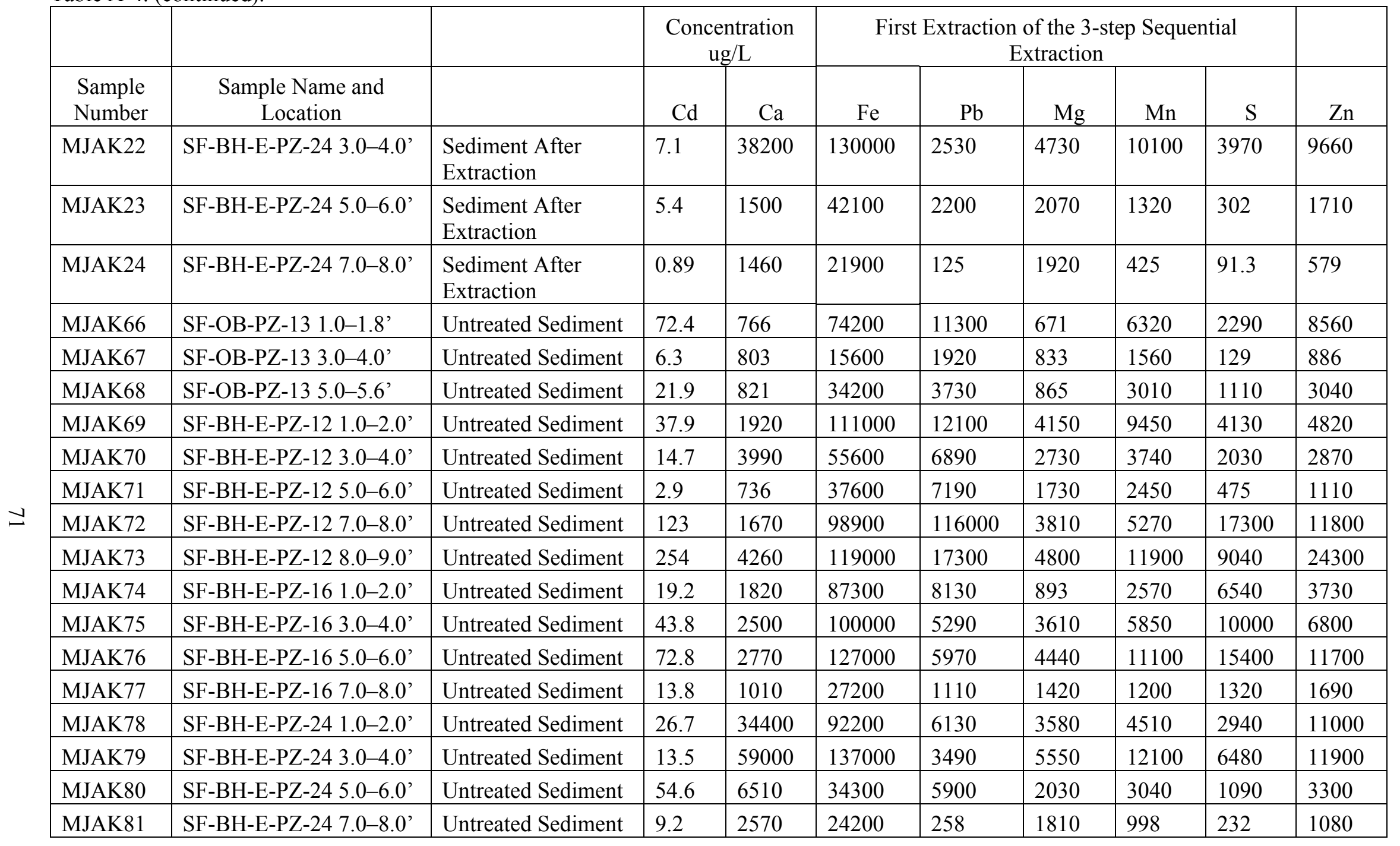


Table A-5. Concentrations from $\mathrm{pH}$ leach test from 0-90 days.

\begin{tabular}{|c|c|c|c|c|c|c|c|c|c|c|}
\hline $\begin{array}{l}\text { Sample } \\
\text { Number }\end{array}$ & $\begin{array}{l}\text { Sample Name and } \\
\text { Location }\end{array}$ & $\begin{array}{l}\mathrm{Cd} \\
\mathrm{ug} / \mathrm{L}\end{array}$ & $\mathrm{Ca}$ ug/L & $\mathrm{Fe} \mathrm{ug} / \mathrm{L}$ & $\mathrm{P} \mathrm{b} \mathrm{ug/L}$ & $\mathrm{Mg} \mathrm{ug} / \mathrm{L}$ & Mn ug/L & $\begin{array}{c}\mathrm{Se} \\
\mathrm{ug} / \mathrm{L}\end{array}$ & Zn ug/L & $\mathrm{S}$ ug/L \\
\hline \multicolumn{11}{|c|}{ Time 0} \\
\hline MJAKD2 & SF-OB-PZ-13 & $\mathrm{U}$ & 3550 & $\mathrm{U}$ & $\mathrm{U}$ & 3030 & $\mathrm{U}$ & 35 & $\mathrm{U}$ & 5770 \\
\hline MJAKD3 & SF-BH-E-PZ-12 & $\mathrm{U}$ & 2960 & 402 & $\mathrm{U}$ & 10700 & $\mathrm{U}$ & $\mathrm{U}$ & $\mathrm{U}$ & 18600 \\
\hline MJAKD4 & SF-BH-E-PZ-16 & $\mathrm{U}$ & 659 & $\mathrm{U}$ & $\mathrm{U}$ & 52800 & $\mathrm{U}$ & $\mathrm{U}$ & $\mathrm{U}$ & 67900 \\
\hline MJAKD5 & SF-BH-E-PZ-24 & $\mathrm{U}$ & 656 & 5200 & $\mathrm{U}$ & 49400 & $\mathrm{U}$ & $\mathrm{U}$ & $\mathrm{U}$ & 72500 \\
\hline \multicolumn{11}{|c|}{ Time 8 Hours } \\
\hline MJAKD6 & SF-OB-PZ-13 pH 2 & 84.2 & 7800 & 573 & 13600 & 2600 & 7450 & 3.8 & 7120 & 2690 \\
\hline MJAKD7 & SF-OB-PZ-13 pH 3 & 20.8 & 5890 & 289 & 759 & 2880 & 2310 & $\mathrm{U}$ & 1460 & 5940 \\
\hline MJAKD8 & SF-OB-PZ-13 pH 4 & 11.4 & 4990 & 1010 & 583 & 2760 & 1710 & $\mathrm{U}$ & 811 & 6210 \\
\hline MJAKD9 & SF-OB-PZ-13 pH 5 & 9.8 & 5310 & 889 & 486 & 2770 & 1470 & $\mathrm{U}$ & 693 & 6230 \\
\hline MJAKE0 & SF-OB-PZ-13 pH 6 & 9.8 & 6080 & 1270 & 672 & 2820 & 1800 & $\mathrm{U}$ & 686 & 6630 \\
\hline MJAKE1 & SF-OB-PZ-13 pH 7 & 9.9 & 5340 & 1870 & 992 & 2840 & 1790 & $\mathrm{U}$ & 765 & 6400 \\
\hline MJAKE2 & SF-BH-E-PZ-12 pH 2 & 130 & 28600 & 32800 & & 14300 & 14800 & 10.4 & 39300 & 1480 \\
\hline MJAKE3 & SF-BH-E-PZ-12 pH 3 & 8.9 & 15600 & 1360 & 1360 & 12000 & 1910 & $\mathrm{U}$ & 4640 & 21700 \\
\hline MJAKE4 & SF-BH-E-PZ-12 pH 4 & 3.2 & 17000 & 1030 & 522 & 11800 & 1370 & $\mathrm{U}$ & 1940 & 23200 \\
\hline MJAKE5 & SF-BH-E-PZ-12 pH 5 & 3.6 & 15200 & 1280 & 695 & 11800 & 1230 & $\mathrm{U}$ & 1870 & 23000 \\
\hline MJAKE6 & SF-BH-E-PZ-12 pH 6 & $\mathrm{U}$ & 11900 & 784 & 545 & 11500 & 1100 & $\mathrm{U}$ & 2020 & 22000 \\
\hline MJAKE7 & SF-BH-E-PZ-12 pH 7 & $\mathrm{U}$ & 12300 & 717 & 439 & 11300 & 1200 & $\mathrm{U}$ & 2100 & 22300 \\
\hline MJAKE8 & SF-BH-E-PZ-16 pH 2 & 523 & 28200 & 46300 & 3040 & 50500 & 29900 & 17.2 & 74900 & 78500 \\
\hline MJAKE9 & SF-BH-E-PZ-16 pH 3 & 139 & 19200 & 1530 & 399 & 49600 & 10700 & 6.7 & 16900 & 88800 \\
\hline MJAKF0 & SF-BH-E-PZ-16 pH 4 & 102 & 21000 & 1710 & 388 & 54100 & 9320 & 4.3 & 12400 & 92600 \\
\hline MJAKF1 & SF-BH-E-PZ-16 pH 5 & 82.3 & 18500 & 663 & 237 & 53600 & 8040 & 5.2 & 9930 & 89300 \\
\hline MJAKF2 & SF-BH-E-PZ-16 pH 6 & 63 & 15200 & 931 & 228 & 35900 & 5910 & $\mathrm{U}$ & 7460 & 62600 \\
\hline MJAKF3 & SF-BH-E-PZ-16 pH 7 & 74.5 & 17800 & 743 & 219 & 53500 & 7320 & 4.7 & 9240 & 87700 \\
\hline MJAKF4 & SF-BH-E-PZ-24 pH 2 & 134 & 68400 & 21100 & 3240 & 54000 & 16600 & $\mathrm{U}$ & 15800 & 79700 \\
\hline MJAKF5 & SF-BH-E-PZ-24 pH 3 & 21.2 & 26600 & 5140 & 186 & 52000 & 4190 & $\mathrm{U}$ & 2630 & 88300 \\
\hline
\end{tabular}


Table A-5. (continued).

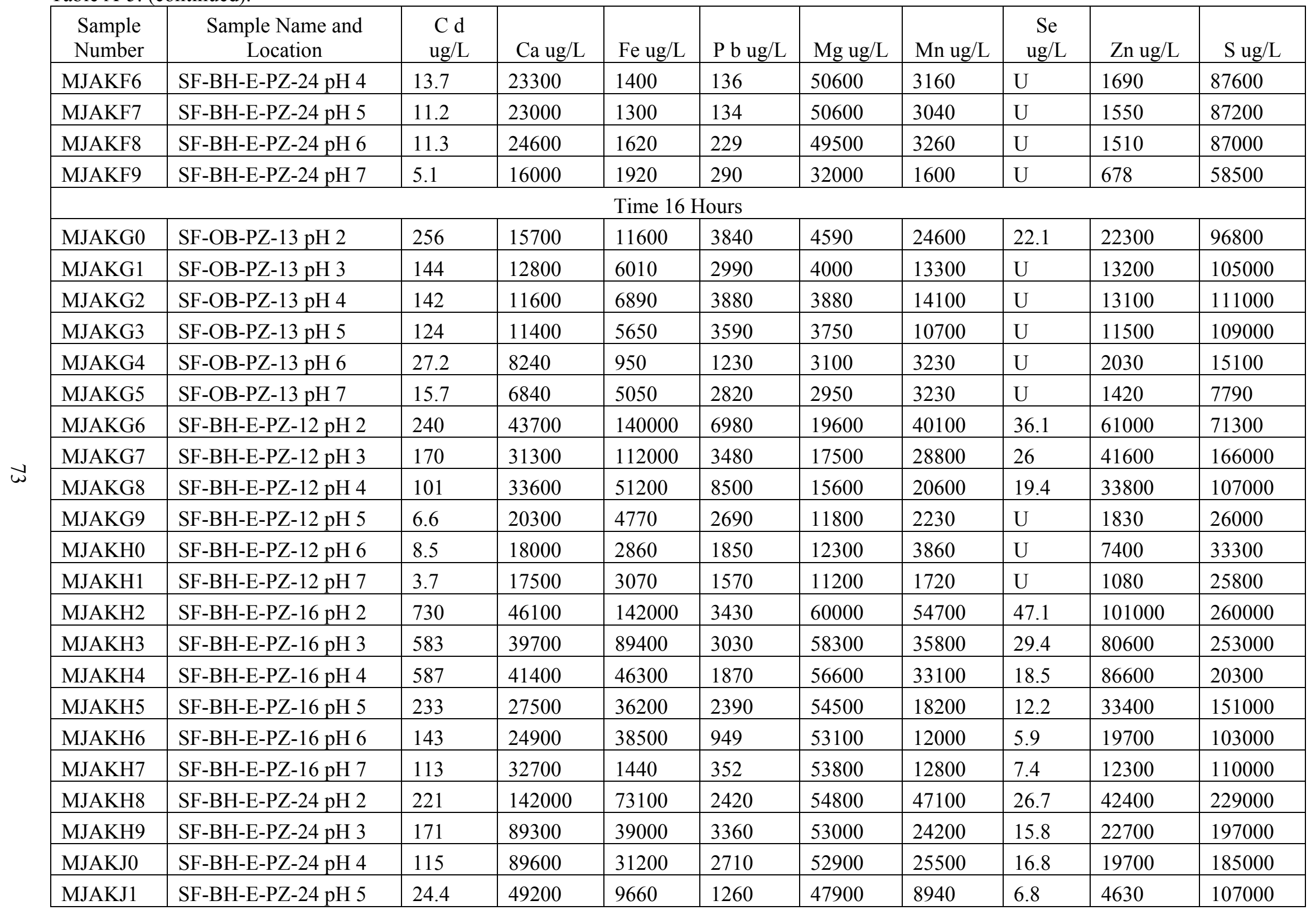


Table A-5. (continued).

\begin{tabular}{|c|c|c|c|c|c|c|c|c|c|c|}
\hline $\begin{array}{l}\text { Sample } \\
\text { Number }\end{array}$ & $\begin{array}{c}\text { Sample Name and } \\
\text { Location }\end{array}$ & $\begin{array}{r}\mathrm{Cd} \\
\mathrm{ug} / \mathrm{L} \\
\end{array}$ & $\mathrm{Ca} \mathrm{ug} / \mathrm{L}$ & $\mathrm{Fe}$ ug/L & $\mathrm{P}$ b ug/L & $\mathrm{Mg} \mathrm{ug} / \mathrm{L}$ & Mn ug/L & $\begin{array}{c}\mathrm{Se} \\
\mathrm{ug} / \mathrm{L}\end{array}$ & Zn ug/L & $\mathrm{S} \mathrm{ug} / \mathrm{L}$ \\
\hline MJAKJ2 & SF-BH-E-PZ-24 pH 6 & 13.6 & 39500 & 7030 & 993 & 45700 & 5230 & 3.5 & 2060 & 87000 \\
\hline MJAKJ3 & SF-BH-E-PZ-24 pH 7 & 7.3 & 35600 & 5040 & 686 & 42500 & 3340 & 3.8 & 994 & 82200 \\
\hline MJAKJ4 & SF-OB-PZ-13 pH 2 & 297 & 16400 & 16300 & 3800 & 4700 & 31500 & 18.7 & 29500 & 120000 \\
\hline MJAKJ5 & SF-OB-PZ-13 pH 3 & 301 & 16900 & 4360 & 3580 & 4410 & 25300 & 16.5 & 29300 & 110000 \\
\hline MJAKJ8 & SF-OB-PZ-13 pH 6 & 29.2 & 8870 & 4010 & 2140 & 3160 & 4330 & 3.4 & 2350 & 14800 \\
\hline MJAKJ9 & SF-OB-PZ-13 pH 7 & 2.7 & 5310 & 1670 & 836 & 2070 & 570 & $\mathrm{U}$ & 314 & 7790 \\
\hline MJAKK0 & SF-BH-E-PZ-12 pH 2 & 198 & 51100 & 154000 & 12200 & 20900 & 52500 & 32.5 & 78500 & 94400 \\
\hline MJAKK1 & SF-BH-E-PZ-12 pH 3 & 114 & 42800 & 85100 & 8990 & 18900 & 40100 & 25.8 & 53000 & 147000 \\
\hline MJAKK2 & SF-BH-E-PZ-12 pH 4 & 108 & 44800 & 31200 & 6350 & 16700 & 32600 & 21.9 & 51800 & 118000 \\
\hline MJAKK6 & SF-BH-E-PZ-16 pH 2 & 662 & 4430 & 167000 & 2750 & 56200 & 62700 & 42.1 & 99400 & 239000 \\
\hline MJAKK7 & SF-BH-E-PZ-16 pH 3 & 514 & 39300 & 93400 & 2220 & 54200 & 41600 & 26.7 & 74900 & 246000 \\
\hline MJAKK8 & SF-BH-E-PZ-16 pH 4 & 624 & 44700 & 65800 & 1800 & 52700 & 45600 & 28.3 & 89600 & 243000 \\
\hline MJAKK9 & SF-BH-E-PZ-16 pH 5 & 278 & 32900 & 28900 & 1430 & 50500 & 23200 & 15.7 & 40800 & 160000 \\
\hline MJAKL0 & SF-BH-E-PZ-16 pH 6 & 151 & 28300 & 3750 & 756 & 49000 & 13500 & 10.5 & 19000 & 127000 \\
\hline MJAKL1 & SF-BH-E-PZ-16 pH 7 & 99.1 & 32500 & 2620 & 457 & 49900 & 11800 & 9 & 10100 & 121000 \\
\hline MJAKL2 & SF-BH-E-PZ-24 pH 2 & 242 & 170000 & 127000 & 3090 & 51800 & 59700 & 38.8 & 50900 & 308000 \\
\hline MJAKL3 & SF-BH-E-PZ-24 pH 3 & 182 & 107000 & 53500 & 2950 & 49900 & 39500 & 25.2 & 35600 & 264000 \\
\hline MJAKL4 & SF-BH-E-PZ-24 pH 4 & 102 & 105000 & 28400 & 1390 & 51500 & 35200 & 23.2 & 21700 & 221000 \\
\hline MJAKL5 & SF-BH-E-PZ-24 pH 5 & 19.3 & 57800 & 14100 & 1930 & 45300 & 11000 & 8.1 & 4150 & 119000 \\
\hline
\end{tabular}


Table A-5. (continued).

\begin{tabular}{|c|c|c|c|c|c|c|c|c|c|c|}
\hline $\begin{array}{l}\text { Sample } \\
\text { Number }\end{array}$ & $\begin{array}{l}\text { Sample Name and } \\
\text { Location }\end{array}$ & $\begin{array}{l}\mathrm{Cd} \\
\mathrm{ug} / \mathrm{L}\end{array}$ & $\mathrm{Ca}$ ug/L & $\mathrm{Fe}$ ug/L & $\mathrm{P}$ b ug/L & $\mathrm{Mg} \mathrm{ug} / \mathrm{L}$ & Mn ug/L & $\begin{array}{c}\mathrm{Se} \\
\mathrm{ug} / \mathrm{L}\end{array}$ & Zn ug/L & $\mathrm{S}$ ug/L \\
\hline \multicolumn{11}{|c|}{ Time 3 Days } \\
\hline MJAKL8 & SF-OB-PZ-13 pH 2 & 532 & 16900 & 25900 & 3550 & 4960 & 74800 & 43.7 & 55600 & 134000 \\
\hline MJAKM0 & SF-OB-PZ-13 pH 4 & 248 & 14300 & 1430 & 2310 & 4100 & 25200 & 16.1 & 22600 & 86800 \\
\hline MJAKM1 & SF-OB-PZ-13 pH 5 & 153 & 12600 & 1070 & 1320 & 3510 & 15100 & 10.7 & 13800 & 97700 \\
\hline MJAKM4 & SF-BH-E-PZ-12 pH 2 & 209 & 60500 & 255000 & 8950 & 25700 & 64600 & 65.7 & 74900 & 164000 \\
\hline MJAKM5 & SF-BH-E-PZ-12 pH 3 & 109 & 50300 & 93800 & 3540 & 20100 & 53300 & 46.7 & 71200 & 178000 \\
\hline MJAKM6 & SF-BH-E-PZ-12 pH 4 & 98.9 & 50600 & 31000 & 4910 & 17200 & 44100 & 36.2 & 62500 & 141000 \\
\hline MJAKM7 & SF-BH-E-PZ-12 pH 5 & 18.1 & 36900 & 4330 & 2870 & 13900 & 11300 & 7.8 & 8390 & 74900 \\
\hline MJAKM8 & SF-BH-E-PZ-12 pH 6 & 5.1 & 23500 & 4450 & 2550 & 12400 & 3900 & 3.9 & 1820 & 37500 \\
\hline MJAKN0 & SF-BH-E-PZ-16 pH 2 & 841 & 69200 & 318000 & 2120 & 73600 & 113000 & 88.1 & 120000 & 372000 \\
\hline MJAKN1 & SF-BH-E-PZ-16 pH 3 & 740 & 66800 & 209000 & 1910 & 69300 & 84900 & 76.1 & 107000 & 390000 \\
\hline MJAKN2 & SF-BH-E-PZ-16 pH 4 & 715 & 58800 & 51800 & 2140 & 65700 & 73800 & 58.1 & 98500 & 263000 \\
\hline MJAKN3 & SF-BH-E-PZ-16 pH 5 & 441 & 46600 & 4180 & 1370 & 58600 & 39100 & 31.4 & 58500 & 170000 \\
\hline MJAKN4 & SF-BH-E-PZ-16 pH 6 & 249 & 44000 & 14700 & 2500 & 55500 & 19800 & 19.3 & 23200 & 136000 \\
\hline MJAKN5 & SF-BH-E-PZ-16 pH 7 & 156 & 41400 & 3330 & 620 & 53700 & 14200 & 14.5 & 9360 & 138000 \\
\hline MJAKN6 & SF-BH-E-PZ-24 pH 2 & 150 & 279000 & 237000 & 2760 & 63700 & 93800 & 75.9 & 77400 & 518000 \\
\hline MJAKN7 & SF-BH-E-PZ-24 pH 3 & 56.8 & 191000 & 75700 & 1200 & 61400 & 64800 & 54.1 & 40000 & 343000 \\
\hline MJAKN8 & SF-BH-E-PZ-24 pH 4 & 91.8 & 166000 & 27300 & 1200 & 58200 & 56100 & 44.6 & 32600 & 297000 \\
\hline MJAKN9 & SF-BH-E-PZ-24 pH 5 & 16 & 75400 & 5750 & 767 & 49800 & 11000 & 10.6 & 1570 & 127000 \\
\hline MJAKP0 & SF-BH-E-PZ-24 pH 6 & 10.5 & 60400 & 4980 & 756 & 45800 & 6660 & 7.1 & 1070 & 98900 \\
\hline MJAKP1 & SF-BH-E-PZ-24 pH 7 & 9 & 41300 & 11500 & 1410 & 41000 & 3780 & 4.5 & 1650 & 155000 \\
\hline & & & & Time 7 & ays & & & & & \\
\hline MJAKP2 & SF-OB-PZ-13 pH 2 & 699 & 18800 & 25100 & 2390 & 6010 & 10900 & 90.5 & 58700 & 146000 \\
\hline
\end{tabular}


Table A-5. (continued).

\begin{tabular}{|c|c|c|c|c|c|c|c|c|c|c|}
\hline $\begin{array}{l}\text { Sample } \\
\text { Number }\end{array}$ & $\begin{array}{c}\text { Sample Name and } \\
\text { Location }\end{array}$ & $\begin{array}{r}\mathrm{Cd} \\
\mathrm{ug} / \mathrm{L} \\
\end{array}$ & $\mathrm{Ca} u g / \mathrm{L}$ & $\mathrm{Fe}$ ug/L & $\mathrm{P}$ b ug/L & $\mathrm{Mg} \mathrm{ug} / \mathrm{L}$ & Mn ug/L & $\begin{array}{c}\mathrm{Se} \\
\mathrm{ug} / \mathrm{L}\end{array}$ & Zn ug/L & $\mathrm{S} \mathrm{ug} / \mathrm{L}$ \\
\hline MJAKP3 & SF-OB-PZ-13 pH 3 & 559 & 19400 & 5220 & 2140 & 5490 & 66000 & 54.5 & 49800 & 158000 \\
\hline MJAKP4 & SF-OB-PZ-13 pH 4 & 362 & 16600 & 850 & 2300 & 4710 & 37600 & 28.7 & 33500 & 106000 \\
\hline MJAKP6 & SF-OB-PZ-13 pH 6 & 18 & 9140 & 1840 & 1170 & 2980 & 3350 & 3.6 & 1140 & 15800 \\
\hline MJAKP7 & SF-OB-PZ-13 pH 7 & 17.3 & 4600 & 9170 & 6800 & 2050 & 3560 & 3.6 & 2460 & 9810 \\
\hline MJAKQ0 & SF-BH-E-PZ-12 pH 4 & 249 & 70800 & 1090 & 2470 & 18000 & 39200 & 32.6 & 50100 & 137000 \\
\hline MJAKQ1 & SF-BH-E-PZ-12 pH 5 & 48.8 & 42900 & 970 & 1210 & 14400 & 16700 & 14.2 & 14400 & 90500 \\
\hline MJAKQ2 & SF-BH-E-PZ-12 pH 6 & 2.7 & 28000 & 764 & 592 & 12000 & 4960 & 4.1 & 1290 & 44700 \\
\hline MJAKQ3 & SF-BH-E-PZ-12 pH 7 & 3.1 & 15800 & 1900 & 1090 & 9970 & 734 & 4 & 415 & 38700 \\
\hline MJAKQ4 & SF-BH-E-PZ-16 pH 2 & 913 & 76000 & 633000 & 1470 & 82900 & 140000 & 103 & 122000 & 585000 \\
\hline MJAKQ8 & SF-BH-E-PZ-16 pH 6 & 247 & 45200 & 2400 & 984 & 53300 & 21100 & 15.8 & 20800 & 132000 \\
\hline MJAKQ9 & SF-BH-E-PZ-16 pH 7 & 118 & 41000 & 1970 & 510 & 50900 & 14300 & 11.8 & 5110 & 138000 \\
\hline MJAKR0 & SF-BH-E-PZ-24 pH 2 & 162 & 204000 & 392000 & 888 & 64300 & 128000 & 77.8 & 128000 & 712000 \\
\hline MJAKR1 & SF-BH-E-PZ-24 pH 3 & 130 & 259000 & 137000 & 1020 & 60000 & 80600 & 58.7 & 75100 & 499000 \\
\hline MJAKR2 & SF-BH-E-PZ-24 pH 4 & 177 & 219000 & 28400 & 738 & 57600 & 65000 & 48.2 & 53500 & 369000 \\
\hline MJAKR3 & SF-BH-E-PZ-24 pH 5 & 15.9 & 86200 & 2850 & 425 & 46500 & 14900 & 12.9 & 2200 & 135000 \\
\hline MJAKR4 & SF-BH-E-PZ-24 pH 6 & 11.2 & 65400 & 3680 & 552 & 44400 & 8090 & 7.4 & 1040 & 111000 \\
\hline MJAKR5 & SF-BH-E-PZ-24 pH 7 & 8.2 & 39900 & 5880 & 825 & 38100 & 3810 & 3.2 & 909 & 81500 \\
\hline \multicolumn{11}{|c|}{ Day 31} \\
\hline MJAKY8 & SF-OB-PZ-13 pH 2 & 746 & 20100 & 62400 & 1780 & 9160 & 164000 & 107 & 80800 & 237000 \\
\hline
\end{tabular}


Table A-5. (continued).

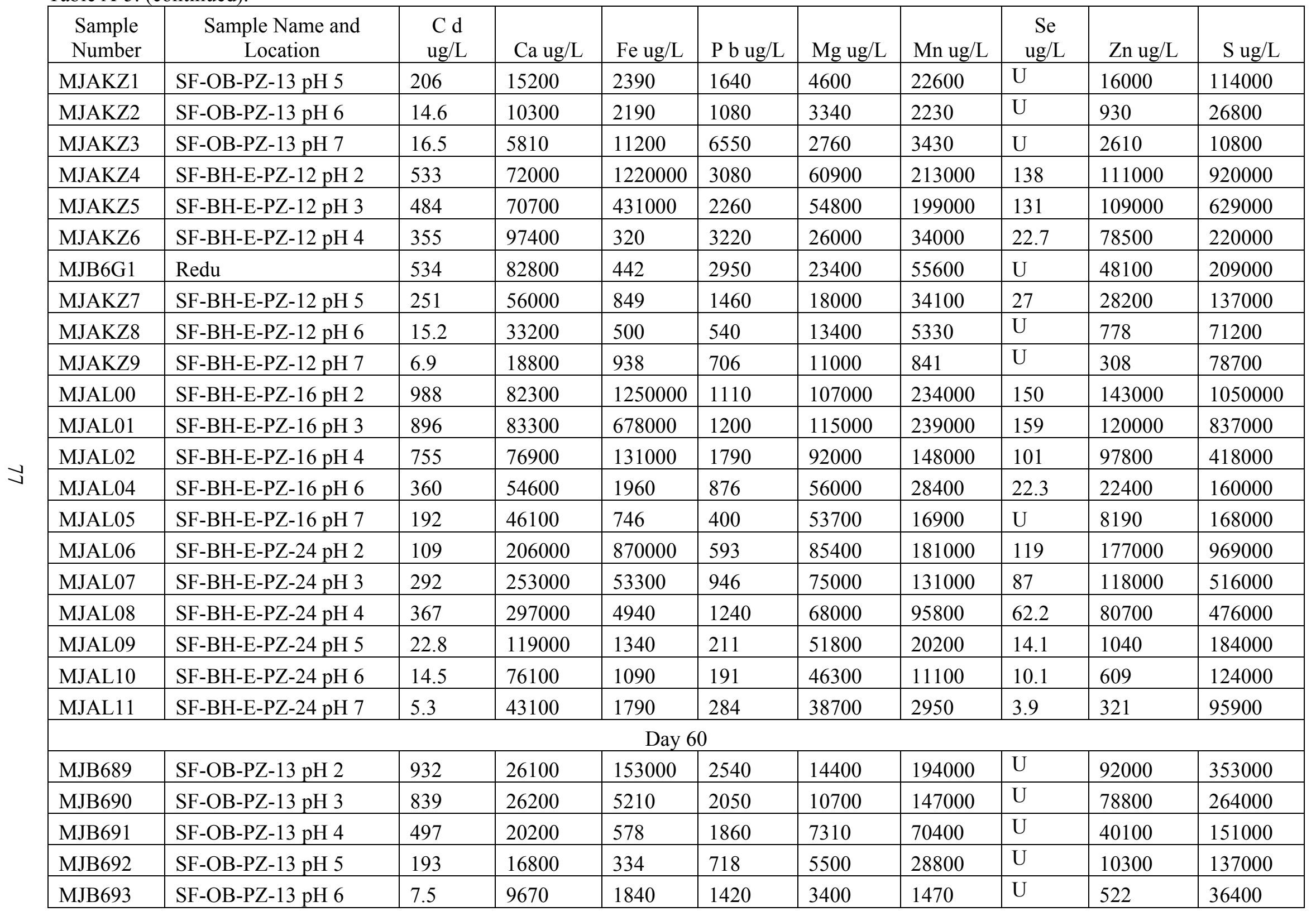


Table A-5. (continued).

\begin{tabular}{|c|c|c|c|c|c|c|c|c|c|c|}
\hline $\begin{array}{l}\text { Sample } \\
\text { Number }\end{array}$ & $\begin{array}{l}\text { Sample Name and } \\
\text { Location }\end{array}$ & $\begin{array}{r}\mathrm{C} \mathrm{d} \\
\mathrm{ug} / \mathrm{L}\end{array}$ & $\mathrm{Ca}$ ug/L & Fe ug/L & $\mathrm{P}$ b ug/L & $\mathrm{Mg} \mathrm{ug} / \mathrm{L}$ & Mn ug/L & $\begin{array}{c}\mathrm{Se} \\
\mathrm{ug} / \mathrm{L}\end{array}$ & Zn ug/L & $\mathrm{S}$ ug/L \\
\hline MJB694 & SF-OB-PZ-13 pH 7 & 47.7 & 5670 & 25300 & 24200 & 1920 & 8680 & $\mathrm{U}$ & 6610 & 5640 \\
\hline MJB695 & SF-BH-E-PZ-12 pH 2 & 739 & 94900 & 1090000 & 3030 & 105000 & 304000 & $\mathrm{U}$ & 116000 & 804000 \\
\hline MJB696 & SF-BH-E-PZ-12 pH 3 & 591 & 90900 & 495000 & 1660 & 94300 & 268000 & U & 95300 & 627000 \\
\hline MJB697 & SF-BH-E-PZ-12 pH 4 & 543 & 86900 & 977 & 3530 & 27100 & 64900 & $\mathrm{U}$ & 47500 & 222000 \\
\hline MJB698 & SF-BH-E-PZ-12 pH 5 & 336 & 65600 & 1440 & 1900 & 21800 & 42000 & $\mathrm{U}$ & 24900 & 167000 \\
\hline MJB699 & SF-BH-E-PZ-12 pH 6 & 45.6 & 40800 & 592 & 642 & 16000 & 7620 & U & 1410 & 105000 \\
\hline MJB6A0 & SF-BH-E-PZ-12 pH 7 & 15.9 & 27300 & 544 & 439 & 14000 & 1890 & $\mathrm{U}$ & 436 & 117000 \\
\hline MJB6A1 & SF-BH-E-PZ-16 pH 2 & 1010 & 102000 & 1360000 & 1340 & 145000 & 266000 & $\mathrm{U}$ & 159000 & 904000 \\
\hline MJB6A2 & SF-BH-E-PZ-16 pH 3 & 1010 & 104000 & 767000 & 1510 & 160000 & 293000 & $\mathrm{U}$ & 128000 & 821000 \\
\hline MJB6A3 & SF-BH-E-PZ-16 pH 4 & 912 & 95200 & 73500 & 1510 & 135000 & 217000 & U & 86400 & 461000 \\
\hline MJB6A4 & SF-BH-E-PZ-16 pH 5 & 800 & 76100 & 643 & 1570 & 78400 & 74100 & U & 70700 & 256000 \\
\hline MJB6A5 & SF-BH-E-PZ-16 pH 6 & 414 & 67800 & 639 & 727 & 67900 & 40000 & U & 22300 & 213000 \\
\hline MJB6A6 & SF-BH-E-PZ-16 pH 7 & 199 & 56300 & 1050 & 412 & 62800 & 24400 & U & 6150 & 209000 \\
\hline MJB6A7 & SF-BH-E-PZ-24 pH 2 & 158 & 268000 & 45400 & 673 & 95200 & 140000 & U & 129000 & 505000 \\
\hline MJB6A8 & SF-BH-E-PZ-24 pH 3 & 67.7 & 242000 & 930000 & 801 & 115000 & 216000 & $\mathrm{U}$ & 216000 & 847000 \\
\hline MJB6A9 & SF-BH-E-PZ-24 pH 4 & 507 & 323000 & 947 & 615 & 76400 & 93400 & U & 80600 & 477000 \\
\hline MJB6B0 & SF-BH-E-PZ-24 pH 5 & 35.2 & 138000 & 1040 & 191 & 57500 & 22000 & U & 1480 & 204000 \\
\hline MJB6B1 & SF-BH-E-PZ-24 pH 6 & 18.4 & 83900 & 4330 & 765 & 52500 & 11500 & U & 982 & 138000 \\
\hline MJB6B2 & SF-BH-E-PZ-24 pH 7 & 5.6 & 46600 & 1870 & 358 & 42300 & 2900 & U & 332 & 109000 \\
\hline \multicolumn{11}{|c|}{ Day 90} \\
\hline MJB6B3 & SF-OB-PZ-13 pH 2 & 950 & 27000 & 204000 & 1860 & 17700 & 207000 & U & 97400 & 425000 \\
\hline MJB6B4 & SF-OB-PZ-13 pH 3 & 868 & 26900 & 1190 & 1720 & 14100 & 161000 & $\mathrm{U}$ & 82900 & 281000 \\
\hline MJB6B5 & SF-OB-PZ-13 pH 4 & 492 & 20000 & 752 & 1650 & 8270 & 76500 & U & 34400 & 153000 \\
\hline MJB6B6 & SF-OB-PZ-13 pH 5 & 152 & 16000 & 410 & 490 & 6080 & 28200 & $\mathrm{U}$ & 5280 & 140000 \\
\hline MJB6B7 & SF-OB-PZ-13 pH 6 & 54.8 & 14200 & 549 & 411 & 5150 & 5360 & U & 2290 & 79200 \\
\hline MJB6B8 & SF-OB-PZ-13 pH 7 & 36.1 & 12200 & 494 & 391 & 4400 & 3980 & $\mathrm{U}$ & 1880 & 63000 \\
\hline MJB6B9 & SF-BH-E-PZ-12 pH 2 & 960 & 104000 & 1220000 & 1940 & 143000 & 468000 & $\mathrm{U}$ & 106000 & 947000 \\
\hline
\end{tabular}


Table A-5. (continued).

\begin{tabular}{|c|c|c|c|c|c|c|c|c|c|c|}
\hline $\begin{array}{l}\text { Sample } \\
\text { Number }\end{array}$ & $\begin{array}{l}\text { Sample Name and } \\
\text { Location }\end{array}$ & $\begin{array}{l}\mathrm{Cd} \\
\mathrm{ug} / \mathrm{L}\end{array}$ & $\mathrm{Ca}$ ug/L & $\mathrm{Fe}$ ug/L & $\mathrm{P}$ b ug/L & $\mathrm{Mg} \mathrm{ug} / \mathrm{L}$ & Mn ug/L & $\begin{array}{c}\mathrm{Se} \\
\mathrm{ug} / \mathrm{L}\end{array}$ & Zn ug/L & $\mathrm{S}$ ug/L \\
\hline MJB6C0 & SF-BH-E-PZ-12 pH 3 & 777 & 107000 & 345000 & 1870 & 158000 & 469000 & 21.2 & 74300 & 745000 \\
\hline MJB6C1 & SF-BH-E-PZ-12 pH 4 & 628 & 86400 & 401 & 2710 & 27800 & 67800 & $\mathrm{U}$ & 50600 & 228000 \\
\hline MJB6C2 & SF-BH-E-PZ-12 pH 5 & 372 & 67700 & 3050 & 4890 & 24600 & 47000 & U & 21400 & 184000 \\
\hline MJB6C3 & SF-BH-E-PZ-12 pH 6 & 150 & 46300 & 435 & 731 & 17900 & 14100 & $\mathrm{U}$ & 5580 & 126000 \\
\hline MJB6C4 & SF-BH-E-PZ-12 pH 7 & 179 & 46400 & 653 & 617 & 17700 & 14300 & $\mathrm{U}$ & 10400 & 175000 \\
\hline MJB6C5 & SF-BH-E-PZ-16 pH 2 & 1050 & 107000 & 1840000 & 1470 & 167000 & 335000 & $\mathrm{U}$ & 158000 & 1670000 \\
\hline MJB6C6 & SF-BH-E-PZ-16 pH 3 & 991 & 107000 & 844000 & 1480 & 174000 & 345000 & $\mathrm{U}$ & 120000 & 921000 \\
\hline MJB6C7 & SF-BH-E-PZ-16 pH 4 & 977 & 104000 & 2060 & 1300 & 163000 & 296000 & $\mathrm{U}$ & 62900 & 516000 \\
\hline MJB6C8 & SF-BH-E-PZ-16 pH 5 & 891 & 77000 & 887 & 1740 & 78700 & 86800 & $\mathrm{U}$ & 69900 & 277000 \\
\hline MJB6C9 & SF-BH-E-PZ-16 pH 6 & 467 & 67400 & 600 & 601 & 65800 & 45500 & $\mathrm{U}$ & 24000 & 236000 \\
\hline MJB6D0 & SF-BH-E-PZ-16 pH 7 & 191 & 55700 & 1930 & 540 & 61600 & 22600 & $\mathrm{U}$ & 5530 & 242000 \\
\hline MJB6D1 & SF-BH-E-PZ-24 pH 2 & 1250 & 106000 & 1970000 & 1400 & 161000 & 335000 & $\mathrm{U}$ & 156000 & 1590000 \\
\hline MJB6D2 & SF-BH-E-PZ-24 pH 3 & 393 & 249000 & 52400 & 863 & 103000 & 178000 & $\mathrm{U}$ & 181000 & 589000 \\
\hline MJB6D3 & SF-BH-E-PZ-24 pH 4 & 410 & 282000 & 922 & 337 & 75800 & 100000 & $\mathrm{U}$ & 63400 & 461000 \\
\hline MJB6D4 & SF-BH-E-PZ-24 pH 5 & 60.3 & 152000 & 905 & 170 & 56700 & 26700 & $\mathrm{U}$ & 2970 & 226000 \\
\hline MJB6D5 & SF-BH-E-PZ-24 pH 6 & 16.6 & 86200 & 1270 & 222 & 51500 & 11100 & U & 578 & 146000 \\
\hline MJB6D6 & SF-BH-E-PZ-24 pH 7 & 5 & 45500 & 1020 & 186 & 40500 & 2520 & U & 223 & 112000 \\
\hline
\end{tabular}


Table A-6. Concentrations for leach tests in the presence and absence of oxygen from 0-90 days.

\begin{tabular}{|c|c|c|c|c|c|c|c|c|c|c|}
\hline & & \multicolumn{2}{|c|}{$\begin{array}{c}\text { Concentration } \\
\text { ug/L }\end{array}$} & \multicolumn{4}{|c|}{ Concentration measured at Lab } & \multirow[b]{2}{*}{$\mathrm{Se}$} & \multirow[b]{2}{*}{$\mathrm{Zn}$} & \multirow[b]{2}{*}{$\mathrm{S}$} \\
\hline & & $\mathrm{Cd}$ & $\mathrm{Ca}$ & $\mathrm{Fe}$ & $\mathrm{Pb}$ & $\mathrm{Mg}$ & $\mathrm{Mn}$ & & & \\
\hline & Wet Dry Time 8 hours & & & & & & & & & \\
\hline MJAKS8 & SF-OB-PZ-13 Surface & 22.4 & 4450 & 12200 & 8650 & 1150 & 4160 & $\mathrm{U}$ & 3140 & 2680 \\
\hline MJAKS9 & SF-OB-PZ-13 Groundwater & & 9010 & 3590 & 2030 & 2930 & 1220 & U & 935 & 8020 \\
\hline MJAKT0 & SF-BH-E-PZ-12 Surface & & 14800 & 2280 & 1140 & 1930 & 512 & U & 463 & 10000 \\
\hline MJAKT1 & SF-BH-E-PZ-12 Groundwater & & 22000 & 9530 & 5120 & 11800 & 1870 & $\mathrm{U}$ & 1870 & 62400 \\
\hline MJAKT2 & SF-BH-E-PZ-16 Surface & 142 & 34300 & 1520 & 297 & 4920 & 12800 & $\mathrm{U}$ & 12000 & 47300 \\
\hline MJAKT3 & SF-BH-E-PZ-16 Groundwater & 144 & 27000 & 7380 & 1040 & 53700 & 13100 & $\mathrm{U}$ & 12500 & 115000 \\
\hline MJAKT4 & SF-BH-E-PZ-24 Surface & 37.5 & 21800 & 49000 & 10000 & 3830 & 6840 & $\mathrm{U}$ & 8100 & 5260 \\
\hline \multirow[t]{2}{*}{ MJAKT5 } & SF-BH-E-PZ-24 Groundwater & & 34000 & 5640 & 875 & 42300 & 2060 & $\mathrm{U}$ & 900 & 87000 \\
\hline & Wet Dry Time 16 hours & & & & & & & & & \\
\hline MJAKT6 & SF-OB-PZ-13 Surface & 30.2 & 4870 & 15400 & 12200 & 1170 & 5540 & $\mathrm{U}$ & 4260 & 3040 \\
\hline MJAKT7 & SF-OB-PZ-13 Groundwater & 14.9 & 10000 & 7760 & 4370 & 3180 & 2440 & $\mathrm{U}$ & 1710 & 8220 \\
\hline MJAKT8 & SF-BH-E-PZ-12 Surface & & 16200 & 9200 & 5260 & 2310 & 1320 & $\mathrm{U}$ & 1300 & 10500 \\
\hline MJAKT9 & SF-BH-E-PZ-12 Groundwater & 16.3 & 17900 & 5740 & 3100 & 8910 & 1860 & U & 2940 & 49000 \\
\hline MJAKW0 & SF-BH-E-PZ-16 Surface & 151 & 33700 & 4090 & 790 & 4680 & 14000 & $\mathrm{U}$ & 12700 & 50500 \\
\hline MJAKW1 & SF-BH-E-PZ-16 Groundwater & 157 & 30700 & 3820 & 646 & 51300 & 13800 & U & 13300 & 118000 \\
\hline MJAKW2 & SF-BH-E-PZ-24 Surface & 53.8 & 26300 & 66300 & 14000 & 5050 & 9630 & U & 11000 & 5550 \\
\hline \multirow[t]{2}{*}{ MJAKW3 } & SF-BH-E-PZ-24 Groundwater & 15.2 & 37700 & 17100 & 2700 & 42600 & 3520 & $\mathrm{U}$ & 2440 & 86400 \\
\hline & Time 24 hours & & & & & & & & & \\
\hline MJAKW4 & SF-OB-PZ-13 Surface & 35 & 5110 & 18100 & 14800 & 1210 & 6780 & $\mathrm{U}$ & 4870 & 3140 \\
\hline MJAKW5 & SF-OB-PZ-13 Groundwater & 18.1 & 9700 & 8440 & 5230 & 2820 & 3090 & $\mathrm{U}$ & 2070 & 8550 \\
\hline MJAKW6 & SF-BH-E-PZ-12 Surface & & 16700 & 2040 & 1070 & 2080 & 515 & $\mathrm{U}$ & 387 & 10900 \\
\hline MJAKW7 & SF-BH-E-PZ-12 Groundwater & 15.8 & 19600 & 4940 & 2670 & 9310 & 2000 & U & 2710 & 50600 \\
\hline MJAKW8 & SF-BH-E-PZ-16 Surface & 161 & 35800 & 942 & 281 & 5170 & 14300 & 12.7 & 13200 & 51300 \\
\hline MJAKW9 & SF-BH-E-PZ-16 Groundwater & 174 & 35300 & 8600 & 1300 & 53200 & 14800 & 11.3 & 15400 & 132000 \\
\hline
\end{tabular}


Table A-6. (continued).

\begin{tabular}{|c|c|c|c|c|c|c|c|c|c|c|}
\hline & & \multicolumn{2}{|c|}{$\begin{array}{c}\text { Concentration } \\
\text { ug/L }\end{array}$} & \multicolumn{4}{|c|}{ Concentration measured at Lab } & \multirow[b]{2}{*}{$\mathrm{Se}$} & \multirow[b]{2}{*}{$\mathrm{Zn}$} & \multirow[b]{2}{*}{$\mathrm{S}$} \\
\hline & & $\mathrm{Cd}$ & $\mathrm{Ca}$ & $\mathrm{Fe}$ & $\mathrm{Pb}$ & $\mathrm{Mg}$ & $\mathrm{Mn}$ & & & \\
\hline MJAKX0 & SF-BH-E-PZ-24 Surface & 53.9 & 27300 & 68500 & 13900 & 5290 & 10000 & 9.9 & 11100 & 5740 \\
\hline \multirow[t]{2}{*}{ MJAKX1 } & SF-BH-E-PZ-24 Groundwater & 14.6 & 40300 & 15800 & 2430 & 43200 & 3430 & $\mathrm{U}$ & 23100 & 86500 \\
\hline & Wet Dry Time 3 Days & & & & & & & & & \\
\hline MJAKX2 & SF-OB-PZ-13 Surface & 14.1 & 4950 & 6710 & 4980 & 1030 & 2870 & $\mathrm{U}$ & 1820 & 3780 \\
\hline MJAKX3 & SF-OB-PZ-13 Groundwater & 9.2 & 10200 & 224 & 104 & 3000 & 635 & $\mathrm{U}$ & 549 & 9020 \\
\hline MJAKX4 & SF-BH-E-PZ-12 Surface & 1.8 & 19500 & 702 & 477 & 2510 & 350 & $\mathrm{U}$ & 164 & 12500 \\
\hline MJAKX5 & SF-BH-E-PZ-12 Groundwater & 8.4 & 22300 & 149 & 181 & 9680 & 1810 & $\mathrm{U}$ & 1400 & 51000 \\
\hline MJAKX6 & SF-BH-E-PZ-16 Surface & 177 & 38800 & 1710 & 403 & 6140 & 17500 & 13.1 & 12800 & 59200 \\
\hline MJAKX7 & SF-BH-E-PZ-16 Groundwater & 187 & 40200 & 192 & 191 & 52000 & 16200 & 12.4 & 16000 & 135000 \\
\hline MJAKX8 & SF-BH-E-PZ-24 Surface & 11.5 & 25200 & 14300 & 2790 & 2790 & 2430 & 3.3 & 2220 & 7900 \\
\hline \multirow[t]{2}{*}{ MJAKX9 } & SF-BH-E-PZ-24 Groundwater & 7.2 & 46300 & 394 & 116 & 41500 & 2430 & 3.5 & 288 & 88100 \\
\hline & Wet Dry Time 7 Days & & & & & & & & & \\
\hline MJAKY0 & SF-OB-PZ-13 Surface & 29.9 & 5360 & 17300 & 13600 & 1390 & 5680 & 3.6 & 4330 & 4320 \\
\hline MJAKY1 & SF-OB-PZ-13 Groundwater & 11.8 & 11100 & 2570 & 1370 & 3170 & 1480 & $\mathrm{U}$ & 918 & 9720 \\
\hline MJAKY2 & SF-BH-E-PZ-12 Surface & 2.9 & 20100 & 1240 & 675 & 2730 & 401 & $\mathrm{U}$ & 240 & 17500 \\
\hline MJAKY3 & SF-BH-E-PZ-12 Groundwater & 6 & 25800 & 984 & 576 & 9890 & 1840 & $\mathrm{U}$ & 557 & 54000 \\
\hline MJAKY4 & SF-BH-E-PZ-16 Surface & 183 & 42800 & 978 & 323 & 7300 & 18900 & 14.1 & 11800 & 65800 \\
\hline MJAKY5 & SF-BH-E-PZ-16 Groundwater & 231 & 46500 & 950 & 413 & 54000 & 19300 & 12.2 & 17900 & 131000 \\
\hline MJAKY6 & SF-BH-E-PZ-24 Surface & 27.3 & 26200 & 32800 & 6870 & 3820 & 4850 & 4.5 & 5550 & 9270 \\
\hline \multirow[t]{2}{*}{ MJAKY7 } & SF-BH-E-PZ-24 Groundwater & 11.8 & 53600 & 2730 & 468 & 41600 & 3450 & $\mathrm{U}$ & 684 & 90800 \\
\hline & Wet Dry Time 30 Days & & & & & & & & & \\
\hline MJB6D7 & SF-OB-PZ-13 Surface & 11.9 & 7480 & 610 & 544 & 1290 & 1170 & $\mathrm{U}$ & 508 & 7470 \\
\hline MJB6D8 & SF-OB-PZ-13 Groundwater & 11.4 & 12500 & 507 & 431 & 3620 & 1580 & $\mathrm{U}$ & 386 & 14800 \\
\hline MJB6D9 & SF-BH-E-PZ-12 Surface & 8.6 & 30400 & 724 & 645 & 4390 & 1120 & $\mathrm{U}$ & 282 & 37400 \\
\hline MJB6E0 & SF-BH-E-PZ-12 Groundwater & 66 & 38500 & 644 & 628 & 12500 & 7330 & $\mathrm{U}$ & 2800 & 91800 \\
\hline MJB6E1 & SF-BH-E-PZ-16 Surface & 381 & 54800 & 514 & 523 & 11900 & 32100 & $\mathrm{U}$ & 23800 & 102000 \\
\hline
\end{tabular}


Table A-6. (continued).

\begin{tabular}{|c|c|c|c|c|c|c|c|c|c|c|}
\hline & & Con & $\begin{array}{l}\text { ntration } \\
\mathrm{g} / \mathrm{L}\end{array}$ & Conc & ntratio & heasurec & t Lab & & & \\
\hline & & $\mathrm{Cd}$ & $\mathrm{Ca}$ & $\mathrm{Fe}$ & $\mathrm{Pb}$ & $\mathrm{Mg}$ & $\mathrm{Mn}$ & $\mathrm{Se}$ & $\mathrm{Zn}$ & $\mathrm{S}$ \\
\hline MJB6E2 & SF-BH-E-PZ-16 Groundwater & 416 & 61000 & 610 & 679 & 63200 & 38000 & $\mathrm{U}$ & 25600 & 192000 \\
\hline MJB6E3 & SF-BH-E-PZ-24 Surface & 7.8 & 31800 & 7140 & 1730 & 3080 & 1740 & $\mathrm{U}$ & 1190 & 15000 \\
\hline MJB6E4 & SF-BH-E-PZ-24 Groundwater & 9.8 & 62900 & 933 & 202 & 44800 & 4810 & $\mathrm{U}$ & 344 & 107000 \\
\hline & Wet Dry Time 60 Days & & & & & & & & & \\
\hline MJB6E5 & SF-OB-PZ-13 Surface & 9.2 & 6590 & 2910 & 2600 & 1410 & 1370 & $\mathrm{U}$ & 828 & 9320 \\
\hline MJB6E6 & SF-OB-PZ-13 Groundwater & 10.2 & 12400 & 919 & 825 & 3760 & 1300 & $\mathrm{U}$ & 426 & 16300 \\
\hline MJB6E7 & SF-BH-E-PZ-12 Surface & 22.3 & 43300 & 373 & 436 & 6160 & 2740 & $\mathrm{U}$ & 744 & 50600 \\
\hline MJB6E8 & SF-BH-E-PZ-12 Groundwater & 293 & 52000 & 869 & 1360 & 16300 & 24100 & $\mathrm{U}$ & 17200 & 126000 \\
\hline MJB6E9 & SF-BH-E-PZ-16 Surface & 549 & 62700 & 2190 & 1140 & 16200 & 44200 & $\mathrm{U}$ & 34400 & 131000 \\
\hline MJB6F0 & SF-BH-E-PZ-16 Groundwater & 525 & 66100 & 1130 & 818 & 66600 & 47000 & $\mathrm{U}$ & 34600 & 215000 \\
\hline MJB6F1 & SF-BH-E-PZ-24 Surface & 4.8 & 34200 & 3810 & 889 & 3110 & 1150 & $\mathrm{U}$ & 596 & 18400 \\
\hline MJB6F2 & SF-BH-E-PZ-24 Groundwater & 11.8 & 65700 & 2500 & 543 & 45300 & 5030 & $\mathrm{U}$ & 559 & 111000 \\
\hline & Wet Dry Time 90 Days & & & & & & & & & \\
\hline MJB6F3 & SF-OB-PZ-13 Surface & 15.2 & 5550 & 8290 & 7030 & 1260 & 2570 & $\mathrm{U}$ & 1900 & 6180 \\
\hline MJB6F4 & SF-OB-PZ-13 Groundwater & 9.3 & 10300 & 3270 & 2660 & 3080 & 1500 & $\mathrm{U}$ & 808 & 13500 \\
\hline MJB6F5 & SF-BH-E-PZ-12 Surface & 38.6 & 50600 & 1080 & 1100 & 7960 & 3170 & $\mathrm{U}$ & 1270 & 61500 \\
\hline MJB6F6 & SF-BH-E-PZ-12 Groundwater & 428 & 57700 & 1400 & 2270 & 18800 & 33000 & $\mathrm{U}$ & 25400 & 147000 \\
\hline MJB6F7 & SF-BH-E-PZ-16 Surface & 681 & 66900 & 2670 & 1510 & 20000 & 56600 & $\mathrm{U}$ & 43100 & 156000 \\
\hline MJB6F8 & SF-BH-E-PZ-16 Groundwater & 621 & 70100 & 1870 & 1230 & 70100 & 56400 & $\mathrm{U}$ & 43200 & 231000 \\
\hline MJB6F9 & SF-BH-E-PZ-24 Surface & 14.1 & 30700 & 14000 & 3390 & 3350 & 2550 & $\mathrm{U}$ & 2330 & 15300 \\
\hline MJB6G0 & SF-BH-E-PZ-24 Groundwater & 13.3 & 54100 & 5860 & 1190 & 35500 & 4630 & $\mathrm{U}$ & 983 & 88000 \\
\hline
\end{tabular}


Table A-7. Groundwater constituents measured previously

\begin{tabular}{|c|c|c|c|c|c|c|c|c|}
\hline Location & Date & DTW (ft) & $\mathrm{pH}$ & Conductivity & $\begin{array}{l}\text { Temp } \\
{ }^{\circ} \mathrm{C}\end{array}$ & DO & ORP & $\begin{array}{l}\mathrm{Ca} \\
(\mathrm{mg} / \mathrm{L})\end{array}$ \\
\hline SF-OB-PZ-13 & $9-22-08$ & 9.8 & 6.47 & 284 & 9.7 & 5.61 & 213 & 15.7 \\
\hline SF-BH-E-PZ-12 & $9-22-08$ & 11.5 & 5.8 & 482.9 & 14.1 & 0.31 & 48 & 35.5 \\
\hline SF-BH-E-PZ-16 & $9-23-08$ & 10.4 & 4.7 & 1528 & 13.3 & 0.44 & 219 & 150 \\
\hline SF-BH-E-PZ-24 & $9-23-08$ & 13.6 & 5.7 & 1499 & 12.9 & 3.9 & 28 & 145 \\
\hline & Date & $\begin{array}{l}\text { Alkalinity } \\
(\mathrm{mg} / \mathrm{L} \\
\left.\mathrm{CaCO}_{3}\right)\end{array}$ & $\begin{array}{l}\text { Nitrate/ } \\
\text { Nitrite }\end{array}$ & $\begin{array}{l}\text { Total P } \\
(\mathrm{mg} / \mathrm{L})\end{array}$ & $\begin{array}{l}\mathrm{Cl} \\
(\mathrm{mg} / \mathrm{L})\end{array}$ & $\begin{array}{l}\mathrm{Mg} \\
(\mathrm{mg} / \mathrm{L})\end{array}$ & $\begin{array}{l}\mathrm{SO}_{4} \\
(\mathrm{mg} / \mathrm{L})\end{array}$ & $\begin{array}{l}\mathrm{Fe} \\
(\mathrm{mg} / \mathrm{L})\end{array}$ \\
\hline SF-OB-PZ-13 & $9-22-08$ & 56 & 0.19 & 0.0073 & 6.0 & 4.9 & 39 & 0.10 \\
\hline SF-BH-E-PZ-12 & $9-22-08$ & 80 & 0.05 & 0.0072 & 4.1 & 15.9 & 122 & 4.27 \\
\hline SF-BH-E-PZ-16 & $9-23-08$ & 10 & 0.10 & 0.177 & 3.7 & 44.4 & 592 & 0.10 \\
\hline SF-BH-E-PZ-24 & $9-23-08$ & 23 & 0.05 & 0.963 & 6.3 & 56.5 & 675 & 22.6 \\
\hline
\end{tabular}




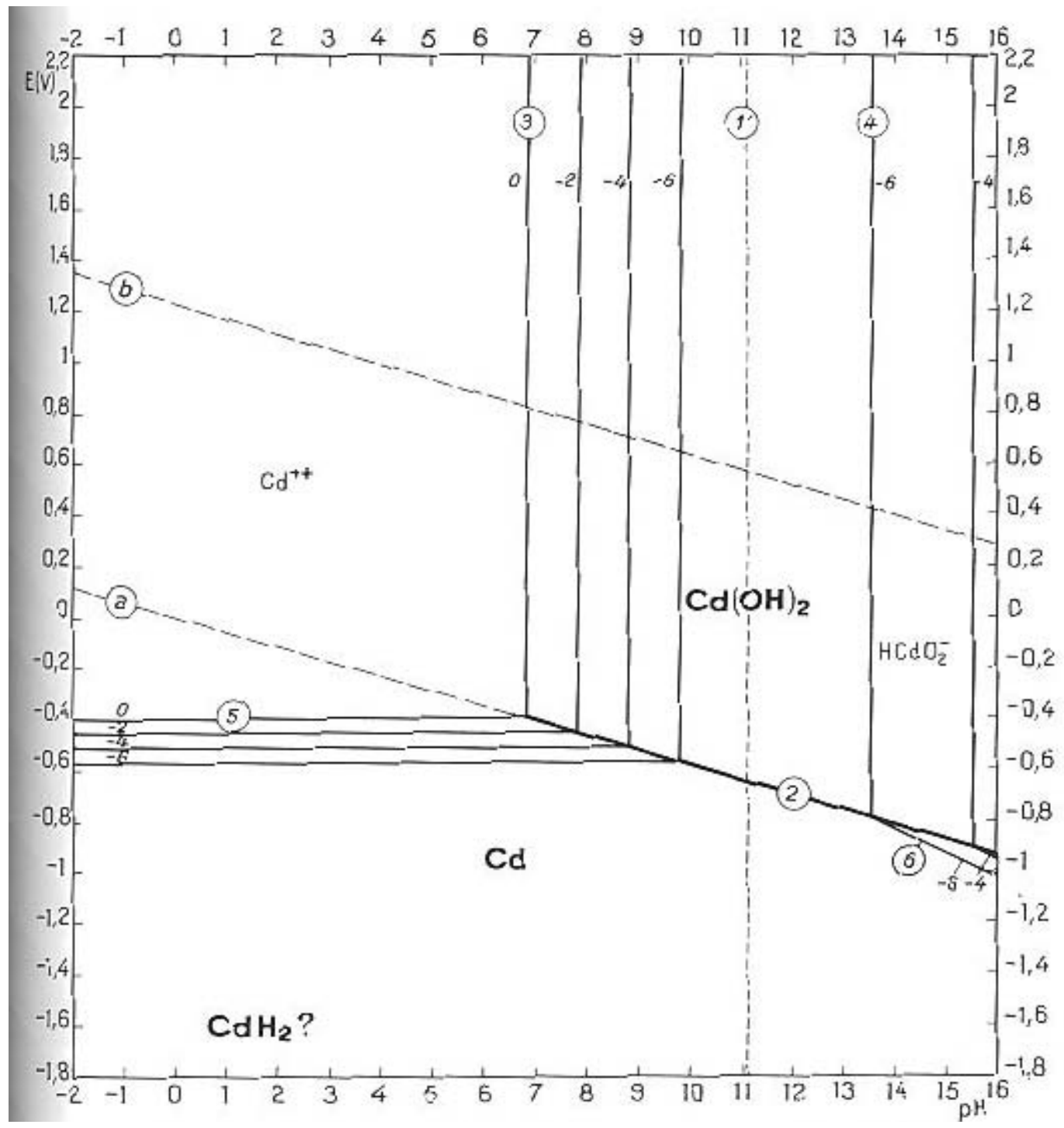

Figure A-1. Cadmium $\mathrm{pH}$ equilibrium diagram at $25^{\circ} \mathrm{C}$. 


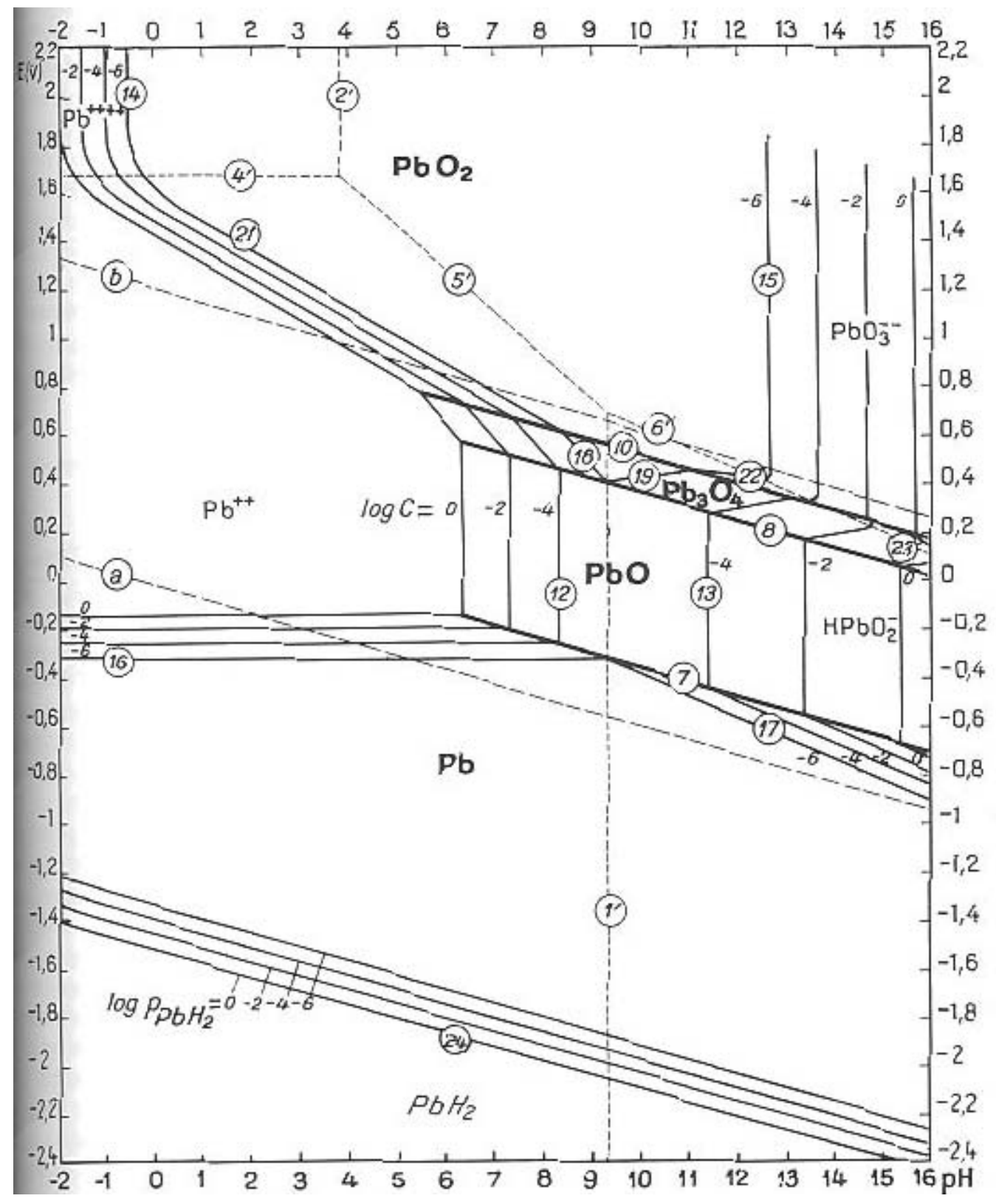

Figure A-2. Lead $\mathrm{pH}$ equilibrium diagram at $25^{\circ} \mathrm{C}$. 


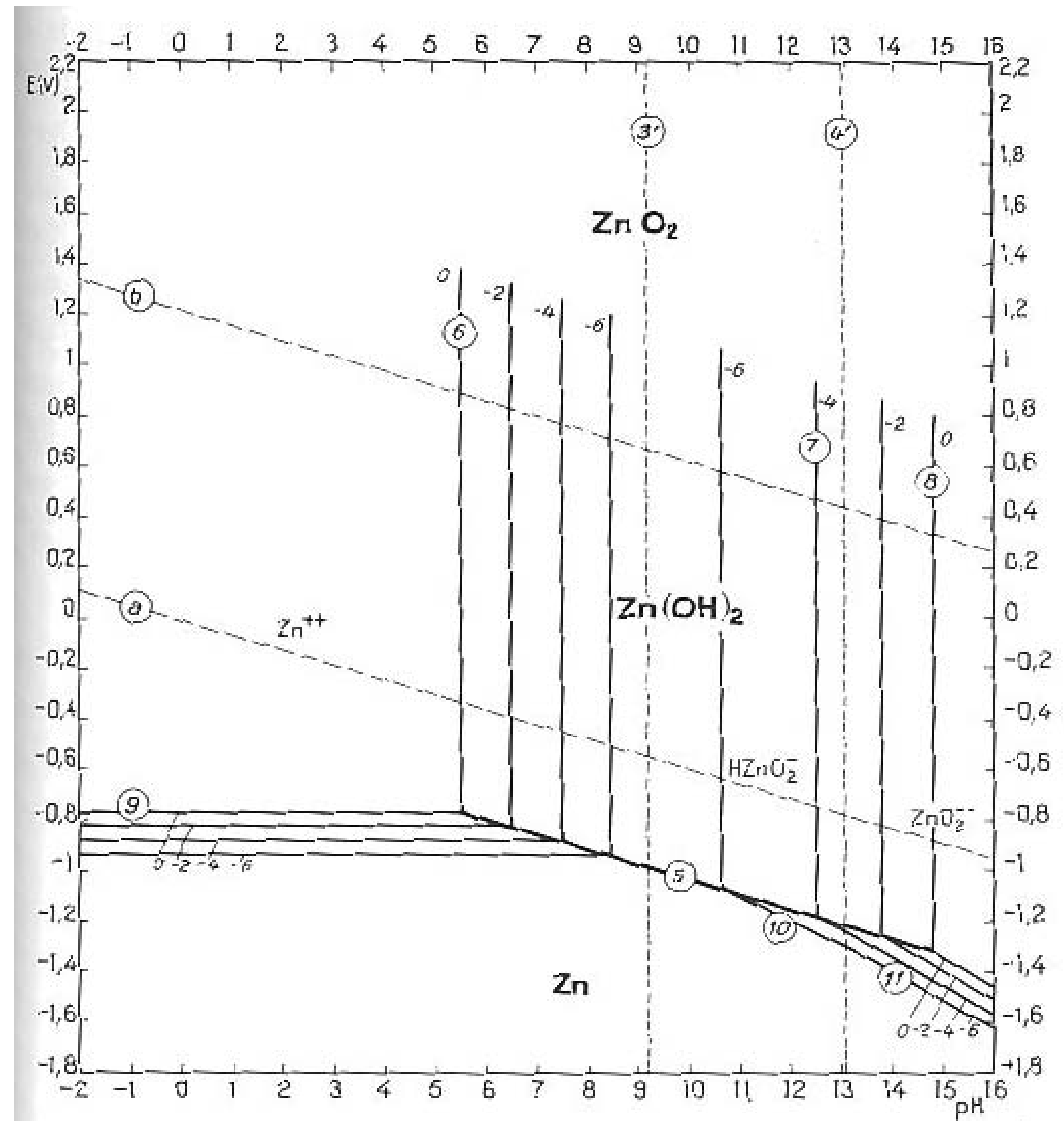

Figure A-3. Zinc $\mathrm{pH}$ equilibrium diagram at $25^{\circ} \mathrm{C}$. 


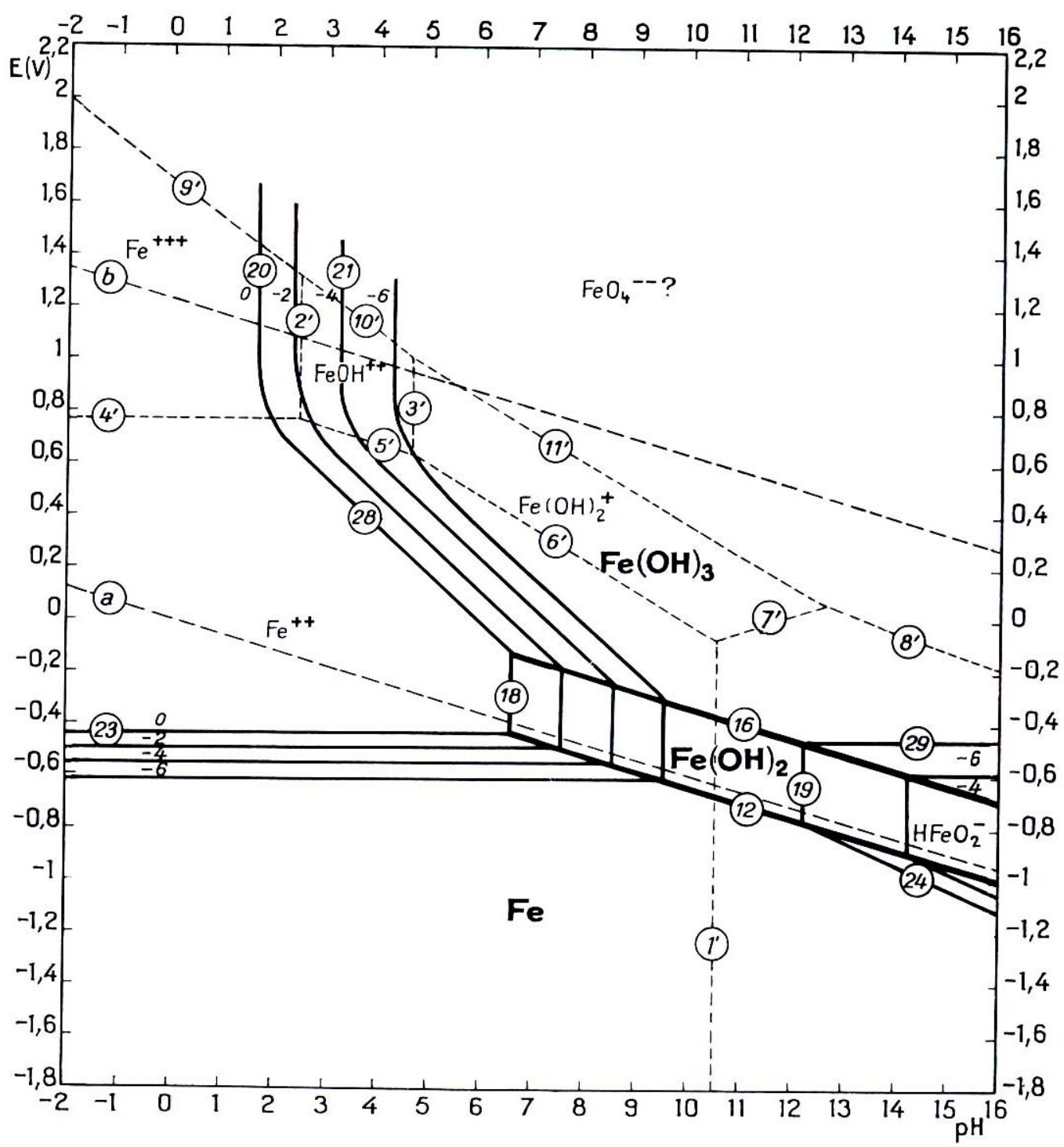

Figure A-4. Iron $\mathrm{pH}$ Equalibrium Diagram at $25^{\circ} \mathrm{C}$. 


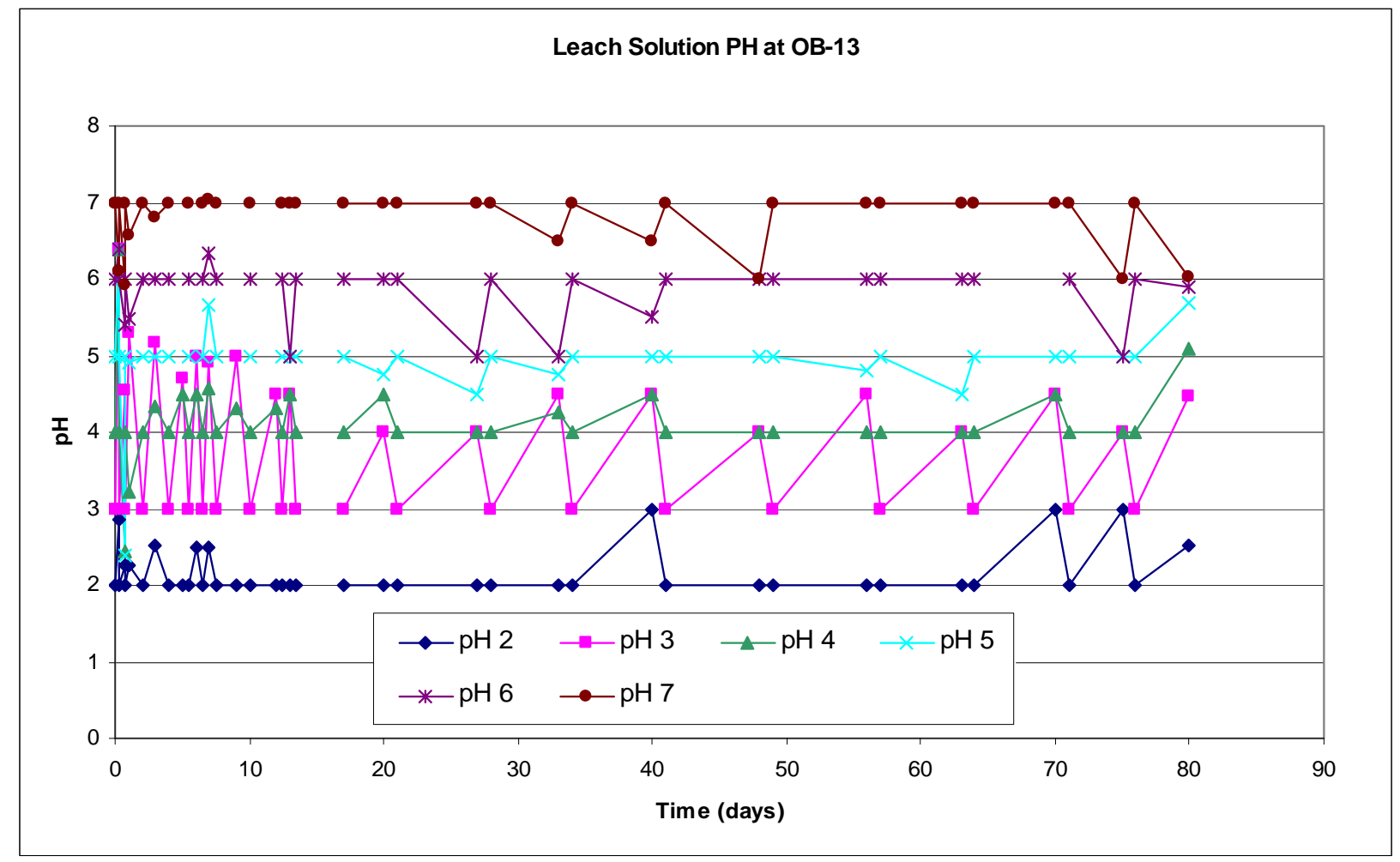

Figure A-5. Leach solution pH for Location SF-OB-PZ-13.

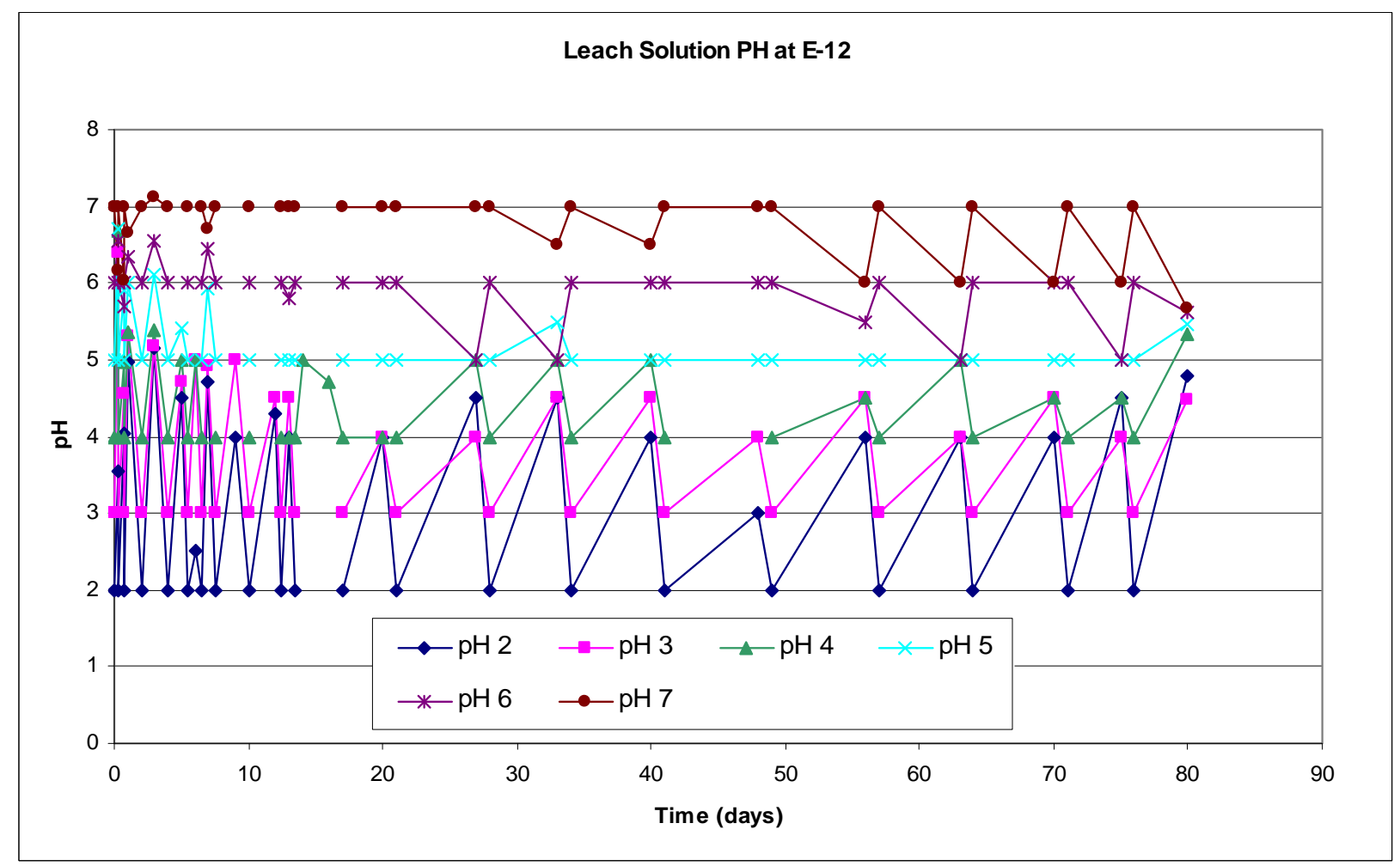

Figure A-6. Leach solution pH for Location SF-BH-E-PZ-12. 


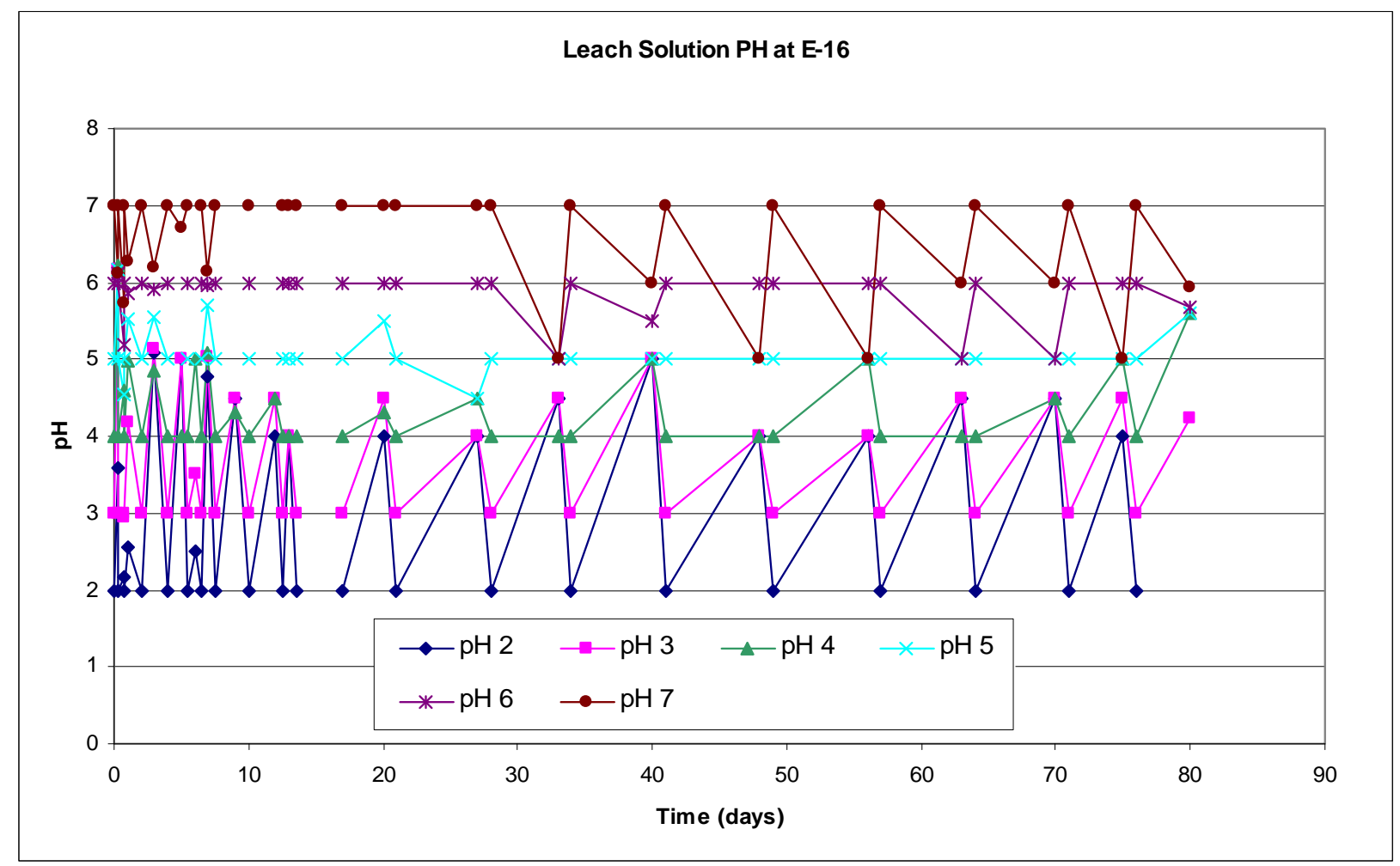

Figure A-7. Leach solution pH for Location SF-BH-E-PZ-16. 


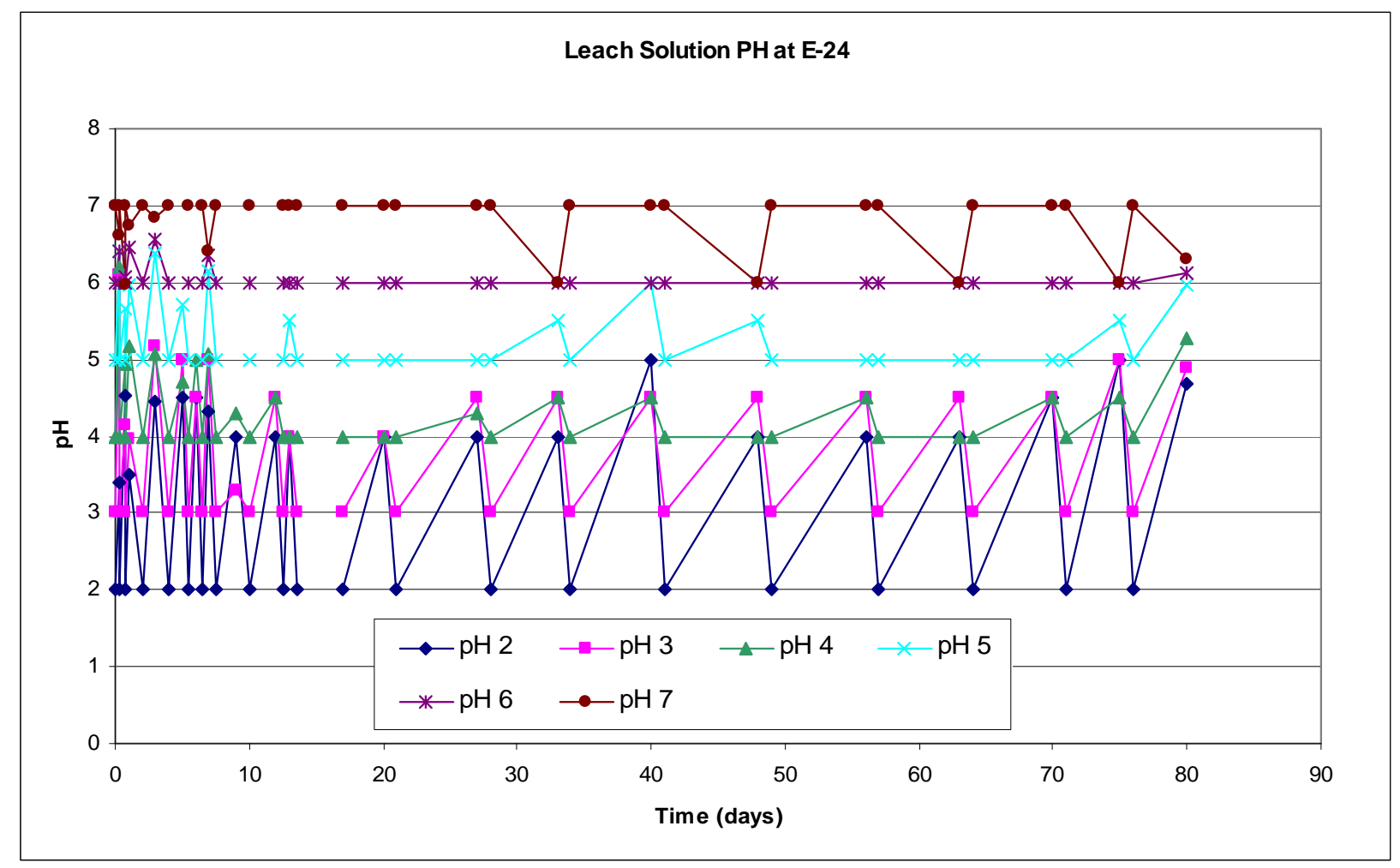

Figure A-8. Leach solution $\mathrm{pH}$ for Location SF-BH-E-PZ-24.

Table A-8. Partial data for Percent soil less than $2 \mathrm{~mm}$.

\begin{tabular}{|c|c|c|c|c|c|}
\hline Core location & Depth & $\begin{array}{l}\text { Mass less than } \\
2 \mathrm{~mm}(\mathrm{gm})\end{array}$ & $\begin{array}{l}\text { Mass greater } \\
\text { than } 2 \mathrm{~mm}(\mathrm{gm})\end{array}$ & $\begin{array}{l}\text { Percent less } \\
\text { than } 2 \mathrm{~mm}(\%)\end{array}$ & $\begin{array}{l}\text { Percent greater } \\
\text { than } 2 \mathrm{~mm}(\%)\end{array}$ \\
\hline Osborn & $1-1.8 \mathrm{ft}$ & 154.7 & 314.2 & 33.0 & 67.0 \\
\hline Osborn & $3-4 \mathrm{ft}$ & 121 & 289.2 & 29.5 & 70.5 \\
\hline Osborn & $5-6 \mathrm{ft}$ & 135.8 & 275.8 & 33.0 & 67.0 \\
\hline E-12 & $1-2 \mathrm{ft}$ & Not Available & Not Available & Not Available & Not Available \\
\hline E-12 & $3-4 \mathrm{ft}$ & Not Available & Not Available & Not Available & Not Available \\
\hline E-12 & $5-6 \mathrm{ft}$ & Not Available & Not Available & Not Available & Not Available \\
\hline E-12 & $7-8 \mathrm{ft}$ & Not Available & Not Available & Not Available & Not Available \\
\hline E-12 & $8-9 \mathrm{ft}$ & 246.3 & 0.65 & 99.7 & 0.3 \\
\hline E-16 & $1-2 \mathrm{ft}$ & Not Available & Not Available & Not Available & Not Available \\
\hline E-16 & $3-4 \mathrm{ft}$ & Not Available & Not Available & Not Available & Not Available \\
\hline E-16 & $5-6 \mathrm{ft}$ & Not Available & Not Available & Not Available & Not Available \\
\hline E-16 & $7-8 \mathrm{ft}$ & Not Available & Not Available & Not Available & Not Available \\
\hline E-24 & $1-2 \mathrm{ft}$ & 468.7 & 102.7 & 82.0 & 18.0 \\
\hline E-24 & $3-4 \mathrm{ft}$ & 687.8 & 54.7 & 92.6 & 7.4 \\
\hline E-24 & $5-6 \mathrm{ft}$ & 255.6 & 78.5 & 76.5 & 23.5 \\
\hline E-24 & $7-7.7 \mathrm{ft}$ & 187.6 & 163.9 & 53.4 & 46.6 \\
\hline
\end{tabular}


